CAMBRIDGE STUDIES IN COMPARATIVE PUBLIC POLICY

\title{
Policy Controversies and Political Blame Games
}

MARKUS HINTERLEITNER

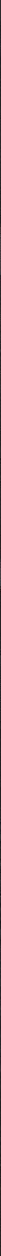




\section{Policy Controversies and Political Blame Games}

In modern, policy-heavy democracies, blame games about policy controversies are commonplace. Despite their ubiquity, blame games are notoriously difficult to study. This book elevates them to the place that they deserve in the study of politics and public policy. Blame games are microcosms of conflictual politics that yield unique insights into democracies under pressure. Based on an original framework and the comparison of fifteen blame games in the UK, Germany, Switzerland, and the USA, it exposes the institutionalized forms of conflict management that democracies have developed to manage policy controversies. Whether failed infrastructure projects, food scandals, security issues, or flawed policy reforms, democracies manage policy controversies in an idiosyncratic manner. This book is addressed not only to researchers and students interested in political conflict in the fields of political science, public policy, public administration, and political communication but to everyone concerned about the functioning of democracy in more conflictual times. This title is also available as Open Access on Cambridge Core.

MARKUS HINTERLEITNER is a postdoctoral researcher at Brown University's Watson Institute and is affiliated with the University of Bern's KPM Center for Public Management. He received his PhD from the University of Bern, Switzerland in 2018 and was a visiting scholar at the University of California, Berkeley during 2019. He is a leading scholar on political blame avoidance. His articles have been published in journals such as the European Journal of Political Research, European Political Science Review, Policy Studies Journal, Journal of European Public Policy, and the Journal of Public Policy. 


\section{Cambridge Studies in Comparative Public Policy}

The Cambridge Studies in Comparative Public Policy series was established to promote and disseminate comparative research in public policy. The objective of the series is to advance the understanding of public policies through the publication of the results of comparative research into the nature, dynamics and contexts of major policy challenges and responses to them. Works in the series will draw critical insights that enhance policy learning and are generalizable beyond specific policy contexts, sectors and time periods. Such works will also compare the development and application of public policy theory across institutional and cultural settings and examine how policy ideas, institutions and practices shape policies and their outcomes. Manuscripts comparing public policies in two or more cases as well as theoretically informed critical case studies which test more general theories are encouraged. Studies comparing policy development over time are also welcomed.

General Editors: M. Ramesh, National University of Singapore; Xun Wu, Hong Kong University of Science and Technology; Michael Howlett, Simon Fraser University, British Columbia and National University of Singapore

In Defense of Pluralism: Policy Disagreement and Its Media Coverage By Éric Montpetit

Asia after the Developmental State: Disembedding Autonomy Edited by Toby Carroll and Darryl S. L. Jarvis

The Politics of Shale Gas in Eastern Europe: Energy Security, Contested Technologies and the Social Licence to Frack By Andreas Goldthau

Healthy or Sick? Coevolution of Health Care and Public Health in a Comparative Perspective 2018 By Philipp Trein

Policy Accumulation and the Democratic Responsiveness Trap By Christian Adam, Steffen Hurka, Christoph Knill and Yves Steinebach 
Hyper-Active Governance: How Governments Manage the Politics of Expertise By Matthew Wood

Policy Consultancy in Comparative Perspective: Patterns, Nuances and Implications of the Contractor State By Caspar van den Berg, Michael Howlett, Andrea Migone, Michael Howard, Frida Pemer and Helen M. Gunter

A Matter of Style? Organizational Agency in Global Public Policy By Louisa Bayerlein, Christoph Knill and Yves Steinebach

Policy Controversies and Political Blame Games By Markus Hinterleitner 


\section{Policy Controversies}

and Political Blame Games

MARKUS HINTERLEITNER

Brown University 


\section{CAMBRIDGE UNIVERSITY PRESS}

University Printing House, Cambridge CB2 8BS, United Kingdom

One Liberty Plaza, 20th Floor, New York, NY 10006, USA

477 Williamstown Road, Port Melbourne, VIC 3207, Australia

314-321, 3rd Floor, Plot 3, Splendor Forum, Jasola District Centre, New Delhi - 110025, India

79 Anson Road, \#06-04/06, Singapore 079906

Cambridge University Press is part of the University of Cambridge.

It furthers the University's mission by disseminating knowledge in the pursuit of education, learning, and research at the highest international levels of excellence.

www.cambridge.org

Information on this title: www.cambridge.org/9781108494861

DOI: $10.1017 / 9781108860116$

(C) Markus Hinterleitner 2020

This work is in copyright. It is subject to statutory exceptions and to the provisions of relevant licensing agreements;

with the exception of the Creative Commons version the link for which is provided below, no reproduction of any part of this work may take place without the written permission of Cambridge University Press.

An online version of this work is published at doi.org/10.1017/9781108860116 under a Creative Commons Open Access license CC-BY-NC-ND 4.0 which permits re-use, distribution and reproduction in any medium for non-commercial purposes providing appropriate credit to the original work is given. You may not distribute derivative works without permission. To view a copy of this license, visit https:/creativecommons.org/licenses/ by-nc-nd/4.0

All versions of this work may contain content reproduced under license from third parties.

Permission to reproduce this third-party content must be obtained from these third-parties directly.

When citing this work, please include a reference to the DOI $10.1017 / 9781108860116$

First published 2020

A catalogue record for this publication is available from the British Library.

Library of Congress Cataloging-in-Publication Data

Names: Hinterleitner, Markus, 1987- author.

Title: Policy controversies and political blame games / Markus Hinterleitner.

Description: Cambridge, United Kingdom ; New York, NY : Cambridge University Press, [2020] I Includes bibliographical references and index.

Identifiers: LCCN 2020002781 (print) | LCCN 2020002782 (ebook) I ISBN 9781108494861

(hardback) I ISBN 9781108860116 (ebook)

Subjects: LCSH: Political culture - Western countries - Case studies. I Government accountability - Western countries - Case studies. I Blame - Political aspects - Western countries - Case studies. I Crisis management in government - Western countries - Case studies. I Political planning - Western countries - Case studies. I Opposition (Political science) Western countries - Case studies. I Democracy - Western countries - Case studies. I

Comparative government. I Western countries - Politics and government.

Classification: LCC JA75.7 .H555 2020 (print) | LCC JA75.7 (ebook) I DDC 306.209182/1-dc23

LC record available at https://lccn.loc.gov/2020002781

LC ebook record available at https://lccn.loc.gov/2020002782

ISBN 978-1-108-49486-1 Hardback

Cambridge University Press has no responsibility for the persistence or accuracy of URLs for external or third-party internet websites referred to in this publication and does not guarantee that any content on such websites is, or will remain, accurate or appropriate. 


\section{Contents}

List of Figures

page ix

List of Tables

$\mathrm{X}$

Acknowledgments

xi

List of Abbreviations

xiii

1 How Political Systems Manage Their Policy Controversies 1

1.1 Setting the Scene: When Political Systems 'Heat Up' to Address the Controversial

1.2 Political Systems and Their Peculiar Ways of Managing Policy Controversies

1.3 Goals and Outline of the Book

1.4 Strategy of Inquiry

2 Blame Games in the Political Sphere

2.1 More Than Routine Political Business: Blame Games as Distinct Political Events

2.2 A Theoretical Framework for the Analysis of Blame Games

3 Blame Games in the UK

3.1 The Child Support Agency Operation Controversy (CSA) $\quad 40$

3.2 The London Underground Renovation Controversy (METRONET)

3.3 The Millennium Dome Controversy (DOME) 56

3.4 The UK Blame Game Style 66

4 Blame Games in Germany 73

4.1 The National Socialist Underground Investigation Controversy (NSU)

4.2 The Berlin Airport Construction Controversy (BER)

4.3 The Drone Procurement Controversy (DRONE)

4.4 The German Blame Game Style 
5 Blame Games in Switzerland 108

5.1 The Youth Offender Therapy Controversy (CARLOS) 108

5.2 The Corporate Tax Reform Controversy (TAX) 114

5.3 The National Exposition Controversy (EXPO) 123

5.4 The Swiss Blame Game Style 130

6 Mapping the Influence of Institutional Factors 139

6.1 Political Interaction Structure 141

6.2 Institutionalized Accountability Structures 141

6.3 Institutional Policy Characteristics 142

7 Mapping the Influence of Issue Characteristics 145

7.1 Distant-Salient Blame Games 145

7.2 Proximate-Nonsalient Blame Games 152

7.3 Distant-Nonsalient Blame Games 160

7.4 Issue Characteristics and Their Influence on Blame

Game Interactions 168

8 A Typological Theory of Blame Games and Their Consequences 176

8.1 Constructing a Typological Theory 177

8.2 Political Systems and How They Manage Policy

Controversies

9 Blame Games and Their Implications for Politics and Democracy under Pressure 185

9.1 What This Book Has to Say about Blame Games 185

9.2 The Study of Blame Games and Its Wider Implications 198

Appendix 206

Notes 217

References 234

Index 245 


\section{Figures}

1 The theoretical framework for the analysis of blame games

page 25

2 The relationship between the public and the blame game

3 Causal diagram of the typological theory 


\section{Tables}

1 The blame games selected for analysis arranged within the compound research design

2 Assessment of theoretical expectations in the CSA case 48

3 Assessment of theoretical expectations in the METRONET case $\quad 57$

4 Assessment of theoretical expectations in the DOME case 64

5 Assessment of theoretical expectations in the NSU case $\quad 80$

6 Assessment of theoretical expectations in the BER case 89

7 Assessment of theoretical expectations in the DRONE case

8 Assessment of theoretical expectations in the CARLOS case

9 Assessment of theoretical expectations in the TAX case

10 Assessment of theoretical expectations in the EXPO case

11 Relationships between public feedback and blame game consequences 


\section{Acknowledgments}

I benefited from the encouragement and company of a wonderful team at the KPM Center for Public Management of the University of Bern while conducting the research for this book. During my time at Bern, I received generous funding from the Swiss National Science Foundation. Particular thanks go to David Kaufmann, Christian Rosser, and Eva Thomann, who accompanied me in my early steps as a social scientist and set examples of what a passion for the social sciences really means. Fritz Sager deserves special praise with regard to my research on blame games and my scientific trajectory in general. Enabler, teacher, encourager, and ironic 'refrainer' are just a few of the roles he flexibly adopted whenever necessary. In doing so, he was at least as judicious and 'context-sensitive' as the savvy politicians in the cases of this book. He was a wonderful $\mathrm{PhD}$ supervisor, and I thank him for supporting me along the way. Special thanks also go to R. Kent Weaver, my second $\mathrm{PhD}$ supervisor. Writing a book about blame games to be read by the pioneering scholar in the field was a motivating treat and a constant source of encouragement. Needless to say, his work, and that of Christopher Hood, constitutes the most important theoretical foundation for my work. Many thanks also go to Craig Parsons for a very inspiring discussion about the consensual foundations of contemporary political science. Chris Ansell supported and encouraged me during the review process. I also want to thank Derek Beach, Andy Bennett, and Benoit Rihoux, who provided me with precious advice on my work during my time as a $\mathrm{PhD}$ student. I would also like to thank Janine Gehrig Lux for her excellent proofreading. Many thanks also go to the series editors, Mike Howlett, M. Ramesh, and Xun Wu, and Joe Ng, Gemma Smith, and James Baker from Cambridge University Press for their excellent support during the revision and publication process. I am also grateful to the four anonymous reviewers for their extremely 
helpful feedback. My greatest thanks go to Livia: for her relentless interest in this project, for the ingenuity with which she accompanied and fostered its evolution, and for simply everything. Finally, I want to thank my parents, Gabriele and Robert, who, with their love, support, and generosity, made this all possible. This book is dedicated to them. 


\section{Abbreviations}

BDP Bürgerlich-Demokratische Partei [Conservative Democratic Party of Switzerland]

BER Flughafen Berlin Brandenburg [Berlin Brandenburg Airport]

BMVEL German Federal Ministry of Consumer Protection, Nutrition and Agriculture

CDU Christlich Demokratische Union Deutschlands [Christian Democratic Union of Germany]

CEO chief executive officer

CHA comparative-historical analysis

CSA Child Support Agency

CTR corporate tax reform

CVP Christlichdemokratische Volkspartei [Christian Democratic People's Party of Switzerland]

FDP Freie Demokratische Partei [Free Democratic Party of Germany] FDP.Die Liberalen [Free Democratic Party of Switzerland]

HCT health care targeting (system)

MOB March on Bern (security controversy)

NHS National Health Service

NSU National Socialist Underground

OECD Organisation for Economic Co-operation and Development PFI public finance initiative

PPP public-private partnership

SP Sozialdemokratische Partei der Schweiz [Social Democratic Party of Switzerland]

SPD Sozialdemokratische Partei Deutschlands [Social Democratic Party of Germany] 
SVP Schweizerische Volkspartei [Swiss People's Party]

UK United Kingdom

USA United States of America

VA (Department of) Veterans Affairs

VHA Veterans Health Administration 


\section{How Political Systems Manage Their Policy Controversies}

In October 2013, the launch of healthcare.gov, a website through which US citizens can buy health insurance, turned into an embarrassing event for the Obama administration. The website crumbled under a heavy user load and citizens were unable to create accounts. As the infrastructural centerpiece of President Obama's Affordable Care Act, the website was vital for expanding healthcare coverage to previously uninsured US citizens. Republicans, who had long opposed the Affordable Care Act, took the chaotic launch of the website as a welcome opportunity to blame the Obama administration for its ineptitude and its overall stance on healthcare. The president admitted that there was no sugar coating of the website's marred performance and promised swift improvements. The president's reaction notwithstanding, Republicans continued to blame the administration for sluggish performance improvements until the secretary of health and human services, who had overseen the website launch, resigned in April 2014.

A year later, in early summer 2015, a lobbying affair kept Swiss politics in suspense. A newspaper revealed that a member of the National Council - the lower house of the Swiss parliament - had submitted a motion under her name, which had in fact been devised by Kazakhstani party functionaries. The controversy triggered a heated discussion about remote-controlled politicians and lobbying regulations in Switzerland. Amid public blame, the parliamentarian justified her conduct but also called the proliferation of documents to Kazakhstani authorities an unfortunate mistake. Calls for disciplinary measures against the parliamentarian and for adaptations of existing lobbying regulations ultimately came to nothing.

At first glance, the chaotic launch of the healthcare.gov website and the Swiss lobbying affair do not have much in common. However, a closer examination reveals that they are examples of the same type of political event. Both instances are political "blame games" in response to policy controversies. Media consumers are intimately 
familiar with the typical political blame game. It starts with the (often accidental) discovery of a controversial event that shows that those in power and office failed to live up to agreed upon rules, standards, or previous promises. Upon this discovery, media outlets, pundits, and politicians in the opposition quickly take up the controversial event and start to assign responsibility and blame for it. Governing actors react to the controversy with excuses and explanations. Sometimes they give in to criticism and engage in activism to address it, and sometimes they kick the can down the road in the hope that the attention will quickly move on to the next controversial event on the political agenda.

Political blame games of this sort happen by the dozens in Western democracies - year in, year out. But why are blame games important? Why care about seemingly routine and minor political quarrels? In a time where big events, like the rise of populism or increased political polarization, need to be accounted for, these questions seem reasonable. Although it may be tempting to sweep political blame games under the rug of normal political competition, this book suggests doing otherwise. It proposes treating blame games as extraordinary political events, whose close study reveals how modern democratic political systems work when they come under pressure.

\subsection{Setting the Scene: When Political Systems 'Heat Up' to Address the Controversial}

Policies are ubiquitous in modern democratic political systems. This is the case because policy has become the preferred problem-solving tool of governments (Orren \& Skowronek, 2017). Modern political systems experience a constant stream of economic, demographic, technological, and societal changes. Be it financial or technological innovations like cryptocurrencies or cloning, soaring house prices or rising economic inequality, or increased levels of migration or shifting social values, all of these changes create situations that governments attempt to regulate through policy interventions. A related explanation for policy's advance is that, over time, the state has come to protect citizens against all kinds of harms, hazards, threats, and risks, ranging from disease outbreaks to industrial accidents to terrorist attacks to instances of consumer fraud (Ansell, 2019). Public demand for protection has prompted governments to respond by means of discretionary policy. As a consequence, governments now set down "prohibitions 
and requirements for everything from hiring practices to the design of entryways for private buildings to the kinds of wordings prohibited or required on consumer packaging" (Pierson, 2007a, pp. 114-115). With governments doing more over a broader range of affairs, policy infrastructure thickens, permeating almost all areas of social, political, and economic life (Adam et al., 2019; Jacobs \& Weaver, 2015; Patashnik \& Zelizer, 2013).

What unavoidably comes with a thickened and more complex policy infrastructure is an increase in the number of policy controversies. Mark Bovens and Paul 't Hart (2016, p. 654) rightly observe that only "a part of this myriad of ambitions and activities unfolds as hoped, expected and planned for by [political and administrative] policymakers. Another part throws up surprises, complications, delays, disappointments and unintended consequences." With policies all over the place, controversies about their configuration, performance, and distribution of benefits are not far behind. Some of these controversies develop into venerable political scandals; others only simmer on the political agenda before disappearing again without anybody addressing them.

What happens to policy controversies that come to the attention of politicians, citizens, and the media? How do political systems manage them? The views commonly held in the fields of political science and public policy give different answers to these questions - and both are incomplete and problematic. The political science literature overwhelmingly considers elections to be the main channel through which citizens influence the management of policy controversies. If voters take umbrage at how politicians address a policy controversy, they can vote them out of office and elect those who promise a better answer to a controversial policy issue. In this conception of politics, 'policy' is treated as a mere commodity in and residual of the 'electoral connection', a term coined by David Mayhew (1974) regarding the interactions between vote-seeking politicians and their voters. In the electoral connection, particular policy controversies usually only play a minor role. Elections have limited issue space, that is, they can only handle a very small number of political problems and policy issues simultaneously. Election campaigns in which a single policy controversy becomes crucial, like with the immigration crisis in the run-up to the 2017 German federal elections, are very rare. Only in these very rare cases is there a clear influence of elections on the political management 
of a policy controversy. Moreover, elections usually only take place every four or five years, with many policy controversies popping up in between. Therefore, with its focus on elections, dominant political science scholarship neglects, and does not grasp the consequences of, a large part of the policy controversies that democratic political systems confront over time.

The public policy literature correctly observes that political science scholarship only studies political conflict with implicit links to public policy (Weible \& Heikkila, 2017). And yet, the public policy literature also lacks an accurate view of policy controversies and their management. The reason is that it usually treats blame games as stages, or even as distracting events of other phenomena, like policy learning or crisis management. The influential works by Arjen Boin and colleagues (2008, 2009a), for example, examine the political management of crises like terrorist attacks or natural disasters. While public blame and blame management are important aspects of crisis management, they are not the main focus of these works. A somewhat different, but likewise consequential, neglect can be observed for policy process research at large. This literature is interested in the combinations of factors that produce policy change. Prominent policy process frameworks do not treat policy controversies as much more than negative focusing events (Birkland, 1998). The large-scale quantitative variant of policy process research (Baumgartner \& Jones, 2009) is especially unlikely to zoom in on the content and actual political management of policy controversies.

The diverse comparative policy literature that adopts a problemprocessing perspective, like literature on policy styles or the governance of problems, comes close to capturing, but still fails to capture, the management of policy controversies during blame games (e.g., Hoppe 2011; Howlett \& Tosun, 2019). Policy styles describe the specific ways in which particular countries address new policy problems (Howlett $\&$ Tosun, 2019; Richardson, 2014). The literature usually distinguishes policy styles along two dimensions: Whether policymakers actively address problems or react to them, and whether policymakers seek consensus with other actors involved in the policy process or if they impose their will on them. However, this line of work does not usually distinguish between more or less conflictual forms of problem processing but rather adopts a more static perspective on policy styles. As I will show, the conflictual interactions over a policy controversy that 
one can observe during blame games are markedly different from routine policymaking patterns. Blame games represent a more conflictual form of problem processing that cannot simply be derived from a country's conventional policy style. For instance, while the UK is known for its adversarial policy style, Germany is known for its much more consensual policy style. With blame games, it is just the opposite. The empirical analyses in this book will reveal that Germany exhibits a much more heated and adversarial blame game style than the UK. Therefore, overall, prominent political science and public policy scholarship ignores political blame games in response to policy controversies.

This book attempts to remedy this neglect. It treats blame games as political events in their own right whose careful study yields crucial insights into how democratic political systems cope with pressure. Much of what follows in the pages of this book finds its basis in the crucial observation that political interactions during blame games are much more conflictual than those that characterize routine political processes, like the occasional debate about pension reform or the next year's budget. Blame games are generally defined as a series of interactions between blame makers and blame takers on the occasion of a controversial political issue (Hood, 2011). I recommend thinking of them as microcosms of conflictual politics. During blame games, politics switches from competition, in which arguments are acknowledged, exchanged, and contested, to outright conflict, in which issues such as guilt, punishment, and redress take center stage. While the goals that political actors pursue during blame games are similar to those pursued during routine times - winning or conserving reputation and votes; gaining or maintaining control over policies - the strategies they apply to achieve these goals are different. Participants in a blame game attack their opponents more fiercely, portray them as utterly incompetent, depict them as guilty, and compel them to make amends. Participants in a blame game not only distort information to get their way (Jones \& Baumgartner, 2007), but they often bend the norms of democratic conduct and argue for their cause in a rather agitated fashion. Moreover, blame makers usually adopt an uncompromising stance: They are unwilling to meet blame takers halfway and want them to yield in full. Overall, the attitudes that political actors exhibit and the strategies that they adopt during blame games are very different from the attitudes and strategies adopted during routine times. Hence, 
to understand how political systems manage their policy controversies, one must appreciate the different, more conflictual, type of politics that occurs during blame games.

\subsection{Political Systems and Their Peculiar Ways of Managing Policy Controversies}

The most important and consequential insight stemming from this book is that political systems have developed peculiar ways of managing policy controversies. This is a very surprising finding given that the policy issues at the root of controversies are so diverse. With a complex and thickened policy infrastructure comes, almost by necessity, an incredibly wide range of policy controversies. They range from marred website launches to porous lobbying regulations to delayed public infrastructure projects to flawed tax reforms. The reason for management similarities across controversy types can be found in the political institutions that preset the political space in which controversy management takes place. As I will demonstrate in this book, it is important to conceive political blame games as context-sensitive events. The interactions between political actors that we observe during blame games - the blame attacks by the opposition and the blame management attempts by those in government - follow patterns that can be explained by looking at the institutional context in which blame games take place.

The best way to provisionally acquaint oneself with the different ways in which political systems manage their policy controversies is to consider an analogy. Suppose that a political system is a bit like a marriage. Actors who have a lot in common decide to spend their lives together. However, as time goes by, disagreements emerge, and conflicts must be endured. Without delving too much into couple's therapy, we can say that every marriage (or at least long-lasting ones) develops its own way of dealing with conflicts. Some couples try to swallow their anger and ignore a conflictual issue for as long as possible. Other couples reconcile their differences rather emotionally. Still, other couples, although perhaps not many, deal with conflicts in a rather unemotional and problem-oriented way. Political systems and their policy controversies follow a similar story. In some political systems, political actors try to suppress controversies for as long as possible, in others they engage in heated blame game interactions. In 
still other systems, political actors engage in rather problem-oriented blame game interactions when addressing a policy controversy.

By looking at the conflictual form of politics that blame games contain, one can learn a tremendous amount about the workings of democratic political systems under pressure. The insights that stem from the effort to understand blame games are vitally important in light of the big events mentioned earlier, like populism, elite polarization, or norm erosion, which currently cripple Western democracies and have prompted many to seriously fear for their health (Levitsky \& Ziblatt, 2018; Mounk, 2018; Snyder, 2018). As I will explain toward the end of this book, the conflictual style of politics contained in blame games resembles the type of conflictual politics that democracies are currently experiencing on a wider scale. Today, it often seems as though blame games are no longer confined to particular issues and instances but that politics as such turns into one huge blame game, with politicians violating norms and attacking each other on a daily basis. This book's explanations of conflictual politics during blame games help to make sense of conflictual politics more broadly. The more conflictual style of politics that emerges when political systems heat up to address controversial events forces us to reconsider, and eventually revise, dominant considerations about policy's role in politics and about the functioning of democracy more broadly.

\subsection{Goals and Outline of the Book}

This book provides a context-sensitive explanation of blame games and their consequences. Drawing on the analysis of fifteen blame games in the UK, Germany, Switzerland, and the USA, this book develops the first middle-range theory of these important political events.

\section{The Three Major Analytical Steps of the Book}

The book proceeds through three major steps. In the theoretical part of the book, I develop a comprehensive theoretical framework for the context-sensitive analysis and comparison of blame games. The guiding idea behind the theoretical framework is that blame games can only be properly understood by considering both the institutional factors that characterize the political system in which blame games occur and the issue characteristics that characterize the controversies at the root of 
blame games. Taking inspiration from the work of E. E. Schattschneider (1975) and Albert Hirschman (1994), I identify institutionalized forms of conflict management that Western democracies have developed to manage policy controversies. Institutional factors, namely the structures around routine political interactions in a democracy, institutionalized accountability structures, and institutional policy characteristics, act as the rules of the game that influence the broad contours of blame games and channel them in certain directions. In addition to institutional factors, I consider a second group of explanatory factors in order to account for the fact that blame games play out in front of an audience. Based on policy feedback theory (Pierson, 1993; Soss \& Schram, 2007), I identify the salience and the proximity of a controversy to average publics as the issue characteristics that determine the public's reaction to a particular blame game and the ways in which the opposition and those in government work with this reaction. A crucial advantage of this framework is that it allows for the meaningful comparison of blame games induced by a diverse set of policy controversies, ranging from food scandals to failed infrastructure projects to procurement scandals to investigation failures. The framework strikes a balance between zooming in on the content of political conflict and securing comparability across controversy types.

The theoretical framework guides and structures the empirical analysis of fifteen blame games in the second part of the book. These blame games occur within four institutional and four issue contexts. The institutional contexts consist of important aspects of the UK, German, Swiss, and US political systems. The issue contexts are four possible combinations of salience and proximity. I show how various combinations of institutional factors and issue characteristics configure different types of blame games. Institutional factors mainly determine the basic form or set-up of a blame game, that is, how participants position themselves and enter into alliances after a policy controversy has become a bone of contention. Participants in a blame game can be divided into 'opponents', who act as blame makers, and 'incumbents', within whose responsibility sphere a controversy develops. Institutional factors further influence the structure of interactions between participants, that is, political opponents' opportunities for blame attacks and the blame barriers available to incumbents. Finally, institutional factors influence the distribution of power between opponents and incumbents. In some institutional settings, 
incumbents are comfortably protected from blame and can adopt an uncompromising stance. In other settings, opponents have a better chance of damaging the reputation of incumbents or changing the course of policy during a blame game. The analysis further reveals that issue characteristics influence the content of interactions between blame game participants. What opponents say and do to attack incumbents and to attract the attention of the public and what incumbents say and do to address a controversy in the face of blame primarily depends on the salience of a controversy and on its proximity to average citizens.

The final part of the book reveals how the configurations of institutional factors and issue characteristics combine to produce blame games that vary in their consequences. For this purpose, it groups blame games according to the level of public interest that they attract and the consequences that they have for the fate of incumbents and policies. This part of the book demonstrates that when distinct controversy types pass through specific institutional systems, one of four possible blame game types can be expected to occur. This outcome reveals that a simplistic view of the relationship between the level of public interest in a blame game and the extent of consequences of it must be replaced with a more accurate (and complex) picture of blame games and their consequences. Blame games that attract the most attention from political actors, media, and the public are not necessarily those that produce significant consequences. Under particular conditions, the blame games that attract the greatest public interest only produce hot air. On the contrary, there are also blame games that slip from the view of the wider public but which nevertheless force incumbents to adjust policies. Overall, the analysis shows that political systems deal with policy controversies in idiosyncratic ways. Every political system has developed its own blame game style for managing policy controversies and does so with a wide variety of controversy types.

\section{Outline of the Book}

The remainder of this book proceeds as follows. Chapter 2 sets out to define blame games as distinct political events that protrude from routine political processes and conceptualizes the process through which a controversy becomes the object of blame game interactions. I conceptualize blame games as instances of intensified conflict during 
which political actors apply distinct sets of strategies to reach their goals. I describe both the blame-generating strategies of opponents and the blame-management strategies of incumbents. Since a variety of controversies, scandals, and (natural) crises trigger blame games in the political sphere, this chapter also revisits the question of why it is particularly important and revealing to study and understand blame games induced by policy controversies. Chapter 2 continues by introducing the theoretical framework used to explain blame game interactions and their consequences. I group the framework's explanatory factors into institutional factors and issue characteristics.

The empirical analysis conducted in Chapters 3-7 revolves around fifteen blame games that occurred in the UK, Germany, Switzerland, and the USA between 1999 and 2016. I analyze several blame games in each of these institutional contexts, each triggered by a controversy with different issue characteristics. I first examine and compare the effects of institutional factors on these blame games, and then I analyze the effects of issue characteristics. Chapter 8 then consolidates the findings into a more parsimonious typological theory of blame games and their consequences. Finally, Chapter 9 summarizes the results of the analysis and reflects on what the study of blame games implies for our understanding of politics and democracy under pressure.

\subsection{Strategy of Inquiry}

Blame games are very complex political events that require in-depth examination. At the same time, getting an idea of how democratic political systems manage their policy controversies requires a comparative approach that analyzes blame games in a variety of institutional and issue contexts. Despite pioneering work on blame games (Hood, 2011; Weaver, 1986), our understanding of these multifaceted and dynamic political events is still limited. Blame games, as spatially and temporally bounded political events (Falleti \& Mahoney, 2015), have proved to be notoriously difficult to conceptualize and study (Hinterleitner \& Sager, 2015). To date, there are no studies that analyze blame games in their entirety, that assess their consequences for the policies at their core and for the politicians involved, and that compare them across countries.

Squeezing very complex events, like political blame games, into a comparative template always involves tricky decisions about which aspects to consider in detail, which aspects to consider in passing, and 
which aspects to overlook. Selecting cases based on a theory or framework that omits important aspects could lead to selection bias. In other words, there is a possibility that one could examine and generalize about blame game styles from an "episodic, narrow, and inadequate exposure to a partial sample" of the blame game universe (Freeman, 1985 , p. 475). In the following, I briefly introduce a strategy of inquiry that can handle these difficulties. The strategy combines the contextsensitive comparison of blame games with detailed case study accounts (George \& Bennett, 2005; Mahoney \& Thelen, 2015).

\section{Method of Analysis}

To examine the effects of contextual factors on blame game interactions, I conduct a comparative-historical analysis (CHA) of each of the fifteen blame games contained in this book (Mahoney \& Thelen, 2015). A CHA treats blame games as sequences of interactions. This allows me to establish the influence of contextual factors on the specific actions of opponents and incumbents and not just on the blame game as a whole. Moreover, by situating blame games in a usually longerrunning policy struggle, one can better grasp the importance and longterm consequences of a blame game. With its reliance on case-based research, a CHA also allows me to proceed exploratively in order to bring "novel explanations to the fore" (Thelen \& Mahoney, 2015, p. 13). This is an important requirement for exposing interaction effects between contextual factors and for specifying the mechanisms through which (combinations of) contextual factors influence blame game interactions. Moreover, an inductive focus allows me to discover and accommodate idiosyncratic factors that are not captured by the theoretical framework but may nevertheless influence blame game interactions (Bennett \& Elman, 2006).

\section{Compound Research Design}

Since the fifteen blame games analyzed in this book occur in very different institutional and issue contexts, they must be arranged in ways that allow for feasible and insightful comparisons. This is achieved by arranging cases within a compound research design, which sorts contextual factors along two dimensions and then allows me to examine their respective influences on a blame game in a systematic way (Levi- 
Faur, 2004, 2006a; Vogel, 1996). As described previously, the contextual factors identified in the theoretical framework are either related to the institutional context in which the blame game plays out or to the controversy at the root of the blame game. I analyze how policy controversies are dealt with and politically processed in the UK, German, Swiss, and US political systems. The different shapes and combinations of relevant institutional factors across these systems produce major differences in blame game interactions and, therefore, constitute ideal institutional settings for comparing how democratic political systems manage policy controversies. The second dimension along which I compare blame games is the interpretive characteristics of the policies at the heart of blame games, that is, the aspects of a policy that determine the public reaction to a blame game. As I will explain in the next chapter, salience and proximity cover the most important interpretive characteristics of policy controversies that occur in modern democratic political systems. Therefore, cases that exhibit the four possible combinations of salience and proximity are representative of the spectrum of policy controversies that political systems process during blame games.

I employ a theory-driven case selection strategy that selects cases based on the independent variables contained in the framework. With four political systems and four possible combinations of salience and proximity, I can analyze and compare sixteen potential cases (corresponding to the sixteen table cells in Table 1). For a blame game to fall into a cell in Table 1 , it must possess a certain combination of contextual factors, that is, it must have occurred in a particular political system and the controversy at the heart of it must exhibit a certain combination of issue characteristics. I selected blame games that developed in response to a controversial policy issue that attracted at least a modicum of political attention and blame. Since the universe of policy controversy-induced blame games also consists of low radar blame games that do not draw too much attention and blame, only focusing on heated blame games is not an option. The intensity of the ensuing blame game interactions is deliberately ignored in order to avoid making a selection based on the dependent variable, that is, only selecting heated blame games that revolved around venerable political scandals. Moreover, I only selected blame games that political actors could not easily see coming. As I will explain in the next section, blame games for which politicians can prepare in advance exhibit a different dynamic than blame games that catch them by surprise. 
Table 1 The blame games selected for analysis arranged within the compound research design

\begin{tabular}{|c|c|c|c|c|}
\hline & UK & Germany & Switzerland & USA \\
\hline Distant-salient & $\begin{array}{l}\text { Child Support Agency } \\
\text { operation } \\
\text { controversy (CSA) }\end{array}$ & $\begin{array}{l}\text { National Socialist } \\
\text { Underground } \\
\text { investigation } \\
\text { controversy (NSU) }\end{array}$ & $\begin{array}{l}\text { Youth offender } \\
\text { therapy controversy } \\
\text { (CARLOS) }\end{array}$ & $\begin{array}{l}\text { Veterans Health } \\
\text { Administration operation } \\
\text { controversy (VHA) }\end{array}$ \\
\hline $\begin{array}{l}\text { Proximate- } \\
\text { nonsalient }\end{array}$ & $\begin{array}{l}\text { London Underground } \\
\text { renovation } \\
\text { controversy } \\
\text { (METRONET) }\end{array}$ & $\begin{array}{l}\text { Berlin Airport } \\
\text { construction } \\
\text { controversy (BER) }\end{array}$ & $\begin{array}{c}\text { Corporate tax reform } \\
\text { controversy (TAX) }\end{array}$ & $\begin{array}{l}\text { Flu vaccine provision } \\
\text { controversy }(F L U)\end{array}$ \\
\hline Distant-nonsalient & $\begin{array}{l}\text { Millennium Dome } \\
\text { controversy (DOME) }\end{array}$ & $\begin{array}{l}\text { Drone procurement } \\
\text { controversy } \\
\text { (DRONE) }\end{array}$ & $\begin{array}{l}\text { National exposition } \\
\text { controversy (EXPO) }\end{array}$ & $\begin{array}{l}\text { Solyndra loan provision } \\
\text { controversy (SOLYNDRA) }\end{array}$ \\
\hline Proximate-salient & $\begin{array}{c}\text { Health Care Targeting } \\
\text { controversy }(\mathrm{HCT})\end{array}$ & $\begin{array}{l}\text { Nitrofen detection } \\
\text { controversy } \\
\text { (NITROFEN) }\end{array}$ & $\begin{array}{l}\text { 'March on Bern' } \\
\text { security policy } \\
\text { controversy (MOB) }\end{array}$ & \\
\hline
\end{tabular}


The compound research design allows for the systematic comparison of blame games situated in the same institutional context (see columns in Table 1) and of blame games where controversies exhibit similar issue characteristics (see rows in Table 1). By identifying similarities within columns, we obtain a view of how blame games typically occur in a specific institutional context, such as the German political system. Likewise, by identifying similarities within rows, we can develop a view of, for instance, a typical distant-salient blame game. The cases to be compared in a column or row exhibit commonalities in one dimension while exhibiting maximum variation in the other dimension. For example, the UK blame games analyzed are situated in the same institutional system, but they exhibit maximum variation in terms of salience and proximity. This type of comparison allows for the identification of a blame game style that applies to the full spectrum of policy controversies typically processed in the UK system. In other words, the comparisons inherent in the compound research design represent an additional protection against false generalizations.

\section{A Two-Step Analysis}

A crucial feature of the compound research design is that it allows me to divide cases into groups. I analyze one group of blame games in great detail (the nine cells in Roman font in Table 1), while another group of blame games serves as test cases for the insights derived from the analyses and comparisons of the first group of blame games (the six cells in italic font in Table 1). I study the first group of blame games in great depth to create a thorough understanding of how contextual factors influence blame game interactions (Falleti \& Lynch, 2009; Hinterleitner, 2018). At the outset of each in-depth case study, the analysis integrates the controversy leading to the blame game into a (usually) longer-running policy struggle. I then reconstruct the various interactive steps of the blame game and infer actors' blame-generation and blame-management strategies from their public accounts. Finally, I assess the influence of (combinations of) contextual factors on incentive structures and the strategy choices of the actors involved.

I analyze the UK, German, and Swiss systems in detail because the relevant institutional differences between these systems are particularly pronounced (see Table A1 in the Appendix for a systematic overview). With regard to controversy types, I examine distant-salient, proximate- 
nonsalient, and distant-nonsalient controversies in detail. These controversy types cover the large majority of controversies that occur in Western democracies. Proximate-salient controversies, like pension scandals or large-scale health scandals, are much rarer in relatively well-functioning political systems. Moreover, I seek to isolate the influence of salience and proximity on blame game interactions. This works best by analyzing and comparing cases that only exhibit one of these issue characteristics.

After analyzing the nine blame games in this way, I compare three cases in a column/row to identify the (combinations of) factors that have similar/comparable causal impact across the column/row. The result is a first impression of what a blame game in a particular institutional setting (e.g., a German blame game) or a blame game with a particular combination of issue characteristics (e.g., a distantnonsalient blame game) typically looks like. I then seek to validate and refine my first impression of blame game styles by testing the findings gleaned from the nine blame games against the remaining six blame games. For example, I test whether, and to what degree, the conclusions drawn from the comparison of the three Swiss cases can be validated in the fourth Swiss case, the blame game about the 'March on Bern' security controversy.

Dividing the fifteen blame games into groups may seem to be an unnecessary complication of the empirical analysis, but it is not. The testing step that is built into the compound research design further increases my confidence that the blame game styles derived from the comparisons of the nine in-depth cases are accurate and generalizable to other cases with the same institutional or issue context. Unlike the three in-depth cases, whose detailed analysis creates strong internal validity, the test cases allow me to systematically target external validity, thus further increasing confidence in the generalizability of the findings (LeviFaur, 2006b). Overall, the theoretical framework, the theory-driven case selection strategy, and the compound research design with its testing step combine to form a powerful analytical strategy that yields reliable and generalizable results about blame game styles.

\section{Data and Measurement}

The fifteen case studies in this book draw on a vast volume of qualitative data systematically coded and analyzed with Nvivo 10 software. 
The data is collected from four data categories that together provide ample evidence of the influence of institutional factors and issue characteristics on blame game interactions. First, I analyze official documents, such as transcripts of debates in parliaments and committees, parliamentary initiatives, inquiry reports, official publications, and press releases to reconstruct how blame game actors interact with each other and with the public. ${ }^{1}$

Second, I draw on background literature on political systems and policy sectors (e.g., on cultural policy in Switzerland, which is relevant in the EXPO case), as well as on background literature on broader political and societal developments (e.g., on the peculiar relationship between Germany and its army, which is relevant for the DRONE case; or the UK's New Public Management reform trajectory, which plays a role in some of the UK cases). Background literature helps me to determine institutional factors and the salience and proximity of a controversy. I made qualitative assessments of the salience and proximity of a policy controversy prior to the start of a blame game to guard against tautological reasoning (i.e., to measure them before they become distorted by the blame generation and blame management approaches of political actors). ${ }^{2}$

The third source of data is the comprehensive media coverage of blame games. For each case, a rather conservative quality paper, a more liberal paper, and a tabloid paper are analyzed. ${ }^{3}$ The consideration of the intensity, variation, and tone of media coverage allows me to measure the public's reaction to a blame game (public feedback). Media may of course misrepresent the reaction of the public (e.g., through bad reporting or by covering a blame game more intensively than the true public interest in that blame game would suggest). However, I argue that a lack of first-hand information on the public's reaction does not carry much weight in light of the present research context. I am ultimately interested in how blame game actors perceive the public's stance and how they react in response. How blame game actors perceive the public's reaction mostly happens through the media. The amount of and variation in coverage reveals how interested different parts of the public are in a blame game. If there is significant tabloid coverage of a blame game in addition to significant quality coverage, one can safely assume that the wider public - and not just the societal elite - is watching the blame game. ${ }^{4}$ The tone of the coverage discloses whether a controversy is perceived to be salient or not. 
Personalized and emotional coverage signals that the public perceives a controversy to be salient while problem-oriented and unemotional coverage indicates that a controversy is perceived to be nonsalient. ${ }^{5}$

Finally, where available, I consult polls held by news agencies during a blame game. Polls are a way for blame game actors to directly sense the public's attitude toward a blame game. Polls thus provide a more direct measure of the public's attitude than media coverage. 
Blame games consist of interactions between at least two sets of actors: "blame makers (those who do the blaming) and blame takers (those who are on the receiving end)" (Hood, 2011, p. 7). Whether an actor is a blame maker or a blame taker during a political blame game largely depends on that actor's political position. In the following, I call these sets of actors opponents and incumbents.

Opponents are the actors that are brought to the scene by a controversy and oppose the way that the controversy is handled by those in power. Opponents in a blame game often match the parliamentary opposition, but they can also include organized interests that are affected by the controversy and thus have a stake in the ensuing blame game. Organized interests are often the first to call attention to an issue, frame it as problematic, and publicly assign responsibility for it. Nevertheless, they ultimately depend on politicians to feed their interests into the political process. I assume that politicians in the opposition play a disproportionately large role because they represent the natural counterpart of political incumbents. Politicians in the opposition can offer a political alternative during a blame game (either a change in personnel or a different approach to addressing the controversy), and they can use their institutional prerogatives (like speaking time in parliament or contacts in the media) to take up a controversy and politicize it.

Incumbents are actors who, by virtue of their office, are called on by opponents to address a controversy and eventually face consequences for actions or omissions that allegedly led to the controversy or for their handling of the controversy as such. Incumbents encompass individual ministers or secretaries, as well as the ruling government as a whole. In addition to the parties that make up the government, incumbents, like opponents, may receive support from organized interests for which the controversy comes at an awkward moment and who may like things to stay as they are. 


\subsection{More Than Routine Political Business: Blame Games as Distinct Political Events}

The occasion of a political blame game is a controversial event that attracts the attention of citizens, media, and politics. Controversial political events can take a wide variety of shapes. The first category of controversial events that usually comes to mind are cases of private misconduct - typical examples include presidents who have extramarital affairs or parliamentarians who misappropriate public funds (Hood, 2011; Sabato, 2000). A government's inability to confront exogenous threats, such as terrorist attacks or natural disasters, may also constitute controversial political events (Boin et al., 2008; Moynihan, 2012). Government decisions that deliberately impose losses on constituents, like pension cuts or closures of military bases, can likewise be controversial (Pal \& Weaver, 2003). Finally, there are the many endogenous malfunctions of a political system, such as policy failures or government blunders, that undoubtedly fall under the rubric of controversial events (Hood et al., 2009; Jennings et al., 2018; King \& Crewe, 2014; Lodge et al., 2010; McConnell, 2010a). The chaotic launch of the healthcare.gov website and the Swiss lobbing affair fall into this category.

While controversial events are at the basis of political blame games, they do not (yet) constitute clearly established political scandals or failures. A scandal or failure already implies a certain level of politicization (during a blame game). A policy controversy only turns into a political scandal if the opponents in a blame game successfully politicize the controversy and force incumbents into heated blame game interactions. Hence, the course of a blame game decides whether a controversy develops into a venerable political scandal or stays a low radar issue. The study of blame games therefore also contributes to our understanding of political scandalization processes (Adut, 2008; Allern \& von Sikorski, 2018, p. 3017; Entman, 2012).

In this book, I focus on blame games triggered by policy controversies because they are at the heart of political struggle in modern democratic political systems. In doing so, I side with political science research that has begun to abandon an overly narrow conception of politics that primarily revolves around vote choice, elections, and campaigns. Following in the footsteps of E. E. Schattschneider (1935), Theodore Lowi (1964), Hugh Heclo (1974), and others who argue that policies 
create their own politics, scholars have developed a policy-focused political analysis (Hacker \& Pierson, 2014; Mettler \& SoRelle, 2014; Pierson, 1993). This research perceives political contestation more broadly, appreciating that politics is not only about winning votes but also about gaining control over particular policies. Policy controversies are commonplace in modern democratic political systems where policy infrastructure thickens as governments set about regulating an increasing number of challenges and situations (Bovens \& 't Hart, 2016; Orren \& Skowronek, 2017). The blame games that develop in their wake are opportunities for actors to change policy trajectories. This is why it is important to know what political actors say and do during policy controversy-induced blame games and what consequences their interactions produce.

Policy controversies stand out from and interrupt routine political processes, attracting more attention than daily political business, such as the occasional debate about pension reform or the quarrel about next year's budget. While most of the issues that linger on the political agenda of a democratic political system must be addressed someday and somehow, the political management of controversies is special. Democratic political systems must process them without delay and under heightened attention from various parties. Incumbents are usually surprised by policy controversies, and they would have preferred to avoid them. As politically responsible actors, they have a lot to lose and not much to win. This constellation is different from the blame games that develop when incumbents deliberately impose losses on constituents, like the aforementioned pension cuts or military base closings. The politics of pain that usually surround these political decisions (Pal \& Weaver, 2003; Vis, 2016) represent an altogether different challenge to political incumbents. While likewise dangerous and risky, incumbents can usually prepare for the politics of pain, that is, they can strategically time a loss-imposing decision or try to present it in a less blame-attracting way.

The processing of policy controversies usually occurs in several, mutually nonexclusive steps. The policy controversy must first be properly understood: What happened and why did it happen? For instance, why did the Obama administration launch the healthcare .gov website in such a chaotic way? Was there an IT breakdown that could have been avoided? Then the controversy must be evaluated: what exactly is bad about it and how bad is it? For example, is it really 
bad if the Kazakhstanis interfere in Swiss domestic affairs, or is it just the way things are nowadays? And finally, consequences, in the form of drawing conclusions, learning, punishment, or course corrections, must be agreed upon and brought about. For instance, should a parliamentarian submitting a motion for a foreign regime have to resign, or is an apology enough? Should the Swiss parliament revise lobbying regulations? Needless to say, the management of policy controversies is almost always a much contested exercise. Policy controversies are not mere factual events, but rather they entail a political assessment of whether and how a policy has failed, and whether this failure should be considered a scandal (Bovens \& 't Hart, 2016; McConnell, 2010b). In short, when it comes to the political management of policy controversies, political actors most often disagree about what happened and why, whether it is good or bad, and about which consequences need to be drawn.

\section{The Motives and Strategies of Opponents}

For those seeking power, policy controversies present an opportunity to damage incumbents and effectuate change. Quite simply, policy controversies provide blaming opportunities for opponents. Blaming the politician in charge, or the whole government, for a controversy is potentially reputation damaging: ministers or secretaries may be weakened in office, be forced to resign, or the government may suffer a drop in its approval ratings. Moreover, opponents may attempt to use the controversy to change policy. Blame pressure from opponents may prompt incumbents to adapt an existing policy or to address an (inconvenient) policy problem. Since conflicts over policy often stretch over considerable time spans, a particular blame game may only represent a phase of intensified conflict in a long-term policy struggle. Therefore, it is likely that opponents may strive to institutionalize their political gains for subsequent rounds of the policy struggle even if imminent policy change is hard to bring about. In short, bringing about a change in the current distribution of reputation and/or changing policy are the substantive goals of opponents during a blame game.

Christopher Hood defines blaming as "the act of attributing something considered to be bad or wrong to some person or entity" (Hood, 2011, pp. 6-7). In order to blame those in office, political opponents thus 
work on emphasizing both the perceived loss and perceived responsibility of a controversy (Hinterleitner \& Sager, 2017; Sulitzeanu-Kenan \& Hood, 2005). Highlighting the perceived loss dimension means convincing the public and media that a controversial event actually constitutes a loss in some way: a loss of money, a loss of time, or even a loss of life. For some controversies, the loss is clearly discernible for everyone. For others, what actually constitutes a loss is less clear. Highlighting the perceived responsibility dimension means that opponents seek to make incumbents responsible for the loss. What happened was not just the consequence of some magical amalgamation of circumstances, but it supposedly directly flowed from the actions or inactions of the government. In the empirical analysis that follows, I will therefore look at whether and how opponents point to and exaggerate the negative aspects of a policy controversy or frame it in moralistic terms (the perceived loss dimension), and ascribe the controversial event to the conduct of incumbents (the perceived responsibility dimension) (Brändström \& Kuipers, 2003; Hinterleitner, 2018; Mortensen, 2012).

\section{The Motives and Strategies of Incumbents}

For incumbents, blame from opponents is dangerous. It threatens their reputation and may force them to yield to policy demands. Therefore, the incumbents' primary motive during a blame game is to stay out of it for as much and as long as possible. However, if they cannot ignore blame pressure, they must begin to address the controversy by adopting various blame-management strategies (Hood, 2011; Weaver, 1986). Numerous categorizations of blame-management strategies exist. Of these categorizations, Hood's (2011) distinction between agency, policy, and presentational strategies is the most widely used. Agency strategies seek to reallocate responsibilities and competencies in order to shift the risk of being blamed to others. An example of an agency strategy is the delegation of activities to actors lower down the administrative hierarchy. Policy strategies address the policy as such. This strategy type seeks to make governmental activities less blameworthy by redesigning policies or changing the ways that they emanate (Hood, 2011). However, incumbents cannot usually rely on agency and policy strategies during policy controversy-induced blame games because these strategies can only be used before blame has materialized, that is, they cannot usually be put in place on an ad hoc basis, or they at least lack credibility if they 
are implemented swiftly (Hinterleitner \& Sager, 2017). During policy controversy-induced blame games, incumbents therefore mainly rely on presentational strategies and forms of discursive interaction (Hansson, 2018a). Instead of reallocating competencies or changing the substance of a policy, presentational strategies intend to shape public impressions and frame the political debate about a controversial event (Boin et al., 2009b; Hood, 2011; König \& Wenzelburger, 2014; McGraw, 1991). Presentational strategies essentially encompass relativizations of the controversy and attempts to deflect blame onto actors and entities somehow involved in the controversy, such as subordinate or adjacent administrative bodies (Hinterleitner, 2018). In addition to genuine presentational strategies, incumbents can take forms of activism, such as launching an inquiry or proposing (symbolic) reforms (Brändström, 2015; Sulitzeanu-Kenan, 2010). Finally, incumbents often seek to signal a specific attitude during a blame game. For instance, they may want to appear as prudent crisis managers, caring mothers or fathers, or energetic problem solvers. Activism and the signaling of a specific attitude are nonverbal forms of presentational blame management (Hansson, 2018b). In the empirical analysis of blame games, I will categorize incumbent behavior along three dimensions: the genuine presentational strategies incumbents apply, the activism they exhibit to address a controversy, and the attitude they adopt during a blame game.

In this conceptualization of the participants in a blame game and their motives and strategies, political actors are not merely conceived as reputation-conscious, vote-seeking political actors (Busuioc \& Lodge, 2016) but also as actors who struggle to reshape a policy area in enduring ways by gaining the prize of policy during a blame game (Bawn et al., 2012; Hacker \& Pierson, 2014; Weaver, 2018). Only this more complex picture of political actors allows us to capture what political actors are really up to when they play a blame game. Hence, as far as policy controversies are concerned, blame games cannot merely be perceived as framing contests (Boin et al., 2009b; Edelman, 1988), they are also conflicts that revolve around substantial policy issues.

\section{The Complexity of Blame Games}

The multitude of blame-generation and blame-management strategies that political actors can adopt and their resulting interactions convey a first impression of the complexity of blame games. Blame games 
emerge due to a wide variety of policy controversies. They involve longer-lasting series of interactions in multiple arenas, and they are embedded in long-running, often confusing, policy struggles. To comprehensively capture blame games, that is, to understand their interactions and their consequences for the politicians involved and the policies at their core, we need to look at the political and policy contexts in which blame games are embedded (Hinterleitner \& Sager, 2015).

So far, however, context-sensitive research on blame games is scarce. Existing attempts to understand context usually focus on only one or a few contextual factors, and they examine their influence on blame games while ignoring the influence of other factors (Brändström \& Kuipers, 2003; Hood et al., 2016; Moynihan, 2012). Moreover, the causal impact of contextual factors is usually only discussed ceteris paribus, meaning that the interrelation between contextual factors remains unconsidered (Boin et al., 2009b, p. 100; McGraw, 1990, p. 129). Perhaps most important, we do not know enough about the success prospects and consequences of different blame-generation and blame-management strategies in particular political and policy contexts. For example, whether and when particular blame-generation strategies lead to reputational damage, or even the resignations of incumbents, and whether and when they lead to policy change, be it fundamental or incremental, are questions largely unaddressed in existing work (Hinterleitner, 2017, 2018). In the next section of this chapter, I will advance the context-sensitive study of blame games by capturing these complex political events in a parsimonious, although comprehensive, framework.

\subsection{A Theoretical Framework for the Analysis of Blame Games}

How can the interactions and consequences of a policy controversyinduced blame game be explained? ${ }^{1}$ In his classic book, The SemiSovereign People (1975), E. E. Schattschneider defines the constitutive parts of political conflicts in a democracy. Since blame games are instances of intensified political conflict, I use these parts as the building blocks for my framework. Schattschneider envisions a political conflict as a fight between two parties. Interactions between the parties occur within and are influenced by the institutional terrain in which they are 


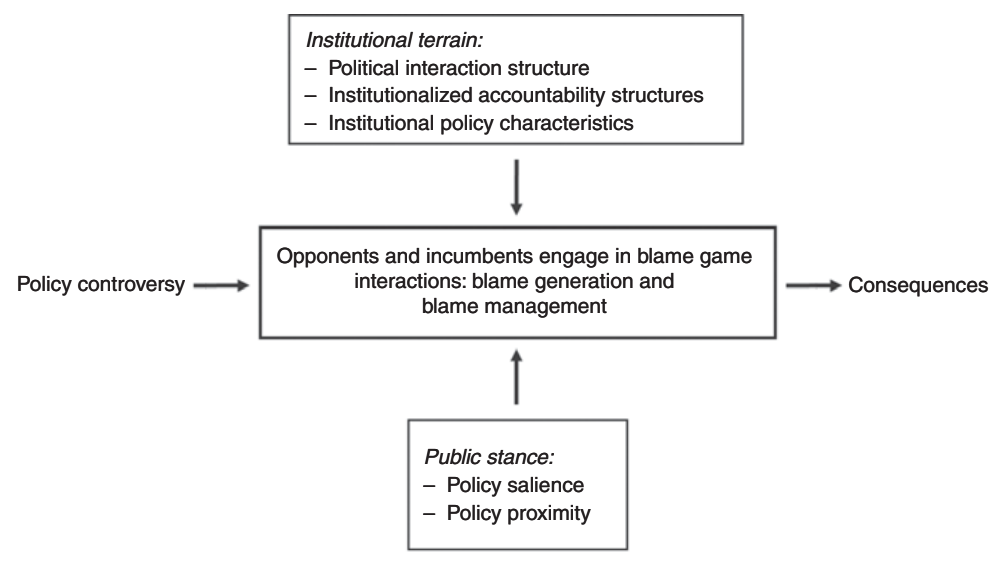

Figure 1 The theoretical framework for the analysis of blame games

embedded. Crucially, in a democracy, important parts of the fight do not occur in the dark but rather in front of an audience. Considering these building blocks and their interrelations will reveal a lot about blame games and their consequences. Figure 1 illustrates the framework that will be developed in the following two sections. The first of these sections charts the institutional terrain in which a blame game is embedded, outlining how institutional factors influence the behavior of opponents and incumbents. The second section conceptualizes the relationship between the public and a blame game and outlines how the public's attitude toward a blame game influences actors and their strategic behavior.

\section{Charting Institutional Terrain: Institutional Factors and Their Influence on Blame Game Interactions}

Political conflict in democracies is governed by rules. As Albert Hirschman (1994, p. 212) famously put it, democracies must digest a "steady diet of conflicts" that constantly arise in modern societies. 'Conflict management', as he called this process, follows certain routines, which a political system institutionalizes over time (see also Schattschneider, 1975, p. 17). In the case of the analysis of blame games, this means that we must expose and describe the institutionalized forms of conflict management that political systems have developed to deal with policy controversies. 
Before we set out to identify institutional factors, it is useful to develop an understanding of how these factors influence blame game interactions. During blame games, institutional factors emit both incentives for and constraints on political actors, channeling them toward particular actions while inhibiting others (Parsons, 2007; Streeck \& Thelen, 2005; Weaver \& Rockman, 1993). For example, when a policy controversy occurs in a particularly complex institutional landscape, far removed from the incumbent minister, it will be difficult for opponents to tie the controversy to the minister, and thus, they can only constrain their blaming on (mostly administrative) entities closer to the controversy. For the incumbent minister, on the contrary, a complex institutional landscape provides incentives to both diffuse blame within that landscape (because in a complex landscape many scapegoats are available) and to ride out the controversy (because political responsibility is opaque in complex landscapes). Therefore, institutional factors can be conceived as the rules of the game that structure blame game interactions (North, 1990; Tsebelis, 1990). The framework treats institutional factors as exogenous structures that blame game actors must take as given during the temporal scope of the analysis (Parsons, 2007). In other words, actors cannot change institutional factors during the blame game. ${ }^{2}$

Due to the widespread neglect of context in the research on blame games, I pursue a syncretic approach in identifying relevant institutional factors, considering factors that have already been treated in the narrower literature on blame games and factors from the wider literature on political conflict. The guiding idea behind the selection of factors is that blame games are influenced by both the political arenas in which they are played out and by policy-related factors, since policies are an important component of the political terrain (Hacker \& Pierson, 2014). ${ }^{3}$ In the following, I identify three groups of institutional factors that chiefly influence blame game interactions: the political interaction structure, institutionalized accountability structures, and institutional policy characteristics. For each group of factors, I outline how their configurations in particular political systems influence blame game interactions. Table A1 in the Appendix contains an overview of the shapes of these institutional factors in the UK, German, Swiss, and US political systems.

\section{Political Interaction Structure}

Every democratic political system has institutionalized rules that structure competition between political actors during routine times. These 
rules are unlikely to completely lose their bite when political actors switch into a more conflictual mode of interaction (Capoccia, 2016). The factors that I deem most important in this category are the organization of the opposition and the stance of governing parties. The organization of the opposition refers to whether the parliamentary opposition, which usually acts as the primary opponent in a blame game, is consolidated or rather fragmented in a political system. For instance, the parliamentary opposition in the UK or the USA consists of only one, or a maximum of two, major parties. In the German or the Swiss system, opposition parties are significantly more numerous. Opponents consisting of multiple opposition parties are likely to have trouble acting as a consolidated actor during a blame game (Scharpf, 1997). Consolidated actors have an easier time coordinating attacks and devising a coherent narrative of a controversy. On the contrary, fragmented opponents are usually less successful in crafting a cohesive blame-generating strategy during a blame game because each party is likely to focus on the aspects of a controversy that they and their supporters deem most important. This should make it more difficult to keep blame pressure on incumbents high.

Along with the organization of the opposition, the stance of the governing party(ies) also influences blame game interactions. Namely, I expect that whether the parliamentary majority is loyal and actively supports the incumbent during a blame game should influence the actions of incumbents. Incumbents that receive support from their party(ies) can more successfully reframe a controversy. With their parties behind them, they can more credibly dismiss opponents' blame attacks as instances of hypocritical vote-seeking behavior. Conversely, a government that confronts criticism from its own ranks or even a backbench revolt during a blame game is likely to have greater trouble downplaying a policy controversy because bipartisan criticism signals that the controversy is indeed problematic. This leads to the following expectations:

Expected effect of the political interaction structure on opponent behavior:

E1: Fragmented opponents, consisting of more than one party, are less successful in crafting a cohesive blame-generating strategy during the blame game than consolidated opponents.

Expected effect of the political interaction structure on incumbent behavior: 
E2: Incumbents that receive support from their party(ies) are more successful in reframing a controversy than incumbents that confront criticism from their own ranks.

\section{Institutionalized Accountability Structures}

Every democratic political system has enshrined rules and norms that detail the responsibilities and duties of political actors (Bovens, 2007; Olsen, 2015). Responsibilities and duties determine who can be credibly involved in a blame game. Opponents can only expect to involve an actor if there is the slightest chance that they can establish a causal link between a policy controversy and that actor. In other words, there must be some sensible basis on which they can make claims of responsibility. Although the reasons behind a policy controversy may be multifaceted and belong to the distant past, a concrete implementation problem usually brings up a controversy. Therefore, administrative actors and entities are the ones who often get caught with their pants down when a controversy begins. During the course of a blame game, it is crucial that opponents can convey that incumbent politicians (and not just administrative actors and entities) bear personal responsibility for the controversy and must be held accountable.

Institutional factors that influence the assignment of responsibility usually take the form of conventions and doctrines of responsibility. Most political systems practice conventions of collective responsibility, such as collegiality principles, which make the government act as a consolidated actor during a blame game. Governments adhering to conventions of collective responsibility can usually, or at least in the beginning of a blame game, leave controversy management to the incumbent politician in whose specific domain the controversy occurred, while the government leader, as well as other government members, can hide behind that politician. As such, the individual politician in charge has a dual role during blame games. For opponents, they are the obvious gateway for blaming the government. For incumbents, they are a blame shield or lightning rod (Ellis, 1994) for the blame coming from opponents.

How much blame the politician receives and how good a blame shield they are for their government depends on conventions of resignation. These conventions detail which occurrences are grounds for the dismissal of individual politicians. In Westminster systems, for 
example, ministerial responsibility obliges ministers to take responsibility for the actions of their department, but the convention states that they only have to resign in cases of personal wrongdoings; a situation that is very unlikely during policy controversies (Hinterleitner \& Sager, 2015; Woodhouse, 2004). While prime ministers can freely make decisions about the fate of their ministers, they will rarely do so during a blame game, as taking a minister away amid blame attacks amounts to a plea of guilt or could be interpreted as a way of caving in. Therefore, conventions of resignation are very restricted in the UK. In Germany and the USA, such conventions are more extensive and vague, while in Switzerland, they are almost absent because federal councilors, ${ }^{4}$ although acting as the principals of their departments, are collectively responsible for controversies. The more extensive such conventions are, the more likely opponents are to concentrate their blaming on the incumbent politician, since extensive conventions allow opponents to formulate straightforward claims of responsibility for a broader range of actions. On the contrary, restrictive conventions are likely to decrease opponents' incentives to involve incumbent politicians in a blame game because the range of issues for which they must resign is smaller. In the case of restrictive conventions, opponents can only blame administrative actors who are more directly involved in the controversy. Conventions thus not only influence whether or not an incumbent has to resign, but they also influence how much blame the incumbent receives in the first place, as opponents take incumbents' attractiveness as blame targets into account.

By influencing the blaming behavior of opponents, conventions of resignation also determine how much is personally at stake for incumbent politicians during a blame game. Incumbent politicians who must comply with extensive conventions (and who thus receive more blame from opponents) will have greater difficulty defending themselves by reframing the controversy or deflecting blame for it than politicians who have to comply with restrictive conventions. Politicians who must comply with extensive conventions of resignation constitute worse blame shields and are more prone to suffer reputational damage during a blame game. This allows me to formulate the following expectations:

Expected effect of institutionalized accountability structures on opponent behavior: 
E3: Opponents facing extensive conventions of resignation concentrate their blaming more on the incumbent politician than opponents facing restrictive conventions, who can only blame administrative actors.

Expected effect of institutionalized accountability structures on incumbent behavior:

E4: Incumbent politicians that must comply with extensive conventions of resignation have greater difficulty defending themselves during a blame game than politicians that must comply with restricted conventions.

\section{Institutional Policy Characteristics}

Since the government of the day carries the overall policy responsibility, it can theoretically be blamed for all policy controversies that erupt under its watch. What counts during blame games, however, is what can realistically be blamed on the government. And this, I suggest, primarily depends on the involvement of the government in a concrete policy issue. As Weaver (1986, p. 390) already observed, the more incumbents appear to be directly involved in a policy issue (e.g., as architects, managers, or decision-makers), "the more likely they are to be held liable for poor performance." However, direct government involvement is far from omnipresent in modern and complex political systems. 'Agencification' or New Public Management reforms adopted in many Western countries in recent decades led to the breakup of monolithic bureaucracies and distanced public-service provision from the direct control of politically responsible actors (Mortensen, 2016; Verhoest et al., 2012). A significant share of policy controversies currently erupt in areas where a considerable number of public and private actors and entities are prominently involved in policymaking and implementation. This is good news for incumbent politicians. The complexity of collaborative structures that result from agencification reforms clouds the clarity of responsibility during a blame game (Bache et al., 2015; Hinterleitner \& Sager, 2017). In cases of low direct government involvement, opponents have greater difficulty pinning down blame on incumbents, while the latter can be expected to have less difficulty deflecting responsibility and blame onto administrative actors. In cases of direct government involvement, I expect that the stakes would be reversed. Opponents can more credibly blame political incumbents for a policy controversy, and the latter have much more difficulties credibly deflecting responsibility 
and blame onto administrative actors. This leads to the following expectations:

Expected effect of institutional policy characteristics on opponent behavior:

E5: Opponents are better able to blame a controversy on incumbents if the latter are directly involved than when the controversy is far removed from incumbents.

Expected effect of institutional policy characteristics on incumbent behavior:

E6: Incumbents are better able to deflect blame for a controversy onto administrative actors if they are not directly involved in the controversy rather than if they are involved.

Demonstrating the effects of political interaction structures, accountability structures, and institutional policy characteristics on blame-game interactions is a relatively straightforward task. As these institutional factors emit incentives and constraints on the actors involved in a blame game, one needs to show that their specific actions constituted rational responses to a particular institutional context while other actions were not feasible in that context (Parsons, 2007, pp. 62-64). For example, with regard to a policy controversy far away from the government, one needs to show that it would have been useless for opponents to lay the controversy at the door of political incumbents and that the only sensible choice was to blame administrative actors. Conceptualizing and demonstrating how the public's stance toward a blame game impacts blamegame interactions requires a different approach, which I will present in the next section.

\section{Listening to the Audience: Issue Characteristics and Their Influence on Blame Game Interactions}

During a boxing match, most spectators do not stand idly by for long. They eventually take an active interest in the match and sympathize with one of the combatants. It is pretty much the same with blame games. When a blame game develops around a policy controversy, the public may watch that blame game and form an opinion on the severity of and responsibility for the controversy at the root of it. Or, the public might largely ignore that blame game, remaining uninterested about its 
details and indifferent with regard to questions of severity and responsibility. Whether the public watches a blame game or largely ignores it has profound implications for blame game interactions. A public that watches a blame game encourages opponents to expand their blaming efforts and drag it on. Incumbents who feel the heat from the public are likely to realize that they must do something to address the controversy and engage in blame management. An indifferent public, on the contrary, makes opponents quickly realize that their initial blamegenerating attempts are futile. Accordingly, they should quickly desist from exploiting the controversy and pay mere lip service to its resolution. Incumbents, in turn, can then adopt a laid-back and uncompromising stance toward the controversy. These stylized scenarios suggest that the public's stance importantly influences blame-game interactions. In order to fully understand blame games, we must thus "keep constantly in mind the relations between the combatants and the audience" (Schattschneider, 1975, p. 2).

But what is it that makes publics watch one blame game while ignoring another? Policy feedback theory and literature on problem construction shows that the public cares about policies (including their changes and controversies) in differentiated ways and to varying degrees (e.g., Mettler \& SoRelle, 2014; Pierson, 1993; Rochefort \& Cobb, 1994). Since the analysis of political information "is costly in time and foregone opportunities," publics usually only spend a little time forming an opinion on particular issues (Page \& Shapiro, 1992, p. 14; Zaller, 1992). Therefore, one must identify the characteristics that make policy controversies protrude from the abundance of mass-mediated events. I suggest that the salience of a controversy and its proximity to the public are crucial in this regard (Hinterleitner, 2018). These characteristics determine the public's answer to two distinct questions regarding a controversy: first, does the public care and, second, is it directly affected by the controversy?

Controversies can be considered salient if they are particularly severe or novel, or if they touch core values that the public holds dear (Brändström \& Kuipers, 2003; Mettler \& Soss, 2004). On the contrary, controversies that are long-standing or recur frequently, or which only produce material costs (instead of ideational costs) can be considered to be nonsalient. Publics can be expected to care much more about salient controversies than about minor or frequently recurring ones. Proximity captures the extent to which a controversy directly 
affects the public, that is, whether the controversy "exists as a tangible presence affecting people's lives in immediate, concrete ways" (Soss $\&$ Schram, 2007, p. 121). In other words, proximity concerns the distribution of material costs. Since proximate controversies activate considerations of self-interest (Campbell, 2012; Page \& Shapiro, 1992, pp. 339-340), they are likely to attract much more public interest and evaluation of their consequences than controversies whose consequences are only felt in the distant future or must be shouldered by a small portion of the overall public (especially if the latter is politically weak). I argue that salience and proximity are the most important issue characteristics for assessing the relationship between blame game actors and the public during a blame game.

In order to fully understand the relationship between the public and blame game actors, we must also take into account that public feedback does not only emerge from the policy controversy as such, but it is also distorted by the communication attempts of the participants in the blame game (Béland, 2010; Patashnik \& Zelizer, 2013). Blame games are mass persuasion situations (Zaller, 1992), during which opponents and incumbents send conflicting messages to publics so as to draw them on their side. In doing so, they work with and are constrained by issue characteristics. In other words, opponents and incumbents try to exploit salience and/or proximity, or the absence of these characteristics, for their purposes. When opponents aim to direct the public's attention to a controversy and persuade it that what it sees is indeed a venerable crisis, they can emphasize particularly salient or proximate aspects of that controversy. When incumbents try to convince the public that a controversy is just a minor incident that does not merit further public attention, they can try to reframe particularly salient aspects of a controversy or, if possible, use the distance of the controversy to downplay its negative effects. Issue characteristics are constructs that opponents and incumbents can accentuate and exploit in order to persuade the public of their interpretation of a controversy. If these persuasion attempts are successful, the public will adopt the interpretation of the controversy presented by either opponents or incumbents (Boin et al., 2009b).

However, when opponents and incumbents try to pull the public on their side, they do not face an anything goes situation. Rather, the direct influence of issue characteristics on the public constrains them. Opponents are unlikely to convincingly portray a controversy as salient 


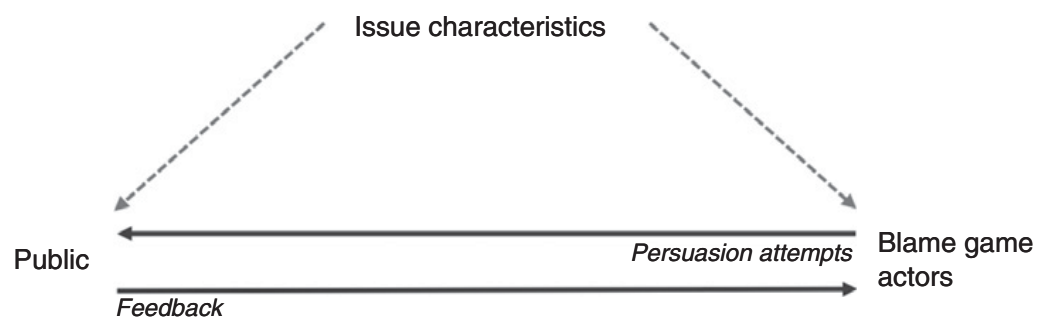

Figure 2 The relationship between the public and the blame game

when the public does not really care about it, for example, because it has seen numerous controversies of a similar sort and has thus become used to them. Neither should incumbents be able to successfully frame a controversy as distant when its impact on large parts of the public is obvious. For instance, incumbents will most likely have difficulties portraying a large-scale public health scandal that potentially threatens everybody as distant. For incumbents and opponents, issue characteristics are malleable, but only to a certain extent. The dashed arrow leading from issue characteristics to the public in Figure 2 captures this constraint. It expresses the idea that the public has preconceived ideas about most controversy types that notably influence public feedback to a controversy. This conceptualization of the relationship between the public and blame game actors reveals a notable difference between the two main categories of explanatory factors outlined in the theoretical framework. While the causal relationship between institutional factors and blame game actors is unidirectional (because blame game actors cannot change institutional structures during the blame game), the relationship with the public is reciprocal (because blame game actors try to work with issue characteristics to influence the public). Figure 2 summarizes this relationship and the influence of issue characteristics on the relationship's concrete shape.

Before I formulate expectations about what the relationship between the public and blame game actors looks like for different combinations of salience and proximity, three complications must be considered. First, the public, in reality, consists of a spectrum of varying attention to an issue (Zaller, 1992). What one part of the public perceives as salient may be interpreted as nonsalient by other parts. Likewise, controversies may be proximate to some parts of the public while appearing distant to others. This aspect requires that I simplify the 
empirical analysis and assess whether the majority of the public perceives a controversy as salient and proximate (Soss \& Schram, 2007).

Second, the public and blame game actors do not communicate directly, rather they do so through the media. On the one hand, the media conveys the public's attitude toward a blame game by covering the issue more or less intensively and excitedly. On the other hand, it transmits communication attempts to the public from opponents and incumbents, as well as background information on a controversy. While pursuing this task, the media does not act as a neutral transmitter but more like a catalyst driven by profit motives. ${ }^{5}$ While the media systems of modern democracies differ on a number of dimensions (Hallin \& Mancini, 2004), they are pretty similar when it comes to their role as catalyst during a blame game. Media systems have mostly converged on the increased commercialization and associated popularization of political news coverage (Umbricht \& Esser, 2016). This development allows me to reasonably assume that the media plays a largely similar role across Western political systems in terms of blame game coverage and scandalization. The media is both a watchdog and a scandalization machine (Allern \& von Sikorski, 2018). Both roles make the media intensively cover the policy controversies that are either very severe or have significant scandal potential.

Although the media's role as a catalyst further complicates the relationship between the public and blame game actors, it also offers the opportunity to measure public feedback to a blame game. Polls held by news agencies would be ideal for measuring public feedback to a blame game. Unfortunately, suitable polls are often scarce. A lack of first-hand information on the public's reaction does not carry too much weight, however, because blame game actors, just like researchers, cannot peer into the heads of citizens but must work with what the media conveys during a blame game. Therefore, by considering the amount, the tone, and the variation of the media coverage of a blame game and the public statements of blame game actors, one can obtain a sufficiently clear picture of how blame game actors react to the public. While tabloids predominantly cover a blame game in a scandalizing fashion, quality papers also inform their audience about the underlying policy controversy and report on the blame game in a more problem-oriented way. If there is not only significant quality coverage of a blame game, but also a significant amount of tabloid coverage, one can safely assume that the wider public - and not just the societal elite - is watching the blame 
game. Moreover, since tabloids are very scandal-driven, they allow me to clearly measure what exact aspect of a policy controversy is considered to be scandalous. ${ }^{6}$ In general, the tone of the coverage discloses whether a controversy is perceived to be salient or not. Personalized and emotional coverage signals that the public perceives a controversy to be salient while problem-oriented and unemotional coverage indicates that a controversy is perceived to be nonsalient. Finally, a look at variations in coverage between left-leaning and conservative outlets helps to control for political parallelism. ${ }^{7}$

A final complication is that the relationship between the public and blame game actors cannot be captured by adopting a snapshot perspective because, during a blame game, the relationship may become distorted by other political events. For example, strong public feedback to a particular blame game may abruptly be suppressed by a natural disaster or by a severe foreign policy crisis. Another possibility is that opponents only receive weak feedback following their blamegenerating attempts on the occasion of a controversy, but that in light of upcoming elections, they decide to nevertheless drag the blame game on. In the empirical analysis that follows, I will account for these distortions by assessing situational factors, such as looming elections or simultaneous, attention-attracting political events. Before, however, I will flesh out the relationship between the public and blame game actors against the backdrop of a distant-salient controversy, a proximatenonsalient controversy, and a distant-nonsalient controversy.

Distant-salient controversies "elicit rapt attention and powerful emotion, but their design features and material effects slip easily from public view because they lack concrete presence in most people's lives" (Soss \& Schram, 2007, p. 122). Because most distant-salient controversies relate to issues of justice and fairness, the public feedback to them is predominantly based on moral considerations. For opponents, a public that passionately watches the ensuing blame game creates strong incentives to invest in blame generation. In such a case, opponents are likely to make the controversy bigger than it is, as the public is less able to evaluate the implications of distant controversies than those of proximate ones. Moreover, opponents can be expected to try to damage incumbents on moral grounds by portraying them as unfaithful leaders. Incumbents should take a distant-salient controversy very seriously. Strong blame pressure from opponents makes it difficult for them to keep out of the ensuing blame game. In an emotionalized 
atmosphere, they are unlikely to successfully reframe the controversy and, therefore, should concentrate on blame deflection and symbolic actions that signal their willingness to address the controversy. This is summarized in the following expectations:

Expected opponent behavior against the backdrop of a distantsalient controversy:

E7: Opponents strongly invest in blame generation on the occasion of a distant-salient controversy and attempt to damage incumbents on moral grounds.

Expected incumbent behavior against the backdrop of a distant-salient controversy:

E8: Incumbents take a distant-salient controversy very seriously and confront it by engaging in blame deflection and symbolic activism.

Proximate-nonsalient controversies affect a large share of the public, but they are not very salient in public discourse, as their impacts are often difficult to grasp or because they do not trigger much anger or emotion among the public. Nevertheless, a controversy of this type is likely to generate stronger public feedback "than one would expect based on the policy's low salience alone" (Soss \& Schram, 2007, p. 122). Due to its proximity, feedback should be primarily based on considerations of self-interest. Opponents confronting a public that attentively watches the ensuing blame game can be expected to try to exploit the proximity of the controversy and invest considerably in blame generation, mainly by activating considerations of self-interest among the public. Incumbents, in turn, do not confront a heated environment, like when they have to address a salient controversy, but they can still not afford to just lay back and mainly ignore the issue. While they are likely to signal that they take the controversy seriously, they may also try to reframe it and eventually engage in activism to eliminate the negative consequences emanating from the controversy. This leads to the following expectations:

Expected opponent behavior against the backdrop of a proximatenonsalient controversy:

E9: Opponents invest considerably in blame generation on the occasion of a proximate-nonsalient controversy and try to activate considerations of selfinterest among the public. 
Expected incumbent behavior against the backdrop of a proximatenonsalient controversy:

E10: Incumbents take a proximate-nonsalient controversy seriously and address it by mainly adopting reframing strategies and forms of activism.

Distant-nonsalient controversies do not usually attract much public attention, as they neither arouse emotions nor directly affect the wider public. Citizens may consider them as elite issues that lack implications for ordinary citizens, or have heard of these controversies so frequently that they have become used to them. Accordingly, public feedback to these controversies is likely to be weak. For opponents, a controversy that is largely ignored by the public is an inappropriate occasion for damaging the reputation of incumbents or for changing the trajectory of a policy. Opponents should thus not invest much in blame generation but should rather quickly desist from pursuing the controversy and pay mere lip service to its resolution. Incumbents, on the other hand, are unlikely to feel threatened by a distant-nonsalient controversy. They can be expected to ignore the controversy for as long as possible, only scarcely engage in blame management, and even adopt an uncompromising stance with regard to its resolution. This allows me to formulate the following expectations:

Expected opponent behavior against the backdrop of a distantnonsalient controversy:

E11: Opponents do not invest much in blame generation on the occasion of a distant-nonsalient controversy.

Expected incumbent behavior against the backdrop of a distantnonsalient controversy:

E12: Incumbents do not take a distant-nonsalient controversy very seriously and only scarcely engage in blame management.

In the next five chapters of this book, I test the explanatory potential of this framework by applying it to different blame games that occurred in the UK, Germany, Switzerland, and the USA. Before we delve into the analysis of blame games, however, a last remark on the explanatory logics that underlie the framework is in order. As already explained, the framework treats institutions as exogenous and unalterable structures that opponents and incumbents must take as given during a blame game. Issue characteristics, on the contrary (and rather counterintuitively), are 
treated as institutions that opponents and incumbents can manipulate, although only to a certain extent. Conceiving the influence of institutions and issue characteristics in this way implies objective rationality on the part of opponents and incumbents because they can be expected to react regularly and reasonably to the external constraints that emanate from structures and institutions (Parsons, 2007). The next chapters will demonstrate that this approach allows for parsimonious and crisp explanations of blame game interactions. 


\section{Blame Games in the UK}

Chapters 3-5 provide detailed accounts of the nine in-depth case studies and detailed analyses of the UK, German, and Swiss blame game styles. Each chapter includes an additional test case that is situated in the respective institutional context. As explained in Section 1.4, I examine the UK, German, and Swiss political systems in detail because the relevant institutional differences between them are most pronounced. The cases situated in the US political system will be discussed in Chapter 7.

This chapter starts by examining the cases situated in the UK political system. The UK political system, with 'the mother of parliaments' at its heart, is famous for its sharp and adversarial political debates (e.g., Moran, 2015). One could expect that an adversarial debate style would be mirrored in heated blame game interactions in response to policy controversies. As the blame games covered in this chapter will demonstrate, however, UK blame games do not often produce much more than hot air.

\subsection{The Child Support Agency Operation Controversy (CSA)}

The Child Support Agency (CSA) operation controversy is about a malfunctioning child maintenance system. The Labour government, under Tony Blair, could afford to leave this distant-salient policy controversy unaddressed for more than ten years without facing any political consequences.

\section{Policy Struggle}

In 1991, the Tory government introduced the Child Support Act to address a new policy problem. The steady increase of children born to lone mothers since the 1970s had produced a paradigmatic case of policy drift (Hacker, 2004). The existing policy solution, a court-based 
system, responsible for child maintenance payments between lone parents and nonresident parents could not keep up with the rising caseload. The CSA, introduced in 1993, was thus commissioned to calculate and collect maintenance payments from nonresident parents and transfer them to lone parents. The maintenance system operated by the CSA was riddled with problems. The CSA used a far too complex formula to calculate maintenance payments. There were no incentives for lone parents to cooperate with the CSA, as maintenance payments were counted entirely against social-security payments. Moreover, the CSA was also advised to take on the cases that had already been successfully settled in court (see e.g., Barberis, 1998; Bates et al., 2002; Harlow, 1999; King \& Crewe, 2014). This poorly designed maintenance system led to slow and erroneous child maintenance assessments, which meant that many lone parents and their children were not getting the money that they were entitled to. Despite a revision of the Child Support Act and other half-hearted attempts to improve the child maintenance system, the CSA continued to struggle with the problems outlined, and it slowly but steadily accumulated an evergrowing backlog of untreated cases.

In response to shocking media stories ${ }^{1}$ about lone mothers and children having to live in poverty due to the CSA's negligence, and pressure from parliamentarians who were bombarded with complaints from constituents, the Labour Party clearly positioned itself with regard to the flawed child maintenance system. In the run-up to the 1997 general elections, it promised a radical reform of the current scheme. A Labour politician involved in developing the party's policy plans for the CSA, said: "To me, the whole culture of the thing is flawed. It has certainly got to change dramatically." ${ }^{2}$ Having won the elections, the new Labour government presented several ad hoc measures and initiated a reform process. It proposed the use of an easier formula for the calculation of payments and the introduction of incentives for lone parents to seek help from the CSA. The implementation of these reform proposals, however, depended on a new IT system, which was not expected to be introduced before $2001 .^{3}$ The Labour government sold these reforms as a giant step toward eradicating child poverty. Alistair Darling, the social security secretary, proclaimed that it "doesn't take a genius to work out that a radical shake-up of the CSA is long overdue and that is exactly what the government is planning." 4 Overall, the reform proposals did not attract much criticism, although, 
already at the time the Liberal Democrats, the second opposition party next to the Tories, urged the government to replace the existing maintenance system instead of painfully and slowly reforming it. ${ }^{5}$

\section{Blame Game Interactions}

In November 2004, after the implementation of the reforms had already been delayed several times, the government finally admitted that the IT system could not be made to work. Untreated cases and complaints continued to pile up. The Sun turned on the "Child Shambles Agency" with a special report. ${ }^{6}$ In the following weeks, opposition parties urged the government to take control of the problem. The Liberal Democrats, joined by Frank Field, an influential Labour politician who argued that the CSA was "teetering on total collapse," repeated their calls to abolish the CSA. ${ }^{7}$ When the prime minister, Tony Blair, commented on the controversy, he admitted that the agency's failures were unacceptable. Amid blame from opponents and critical media coverage, the CEO of the CSA had to resign. However, the government resisted abolishing the CSA and deflected the responsibility for its problems onto the company charged with the implementation of the IT system and onto the child maintenance system inherited from the previous Tory government. ${ }^{8}$

In September 2005, opponents initiated a new blame attack when the CSA's performance worsened further and rumors about its imminent collapse emerged. They increased pressure on the government to act boldly, instead of patching things up, and used the CSA to blame the Labour government for not delivering on welfare issues. ${ }^{9}$ In response, the government apologized for the poor situation and announced its intention to initiate another root-and-branch reform. Two months later, the prime minister admitted that the CSA was "not properly suited" to its job, but, again, argued that the nature of the task that the CSA was supposed to perform - and which had been concocted by the previous Tory government - was extremely difficult. Also in line with previous blame management, he resisted immediate action but played for time by expressing his intention to wait for reform recommendations from the new CEO of the CSA. ${ }^{10}$ During this phase of the blame game, media coverage became increasingly critical of the government, which, in eight years, had 
proved unable to address this policy problem. In November 2005, The Guardian wrote that there "ought to be some kind of official cut-off point, when a government is no longer allowed to blame its cock-ups on the previous government." 11

When in January 2006, the CEO's reform proposals proved too costly to be implemented, the minister for work and pensions announced that another review of the problems at the CSA would be completed by summer. The government's sidestepping once again triggered far-reaching criticism from opponents. The Liberal Democrats repeated their calls to abolish the CSA. In addition, the Tories urged the government to leave its bunker mentality and commit itself to fundamental reform. ${ }^{12}$ The Tory Philip Hammond said that there is "too much at stake for the families currently stuck on the present CSA system for this issue to be, once again, kicked into the long grass." 13

The review commissioned by the minister, as well as a very critical report published by the National Audit Office ${ }^{14}$ in the summer, put the last nails in the coffin of the Labour government's reform efforts. The minister for work and pensions subsequently announced that the CSA was to be dismantled and replaced by a simpler and tougher system. However, even this admission triggered criticism from opponents. They called it another move of "rebranding, further delay and more gimmicks." "Indeed, the flawed CSA occasionally haunted the Labour government until it was voted out in the 2010 general elections, as it received continued criticism for protracting reforms and not acting boldly enough.

\section{Consequences of the Blame Game}

There were no significant consequences following the blame game that accompanied the slow demise of the CSA. Incumbent politicians were never put under pressure and only public managers were forced to resign. Opponents were also unable to make incumbents act boldly. At no point during the blame game did the government change its decision to play for time, patch things up, and instead boldly address the policy problem. ${ }^{16}$ It was only in November 2008 that the government replaced the CSA with the Child Maintenance and Enforcement Commission, a new nondepartmental body for the organization of maintenance payments. 


\section{Context-Sensitive Analysis of Blame Game Interactions}

It is quite puzzling that the Labour government could leave one of the most severe and long-lasting policy controversies of the modern British welfare state largely unaddressed without facing any political consequences. Verdicts by opponents and experts suggest that the government had a real choice to address this policy problem. As early as 1999 , experts asked for a complete redesign of the system and argued that the CSA could never be made to work properly (Harlow, 1999). To understand the government's decision to leave the problem unaddressed, one must keep in mind that the problems at the CSA were very difficult to fix and public credit for fixing them would have been rather low because only weak constituencies had a stake in the controversy. When confronted with difficult-to-fix and electorally unattractive policy problems, governments often "choose to rely as far as possible on following whatever they have inherited, so that blame attaches as much to their predecessors in office as to themselves" (Hood, 2011, p. 20). However, governments only follow this strategy as long as the political costs attached to leaving the policy problem unaddressed do not exceed the costs of boldly addressing it. The consideration of contextual factors explains why these costs remained low for so long and, therefore, tell us why the government could afford to leave this policy problem unaddressed.

\section{Issue Characteristics}

Both quality outlets and tabloids intensively covered the CSA controversy. During the blame game, coverage constantly increased. The media reported on the controversy in a scandalizing and emotional way and used shocking examples of CSA mistreatment to illustrate the severity of the policy problem. Additionally, quality outlets occasionally covered the controversy in a problem-centered way, focusing on the intricacies of the child maintenance system. The strong public feedback that can be gleaned from the intensity and tone of media coverage is very much in line with what I expect in distant-salient controversies. The CSA controversy violated several of the public's core values. Progressives took umbrage at the fact that children and lone mothers, weak and positively viewed target populations (Schneider \& Ingram, 1993), suffered from the government's ineptitude. For conservatives, it was problematic that the government left 
nonresident parents, an epitome of the destruction of traditional family values, and a reason for rising social-security payments, off the hook. ${ }^{17}$ Although there was a significant amount of affected individuals, which increased over time due to changing demographic trends, only a small portion of society was in contact with the CSA. Since new policies need time to create their own vocal constituencies (Mettler \& SoRelle, 2014), there was no policy experience among the majority of the public. This implies that the design features of the child maintenance system, namely its tremendous technical and logistic implementation effort, slipped from the public's view. For the ordinary citizen, the CSA controversy was simply about a government that did not succeed in making fathers pay their due share for their children.

During the blame game, opponents repeatedly urged incumbents to boldly address the controversy and criticized them for only announcing gimmicks and reviews. In order to bring the public on their side, opponents concentrated on the salience of the controversy, frequently accusing the government of failing to protect children. ${ }^{18}$ Incumbents, on the other hand, admitted the existence of a serious problem right from the beginning. They never downplayed the seriousness of the controversy and only cautiously emphasized (modest) performance improvements brought about by reforms. Throughout the blame game, incumbents engaged in patch-up activism and played for time by announcing evernew reviews into the CSA. To signal their commitment and dedication, they garnished their reform proposals with grand rhetorical announcements. Simultaneously, incumbents amply deflected responsibility and blame onto various entities, namely onto the previous government, onto the IT company, onto the CSA, and onto errant fathers who were unwilling to pay maintenance for their children. ${ }^{19}$ Overall, public feedback to the CSA controversy was strong and opponents clearly exploited the salience of the policy problem. While the distance of the controversy should have allowed incumbents to cover up the inadequacy of their reform efforts for a while, distance was not the full story behind the government's inertia toward the controversy. The latter strongly profited from an institutional configuration that protected politicians from blame by diverging it to the administrative level.

\section{Institutional Factors}

As outlined in the previous chapter, ministers in the UK political system only resign in a case of personal wrongdoing (Woodhouse, 2004). In 
the present case, it is obvious that the minister for work and pensions was far removed from the problems of one of the department's several agencies. Restrictive conventions of resignation decreased blame pressure for ministers, as opponents never tried to hold them personally responsible for the flawed child maintenance system. The case further reveals that UK ministers not only profited from restrictive conventions of resignation but also from frequent job rotations at political and agency levels. During the protracted blame game, several politicians held the post as minister for work and pensions. In 2005 alone, a year that covered important blame game interactions, four politicians held the post. Ministers clearly benefited from these frequent job rotations. ${ }^{20}$ While departing ministers simply disappeared from the blame game, incoming ministers enjoyed a honeymoon period (Hood, 2011), during which they could ask opponents and the public for time to acquaint themselves with the controversy. Moreover, ministers profited from job rotations at the agency. The resignations of public managers not only helped to signal the government's indignation but they also allowed it to request a settling-in period for the new public manager, during which the latter could analyze the problem and submit adequate reform proposals. This protracted the blame game and allowed the government to play for time.

During the blame game, the government also profited from low direct involvement in this policy area. Despite the supervisory role of the Department for Work and Pensions, the CSA held significant operational responsibility (Harlow, 1999). Opponents predominantly focused their attacks on the agency, calling the controversy a public administration scandal, instead of a policy failure for which the government should be held responsible. ${ }^{21}$ Tabloids also framed the controversy as an implementation failure, and they held public managers responsible while only imploring that incumbent ministers address the problems at the CSA. ${ }^{22}$ The focus on the agency, by both opponents and the media, injected an administration bias into the blame game, making it easier for incumbents to deflect responsibility and to frame the controversy as an implementation failure.

Finally, incumbents also profited from the fragmentation of opponents. While the Liberal Democrats and some interest groups urged the government to abolish the CSA early on, the Tories only attacked the government later in the blame game. Lone mothers were not one of their primary target groups and blame attacks in the early stages of the 
reform efforts would have rung hollow given the Tories' responsibility for the Child Support Act. Moreover, Tories were less clear in their concrete policy demands than Liberal Democrats. ${ }^{23}$ Only in the later phase of the blame game did they join Liberal Democrats and interest groups in asking for the agency's abolishment. Disagreement among opponents about the right way forward allowed the government to maintain the impression that its reform proposals were an adequate response to the problem because there was no uncontroversial policy alternative on the table. Imprecisions about what constituted a viable alternative to Labour's reform proposals should have been important for the government during this blame game, especially since there were also audible calls from Labour politicians to abolish the CSA. In sum, an institutional configuration that dispersed attacks from opponents and kept political incumbents out of the firing line explains why the government could afford to neglect calls for boldly addressing the controversy, even in the face of strong public feedback (see Table 2 for a schematic assessment of the theoretical expectations).

\subsection{The London Underground Renovation Controversy (METRONET)}

The London Underground renovation controversy refers to the 2007 bankruptcy of a public-private partnership (PPP) charged with renovating large parts of the London Underground. The ensuing blame game about this proximate-nonsalient controversy did not force Gordon Brown's Labour government to veer off its course to prominently involve the private sector in public service delivery.

\section{Policy Struggle}

After having won the general election in 1997, the Labour government needed to deliver on its promise to end the underfunding of infrastructure. This particularly applied to the London Underground, whose overall condition was the result of years of underinvestment (Jupe, 2009). The government chose to renovate the underground through a so called public finance initiative (PFI). A PFI is a special type of PPP in which the government tenders a public service or project to a private actor, who finances, builds, and often even operates the service or project in return for an annual fee (Flinders, 2005). PFIs are a very 
Table 2 Assessment of theoretical expectations in the CSA case

\begin{tabular}{|c|c|c|c|}
\hline & Explanatory factor(s) & Expectation & Assessment \\
\hline \multirow[t]{4}{*}{ Opponents } & $\begin{array}{l}\text { Political interaction } \\
\text { structure (fragmented/ } \\
\text { consolidated opposition) }\end{array}$ & $\begin{array}{l}\text { E1: Fragmented opponents, consisting of } \\
\text { more than one party, are less successful } \\
\text { in crafting a cohesive blame-generating } \\
\text { strategy during the blame game than } \\
\text { consolidated opponents. }\end{array}$ & $\begin{array}{l}\text { Confirmed. Opponents follow different } \\
\text { goals and do not craft a cohesive blame- } \\
\text { generating strategy. However, } \\
\text { opposition in the UK system is more } \\
\text { fragmented than expected. }\end{array}$ \\
\hline & $\begin{array}{l}\text { Institutionalized } \\
\text { accountability structures } \\
\text { (conventions of } \\
\text { resignation) }\end{array}$ & $\begin{array}{l}\text { E3: Opponents facing extensive } \\
\text { conventions of resignation concentrate } \\
\text { their blaming more on the incumbent } \\
\text { politician than opponents facing } \\
\text { restrictive conventions, who can only } \\
\text { blame administrative actors. }\end{array}$ & $\begin{array}{l}\text { Confirmed. Opponents concentrate their } \\
\text { blaming on the agency because it is } \\
\text { obvious that incumbent ministers are } \\
\text { not personally responsible. }\end{array}$ \\
\hline & $\begin{array}{l}\text { Institutional policy } \\
\text { characteristics (direct } \\
\text { government } \\
\text { involvement) }\end{array}$ & $\begin{array}{l}\text { E5: Opponents are better able to blame a } \\
\text { controversy on incumbents if the latter } \\
\text { are directly involved than when the } \\
\text { controversy is far removed from } \\
\text { incumbents. }\end{array}$ & $\begin{array}{l}\text { Confirmed. Opponents are not able to } \\
\text { relate the controversy to political } \\
\text { incumbents due to low direct } \\
\text { government involvement. }\end{array}$ \\
\hline & Distant-salient controversy & $\begin{array}{l}\text { E7: Opponents strongly invest in blame } \\
\text { generation on the occasion of a distant- } \\
\text { salient controversy and attempt to } \\
\text { damage incumbents on moral grounds. }\end{array}$ & $\begin{array}{l}\text { Partly confirmed. Some opponents invest } \\
\text { more in blame generation, others less } \\
\text { so. However, all opponents attempt to } \\
\text { damage incumbents on moral grounds. }\end{array}$ \\
\hline
\end{tabular}


Incumbents

Political interaction structure (loyal/critical governing majority)

Institutionalized accountability structures (conventions of resignation)

Institutional policy characteristics (direct government involvement)

Distant-salient controversy
E2: Incumbents that receive support from their party(ies) are more successful in reframing a controversy than incumbents that confront criticism from their own ranks.

E4: Incumbent politicians that must comply with extensive conventions of resignation have greater difficulty defending themselves during a blame game than politicians that must comply with restricted conventions.

E6: Incumbents are better able to deflect blame for a controversy onto administrative actors if they are not directly involved in the controversy rather than if they are involved.

E8: Incumbents take a distant-salient controversy very seriously and confront it by engaging in blame deflection and symbolic activism.
Not relevant. Incumbents receive occasional criticism from their party, but this is offset by incoherent attacks from opponents.

Confirmed. Opponents never attack incumbent ministers in person because it is obvious to everyone that they are not personally responsible.

Confirmed. Low direct involvement allows incumbents to deflect blame onto administrative actors.

Confirmed. Incumbents take the controversy very seriously and address it by engaging in blame deflection and symbolic activism. 
controversial public policy tool. Critics emphasize that PFIs frequently fail to transfer risk to the private sector, cannot be properly subjected to parliamentary control, and lock governments into inflexible long-term commitments (Flinders, 2005; Jupe, 2009). Supporters, on the contrary, claim that PFIs promise faster procurement, efficiency savings through private-sector management expertise, risk transfer to the private sector, and the possibility of keeping public debt off-balance. The latter was an especially compelling reason for the Labour government to make PFIs "a cornerstone of [its] modernization programme," 24 as it had previously committed to keep public spending in check. ${ }^{25}$

In 2001, the government finally tendered the renovation project to two consortia that each founded a special purpose vehicle to carry out the renovation works. Metronet and Tube Lines, as the special purpose vehicles were called, received a monthly service charge for infrastructure improvements and refurbishments from the government and the City of London. The Labour government estimated that the amount of service charges would be approximately $£ 17$ billion over fifteen years, and expected that efficiency savings would be around $£ 4$ billion from the PPP scheme over the same time. ${ }^{26}$ Critics of the deals quickly pointed out that the government had made several mistakes when tendering the renovation works. First, the deals were based on overly complex contracts that provided the special purpose vehicles with several loopholes. Second, there was an insufficient risk transfer to the private sector because the government had simultaneously given large loan guarantees to the consortia behind the special purpose vehicles. And third, Metronet only distributed work to consortium members instead of tendering them in a competitive process (Jupe, 2009).

From its inception in 2003 until the collapse of Metronet in 2007, the special purpose vehicles received constant criticism from various sides. In particular, the mayor of London, Ken Livingstone, who had always opposed a PFI solution, and transport unions, criticized the special purpose vehicles for compromising safety in order to hold down costs. From 2005 on, the situation with Metronet became ever more problematic. The Transport Committee ${ }^{27}$ concluded in an inquiry report that the improvements accomplished thus far were "not in proportion to the huge sums of money flowing through the PPP." 28 In November 2006, rumors emerged about a $£ 750$ million cost overrun of Metronet's budget for the first 7.5 years of the contract. Also the 
arbiter, a neutral actor in charge of monitoring the PFI arrangement and mediating during conflicts, criticized the management performance of Metronet.

\section{Blame Game Interactions}

In June 2007, Metronet went bankrupt when it announced that it expected cost overruns of up to $£ 2$ billion. ${ }^{29}$ The Tories quickly took up the issue by calling for a National Audit Office investigation into Metronet's collapse and by connecting the failure to Brown, then treasury secretary, and widely considered as the architect behind the PPP scheme. ${ }^{30}$ However, they did not use the controversy to attack the Labour government for using PFIs. The shadow transport secretary of the Tories said that she did not "believe that taking this contract back in-house will necessarily solve the problems of the [PPP]." ${ }^{31}$ The other main opponent in the blame game, Mayor Livingstone, did not blame the government after the collapse but quickly signaled his intention to renationalize Metronet by taking over its operations. ${ }^{32}$ The government sent Ruth Kelly, the transport minister, to explain the collapse of Metronet. During the blame game, Gordon Brown, who had become the new prime minister one month before Metronet's collapse, remained almost completely out of the blame game and only commented on the controversy once. The transport minister admitted that Metronet's incentives had not been sharp enough and assured that there were "lessons to be learnt here." 33 However, she defended the PPP policy solution and assured the public that the contracts could be sold back to the private sector. Moreover, she denied any responsibility for Metronet's collapse and downplayed the taxpayer losses caused by it: "I do not accept that characterization as to the cost to the taxpayer," which, besides, "is nothing like the figure you are quoting." ${ }^{34}$ In his only statement, Brown also reassured the public that another private company would be found to take over Metronet's contracts. ${ }^{35}$ Overall, the government clearly stayed on its policy path. It opposed a major investigation into the controversy ${ }^{36}$ and signaled its intention to keep the private sector involved.

In early 2008, two events gave rise to another round of blame game interactions. The Transport Committee published a very critical report that called Metronet a spectacular failure. ${ }^{37}$ Moreover, the government was finally forced to accept that its attempts to find a private buyer for 
the Metronet contract had been in vain. Both the Tories and the Liberal Democrats subsequently blamed the government for its handling of the controversy. The shadow transport secretary of the Tories claimed that the "taxpayer is picking up a $£ 2$ billion tab for Gordon Brown's incompetence when he set up the Metronet PPP. But the total cost of this shambles is still unclear." 38 In response, the transport minister adopted a blame management approach that was very similar to the one observed during the first round of the blame game. She downplayed the losses produced by Metronet's collapse and the subsequent debt takeover by the government and deflected blame onto Metronet. ${ }^{39}$ Despite obvious contradictions to previous statements (see later), the government mainly ignored criticism and stayed on the policy path. A last round of interactions occurred in June 2009 after the publication of a critical report on Metronet's failure by the National Audit Office. ${ }^{40}$ Opposition parties saw this as a further indictment of Brown's PPP scheme. However, Sadiq Kahn, the new transport minister, reasserted that PPPs are generally good value for the money, framed Metronet as an exception, and expressed optimism that lessons had been learned. ${ }^{41}$ Even after December 2009, when the Metronet fiasco finally repeated itself - although on a smaller scale - with the collapse of Tube Lines, the other special purpose vehicle, the blame game did not take a different turn.

\section{Consequences of the Blame Game}

The blame game that occurred in the wake of Metronet's collapse did not lead to political or administrative resignations. Despite the prime minister's significant personal exposure as the architect of the PPP scheme, the blame game did not negatively affect his approval ratings. While the Department for Transport voluntarily implemented some of the recommendations provided by the Transport Committee and the National Audit Office, there was no major policy change as the Labour government did not adapt its policy position. Despite broad agreement that "Metronet's failure cost taxpayers millions of pounds and that the structure of the PPP left taxpayers to bear a large financial risk," ${ }^{42}$ the government continued to promote PFIs for public infrastructure investments. ${ }^{43}$ The renationalization of Metronet did not contradict this course, since the government openly claimed that it would have continued to adhere to the private solution had it found a bidder. 


\section{Context-Sensitive Analysis of Blame Game Interactions}

Why was it so easy for the government to shrug off the collapse of one of the world's biggest PPPs and continue to use PFIs as its preferred infrastructure investment solution? This must have come as a surprise to experts and the media, who had considered the project's success as decisive for the government's future stance on PPPs and PFIs. For example, already in 2003, a professor from the London School of Economics predicted that the problems with the two PFIs would lead to policy change: "I think we'll look back on the tube as the high watermark of PPPs and PFIs. In years to come, it will look like a huge whale beached by the disappearing tide." ${ }^{44}$ In addition to an important policy goal being up for grabs, opponents also had the chance to damage Brown's reputation, given that he had become prime minister shortly before Metronet's collapse. As I will show in the following, moderate feedback from the public, a fragmented opposition following different goals during the blame game, and low direct government involvement account for this surprising outcome.

\section{Issue Characteristics}

Media coverage suggests that there was only moderate public feedback to the Metronet controversy. Quality outlets consistently covered the controversy, but they did so in a very problem-centered way, illuminating the opaque and complex nature of the PPP scheme. Although this coverage clearly identified Gordon Brown as the architect of the scheme, ${ }^{45}$ polls show that the controversy did not have a negative effect on his approval ratings. ${ }^{46}$ The sluggish coverage by the tabloids also suggests that the wider public did not care much about the controversy. Over the duration of the blame game (June 2007-June 2010), The Sun only published twelve articles on the Metronet controversy. ${ }^{47}$ As The Guardian duly remarked, the Metronet fiasco "has not produced the outrage it should have done." 48

If we consider the proximity of the controversy to the wider public, which was affected both as passengers and taxpayers, the weak public feedback is quite surprising. The endurance of bad service - manifest in delays, overcrowding, and Tube closures due to renovations - was directly felt by many. The losses supposedly accruing onto taxpayers must have appeared enormous to ordinary citizens. While widely diverging numbers were circulating, some sources claimed that the losses to 
taxpayers could be in the billions. ${ }^{49}$ The proximity of the controversy prompted opponents to make claims of personal relevance. Already before the collapse of Metronet, the mayor, transport unions, and Labour backbenchers mobilized against the PPP by connecting it to an increase in the number of accidents. By turning the special purpose vehicles into a safety issue, they signaled that the problems with Metronet were relevant to every (potential) passenger. Moreover, opponents also emphasized the financial consequences of the controversy to attract the attention of the wider public. They condemned the huge bill that had been 'forced upon Londoners' ${ }^{50}$ and promised to do everything in their power to make sure that losses would not be passed on to passengers in the form of price hikes and would not result in job and pension losses.

The weak feedback to opponents' claims of personal relevance was primarily due to the low salience of the controversy. While Londoners traditionally care about the Tube and its reliability, the concrete form of public-service delivery is not what arouses public emotions. "The passenger is interested in whether the Tube is running reliably, rather than how that reliability is achieved." ${ }^{51}$ A related reason for the low salience of the controversy was the opaque and complex nature of the PPP scheme. The intricacies of PFI arrangements and the unclear consequences of Metronet's bankruptcy - who would foot the bill, who would take over Metronet's work and contracts - may have blurred ordinary citizens' picture of the controversy. After the collapse of Tube Lines, Christian Wolmar, a transport journalist, remarked that one of the "great scandals of the decade is about to come to an end, but because of its complexity and arcane nature, it has passed almost unnoticed - even though the man largely responsible for it occupies No 10 Downing Street." 52 Against this background, opponents first had to establish that the collapse of the PPP scheme was an important political event. In a Transport Committee hearing, opponents therefore attempted to force incumbents to publicly admit that the whole issue was a scandal. ${ }^{53}$

The low salience of the controversy was advantageous to incumbents. Although the government admitted that there was a serious problem, it exhibited a very confident stance during the whole blame game. The transport minister confidently reframed the controversy by defending PPPs in principle and by qualifying the purported losses resulting from Metronet's collapse. These reframing attempts clearly 
aimed to dispel opponents' claims of personal relevance. Furthermore, the minister deflected blame onto Metronet and rejected calls for an inquiry into its collapse. Another fact that illustrates the government's confident handling of this nonsalient controversy is that it did not shy away from attracting further criticism by awarding the shareholders of Metronet with new PPP contracts, despite its earlier statements to the contrary. Next to weak public feedback, institutional factors explain why the government could so easily shrug off the controversy.

\section{Institutional Factors}

An institutional factor that made it easier for the government to continue with its PFI policy was the fragmentation of opponents during the blame game. While the Liberal Democrats generally opposed PFIs, the Tories were not categorically against them and, unlike Liberal Democrats, they argued for complete privatization. The mayor of London, on the other hand, focused instead on the prize of policy and quickly moved to renationalize operations when the right moment arose, instead of overtly blaming the government for its PFI ventures. Like in the CSA case, opponents' different priorities prevented the formation of a coherent and visible policy alternative to the status quo.

In addition to incoherent attacks from opponents, the government further profited from a low degree of direct involvement in the policy area. PPPs are usually very complex arrangements and are considered to be one of the main reasons for increasingly blurred accountability and fuzzy governance structures (Flinders, 2005). In the present case, an institutional structure that involved actors at the national and at the local level increased the inherent complexity of the PPP scheme even further. Overall, this led to an administration bias within the blame game. Media coverage suggests that the two special purpose vehicles, the arbiter, and the mayor received most of the public's attention. During the blame game, opponents did not correlate the controversy with the political incumbent, but instead they focused the majority of their blaming on administrative actors.

A factor that reinforced this effect was the narrow focus of the inquiry reports produced during the blame game. Although the UK political system reliably and frequently produces inquiry reports that can act as blaming occasions for opponents, they usually do not question policy. Instead, they seek to grapple with the implementation structures created by the government. In this case, the reports from 
the National Audit Office and the Transport Committee did not question the PPP solution in its own right, nor did they compare it to other hypothetical procurement solutions, but rather they focused on technical implementation problems. For political incumbents, this had the welcome advantage that political responsibility was not a main point of debate during the blame game. Moreover, the government also made use of the ample blame deflection possibilities provided by the complex implementation structure. These factors explain why in this case the limited conventions of resignation, on which the transport minister could have relied on to protect herself from the consequences of personal allegations, were not causally relevant. Also, the fact that criticism from the governing majority was audible during this blame game did not carry much weight against the backdrop of low public feedback, incoherent attacks from opponents, and ample institutional blame protection resulting from low direct government involvement (see Table 3 for a schematic assessment of the theoretical expectations).

\subsection{The Millennium Dome Controversy (DOME)}

The distant-nonsalient Millennium Dome controversy involves a national exhibition held in Greenwich, London, during the year 2000 to celebrate the new millennium. The exhibition attracted fewer visitors than expected and cost more than anticipated, resulting in an inconvenient blame game for the Labour government leading up to the 2001 elections.

\section{Policy Struggle}

The story of the Dome controversy goes back to 1994, when the Tory government of the time decided to finance public projects celebrating the coming millennium. It was expected that these projects would center around a grand millennium exhibition running throughout the year 2000. To organize and run the exhibition, the Tory government founded the New Millennium Exhibition Company. In June 1997, the incoming Labour government revealed its intention to continue with the project. As became clear later when cabinet memos were leaked, ${ }^{54}$ the Labour government only made this decision after heavy intracabinet disagreement. Some ministers feared that a go-ahead would be too risky and that, once the government endorsed the project, it 
Table 3 Assessment of theoretical expectations in the METRONET case

\begin{tabular}{|c|c|c|c|}
\hline & Explanatory factor(s) & Expectation & Assessment \\
\hline \multirow[t]{4}{*}{ Opponents } & $\begin{array}{l}\text { Political interaction } \\
\text { structure (fragmented/ } \\
\text { consolidated opposition) }\end{array}$ & $\begin{array}{l}\text { E1: Fragmented opponents, consisting of } \\
\text { more than one party, are less successful } \\
\text { in crafting a cohesive blame-generating } \\
\text { strategy during the blame game than } \\
\text { consolidated opponents. }\end{array}$ & $\begin{array}{l}\text { Confirmed. Opponents follow different } \\
\text { goals and do not craft a cohesive blame- } \\
\text { generating strategy. However, } \\
\text { opposition in the UK system is more } \\
\text { fragmented than expected. }\end{array}$ \\
\hline & $\begin{array}{l}\text { Institutionalized } \\
\text { accountability structures } \\
\text { (conventions of } \\
\text { resignation) }\end{array}$ & $\begin{array}{l}\text { E3: Opponents facing extensive } \\
\text { conventions of resignation concentrate } \\
\text { their blaming more on the incumbent } \\
\text { politician than opponents facing } \\
\text { restrictive conventions, who can only } \\
\text { blame administrative actors. }\end{array}$ & $\begin{array}{l}\text { Not relevant. Low government } \\
\text { involvement blocks opponents from } \\
\text { overtly attacking political incumbents. }\end{array}$ \\
\hline & $\begin{array}{l}\text { Institutional policy } \\
\text { characteristics (direct } \\
\text { government } \\
\text { involvement) }\end{array}$ & $\begin{array}{l}\text { E5: Opponents are better able to blame a } \\
\text { controversy on incumbents if the latter } \\
\text { are directly involved than when the } \\
\text { controversy is far removed from } \\
\text { incumbents. }\end{array}$ & $\begin{array}{l}\text { Confirmed. Opponents are not able to } \\
\text { connect the controversy to political } \\
\text { incumbents due to low direct } \\
\text { government involvement. }\end{array}$ \\
\hline & $\begin{array}{l}\text { Proximate-nonsalient } \\
\text { controversy }\end{array}$ & $\begin{array}{l}\text { E9: Opponents invest considerably in } \\
\text { blame generation on the occasion of a } \\
\text { proximate-nonsalient controversy and } \\
\text { try to activate considerations of self- } \\
\text { interest among the public. }\end{array}$ & $\begin{array}{l}\text { Partly confirmed. Opponents try to } \\
\text { activate considerations of self-interest, } \\
\text { but not all opponents invest } \\
\text { considerably in blame generation. }\end{array}$ \\
\hline
\end{tabular}


Table 3 (cont.)

\begin{tabular}{|c|c|c|c|}
\hline & Explanatory factor(s) & Expectation & Assessment \\
\hline \multirow[t]{4}{*}{ Incumbents } & $\begin{array}{l}\text { Political interaction } \\
\text { structure (loyal/critical } \\
\text { governing majority) }\end{array}$ & $\begin{array}{l}\text { E2: Incumbents that receive support from } \\
\text { their party(ies) are more successful in } \\
\text { reframing a controversy than } \\
\text { incumbents that confront criticism from } \\
\text { their own ranks. }\end{array}$ & $\begin{array}{l}\text { Not relevant. Incumbents receive } \\
\text { occasional criticism, but the latter does } \\
\text { not carry much weight. }\end{array}$ \\
\hline & $\begin{array}{l}\text { Institutionalized } \\
\text { accountability structures } \\
\text { (conventions of } \\
\text { resignation) }\end{array}$ & $\begin{array}{l}\text { E4: Incumbent politicians that must } \\
\text { comply with extensive conventions of } \\
\text { resignation have greater difficulty } \\
\text { defending themselves during a blame } \\
\text { game than politicians that must comply } \\
\text { with restricted conventions. }\end{array}$ & $\begin{array}{l}\text { Not relevant. The minister is never } \\
\text { attacked by opponents due to low } \\
\text { government involvement. }\end{array}$ \\
\hline & $\begin{array}{l}\text { Institutional policy } \\
\text { characteristics (direct } \\
\text { government } \\
\text { involvement) }\end{array}$ & $\begin{array}{l}\text { E6: Incumbents are better able to deflect } \\
\text { blame for a controversy onto } \\
\text { administrative actors if they are not } \\
\text { directly involved in the controversy } \\
\text { rather than if they are involved. }\end{array}$ & $\begin{array}{l}\text { Confirmed. Low direct involvement } \\
\text { allows incumbents to deflect blame } \\
\text { onto administrative actors. }\end{array}$ \\
\hline & $\begin{array}{l}\text { Proximate-nonsalient } \\
\text { controversy }\end{array}$ & $\begin{array}{l}\text { E10: Incumbents take a proximate- } \\
\text { nonsalient controversy seriously and } \\
\text { address it by mainly adopting reframing } \\
\text { strategies and forms of activism. }\end{array}$ & $\begin{array}{l}\text { Partly confirmed. Incumbents take the } \\
\text { controversy seriously and address it by } \\
\text { mainly adopting reframing and } \\
\text { deflection strategies. However, activism } \\
\text { is very limited. }\end{array}$ \\
\hline
\end{tabular}


would not be able to blame the Tories if the exhibition failed. Other cabinet members, among them Tony Blair and Peter Mandelson, his close ally, emphasized the negative consequences of canceling, including a $£ 144$ million write-off of investments already made and anticipated blame from the Tories for being cowardly and unreliable. But most importantly, the exhibition was "conceived with a political payoff in mind." 55 Blair and Mandelson saw a chance to use the exhibition as a symbol for 'New Labour', the slogan used by the party to distinguish itself from earlier, less market-friendly versions of the British Labour Party.

After the decision had been made, Mandelson became the minister responsible for the exhibition. He assured the public that the latter would create a lasting legacy and "give an unforgettable thrill" to visitors. ${ }^{56}$ However, it did not take long for uncertainties regarding the concrete contents of the exhibition to attract negative media coverage. Moreover, the 'Dome' (the colloquial name of the exhibition due to the flashy construction hosting it in Greenwich, London) became a symbol for the media when discussing the New Labour phenomenon after eighteen years of Conservative rule. To brace themselves against negative coverage, Blair, Mandelson, and Lord Falconer (Mandelson's successor as millennium minister in late 1998 after a personal affair forced Mandelson to step down) started a publicity offensive. ${ }^{57}$ In Tony Blair's words, the exhibition would be a "triumph of confidence over cynicism, boldness over blandness, excellence over mediocrity." 58 Their statements already foreshadowed the blame-management approach that the government would later adopt during the blame game. They spread optimism by framing the exhibition as a great cultural project on the path to success and asked for unity and support from the public. Despite its timely opening, the exhibition became a heavily mediatized controversy in the run-up to the 2001 elections.

\section{Blame Game Interactions}

During 2000, the government was repeatedly blamed for lower-thanexpected visitor numbers and for a lack of funding, which had to be plugged with public money to prevent the premature and embarrassing closure of the exhibition. Already in January, revenue losses due to unexpectedly low visitor numbers led to the first additional public cash injection. Amid criticism from the media, the CEO of the New 
Millennium Exhibition Company resigned. ${ }^{59}$ Tories and Liberal Democrats quickly criticized this step as a cowardly form of scapegoating, denounced newly introduced measures to increase the exhibition's attractiveness as quick fixes, and framed the problems at the Dome as emblematic of the Labour government's overall performance. The Tory leader William Hague asserted that the Dome epitomized "the Labour Government that built it - massive hype, huge amounts of money wasted, long queues and a great disappointment." 60

Another cash injection of $£ 30$ million in May triggered a second major blame attack and sparked a public discussion about prematurely closing the Dome. Tories and Liberal Democrats criticized the government for throwing good money after bad and called the exposition a "monument to the vanity and emptiness of New Labour." ${ }^{61}$ Labour backbenchers also began to press for a financial inquiry. The government retorted that the cash injection was tied to harsh financial and operational conditions imposed on the management of the New Millennium Exhibition Company. The Guardian duly observed that there were no signs that the government was "prepared to offer any olive branches" to the Dome's critics. ${ }^{62}$ In the following months, the Dome was never able to throw off negative coverage for very long. Below-target visitor numbers and rumors about cash shortfalls were duly reported in the media.

In late summer, an all-party parliamentary report that criticized the unwarranted political intrusion into the management of the Dome and two further cash injections of $£ 43$ million and $£ 47$ million triggered the most intensive phase of the blame game. The Tories pressured Falconer to resign as millennium minister because he had allegedly ignored warnings about the exhibition's solvency. Moreover, they urged the government to close the Dome and launch an inquiry into its financial management. ${ }^{63}$ The government reacted to these allegations by once again criticizing the New Millennium Exhibition Company and demoting its new CEO. However, Falconer was kept in place as the minister in charge. Both Blair and Falconer expressed their regret about the situation, but also made rallying calls, claiming that providing cash support to keep the Dome open was "the right course to take." 64 Moreover, they stressed that the exhibition was a clear economic development success. During this phase of the blame game, two Labour government ministers distanced themselves from the Dome. ${ }^{65}$ In addition, criticism from the media increased significantly. Media 
outlets expressed their indignation at the government's unchanged blame-management approach and portrayed the Dome as emblematic of New Labour.

Despite ongoing media coverage, occasional skirmishes about the future usage of the Dome, and the publication of a critical report by the National Audit Office, ${ }^{66}$ which outlined the problems and mistakes that had led to the underperformance of the exhibition, the government stood firm in its decision until the closure of the Dome at the end of the year. The blame game surrounding the Dome proved unable to harm the Labour government, which won the 2001 general elections in a landslide.

\section{Consequences of the Blame Game}

Overall, the consequences of this blame game are as negligible as the consequences of the other two blame games studied thus far. Despite strong attacks directed at political incumbents, resignations only occurred at the managerial level. With the Labour government confidently pulling through with the exhibition until the end of the year, there were no noteworthy policy consequences.

\section{Context-Sensitive Analysis of Blame Game Interactions}

The interesting question behind this blame game is why the government, despite strong and personalized attacks, could relatively easily weather the blame arising from opponents and avoid negative consequences in the form of political resignations, a popularity slump, or the premature closing of the Dome. The answer to this question, as the following analysis will demonstrate, primarily lies in weak public feedback and institutional blame barriers that allowed political incumbents to ride out personalized blame.

\section{Issue Characteristics}

Contrary to what the media coverage of this blame game suggests, there was only weak public feedback to this distant-nonsalient controversy. ${ }^{67}$ A closer look at the meticulous and agitated coverage in both quality outlets and tabloids suggests that media outlets overestimated public feedback. Quite a big share of this coverage dealt with artistic aspects instead of with the controversy. This can be read from the fact 
that coverage was already high in the run-up to the exposition when the blame game had not yet started. Moreover, the media treated the Dome as a symbolic issue to discuss the New Labour phenomenon. Like many cultural projects, the Dome only reached a minority of the public. Many citizens indicated that they did not want to visit the exhibition. ${ }^{68}$ Those who had bought tickets and went to the exhibition were not negatively affected by the controversy, as the high satisfaction rate of visitors confirms. ${ }^{69}$ In addition, the financial losses that accrued on to the public as a whole were comparatively minor. Overall, the public's stance toward the Dome was largely uncontroversial.

Opponents clearly had difficulty generating feedback to this distantnonsalient controversy. They could only blame the government for money waste, using unspecific truisms like when you put "your money on the wrong horse, you stop betting on it." ${ }^{70}$ Opponent claims to personal relevance remained similarly vague. ${ }^{71}$ Due to strong direct government involvement (see later), incumbents could not stay passive with regard to the controversy. Throughout the blame game, incumbents managed blame by reframing the controversy and by occasionally deflecting responsibility and blame onto the New Millennium Exhibition Company. The government confidently admitted mistakes but never apologized, and instead it attacked the media for bashing the Dome. A statement by Mandelson further reveals that the government realized early on that media coverage was overestimating public feedback: "I think we are getting two quite distinct judgments: one from the public and the other from a section of the media who want to see the dome fail." 72 This helps to explain the quite jovial, self-confident stance that especially Blair and Falconer exhibited toward the controversy $-\mathrm{a}$ stance the media likened to an aristocratic attitude of 'never apologize, never resign'.

\section{Institutional Factors}

Incumbents not only benefited from weak public feedback but also from institutional factors that allowed them to ride out personalized blame. In the present case, the government was directly involved in the policy project. Its decision to endorse the exhibition after taking office in 1997 and to offensively portray it as a symbol for the politics of New Labour produced a strong association between the government and the controversy. The fact that Mandelson and Falconer, two well-known 'Tony Cronies' ${ }^{74}$ held the post of millennium minister further strengthened this association. Strong government involvement allowed 
opponents to involve political incumbents in the blame game from the start. They urged Blair to apologize and acknowledge responsibility by sacrificing Falconer. The government's substantial involvement also made it trickier for incumbents to deflect blame. In marked difference to the two previous cases, media outlets and opponents criticized occasional blame-deflection attempts onto the New Millennium Exhibition Company as a form of scapegoating. ${ }^{75}$

During the blame game about the Dome, opponents acted in concert. Both the Tories and the Liberal Democrats were mainly in line with their requests to the government. As a result, personal options (Falconer to resign or not to resign) and policy options (close the exhibition or keep it open) were very obvious during this blame game. It is clear that the government did not just shrug off these specific requests. As the aforementioned statements by two ministers reveal, at least parts of the government were predisposed to prematurely close the exhibition. On the contrary, occasional criticism from the governing majority should have been less relevant for the course of this blame game because this criticism was offset by occasional support for the exposition from Tories, notably by David Heseltine. As the Guardian put it, "Heseltine's continuing support has provided the government with important political cover in the face of the Tories' relentless criticism of the Greenwich attraction." 76

An important institutional factor that allowed the government to keep its minister in office amid coherent and personalized attacks from opponents is the restrictive conventions of ministerial resignation to be found in the UK political system. The public statements of opponents suggest that - at least in cases of high direct government involvement or looming elections - restrictive conventions of resignation alone do not make opponents avoid attacking political incumbents. Opponents tried to compel the minister to resign by convicting him of personal wrongdoings. However, restrictive conventions allowed the government to keep the minister in place, even in the face of strong personalized attacks, since opponents could not formulate convincing accusations of personal wrongdoings on the part of the minister. In sum, weak public feedback to a distant-nonsalient controversy and an institutional configuration that allowed political incumbents to withstand personalized blame allowed the government to come through the blame game undamaged and without having to make any concessions (see Table 4 for a schematic assessment of the theoretical expectations). 
Table 4 Assessment of theoretical expectations in the DOME case

\begin{tabular}{cll} 
& Explanatory factor(s) & Expectation \\
\hline Opponents & $\begin{array}{c}\text { Political interaction } \\
\text { structure (fragmented/ } \\
\text { consolidated opposition) }\end{array}$ & $\begin{array}{c}\text { E1: Fragmented opponents, consisting of } \\
\text { more than one party, are less successful } \\
\text { in crafting a cohesive blame-generating } \\
\text { strategy during the blame game than }\end{array}$ \\
& consolidated opponents. \\
Institutionalized & E3: Opponents facing extensive \\
accountability structures & conventions of resignation concentrate \\
(conventions of & their blaming more on the incumbent \\
resignation) & politician than opponents facing \\
& restrictive conventions, who can only \\
& blame administrative actors. \\
Institutional policy & E5: Opponents are better able to blame a \\
characteristics (direct & controversy on incumbents if the latter \\
government & are directly involved than when the \\
involvement) & controversy is far removed from \\
& incumbents. \\
Distant-nonsalient & E11: Opponents do not invest much in \\
controversy & blame generation on the occasion of a \\
& distant-nonsalient controversy.
\end{tabular}

Assessment

Rejected. Fragmented opponents

formulate a cohesive blame-generating strategy.

Rejected. Despite restrictive conventions, opponents concentrate their blaming on political incumbents (interrelated effect with direct government involvement).

Confirmed. Opponents are able to clearly relate the controversy to the government.

Rejected. Opponents invest substantially in blame generation. 
Incumbents

Political interaction structure (loyal/critical governing majority)

Institutionalized accountability structures (conventions of resignation)

Institutional policy characteristics (direct government involvement)

Distant-nonsalient controversy
E2: Incumbents that receive support from their party(ies) are more successful in reframing a controversy than incumbents that confront criticism from their own ranks.

E4: Incumbent politicians that must comply with extensive conventions of resignation have greater difficulty defending themselves during a blame game than politicians that must comply with restricted conventions.

E6: Incumbents are better able to deflect blame for a controversy onto administrative actors if they are not directly involved in the controversy rather than if they are involved.

E12: Incumbents do not take a distantnonsalient controversy very seriously and only scarcely engage in blame management.
Not relevant. Criticism from governing majority is offset by occasional support from the opposition.

Confirmed. The minister clearly benefits from restricted conventions.

Confirmed. Incumbents have difficulty deflecting blame.

Partly confirmed. Incumbents must engage in blame management from the outset, but they exhibit a confident and uncompromising stance. 


\subsection{The UK Blame Game Style}

In this section, I compare the CSA, METRONET, and DOME cases and subsequently examine a test case to verify and refine the conclusions obtained from the comparison of these three in-depth case studies. These two steps allow me to gain robust and generalizable insights into the UK blame game style.

\section{Political Interaction Structure}

In the UK political system, governments are on their own during blame games. In all three cases, the governing majority adopted a rather passive, and at times critical, role, as suggested by the occasional criticism from backbenchers or influential policy entrepreneurs. This is an interesting aspect of UK blame games, especially when considering the strong party discipline for which the UK system is known (Beyme, 2013, p. 187). In Chapter 2, I formed the expectation that incumbents would be interested in a loyal governing majority because bipartisan criticism would signal that a controversy is not just exaggerated but is indeed problematic. The fact that strong party discipline does not translate into cohesive support for the government during a blame game is an important aspect that distinguishes blame games from more routine forms of political interaction. However, the cases also suggest that political incumbents can usually relinquish support from the governing majority because they are in a very comfortable position during blame games.

A first aspect that works in incumbents' favor is the frequently incoherent attacks by opponents. In the CSA and METRONET cases, the much smaller Liberal Democrats significantly diverged from the Tories in their concrete blaming strategy and in the goals they pursued. This points to another interesting difference between routine political interaction and political conflict during blame games. Due to the media's interest in poignant statements about a controversy, smaller parties manage to punch above their weight and increase their influence on the framing of an issue during a blame game. For incumbents, this has the welcome effect of clouding the issue, given that policy alternatives to the status quo are not as clear as they could be if they had only come from one opposition party. Incoherence between opponents can create room for the government to stick to its policy goals during a blame game. 


\section{Institutionalized Accountability Structures}

Another advantageous institutional factor for incumbents is the restrictive conventions of ministerial resignation. In the UK, ministers only resign in cases of personal fault - a constellation of events that is very unlikely in most policy controversies. Moreover, incumbent ministers benefit from the frequent ministerial reshufflings for which the UK system is known (King \& Crewe, 2014). Ministerial reshufflings allow a minister to be taken out of the firing line and the incumbents to buy time since incoming ministers usually enjoy a honeymoon period during which criticism is more muted. Even in cases where personal attacks occur, like in the DOME case, ministers have a good probability of enduring them until the end of the blame game, or until they move to another post in the government machinery. These characteristics of the UK political system make incumbent ministers unpromising targets for individualized blame attacks from opponents. Conventions thus not only influence whether or not an incumbent has to resign but also how much blame the incumbent receives in the first place, as opponents take the attractiveness of incumbents into account.

\section{Institutional Policy Characteristics}

The UK's strong endorsement of agencification reforms has long been discussed under the rubric of accountability deficits, fuzzy governance structures, and depoliticization (Bache et al., 2015; Flinders \& Buller, 2006; Mortensen, 2016). The blame games analyzed add important insights to this literature. They show that the low direct government involvement resulting from agencification reforms injects an administration bias into a blame game. In both the CSA and METRONET cases, opponents and the media focused their attention on what was going on at the administrative level, while political incumbents largely remained in the background. The work of parliamentary committees and the reports that they produce reinforce the visibility of the administrative level during blame games. In all three cases, parliamentary committees mainly scrutinized administrative, technical, and managerial problems, while disregarding the question of whether the policy at the root of these problems was flawed. As the media uses these reports as information sources, and opponents use them as blaming opportunities, attention and blame automatically shift to administrative actors 
and entities. An administration bias results in two advantages for incumbents. First, it allows them to more credibly frame a controversy as an administrative problem, and second, it helps them to avoid a debate about the policy problem(s) behind the controversy. Taken together, restrictive conventions of resignation and low direct government involvement increase the incentives for political incumbents to ride out a policy controversy instead of addressing it.

\section{Test Case: Health Care Targeting Controversy (HCT)}

In the following, I test the findings derived from the three in-depth case studies against a fourth case situated in the UK political system, in order to refine and consolidate our understanding of the UK blame game style. The Health Care Targeting Controversy (HCT) is about a performance targeting system that emitted adverse incentives in the health care system and thereby contributed to appalling care standards at an English hospital. The proximate-salient controversy developed into a blame game for the Cameron-Clegg government of the Tories and the Liberal Democrats. During the blame game, opponents urged the government to implement far-reaching reforms and to hold top-level health managers accountable. After briefly outlining the policy struggle and providing a chronology of the blame game, I test whether the influence of institutional factors is in line with the previous findings.

\section{Policy Struggle}

Before the turn of the millennium, the first Labour government under Blair introduced a wide-spanning performance targeting system within the National Health Service (NHS). The performance of NHS organizations, such as hospitals or ambulances, was rated, and, based on these ratings, NHS organizations and their managers were either rewarded or penalized (e.g., through bonuses, renewed tenure, budgetary allocations, or public naming and shaming). It soon became clear that this system emitted perverse incentives that led to gaming by NHS organizations and their managers (Bevan \& Hood, 2006). In order to 'get the numbers right', some health managers adopted practices that led to the deterioration of care standards. At Stafford Hospital, a culture of gaming led to appalling care standards between 2005 and 2009. Patients were sent home too early, remained untreated for too 
long, and basic services such as washing, feeding, or pain relief were not properly provided. ${ }^{77}$

From 2007 on, unusually high death rates at the hospital caught the attention of the oversight system and led the Healthcare Commission to investigate the hospital for the first time. Affected individuals who had lost a relative in the hospital due to poor care began to mobilize. They founded the 'Cure the NHS' campaign, which asked for a thorough public inquiry into the controversy and for measures to hold responsible actors accountable. The Labour government under Brown promptly acknowledged the severity of the scandal, apologized to patients and their relatives, and commissioned a first, although limited, inquiry into the controversy. ${ }^{78}$ The publication of the inquiry report in early 2010 prompted the incoming Cameron-Clegg government to address the controversy again. The new government adopted an approach that was very much in line with that of the previous Labour government. It signaled its determination to address the issue and commissioned a second, but this time more comprehensive, inquiry into the controversy.

\section{Blame Game Interactions}

In February 2013, the publication of the second inquiry report triggered the main round of blame game interactions. In response to the report, the Cameron-Clegg government displayed an active and determinate stance. It announced substantial changes to eradicate the "culture of complacency" in the NHS. ${ }^{79}$ Labour and patient groups, backed by a vociferous media campaign, criticized the government's response to the report. ${ }^{80}$ They voiced their doubts in the government's determination to implement the far-reaching recommendations made in the report and attacked the government for deflecting blame onto practitioners while letting top-level executives at the NHS off the hook. Most importantly, they wanted David Nicholson, the 'shameless' man heading the NHS, to resign. ${ }^{81}$ Nicholson was a particularly blameattracting figure during the blame game as he had previously served as the regional NHS official charged with overseeing the Stafford Hospital when care standards at the hospital had been at their worst. A considerable number of Tory politicians also urged the government to fire Nicholson. ${ }^{82}$ Despite these attacks, David Cameron and his health secretary, Jeremy Hunt, backed Nicholson, whom they needed to carry through important - although unrelated - reforms within the 
NHS. Instead of ceding to the demands for Nicholson's head, they accused the previous government of fostering "a culture of targets at any cost." 83 After the hot phase of the blame game, patient groups and the media continued to pressure the government for a while so that it would implement the recommendations made in the inquiry report.

\section{Consequences of the Blame Game}

Despite the government's detailed plans of how it wanted to respond to the recommendations in the inquiry report, it fell significantly short of implementing the report's recommendations. Although the government invoked a raft of smaller changes intended to increase and better monitor quality care at NHS facilities, it opposed important recommendations such as the introduction of minimum staffing levels. ${ }^{84}$ The reforms adopted by the government did not lead to fundamental change in the targeting system. ${ }^{85}$ In addition, the personal consequences of the blame game were negligible. Neither politicians nor top-level bureaucrats could be forced to resign.

\section{Test of Preliminary Findings and Summary}

In the following, I test whether the political interaction structure, institutionalized accountability structures and institutional policy characteristics influenced this blame game in a way that is congruent with the previous findings.

\section{Political Interaction Structure}

Like in the other three cases, the government could not count on unmitigated support from the governing majority during the blame game. Members of the governing majority openly voiced their criticism of the government's handling of the controversy. Several Tory politicians signed a motion asking for Nicholson's resignation, despite their prime minister advocating for the exact opposite. In the HCT case, blame generation from opponents was quite coherent and consistently focused on two goals: a comprehensive inquiry into the scandal and personal accountability, not only by practitioners, but also further up the hierarchy within the NHS. This case does not allow for the assessment of whether opponent parties followed different blame-generation strategies and goals because the main phase of this blame game occurred during a time when there was only one opposition party. 


\section{Institutionalized Accountability Structures}

Restrictive conventions of resignation spared the health secretary from personalized attacks. Since the controversy had occurred prior to his time in office, the health secretary could only be held accountable for his actions in response to the second inquiry report. The latter strongly focused on concrete implementation problems (see later), while not directly addressing the question of political accountability. Holding the head of the NHS to account was thus never politically required. Therefore, the refusal to do so did not lead to fervent attacks on the minister. The behavior of Labour's shadow secretary for health further confirms that politicians can confidently rebuff demands to step down in the absence of personal wrongdoings. The shadow secretary had been health secretary during the time when the controversy had occurred. During the blame game, when Labour urged the CameronClegg government to fire Nicholson, the government retorted that if someone had to resign, it would be the shadow health secretary, due to his prior political responsibility for the performance of the NHS. In response, the shadow health secretary confidently claimed that he was "fed up" with calls for his resignation. ${ }^{86}$ This very confident response to a serious controversy indicates the strong blame-insulating effects of restrictive conventions of responsibility.

\section{Institutional Policy Characteristics}

Like in the CSA and METRONET cases, low direct government involvement injected an administration bias into the blame game. The head of the NHS quickly became the most prominent figure during the blame game, with media attention and opponent attacks focusing on him. The concrete wrongdoings of practitioners, and, to a lesser degree, oversight neglect on the part of regulatory bodies, took center stage in the public debate. Political actors and their responsibility for the controversy were mostly neglected. The only exceptions to this pattern were occasional hints by the government that the Labour target system lay at the root of the problem. In the HCT case, one can also observe the effect that reports had on reinforcing the administration bias in the blame game. Like in the other three cases, reports played an important role in bringing the controversy to light, and they provided opponents with blame occasions while simultaneously exonerating incumbents from a heated discussion about the design flaws of the targeting system and their eventual correction. As a Labour source confidently put it in 
response to the Tories' blame deflection attempts, this "seems to be a pretty shabby and cheap attempt to politicise the [inquiry] report. It made clear that no ministers were to blame." ${ }^{87}$ The inquiry report thus served as a depoliticization instrument, allowing politicians to deny responsibility for a policy scheme for which they were ultimately responsible. Overall, the HCT case confirms the finding that low government involvement and restrictive conventions of resignation create a comfortable situation for political incumbents in the UK system; a situation that allows them to tolerate criticism from their own ranks, brace themselves against coherent blame generation from opponents, and resist opponents' calls for resignation and policy changes.

\section{Summary}

Institutional factors in the UK political system make it difficult for opponents to reach their reputational and policy goals during a blame game. Ministers who are usually only in office briefly and who are not personally responsible for a controversy constitute very strong blame shields for the government of the day. The administration bias injected by forms of agencification and reinforced by the work of parliamentary committees and their reports ensures that the ministerial blame shield is often not even checked for its resilience during a blame game. For opponents, low government involvement thus represents a problem amplifier, which makes it even more difficult to get a hold of political incumbents. The latter, in turn, develop strong incentives to ride out or to protract a controversy and leave the underlying policy problem(s) unaddressed. In the cases examined, strong institutional blame protection allowed political incumbents to adopt a consistent blame-management approach instead of hastily changing blame-management strategies throughout the blame game. 


\section{$\left.4\right|_{\text {Blame Gamesin Germany }}$}

The three blame games that occurred in the UK did not produce significant consequences. First and foremost this was because institutional factors comfortably protected political incumbents from inconvenient blame. This chapter reveals that the German political system exhibits much more heated, and oftentimes more consequential, blame games.

\subsection{The National Socialist Underground Investigation Controversy (NSU)}

The National Socialist Underground (NSU) investigation controversy is about the inability of the German police and secret services to detect a right extremist terror cell. This terror cell, referred to as the 'Nationalist Socialist Underground', had committed a number of severe crimes against people with migrant backgrounds. The terror cell was only accidentally discovered in 2011. The failure to detect the NSU earlier constituted a distant-salient controversy that led to a blame game for the second Merkel government.

\section{Policy Struggle}

Between 2000 and 2007, a murder series claimed ten victims (nine men with migrant backgrounds and one police officer) in Germany. The perpetrators of these murders remained undiscovered until 2011, when police forces accidentally detected the NSU. There are two major reasons why the NSU remained undetected for so long. First, police and secret service investigations across the country were not consolidated at the federal level. Investigations remained at the state level, where police investigations in Germany are usually carried out. Stronger information exchange between state-level authorities almost certainly would have led to the earlier detection of the NSU (Seibel, 
2014). Second, initial investigations were based on the flawed suspicion that the crimes were milieu-specific, that is, investigation bodies presumed that the perpetrators had an organized crime or drug background. This presumption led the investigations down the wrong path and thereby to blatant errors.

According to German law, the minister of the interior has the ability to consolidate state-level investigations at the Bundeskriminalamt (Federal Criminal Police Office) if doing so may increase the chances of a successful manhunt. As revealed later, there were two key episodes during which a consolidation of the investigations at the Bundeskriminalamt would have been possible but had not been mandated by the minister of the interior (Seibel, 2014). In 2004, state-level police forces asked for a consolidation of the investigations at the federal level, but the Bundeskriminalamt had opposed this request. Two years later, the Ministry of the Interior, then headed by the CDU (Christian Democratic Union) politician Wolfgang Schäuble, ignored renewed attempts to consolidate investigations.

The accidental discovery of the NSU in 2011 led to strong public outcry, especially due to Germany's national socialist past. The media covered the controversy very intensively. Until the accidental discovery of the NSU, most media outlets had uncritically adopted the investigation narrative put forward by the police. Several German newspapers had referred to the murder series as 'kebab murders'. ${ }^{1}$ Moreover, there was bewilderment at the fact that the many state- and federal-level police and secret service forces involved in the case had not communicated with each other better and had not exchanged information relating to the murders.

\section{Blame Game Interactions}

In November 2011, shortly after the discovery of the NSU, the German parliament discussed the controversy and commemorated the victims. The coalition government of the CDU and the FDP (Free Democratic Party), headed by chancellor Angela Merkel, apologized to the relatives of the victims. Politicians from all parties acknowledged the seriousness of the investigation failure and expressed their intention to inquire into what had gone wrong. ${ }^{2}$ The government and the SPD (Social Democratic Party) initially wanted these inquiries to primarily take place in the respective states where the crimes had occurred. However, the Green 
Party and the Left Party called for a federal inquiry that would also look at the role of the federal authorities in the flawed investigations. ${ }^{3}$ The government quickly gave in to this request and, together with the opposition, endorsed the appointment of a federal inquiry commission. The government expressed its willingness to thoroughly investigate the issue and learn from the mistakes committed. Chancellor Merkel assured the public that the government would "do everything to clear things up." 4

The inquiry commission began its investigation in January 2012, and, at the end of the year, it began to focus on the missed opportunities for consolidating the investigations at the federal level. When the former minister for the interior, and current finance minister, Schäuble, appeared before the inquiry commission, he rejected political responsibility for the controversy and claimed that he had not been confronted with a request to consolidate the investigations. In his view, the latter would not have proven successful anyway. Schäuble claimed that he had only "marginally been concerned" with the investigation and that he had never considered himself "to be the chief police officer of the country." While his confidence before the inquiry commission attracted slight criticism from opposition parties and the media, ${ }^{6}$ a public debate about the political responsibility for the controversy did not gain momentum. Instead, opponents continued to focus their criticism on administrative entities and kept pressuring incumbents to thoroughly investigate the controversy. ${ }^{7}$ In response to these calls, the government repeatedly signaled its support for the inquiry and blamed administrative entities every time the inquiry discovered a new investigation slip-up. For example, Chancellor Merkel criticized that "the investigation, in many ways, does not progress how we [as politicians] want it to progress. Appropriate action needs to be taken." 8

In August 2013, the inquiry commission published its final report. The report predominantly focused on investigation mistakes and formulated dozens of concrete suggestions on how to reform the investigative apparatus in the areas of police, justice, and secret services. ${ }^{9}$ The question of political responsibility was only a minor issue in the report. Only the Green Party, in a separate statement, expressed its indignation that not a single politician had faced personal consequences for the controversy: "In a democracy, elected superiors carry political responsibility for the actions of administrative entities. It is thus a bad sign, and not just a consequence of the events, that not one responsible politician resigned in response to the many mistakes and omissions." 10 While the 
controversy remained prominently in the media due to the court trial against the NSU that had begun in May 2013 (and which would last until July 2018), the question of political responsibility did not become an issue of debate again.

\section{Consequences of the Blame Game}

The blame game on the NSU controversy led to several resignations of presidents of federal or national intelligence services. Moreover, there were considerable reforms to improve the information exchange between state- and federal-level authorities. An anti-terror database was set-up and cooperation between the secret services of the states and those of the Federal Republic became institutionalized within a center against rightwing terrorism. ${ }^{11}$ Moreover, the Bundesamt für Verfassungsschutz (Federal Office for the Protection of the Constitution), which had played an inglorious role during the investigations, was reorganized. While these reforms did not go as far as the Green Party and the Left Party wanted them to, they are nevertheless extensive and a direct result of the heavy pressure that all parties put on the administrative level during the blame game.

\section{Context-Sensitive Analysis of Blame Game Interactions}

But why was the blame game so strongly oriented toward the administrative level from start to end? Why did the question of political responsibility for the investigation mistakes never come close to triggering heated attacks toward political incumbents? As a look at the sparse blame game interactions suggests, political incumbents could largely avoid an inconvenient discussion about their omissions; omissions that had contributed to a fatal investigation failure. It is likely true that the severity of the controversy prompted opponents to adopt a particularly problem-oriented approach instead of exploiting the controversy for political purposes. As the following analysis seeks to demonstrate, however, opponents did not have the chance to shift the focus of the blame game to the political level, even if they had wanted to. Strong public feedback, directed at the administrative level, incoherent attacks from opponents, and low direct government involvement in the policy area made it almost impossible for opponents to get a hold of political incumbents. 


\section{Issue Characteristics}

As the biggest right-wing terrorist attack in the history of the Federal Republic, the NSU controversy revealed an unprecedented investigation failure in Germany. In the light of Germany's past, the controversy violated core values held by many Germans, namely that of a welcoming culture and tolerance toward migrants and persons with migrant backgrounds. At the same time, the larger public never directly felt the consequences of the controversy. The right-wing terrorism by the NSU was targeted at a rather small, clearly defined part of the population. Moreover, at the start of the blame game, the members of the terror cell were already dead or had been arrested and, therefore, no longer posed any danger to the public. Media coverage suggests that there was strong and emotionally charged public feedback to this distant-salient controversy. All media outlets covered this unprecedented investigation failure in an intensive and scandalizing way. Quality outlets gave very detailed accounts of the many investigation slip-ups and placed the controversy in the larger problem-context of racism and antisemitism in Germany, while also reporting in a scandalizing way. ${ }^{12}$ While one could expect that intensive and scandalizing coverage would constitute a problem for political incumbents, it is important to note that the coverage was overwhelmingly directed at the administrative level. Although the media duly reported about Minister Schäuble's appearance in front of the inquiry commission and subsequently criticized his confident stance as inopportune, it never intensively debated the question of political responsibility, primarily due to the low direct involvement of the government in the policy area (see later).

Opponents thus focused their criticism at political incumbents' handling of the controversy. They repeatedly claimed that incumbents had a moral responsibility to commit themselves to adamantly investigating the controversy and occasionally criticized incumbents for not living up to this responsibility. For instance, opponents criticized the fact that incumbents only acted as if they were interested in investigating the issue by founding ever new and obscure commissions. ${ }^{13}$ Moreover, some opponents also used the salience of the issue to block overt blame deflection onto the administrative level, arguing that the respect for victims and their families demanded the assumption of political responsibility. ${ }^{14}$ Incumbents, on the other hand, immediately realized the dramatic scale of the controversy and apologized to 
the victims. However, the public's focus on the administrative level created significant space for incumbents to maneuver since they only had to justify their handling of the controversy and not the omissions that had contributed to the investigation failure. They were anxious to ensure their engagement with the controversy by stressing their determination to thoroughly investigate the controversy and by repeatedly signaling that they would keep an eye on investigation authorities. ${ }^{15}$

\section{Institutional Factors}

The most important institutional factor that explains the low pressure on incumbent politicians during this blame game is low direct government involvement. In Germany, domestic security is a policy area that traditionally enjoys high bureaucratic autonomy. ${ }^{16}$ When the many investigation slip-ups were gradually discovered, it was clear to everyone that the investigation authorities had failed and opponents accordingly directed most of their blame down onto the administrative level. As already described, this created a comfortable situation for political incumbents. They did not have to justify the omissions that had contributed to the investigation failure, but they only had to signal their will and determination for thoroughly investigating the mistakes made by the investigation authorities. The minister of the interior could easily shrug off criticism pertaining to his personal responsibility and claim that he was not the "chief police officer of the country" 17 - a statement that would have hardly been possible in the case of stronger government involvement, especially against the backdrop of a delicate controversy. Moreover, low government involvement allowed political incumbents to downplay the importance of their actions and decisions for the overall controversy. The minister of the interior, for example, argued that consolidating investigations at the national level would not have proven successful. In his line of argument, the more proximate mistakes by police and secret service forces had caused the investigation failure.

Another factor that benefited incumbents was the incoherent focus of opponents during the blame game. The Green Party was alone in emphasizing the issue of political responsibility. The SPD in particular kept quiet on this point. Many of the crimes had happened during a time when the SPD had still been in government and had been heading the Ministry of the Interior. Blaming Schäuble while sparing its own former minister of the interior from blame would not have looked 
credible. Moreover, while the Green Party and the Left Party called for more far-reaching policy change, the SPD was largely on board with the suggestions made in the inquiry report. The government could thus safely support the report's suggestions and express its will to implement them while ignoring more far-reaching proposals from the Green Party and the Left Party.

Low pressure on incumbent politicians due to low government involvement and incoherence among opponents also explains why the stance of the governing majority and conventions of resignation were not causally relevant during this blame game. Since the government was not fiercely attacked, the governing majority could mostly keep out of the blame game. Moreover, opponents never requested Schäuble's resignation from his new post due to the NSU controversy (see Table 5 for a schematic assessment of the theoretical expectations).

\subsection{The Berlin Airport Construction Controversy (BER)}

The Berlin Airport construction controversy describes the repeatedly delayed opening of the Berlin Brandenburg Airport (BER) in Germany. ${ }^{18}$ Delays and cost overruns triggered a blame game in the city state of Berlin. Recurrent blame attacks by opponents brought Berlin's popular mayor, the SPD politician Klaus Wowereit, to resign due to the proximate-nonsalient controversy.

\section{Policy Struggle}

Following German reunification in 1990, political discussions began regarding the creation of a modern hub airport in the former Eastern German territory around Berlin. The new airport was intended to replace the three small existing airports of Tempelhof, Tegel, and Schönefeld. The city state of Berlin, together with the State of Brandenburg and the federal government, decided to build the new hub at the site of the former Schönefeld airport close to the city. After a failed attempt in 1999 to tender the project concession to a private contractor, the three shareholders decided to build the airport under the aegis of a public holding. Under this implementation structure, the shareholders assumed significant entrepreneurial risk because the tendering and the coordination between different construction projects and processes had to be managed by the public holding. 
Table 5 Assessment of theoretical expectations in the NSU case

\begin{tabular}{|c|c|c|c|}
\hline & Explanatory factor(s) & Expectation & Assessment \\
\hline \multirow[t]{4}{*}{ Opponents } & $\begin{array}{l}\text { Political interaction } \\
\text { structure (fragmented/ } \\
\text { consolidated opposition) }\end{array}$ & $\begin{array}{l}\text { E1: Fragmented opponents, consisting of } \\
\text { more than one party, are less successful } \\
\text { in crafting a cohesive blame-generating } \\
\text { strategy during the blame game than } \\
\text { consolidated opponents. }\end{array}$ & $\begin{array}{l}\text { Confirmed. Opponents follow different } \\
\text { goals and do not craft a cohesive blame- } \\
\text { generating strategy. }\end{array}$ \\
\hline & $\begin{array}{l}\text { Institutionalized } \\
\text { accountability structures } \\
\text { (conventions of } \\
\text { resignation) }\end{array}$ & $\begin{array}{l}\text { E3: Opponents facing extensive } \\
\text { conventions of resignation concentrate } \\
\text { their blaming more on the incumbent } \\
\text { politician than opponents facing } \\
\text { restrictive conventions, who can only } \\
\text { blame administrative actors. }\end{array}$ & $\begin{array}{l}\text { Not relevant. Due to low direct } \\
\text { government involvement and } \\
\text { incoherent attacks from opponents. }\end{array}$ \\
\hline & $\begin{array}{l}\text { Institutional policy } \\
\text { characteristics (direct } \\
\text { government } \\
\text { involvement) }\end{array}$ & $\begin{array}{l}\text { E5: Opponents are better able to blame } \\
\text { a controversy on incumbents if the } \\
\text { latter are directly involved than when } \\
\text { the controversy is far removed from } \\
\text { incumbents. }\end{array}$ & $\begin{array}{l}\text { Confirmed. Opponents are not able to } \\
\text { relate the controversy to political } \\
\text { incumbents. }\end{array}$ \\
\hline & Distant-salient controversy & $\begin{array}{l}\text { E7: Opponents strongly invest in blame } \\
\text { generation on the occasion of a distant- } \\
\text { salient controversy and attempt to } \\
\text { damage incumbents on moral grounds. }\end{array}$ & $\begin{array}{l}\text { Partly confirmed. Some invest more in } \\
\text { blame generation, others less so. } \\
\text { However, all opponents attempt to } \\
\text { damage incumbents on moral grounds. }\end{array}$ \\
\hline
\end{tabular}


Incumbents

Political interaction structure (loyal/critical governing majority)

Institutionalized accountability structures (conventions of resignation)

Institutional policy characteristics (direct government involvement)

Distant-salient controversy
E2: Incumbents that receive support from their party(ies) are more successful in reframing a controversy than incumbents that confront criticism from their own ranks.

E4: Incumbent politicians that must comply with extensive conventions of resignation have greater difficulty defending themselves during a blame game than politicians that must comply with restricted conventions.

E6: Incumbents are better able to deflect blame for a controversy onto administrative actors if they are not directly involved in the controversy rather than if they are involved.

E8: Incumbents take a distant-salient controversy very seriously and confront it by engaging in blame deflection and symbolic activism.
Not relevant. Attacks on political incumbents are negligible.

Not relevant. Attacks on political incumbents are negligible.

Confirmed. Low direct involvement allows incumbents to deflect blame onto administrative actors.

Confirmed. Incumbents take the controversy very seriously and address it by engaging in blame deflection and symbolic activism. 
Political involvement did not do the BER much good. Severe planning mistakes, mismanagement, and occasional intrusion from political actors that necessitated planning adaptations and thereby complicated the construction of the airport, led to significant delays and cost overruns. ${ }^{19}$ When construction began in September 2006, estimated costs were quoted at $€ 2.1$ billion, with the airport scheduled to open in October 2011. At the time of writing (November 2019), the opening date is scheduled for October 2020, at the earliest, and costs are expected to exceed $€ 7$ billion by completion. Klaus Wowereit, the popular mayor of the city state of Berlin, became the main political incumbent held responsible for the delayed and over expensive airport. The mayor had been the visible driving force and political ambassador of the project and was also the chairman of the public holding. His prominent position, and the widespread belief that the BER would be 'Berlin's airport', made the mayor and his city government the entities that would be held politically responsible and would take center stage in the ensuing blame game.

\section{Blame Game Interactions}

The first round of blame game interactions started in June 2010, when the mayor announced that the opening of the airport would be postponed from October 2011 to June 2012. The main opposition parties at this point of the blame game, the CDU and the Green Party, accused the government of being responsible for the delay. ${ }^{20}$ The mayor justified the first delay by citing the unanticipated bankruptcy of a construction planning company and the stricter safety requirements mandated by the European Union, which had to be incorporated into the construction process. ${ }^{21}$ His party, the SPD, stressed that planning mistakes had already been made under the previous government, and it summoned all parties to support the project instead of obstructing it. In the September 2011 elections of the Berliner Abgeordnetenhaus (Berlin House of Representatives), the SPD confirmed its position as the strongest party and formed a coalition government with the CDU. The main opposition parties became the Green Party, the Left Party, and the Pirate Party.

In May 2012, the mayor announced the second postponement of the opening date, from June 2012 to March 2013. The opposition subsequently criticized him for not properly informing the public about the 
true situation of the airport, expressed doubts about his claim that he had been surprised by the announcement of delay, and asked for personal consequences for the mismanagement of the public holding. In response to these allegations, the mayor apologized before parliament and assured it that he had believed in the opening date: "I ask you, with all due respect and despite all the justified criticism, to not consider us naïve and to believe us that we were totally committed to this [June 2012] date." ${ }^{22} \mathrm{He}$ announced the demotion of the technical manager of the public holding and the replacement of one of the several planning companies involved in the construction of the airport. Despite the delays, he continued to refer to the BER as a clear success story. He claimed that the extra costs would be more than offset by the positive economic development effects of the airport and "that this magnificent airport project should not be discredited." 23 The SPD accordingly attacked opposition parties for obstructing the project and called for political reason and collaboration in the face of such an important infrastructure project.

Only four month later, in September 2012, the mayor announced another delay, this time from March to October 2013. At the root of the delays during this time was an overly complex fire protection system that was rejected by German authorities. The public holding had hoped that the system would be approved by making minor adjustments to it, but it ultimately had to admit that the system needed a major overhaul. In a government statement, the mayor blamed the management of the holding for the problems at the root of the delays and criticized the opposition for its unconstructive stance toward the airport. ${ }^{24}$ However, he continued to make morale-boosting slogans and to frame the airport as a success: "Today, four month later, we can say that the additional time was necessary to put things on the right track. All those involved have their eyes firmly set on the goal to complete the most important infrastructure project of the region. This is our goal, and in order to achieve it, we must all now pool our strengths." 25 The government's announcement triggered heated criticism from opponents, who requested that an inquiry commission be established to systematically assess the reasons and responsibility for the delays. The Green Party also asked for the demotion of the management and the board of the public holding. ${ }^{26}$

In January 2013, a fourth postponement of the opening date triggered another heated round of blame game interactions. For opposition 
parties, the renewed delay of the opening date represented a clear motive for Wowereit to resign as mayor. However, their vote of no confidence against the mayor did not reach a majority. Amid criticism, the coalition government deflected blame onto the companies building the airport and attacked the opposition for its "great feat of personalizing a construction problem in a unique way." ${ }^{27}$ In addition, the CEO of the holding was forced to resign. During 2013, it became increasingly clear that the airport could not open before 2016 since the problems with the fire protection system could not be fixed. Wowereit thus publicly announced that he would resign as both chairman of the holding and as mayor by the end of 2013.

\section{Consequences of the Blame Game}

Several public managers of the holding were forced to resign during the blame game. The mayor of Berlin also stepped down. While this was a voluntary decision, it is unlikely that he could have remained in office for much longer. Opponents did not grow tired of calling for his resignation and his popularity suffered significantly during the blame game. The idiosyncratic nature of the policy problem made it difficult for incumbents to do more to address the problem. When the blame game started, it was already too late for incumbents to adapt or terminate the project. Therefore, all the government could do was hope that the difficulties caused by the fire protection system could somehow be solved.

\section{Context-Sensitive Analysis of Blame Game Interactions}

In the blame game about the BER controversy, a very popular political incumbent initially weathered blame in a confident and successful way and easily secured his reelection. However, constant attacks by opponents gradually forced him onto the defensive and ultimately made him resign. At first sight, a controversy that could not be cleared up for good and remained on the political agenda for so long sealed the mayor's fate. However, the context-sensitive analysis of blame game interactions reveals that this outcome was far from certain since the mayor enjoyed several advantages during the blame game. The Wowereit government benefited from low public feedback, dispersed attacks from opponents, and a loyal governing majority. In the end, direct 
government involvement in the construction of the airport and extensive opportunities to hold the mayor personally responsible provided opponents with recurring opportunities to attack and thereby gradually diminished his chances of surviving the controversy around the BER.

\section{Issue Characteristics}

Media coverage and polls suggest that there was moderate public feedback to the BER controversy. Both quality outlets and tabloids reported on the controversy in a rather dispassionate, problemcentered way. Quality outlets attempted to reconstruct the problems at the root of the delays and discussed eventual consequences for the passengers and companies who would depend on the airport. ${ }^{28}$ Only later, when the airport's opening receded into the dim future, did the coverage in quality outlets and tabloids get more person-centered and cynical. The media referred to the airport as a 'living grievance' and 'perennial satire' for which Wowereit should finally assume political responsibility. The mayor was dubbed an educated babbler (Schwurbelmeister) who prevaricated whenever necessary. ${ }^{29}$ The strong focus on the mayor also manifested itself in his approval ratings. During later rounds of the blame game, his approval ratings suffered considerably. However, there was never a majority that wanted him to resign as mayor. ${ }^{30}$

Opponents primarily attempted to generate public feedback to the controversy by making claims of personal relevance. The cost overruns accruing to the city of Berlin should have appeared quite enormous to ordinary citizens, especially to those living in a notoriously cashstrapped state like Berlin. ${ }^{31}$ Berliners have ample experience with malfunctioning public services and should have feared higher taxes as well as infrastructure investment stops in response to rising expenses for the airport (Bach \& Wegrich, 2016). Moreover, the controversy about the BER affected a significant share of the public as passengers: 17 percent of the population of Berlin flies frequently and must endure - until the BER opens - chaotic conditions at the overcrowded old airports of the city. ${ }^{32}$ During the blame game, opponents emphasized the costs accruing to taxpayers and stressed the massive impact of the controversy on Berlin's budget. Moreover, they stressed that the cost overruns could have been used for other public investments such as the renovation of Berlin's run-down schools. ${ }^{33}$ In the eyes of opponents, incumbents had 
not only wasted scarce public money, but they had also brought humiliation to the city of Berlin and its citizens. ${ }^{34}$

What limited public feedback to these blame-generation attempts, however, was the low salience of the BER controversy. Despite occasional protests by local residents relating to fly-over noise, the airport enjoyed broad public support. The public should also not have been too surprised by an over-expensive and delayed public infrastructure project. The latter had become commonplace in Germany in recent years, as a look at Stuttgart's central station, Hamburg's Elbphilharmonie, or Berlin's State Opera suggests. The media duly noted that there was no outcry (Aufschrei) on the part of Berliners because they were simply used to their city government's terrible infrastructure record. ${ }^{35}$ The mayor clearly benefited from moderate public feedback. Given his high personal involvement, he indicated that he would take the controversy very seriously. However, he also exhibited a very confident stance throughout the blame game. In his attempts to keep up the impression that the airport would develop into a success story that would offset delays and cost overruns, the mayor and his party repeatedly emphasized the many positive effects of the airport for all Berliners. He maintained that Berliners should be patient and stand together and then everyone would benefit. Hence, we see clear attempts from both opponents and incumbents to gain dominance on the public's interpretation of what this controversy meant for it as a whole.

\section{Institutional Factors}

In addition to moderate public feedback, the Wowereit government also benefited from incoherent attacks from opponents. With the exception of the first round of the blame game, the government confronted three opposition parties that focused on different aspects of the controversy. While the Left Party and the Pirate Party focused on technical aspects, the Green Party focused more on assigning political responsibility. ${ }^{36}$ The focus on technical aspects allowed political incumbents to expatiate on the problems at the airport in lengthy statements and to choose which aspects to concentrate on in their responses. ${ }^{37}$ Unlike in the NSU case, where attacks on political incumbents were negligible, in the BER case, the mayor benefited from a loyal and active governing majority that attempted to undermine the credibility of opponents' blame-generation attempts. Throughout the blame game, the governing majority served as an attack device for the mayor. Especially during the earlier rounds of the 
blame game, the mayor continued to act in a statesman-like way and had not yet deflected blame onto the management of the holding or accused opponents of obstructionism, despite the governing majority already having done so. This allowed the mayor, at least for a time, to remain in the background of the blame game. How strongly governing parties adhered to their supporting role is particularly visible in the behavior of the CDU. The CDU had been part of the opposition during the first round of the blame game and had been the Wowereit government's loudest critic and the first party to attack him personally. After the elections, when it formed a coalition government with the mayor's SPD, the CDU became a strong supporter of the airport and indirectly defended the mayor in parliament by deflecting blame onto the management level.

Several institutional factors were disadvantageous to the government. The most important of these factors was the direct involvement of the government in the construction of the airport. Despite a complex implementation structure with two states, the federal government, and different companies, the mayor was clearly perceived to be responsible for the fate of the airport due to his role as the chair of the supervisory board of the public holding. Strong direct government involvement allowed opponents to clearly direct their blame-generation attempts at the mayor. Extensive conventions of resignation allowed opponents to step up their attacks by plausibly calling into play the resignation of the mayor over the controversy when a timely opening of the airport had become increasingly unlikely. The latter could not reject such claims as utter nonsense, rather he could only express his determination to 'stay on board' and strive toward a timely opening of the airport.

The case further reveals that opponents benefited from their ability to appoint an inquiry commission. In the German political system, a minority in parliament can appoint an inquiry commission to investigate a controversy. In the BER case, opponents used the inquiry commission to obtain information on the mayor's personal responsibility for the controversy. Specifically, opponents wanted to know whether the mayor had violated his oversight duties as the chair of the supervisory board and whether he had communicated delays early enough and to the best of his knowledge. Hence, in the German system, opponents can use inquiry commissions to dig up information that allows them to formulate credible allegations of personal wrongdoings. However, we also see that the appointment of an inquiry commission 
channels the blame game into a more technical arena in which opponents' blame generation risks becoming hypocritical. An ongoing inquiry allows incumbents to avoid blame game interactions in other venues, such as in the media or during parliamentary debate. After the inquiry commission had started its work and the Green Party kept attacking the mayor during debates in parliament, the SPD duly pointed to the commission's work and urged the Green Party not to anticipate its results. ${ }^{38}$ Taken together, strong direct government involvement and extensive conventions of resignation allowed opponents to keep the mayor under constant fire and force him to resign despite only moderate public feedback, dispersed attacks from opponents, and support from the governing majority (see Table 6 for a schematic assessment of the theoretical expectations).

\subsection{The Drone Procurement Controversy (DRONE)}

The distant-nonsalient drone procurement controversy (DRONE) is about the failed procurement of reconnaissance drones by the German armed forces, which developed into a blame game for the defense minister of the second Merkel government, the CDU politician, Thomas de Maizière.

\section{Policy Struggle}

In the 2000s, the Bundeswehr (German armed forces) was in the middle of a large-scale structural reform: transitioning from a volunteer to a professional army and suspending universal conscription. A major problem to be addressed by the reform was the flawed military procurement system. Many military procurements did not perform as expected, arrived too late, or became too expensive. In 2010, an expert commission recommended the installation of an independent controlling system and a centralized procurement agency. ${ }^{39}$ While the Defense Ministry subsequently implemented some institutional reorganizations, the reforms that were implemented fell significantly short of the original recommendations. ${ }^{40}$

In 2013, the failed procurement of unmanned aircraft vehicles, commonly known as drones, exposed several of the problems with the procurement system that had been left unaddressed since 2010. Years earlier, the German government had decided to procure reconnaissance 
Table 6 Assessment of theoretical expectations in the BER case

\begin{tabular}{|c|c|c|c|}
\hline & Explanatory factor(s) & Expectation & Assessment \\
\hline \multirow[t]{4}{*}{ Opponents } & $\begin{array}{l}\text { Political interaction } \\
\text { structure (fragmented/ } \\
\text { consolidated opposition) }\end{array}$ & $\begin{array}{l}\text { E1: Fragmented opponents, consisting of } \\
\text { more than one party, are less successful } \\
\text { in crafting a cohesive blame-generating } \\
\text { strategy during the blame game than } \\
\text { consolidated opponents. }\end{array}$ & $\begin{array}{l}\text { Confirmed. Opponents follow different } \\
\text { goals and do not craft a cohesive blame- } \\
\text { generating strategy. }\end{array}$ \\
\hline & $\begin{array}{l}\text { Institutionalized } \\
\text { accountability structures } \\
\text { (conventions of } \\
\text { resignation) }\end{array}$ & $\begin{array}{l}\text { E3: Opponents facing extensive } \\
\text { conventions of resignation concentrate } \\
\text { their blaming more on the incumbent } \\
\text { politician than opponents facing } \\
\text { restrictive conventions, who can only } \\
\text { blame administrative actors. }\end{array}$ & $\begin{array}{l}\text { Confirmed. Extensive conventions of } \\
\text { resignation allow opponents to } \\
\text { plausibly call into play the resignation } \\
\text { of the political incumbent. }\end{array}$ \\
\hline & $\begin{array}{l}\text { Institutional policy } \\
\text { characteristics (direct } \\
\text { government } \\
\text { involvement) }\end{array}$ & $\begin{array}{l}\text { E5: Opponents are better able to blame } \\
\text { a controversy on incumbents if the } \\
\text { latter are directly involved than when } \\
\text { the controversy is far removed from } \\
\text { incumbents. }\end{array}$ & $\begin{array}{l}\text { Confirmed. Strong direct government } \\
\text { involvement allows opponents to } \\
\text { credibly assign responsibility to the } \\
\text { political incumbent right from the start } \\
\text { of the blame game. }\end{array}$ \\
\hline & $\begin{array}{l}\text { Proximate-nonsalient } \\
\text { controversy }\end{array}$ & $\begin{array}{l}\text { E9: Opponents invest considerably in } \\
\text { blame generation on the occasion of } \\
\text { a proximate-nonsalient controversy }\end{array}$ & $\begin{array}{l}\text { Confirmed. Opponents invest } \\
\text { considerably in blame generation and } \\
\text { try to activate considerations of self- } \\
\text { interest. }\end{array}$ \\
\hline
\end{tabular}


Table 6 (cont.)

\begin{tabular}{|c|c|c|c|}
\hline & Explanatory factor(s) & Expectation & Assessment \\
\hline & & $\begin{array}{l}\text { and try to activate considerations of } \\
\text { self-interest among the public. }\end{array}$ & \\
\hline \multirow[t]{4}{*}{ Incumbents } & $\begin{array}{l}\text { Political interaction } \\
\text { structure (loyal/critical } \\
\text { governing majority) }\end{array}$ & $\begin{array}{l}\text { E2: Incumbents that receive support from } \\
\text { their party(ies) are more successful in } \\
\text { reframing a controversy than } \\
\text { incumbents that confront criticism from } \\
\text { their own ranks. }\end{array}$ & $\begin{array}{l}\text { Confirmed. Strong support from the } \\
\text { governing majority helps the political } \\
\text { incumbent to reframe the controversy. }\end{array}$ \\
\hline & $\begin{array}{l}\text { Institutionalized } \\
\text { accountability structures } \\
\text { (conventions of } \\
\text { resignation) }\end{array}$ & $\begin{array}{l}\text { E4: Incumbent politicians that must } \\
\text { comply with extensive conventions of } \\
\text { resignation have greater difficulty } \\
\text { defending themselves during a blame } \\
\text { game than politicians that must comply } \\
\text { with restricted conventions. }\end{array}$ & $\begin{array}{l}\text { Confirmed. Extensive conventions } \\
\text { prevent the political incumbent from } \\
\text { brusquely rejecting calls for his } \\
\text { resignation. }\end{array}$ \\
\hline & $\begin{array}{l}\text { Institutional policy } \\
\text { characteristics (direct } \\
\text { government } \\
\text { involvement) }\end{array}$ & $\begin{array}{l}\text { E6: Incumbents are better able to deflect } \\
\text { blame for a controversy onto } \\
\text { administrative actors if they are not } \\
\text { directly involved in the controversy } \\
\text { rather than if they are involved. }\end{array}$ & $\begin{array}{l}\text { Confirmed. Strong direct involvement } \\
\text { renders blame deflection attempts onto } \\
\text { management incredible. }\end{array}$ \\
\hline & $\begin{array}{l}\text { Proximate-nonsalient } \\
\text { controversy }\end{array}$ & $\begin{array}{l}\text { E10: Incumbents take a proximate- } \\
\text { nonsalient controversy seriously and } \\
\text { address it by mainly adopting reframing } \\
\text { strategies and forms of activism. }\end{array}$ & $\begin{array}{l}\text { Partly confirmed. Political incumbents } \\
\text { take the controversy seriously and } \\
\text { address it by adopting reframing } \\
\text { strategies. Activism is very limited. } \\
\text { Moreover, incumbents use blame- } \\
\text { deflection strategies. }\end{array}$ \\
\hline
\end{tabular}


drones from the European EADS (European Aeronautic Defence and Space Company) and the US-based company Northrop Grumman. The latter was commissioned to develop and manufacture the drones while EADS was supposed to develop the sensor technology. From March 2013 on, rumors emerged that the Bundeswehr had problems obtaining flight permission for the drones. In fact, the European Aviation Safety Agency denied flight permission to the prototype that Northrop Grumman had delivered because it had no automated collision avoidance system. It was later revealed that the actors in charge had completely underestimated the problem of obtaining a flight permission. ${ }^{41}$

Since the Bundeswehr expected prohibitively high additional costs of up to $€ 800$ million to obtain a belated flight permission, the German minister of defense and member of the ruling CDU under Angela Merkel, Thomas de Maizière, canceled the project in early May 2013. At this time, the more than $€ 500$ million already invested seemed largely unrecoverable. Immediately following the project's cancellation, the minister failed to inform the parliament about the decision. When the latter found out about the cancellation, the DRONE controversy became an inconvenient blame game for the Merkel government preceding the 2013 German federal elections.

\section{Blame Game Interactions}

The attack on the minister by the opposition parties (the SPD, the Green Party, and the Left Party) was due less to the failure of the procurement project, which had already been initiated before the minister's time in office, and more because they took umbrage at the minister's reluctance to properly inform the parliament and the Bundesrechnungshof (Federal Audit Office) about the cancellation. They criticized the minister's information policy, asked for clarifications, and urged Chancellor Merkel to prioritize the controversy. In a public statement, the minister promised that he would provide the Bundesrechnungshof with full access to relevant documents. He framed the cancellation as the right step to avert further damage and announced that he would provide a detailed account of the issue only after all internal processes had been reviewed. Overall, however, he still exhibited a confident stance: "If we were to pull the plug on complicated procurement projects after the slightest problem, then we would 
have no armaments projects at all. There is not a single procurement procedure of this magnitude without problems." 42

Shortly after the first round of the blame game, a second bone of contention led to intensified interactions. The German weekly, Der Spiegel, uncovered information that the Defense Ministry must have already possessed detailed knowledge about the problems getting flight permission in February and that the Bundeswehr had tried to camouflage the issue. ${ }^{43}$ Following this publication, opposition parties began to personally attack the minister. The SPD and the Green Party accused him of lying to the public and to parliament and saw therein a clear reason for him to resign. An SPD politician clearly urged him to assume personal responsibility: "You can't put this responsibility on anyone else's shoulders if you still have a spark of respect for your task." "The minister responded to these allegations by downplaying his decision, which had led to the overall controversy, and reminded the opposition that the project had been initiated by a coalition government of the SPD and the Green Party. Moreover, he promised an overhaul of the procurement system and deflected responsibility for the late cancellation onto his undersecretaries, claiming that the latter had not properly informed him and that he was furious at them: "It really pisses me off. Anyone who knows me knows that this is a cautious formulation." 45 The governing majority, consisting of the CDU and the FDP, supported the minister by stressing the SPD's and the Green Party's involvement in the launch of the project. In the parliamentary debate, the governing majority accused the opposition of scandalizing the issue before the elections and detracted from the controversy by focusing on the state of the Bundeswehr and the use of drones in military interventions more generally. During the second round of blame game interactions, the minister's popularity suffered considerably. However, only 33 percent of the public wanted him to resign due to the controversy.

As the opposition could not convict the minister of lying, they appointed an inquiry commission to investigate the government's involvement in the controversy. During the sessions of the commission, they reaffirmed their position against the minister, calling him a liar who was no longer fit to lead the Bundeswehr. ${ }^{46}$ However, it became clear quite quickly that the opposition could not substantiate the allegations of lying. The minister now adopted a much more 
proactive and confident stance when before the commission. While he continued to deflect blame onto his predecessors, he began to defend his undersecretaries. In a partial contradiction of his previous statements, he argued that their actions with regard to the cancellation had been correct. ${ }^{47}$ The publication of the inquiry's results shortly before the elections no longer attracted much public interest.

\section{Consequences of the Blame Game}

At first sight, the blame game surrounding the DRONE controversy did not produce notable consequences. The minister remained in office and did not have to sacrifice his undersecretaries. While the minister's reputation temporarily suffered in the polls, the majority of the public never wanted him to resign. The opposition did not succeed in using the DRONE controversy to undermine the government before the upcoming elections.

However, the case reveals a different picture in regard to policy consequences. During the blame game, the minister had already promised to introduce a controlling system for large procurement projects - one of the key recommendations the expert commission had made back in 2010. After the elections in September 2013, in which the CDU managed to remain the strongest party, the CDU politician Ursula von der Leyen replaced Thomas de Maizière as the new defense minister. In the wake of the blame game surrounding the DRONE controversy, the new minister saw herself confronted with a widespread debate about the procurement problems of the Bundeswehr. ${ }^{48}$ The new minister took a tough stance on procurement problems in order to distance herself from her predecessor and introduced several reforms. First, she fired one of her predecessor's undersecretaries to signal that she was not happy with the current information policy within the ministry. Second, she started a transparency initiative by commissioning an evaluation of the largest current procurement projects and established a report system to regularly inform the parliament of the current procurement situation. ${ }^{49}$ Taken together, while the blame game did not lead to immediate personal consequences, it nevertheless sparked an intensive public debate that forced politicians to more proactively address a policy problem that had already existed for a long time. 


\section{Context-Sensitive Analysis of Blame Game Interactions}

In the following, I show that the extensive policy consequences of the blame game primarily resulted from personalized pressure on political incumbents. Despite low public feedback to the controversy, direct government involvement and extensive conventions of ministerial resignation allowed opponents to attack the minister and, through their attacks, compelled the minister (and his successor) to speed up the policy reform process.

\section{Issue Characteristics}

Media coverage and polls suggest that public feedback to the DRONE controversy was rather weak. During the first round of interactions, quality outlets covered the blame game in a detailed but problemcentered way. Tabloids only took up the controversy after the accusation of lying had become a matter of debate, at which point overall coverage became more person-centered and scandalizing. During this more heated phase, the minister took center stage while the controversy as such no longer attracted much attention. Polls also suggest that the public never showed great interest in the controversy. As already mentioned, although the minister's popularity temporarily suffered, there was never a majority that wanted him to resign, despite his prominent involvement in the controversy. ${ }^{50}$ With the exception of the oversea deployment of German troops, military policy issues seldom attract the interest of the German public. The relationship between Germans and their military is, as the former Federal President Horst Köhler put it, characterized by a friendly indifference. ${ }^{51}$ Moreover, the public is very used to procurement controversies as Germany has had many of them in recent years. When the media began to cover the DRONE controversy, it initially classified it as a further military procurement fiasco. ${ }^{52}$ What is more, in the long tradition of procurement failures, the financial loss of about $€ 500$ million did not stick out much. Nor did the lack of drones immediately threaten German security. Overall, the controversy "basically remained an issue for the political-media complex. The mass of voters didn't care." 53

The low salience of the controversy and the absence of implications for ordinary citizens clearly constrained opponents in their blamegeneration attempts. During the first round of blame game interactions, they had not yet invested much into blame generation. Instead, their criticism was rather routinized. ${ }^{54}$ While the Left Party tried to connect 
the DRONE controversy to a wider debate about the use of drones in military interventions, the SPD and the Green Party proclaimed that the government was simply continuing a sad tradition of money waste. Only once opponents discovered a chance to personalize the controversy by convicting the minister of lying (right before an important election), did they step up their blame-generation efforts and sought to turn the minister into a moral liability for the government (see later). When attacking the minister, opponents duly disregarded the policy problem at the root of the controversy. The latter only acted as background information for personal allegations that, in principle, could have surfaced as part of any other controversy. As the Süddeutsche Zeitung observed, the "debate is mainly about whether the minister lied. The very expensive failure of the high-tech project is too much in the background." ${ }^{55}$ That opponents abruptly changed strategy after the accusation about lying had become a matter of debate further confirms the constraining influence of a distant-nonsalient controversy on blame generation.

The minister also adapted his blame-management approach to changing circumstances. In the beginning of the blame game, he initially ignored criticism and played for time. In a parliamentary debate about the reform of the Bundeswehr, he only mentioned the issue in passing and exhibited a confident stance with regard to its investigation. $\mathrm{He}$ also defended the use of drones for reconnaissance purposes and did not yet deflect blame onto his undersecretaries. The minister only adopted a more active blame-management approach after opponents had begun to urge him to resign. In other words, personal attacks triggered a clear change in blame-management strategies. He promised reforms to the procurement system and began to deflect blame onto his undersecretaries. As soon as it had become clear that the inquiry commission could not convict him of personal wrongdoings, he stopped deflecting and reassumed a very confident stance. The media duly noted that the minister had started a frontal attack on his critics. ${ }^{56}$ This effectively shows that the distant-nonsalient controversy alone did not prompt the minister to intensively engage in blame management.

\section{Institutional Factors}

During the blame game about the DRONE controversy, the minister benefited from incoherent attacks by opponents. As already mentioned, only the SPD and the Green Party focused their blaming on the minister 
and urged him to resign. Meanwhile, the Left Party was more interested in a general discussion about the use of drones in military interventions. The Left Party's diverging focus allowed the government to engage in a lengthy policy debate during which it only had to address the DRONE controversy in passing. ${ }^{57}$

The minister also enjoyed important support from the governing majority. In the beginning of the blame game, while the minister was playing for time and had refrained from making statements before obtaining an overview of what had gone wrong in his ministry, the governing majority had already attacked the opposition for scandalizing the issue and reminded it of its prior involvement in the procurement project. During the second and third round of blame game interactions, when opponents heavily attacked the minister, counterattacks from the governing parties exonerated the minister to some degree and allowed him to act more like a committed crisis manager than an embattled minister dealing out blows left and right. As in the BER case, the governing majority acted as the government's attack device, allowing the political incumbent to take a step back from heated blame game interactions.

Direct government involvement and extensive conventions of ministerial resignation ultimately put the minister in a precarious situation. Although a complex procurement system lay at the root of the canceled project, the blame game quickly centered on the minister's personal involvement in the controversy. In August 2012, before the start of the blame game, the minister had already exhibited a positive stance with regard to the use of drones in armed conflict. ${ }^{58}$ This stance made it particularly implausible for him to claim that he had not been properly informed about the procurement problems of the Bundeswehr's most prestigious drone project at the time. The media thus expressed their doubts when the minister started to deflect blame onto his undersecretaries. High direct government involvement clearly reduced the minister's chances to credibly deflect blame and portray the controversy as an administrative issue.

During the later phases of the blame game, opponents not only blamed the minister for the canceled project; they also portrayed the controversy as a clear reason for him to resign. To achieve this goal, opponents targeted the minister's credibility and integrity. They claimed that if he had a 'spark of decency and respect' for his duties, he should pack his bags and go. ${ }^{59}$ Extensive conventions of resignation explain why opponents tried to turn the minister into a moral liability 
for the government. While German government ministers are directly responsible before parliament, the latter lacks instruments to enforce this responsibility. Since, unlike in the British system, there are no rules that define the reasons for which ministers have to resign, the decision about a minister's fate ultimately rests with the chancellor. The latter accordingly makes a cost-benefit analysis over whether it is better for the government to retain or dismiss the minister (Fischer, 2012). Hence, attacking the minister on moral grounds serves to increase the costs of retaining the minister. In the present case, opponents left no doubt about the trade-off the chancellor had to make. They repeatedly urged Merkel to comment on the controversy and reminded her that the minister had become untenable. However, when it turned out that the minister could not be convicted of personal wrongdoings, it was easy for the chancellor to keep the minister.

Finally, the DRONE case reveals further insights into the advantages and disadvantages that opponents have for appointing an inquiry commission during a blame game. The opposition pondered calling for an inquiry commission, and after the interactions in parliament had worn off, they opted to appoint one. The decision was clearly driven by the opposition's goal to create an information basis on which to draw accusations of personal wrongdoings. During the inquiry, however, they had to stop attacking the minister in other venues, in order to avoid appearing hypocritical. ${ }^{60}$ In sum, direct government involvement and extensive conventions of resignation allowed political opponents to put direct pressure on incumbents and prompted them to address a long-existing policy problem (see Table 7 for a schematic assessment of the theoretical expectations).

\subsection{The German Blame Game Style}

In this section, I compare the NSU, BER, and DRONE cases and subsequently consult a test case to verify and refine the conclusions obtained from the comparison. These analytical steps allow me to obtain a clear picture of the German blame game style.

\section{Political Interaction Structure}

During German blame games, political incumbents can rely on a loyal and active governing majority. If necessary (see the role of direct 
Table 7 Assessment of theoretical expectations in the DRONE case

\begin{tabular}{|c|c|c|c|}
\hline & Explanatory factor(s) & Expectation & Assessment \\
\hline \multirow[t]{4}{*}{ Opponents } & $\begin{array}{l}\text { Political interaction } \\
\text { structure (fragmented/ } \\
\text { consolidated opposition) }\end{array}$ & $\begin{array}{l}\text { E1: Fragmented opponents, consisting of } \\
\text { more than one party, are less successful } \\
\text { in crafting a cohesive blame-generating } \\
\text { strategy during the blame game than } \\
\text { consolidated opponents. }\end{array}$ & $\begin{array}{l}\text { Confirmed. Opposition parties make } \\
\text { incoherent attacks on political } \\
\text { incumbents. }\end{array}$ \\
\hline & $\begin{array}{l}\text { Institutionalized } \\
\text { accountability structures } \\
\text { (conventions of } \\
\text { resignation) }\end{array}$ & $\begin{array}{l}\text { E3: Opponents facing extensive } \\
\text { conventions of resignation concentrate } \\
\text { their blaming more on the incumbent } \\
\text { politician than opponents facing } \\
\text { restrictive conventions, who can only } \\
\text { blame administrative actors. }\end{array}$ & $\begin{array}{l}\text { Confirmed. Opponents concentrate their } \\
\text { blaming on the minister and portray the } \\
\text { controversy as a clear reason to resign. }\end{array}$ \\
\hline & $\begin{array}{l}\text { Institutional policy } \\
\text { characteristics (direct } \\
\text { government } \\
\text { involvement) }\end{array}$ & $\begin{array}{l}\text { E5: Opponents are better able to blame } \\
\text { a controversy on incumbents if the } \\
\text { latter are directly involved than when } \\
\text { the controversy is far removed from } \\
\text { incumbents. }\end{array}$ & $\begin{array}{l}\text { Confirmed. Opponents succeed in making } \\
\text { the minister appear responsible for the } \\
\text { controversy. }\end{array}$ \\
\hline & $\begin{array}{l}\text { Distant-nonsalient } \\
\text { controversy }\end{array}$ & $\begin{array}{l}\text { E11: Opponents do not invest much in } \\
\text { blame generation on the occasion of } \\
\text { a distant-nonsalient controversy. }\end{array}$ & $\begin{array}{l}\text { Partly confirmed. Before the accusation of } \\
\text { lying becomes salient, opponents do not } \\
\text { invest much in blame generation. }\end{array}$ \\
\hline
\end{tabular}




\section{Incumbents
Political interaction structure (loyal/critical governing majority)

\section{Institutionalized accountability structures (conventions of resignation)}

Institutional policy characteristics (direct government involvement)

Distant-nonsalient controversy
E2: Incumbents that receive support from their party(ies) are more successful in reframing a controversy than incumbents that confront criticism from their own ranks.

E4: Incumbent politicians that must comply with extensive conventions of resignation have greater difficulty defending themselves during a blame game than politicians that must comply with restricted conventions.

E6: Incumbents are better able to deflect blame for a controversy onto administrative actors if they are not directly involved in the controversy rather than if they are involved.

E12: Incumbents do not take a distantnonsalient controversy very seriously and only scarcely engage in blame management.
Partly confirmed. Support from the governing majority does not help the incumbent minister to reframe the controversy but allows him to step out of the firing line.

Confirmed. The minister has greater difficulty defending himself and therefore steps up his blame management.

Confirmed. Incumbents have difficulty credibly deflecting blame onto the administrative level.

Partly confirmed. Before the accusation of lying becomes salient, the incumbent only scarcely engages in blame management. 
government involvement referenced later), political incumbents can use the governing majority as an attack device that engages in blame game interactions with opponents. A loyal and active governing majority provides political incumbents with several advantages. During the early phases of a blame game, political incumbents can keep out of the firing line and play for time until they possess a better overview of the controversy. Meanwhile, the governing majority already begins to contest and refute opponents' allegations.

Moreover, an active governing majority allows political incumbents to keep out of heated blame game interactions to some degree and to assume a more neutral role as a committed crisis manager. This division of labor also helps political incumbents offset a contradiction inherent in blame-management approaches that aim to reframe a controversy. A political incumbent who downplays a controversy cannot simultaneously deflect blame for it because blame for a controversy 'that actually is no controversy' is unjustified and thus cannot be deflected. Distributing positive reframing and blame deflection onto several shoulders weakens this contradiction to some degree. While the governing majority deflects blame onto other actors somehow involved in the controversy, political incumbents can concentrate on reframing the controversy. Another advantage of an active and loyal governing majority that is apparent in the three cases is that it reminds opponents (early in the blame game) of their prior involvement in a controversy.

Fragmentation between opponents further benefits incumbents during a blame game. In the three cases, there is ample evidence that opponents' different strategies and goals broaden the diversity of issues treated during a blame game. This complicates the blame game and increases the space for political incumbents to maneuver since they can focus on the facets of a controversy that are least threatening to them.

\section{Institutionalized Accountability Structures}

While the political interaction structure benefits incumbents, accountability structures in the German political system clearly favor opponents. The cases reveal that extensive conventions of resignation provide opponents with a gateway for personalizing attacks against political incumbents. In the German system, the resignation of a political incumbent over a controversy is not automatically ruled out through clear-cut conventions. Instead, whether or not a political 
incumbent is forced to resign is controversy-specific and must be argued out during a blame game. Therefore, opponents have a strong incentive to turn a political incumbent into a moral liability for the government. To do so, opponents must make convincing accusations that the actions or omissions of a political incumbent caused, or at least contributed to, a controversy, or that the incumbent's handling of a controversy was misguided.

The cases suggest that opponents can use an inquiry commission during a blame game to enhance their chances of formulating persuasive accusations. In the German political system, an inquiry commission can be appointed with the support of only a quarter of parliamentarians. ${ }^{61}$ An inquiry commission allows opponents to drag a blame game on and to keep a controversy on the political agenda given that summoning political incumbents to testify provides an occasion for future blame game interactions. Moreover, inquiry commissions are a powerful tool through which opponents can retrieve information that allows incumbents to be convicted of personal wrongdoings. In other words, inquiry commissions can provide the informational basis from where to formulate convincing demands to resign.

However, there is a trade-off to appointing an inquiry commission. It induces a venue change that shifts the blame game into a more technical and objectified arena. During the inquiry, opponents must adopt a more constructive approach toward the controversy and refrain from attacking incumbents in other arenas such as in parliament or in the media. Otherwise, opponents risk appearing hypocritical and of being accused of judging before the trial. Hence, opponents must carefully weigh the advantages and disadvantages of appointing an inquiry commission during a blame game. The likelihood of obtaining decisive information during the inquiry and the advantages expected from protracting a blame game are decisive factors in this trade-off.

These insights provide us with a nuanced understanding of the role of inquiry commissions in political conflict. Extant literature mainly focuses on the UK, where the decision to appoint an inquiry commission rests with the government. In this setting, as scholars demonstrate, inquiry commissions facilitate incumbents' nonengagement during blame games and allow them to block other forms of investigation into a controversy (Elliott \& McGuinness, 2002; Sulitzeanu-Kenan, 2010). While the German cases confirm these findings, they also show 
that in political systems where a minority can easily appoint an inquiry commission, appointment decisions must also be studied from the perspective of opponents.

\section{Institutional Policy Characteristics}

Whether or not institutionalized accountability structures develop into a problem for political incumbents largely depends on the degree of direct government involvement in a policy controversy. In the NSU case, low direct government involvement deprived opponents of the opportunity to credibly attack political incumbents. On the contrary, in the BER and DRONE cases, conventions of resignation became causally relevant since direct government involvement allowed the blame for the controversy to be laid onto political incumbents. Direct government involvement is thus an important mediating factor that influences the distribution of power between opponents and incumbents during German blame games.

\section{Test Case: Nitrofen Controversy (NITROFEN)}

In this section, I test the findings derived from the three in-depth case studies against a fourth case to improve our picture of the German blame game style. The NITROFEN controversy is a German food scandal that became the object of political conflict in May 2002. Parts of the opposition used the proximate-salient controversy to attack the 'agricultural turnaround' policy (Agrarwende) of the SPD and Green Party coalition government.

\section{Policy Struggle}

In the early 2000s, nitrofen, an unauthorized carcinogenic herbicide, found its way into the food chain from a warehouse in Malchin, Mecklenburg-Western Pomerania, on former Eastern German territory. The warehouse, that stored organic cereals for feed production, had been used as storage for plant protection products before German reunification. Although polluted by these products, the warehouse had not been decontaminated before it had become a cereal storage facility. In November 2001, a baby food producer found nitrofen residues in meat ingredients and subsequently informed the relevant food producer. This set a series of private controls in motion by a number of food 
and feed producers. Although contaminants were found, food and feed producers and local authorities did not report the results of these controls to federal authorities because they did not consider them to be a serious health risk. However, in May 2002, organic producer associations directly informed the Federal Ministry of Consumer Protection, Nutrition and Agriculture (BMVEL). The controversy thus revealed the deficiencies of a food safety regulation system that had only recently been updated in response to the BSE (mad cow disease) crisis of 2000.

After the controversy reached the news, federal, state, and local authorities began to frantically search for the source of the contamination, and they finally found it in the Malchin warehouse. Afterward, they quickly announced that the crisis had been solved. However, only shortly after, on June 4, new rumors emerged that the warehouse could not be the sole origin of such large quantities of contaminated feed and food and that conventional (i.e., nonorganic) food was also contaminated. For the coalition government of the SPD and the Green Party, and particularly for the Green politician, Renate Künast, the minister heading the BMVEL, the controversy threatened one of its core policies, the agricultural turnaround, which aimed to markedly increase organic food production in Germany.

\section{Blame Game Interactions}

The first round of blame game interactions occurred between the public discovery of the contamination and the premature announcement on June 4 that the source of the contamination had been found. The opposition parties - the CDU, its Bavarian sibling, the Christian Social Union (CSU), and the liberal FDP - and influential agricultural associations detected a chance to damage the government before the federal elections in autumn and to zero in on the agricultural turnaround. They accused Künast of not having detected the contamination earlier, for not having drawn lessons from the BSE crisis, and for failing to install a functioning early-warning system. During the first round of blame game interactions, opponents were already repeatedly urging the minister to resign because she had allegedly known about the contaminations earlier. ${ }^{62}$ The minister quickly reacted to the controversy, which she called an "outrageous" event. ${ }^{63}$ She promised that there would be a complete clarification of the controversy and introduced several ad hoc measures to find the source(s) of the contamination. She 
also tried to decouple the controversy from the agricultural turnaround, portraying the controversy as the result of the old structures that she was in the middle of reforming. Moreover, she deflected blame onto agricultural associations for trying to cover up the scandal and also onto the CDU and the CSU, which had tolerated the old structures at the root of the controversy for too long. ${ }^{64}$ Throughout the first round of the blame game, Künast received ample support from the governing coalition, which mainly deflected blame onto the feed production industry. ${ }^{65}$

The blame game went into a second round when nitrofen was also found in conventional products and the European Union started to investigate and threatened to impose an export ban on German organic food. The opposition parties used these events to repeat their accusations and demands for Künast's resignation. They blamed the minister for a sluggish crisis response and for having given a premature all-clear signal. As an FDP politician put it: "I think the best consumer information policy would be if you resign today. Consumers would then actually be able to breathe a sigh of relief." ${ }^{66}$ However, the minister did not admit any personal fault and continued to blame companies for not having properly informed public bodies. Moreover, she continued to defend the agricultural turnaround and announced compensation payments for organic farmers. ${ }^{67}$ Also, during the second round of the blame game, the governing coalition consistently defended Künast and accused the CDU/CSU of having created structures that were conducive to such contaminations. Bärbel Höhn from the Green Party attacked the opposition: "I ask you: Who is actually responsible for the laws now in force?... You have for decades been responsible for agricultural policy in this country and are now trying to blame Mrs Künast for what she has not changed yet. I tell you: You are responsible for the laws that are in force today. ${ }^{68}$ As no additional sources of contamination could be identified and because the European Union opted against an export ban, the controversy quickly faded from public interest.

\section{Consequences of the Blame Game}

During the blame game, the CDU/CSU clearly failed to tie the controversy to the ruling government and its agricultural turnaround. Nevertheless, the government intensified its nitrofen monitoring scheme, implemented stricter reporting obligations for feedstuff operators and private inspection bodies, and detailed the communication 
obligations of these entities. ${ }^{69}$ Moreover, the controversy contributed to putting the issue of toxic residues in feed and food much more prominently on the political agenda for a while.

\section{Test of Preliminary Findings and Summary}

In the following, I assess whether the political interaction structure, the institutionalized accountability structures, and the institutional policy characteristics influenced this blame game in ways congruent with the previous findings.

\section{Political Interaction Structure}

The blame game regarding the NITROFEN controversy is characterized by an active and loyal governing majority and fragmented opponents. During the two rounds of blame game interactions, the government received constant support from the governing majority, which contested opponents' attempts to tie the controversy to the agricultural turnaround and reminded them of their prior involvement. Moreover, there were clear signs of fragmentation between opponents. During the blame game, the Left Party differed from the CDU/CSU and the FDP in that it refrained from attacking the minister. ${ }^{70}$ Moreover, the CDU/CSU were alone in tying the controversy to the agricultural turnaround. As a traditional supporter of conventional farming methods, the CDU/CSU portrayed the controversy as an organic scandal. This stance is not evident in the FDP's blame-generation attempts. ${ }^{71}$ Media coverage suggests that the CDU/CSU's framing of the controversy did not become too dominant during the blame game, especially after nitrofen was also discovered in conventional feed. ${ }^{72}$

\section{Institutionalized Accountability Structures}

Like in the BER and DRONE cases, the political incumbent saw herself confronted with fierce personal attacks and demands for her resignation. Opponents called on the chancellor to decide on the minister's fate. Consequently, the minister could not stay passive during the blame game and had to actively fend off the many personal attacks from opponents. While opponents' chances of turning the minister into a liability for the government had been modest due to low direct government involvement (see later), extensive conventions of resignation still allowed opponents to attack the minister and urge her to 
resign. Especially in the run-up to elections, opponents may be tempted to clutch at any straw and accuse political incumbents of being responsible for a controversy, even in situations where their noninvolvement is relatively obvious. In the NITROFEN case, there are no signs that the opposition considered appointing an inquiry commission. This is not surprising if we consider the previously outlined trade-off inherent in doing so. The accusation that Künast had concealed the contaminations from the public quickly turned out to be unsubstantiated. Therefore, it is unlikely that opponents saw an advantage to uncovering additional information during an inquiry in order to pressure the minister.

\section{Institutional Policy Characteristics}

Direct government involvement in the NITROFEN controversy was low. As described earlier, the government could decouple the inspection failure from the agricultural turnaround quite early in the blame game, and it convincingly argued that the inspection failure had been a result of the old inspection regime. While low direct government involvement did not prevent opponents from attacking the minister, it provided her with several advantages. First, low government involvement rendered opponents' attacks less credible. The media clearly realized that the controversy had occurred at considerable arm's length from the minister and thus criticized the opposition for too crudely assigning political responsibility to the minister. ${ }^{73}$ Second, low government involvement allowed the minister to deflect blame onto a wide array of actors and organizations. And third, low government involvement allowed the minister to brusquely reject calls for her resignation. Hence, while we cannot conclude that low direct government involvement completely spares incumbents from personalized attacks, it does provide them with several crucial advantages with which to withstand them.

\section{Summary}

Institutional factors in the German political system are conducive to creating a rather aggressive, incumbent-centered blame game. Extensive conventions of resignation and the opportunity to retrieve salient information about a controversy through the appointment of an inquiry commission are powerful tools that opponents can use to hold political incumbents accountable and to force them into heated blame 
game interactions. Consequently, blamed incumbents must actively engage in blame management and may be forced to give in to opponents' policy demands. Unlike in the UK system, where institutional factors allow political incumbents to stick to the same blame-management approach throughout a blame game, in the German system, incumbents are forced to adapt their blame-management strategies to rising levels of blame. However, political incumbents also benefit from institutional factors, including an active and loyal governing majority and fragmentation among opponents. Whether the overall institutional configuration is more favorable to opponents or to incumbents largely depends on the degree of government involvement in a policy controversy. 


\section{Blame Games in Switzerland}

The German blame games covered in the previous chapter featured interactions between opponents and incumbents that were more heated and oftentimes more consequential than those in the UK political system, even in the absence of strong public feedback. The Swiss blame games in this chapter will reveal yet another type of blame game interaction.

\subsection{The Youth Offender Therapy Controversy (CARLOS)}

The distant-salient youth offender therapy (CARLOS) controversy is about a costly therapy setting for a repeat juvenile offender, which led to a heated blame game for the justice minister of the canton of Zurich. Conservative right parties accused the minister of tolerating a soft, 'leftish' legal practice. ${ }^{1}$

\section{Policy Struggle}

In 2011, a repeat juvenile offender, referred to in the media as 'Carlos', committed a knife attack in Zurich that nearly killed another adolescent. The conviction for this knife attack was the last in a series of thirty-four convictions. Having exhausted all other available sanctions to no avail, and following an expert opinion, Carlos was placed in a special therapy setting where he lived $24 / 7$ with a personal custodian. These settings are supposed to reintegrate youth offenders into society and teach them to live a responsible life. The setting was the first successful measure ever tried on Carlos and there were no major incidents for more than a year. In August 2013, Swiss National Television broadcasted a film about the youth advocate directly responsible for Carlos. The film drew heavily on his most prominent case at that time - the therapy setting for Carlos. Although the setting was portrayed as a success, the film revealed many delicate details. For example, it disclosed information about the Thai boxing training that 
Carlos attended to learn to accept authority, as well as the monthly costs of the therapy, totaling almost 30,000 Swiss Francs. Two days later, on August 27, the largest tabloid in Switzerland ran the story, portraying the setting as a shocking and scandalous example of lax legal practice and an utter waste of taxpayer money. The front-page story triggered a process of scandalization during which media outlets attempted to outdo one another to uncover new details about the setting, many of which were factually incorrect or misrepresented. ${ }^{2}$

For conservative right parties, the CARLOS controversy was a welcome opportunity to attack one of their bête noire policies, the Swiss juvenile justice policy. The latter deviates from outdated concepts of youth offenders as ordinary criminals whose misdeeds must be punished and atoned for. Its primary goals are the protection, education, and the (re)integration of young offenders into society (Aebersold, 2011). The juvenile justice policy is a national policy that must be implemented and applied by the cantons. Youth advocates can usually choose from appropriate measures in a problem-oriented way, without being dependent on the authorization of the upper youth advocate in each case. ${ }^{3}$ While this approach allowed for the prescription of a successful therapy setting in the CARLOS case, the latter was interpreted quite differently by the public when the media reported on its details. Opponents were able to frame the expensive therapy setting as a blatant instance of policy failure and accused the justice minister, a politician of the Green Party, of tolerating a soft, leftish legal practice and of wasting taxpayer money.

\section{Blame Game Interactions}

As a reaction to public and political outrage, the cantonal authorities quickly terminated the therapy setting and returned Carlos to a closed institution. ${ }^{4}$ After trying to ride out the blame for almost two weeks and muzzling the youth advocate, the latter's superior, the senior youth advocate, and the justice minister held a press conference to explain their handling of the controversy. During the press conference, they admitted to minor mistakes concerning cost control and presented some quick fixes intended to improve the oversight of youth advocates. However, their main strategic move was to blame the youth advocate and to deflect all responsibility onto him while claiming to be utterly uninvolved in the case and uninformed of the details. "Adventurous care 
regimes" like the one for Carlos would be prohibited from now on. ${ }^{5}$ The tough stance toward the youth advocate was subsequently reinforced by the minister during press interviews, where he explicitly presented himself as a strong leader and continued to blame the youth advocate, whose dismissal was not necessary because he was due to retire in any case. He claimed that "This can't be true!" was his first reaction to the film, and that he "would have cut 'Carlos's' allowance" had he been in charge. Despite the termination of the setting and the dismissal of the youth advocate, blame pressure continued by the Swiss People's Party (SVP), the right-conservative party, which, in Switzerland's proportional voting system, is the strongest party, both at the national level and in the canton of Zurich in terms of voter share. At the national level, the SVP submitted a parliamentary motion to tighten the juvenile justice policy and at the cantonal level, it called for a parliamentary inquiry commission that would have granted the cantonal parliament far-reaching rights to further investigate the controversy. ${ }^{7}$

In February 2014, the abrupt termination of the therapy setting boomeranged to the justice minister. Legal experts had begun to criticize cantonal authorities for terminating the setting due to media and political pressure and portrayed this step as a strategic, but unlawful, move to calm the media. In response to this criticism, the Swiss Federal Court issued a ruling that the termination of the therapy setting had indeed been unlawful, prompting the cantonal authorities to immediately reinstate the setting. ${ }^{8}$ When the cantonal parliament subsequently debated the controversy in April 2014, nearly all parties blamed the minister for his lack of leadership and his unlawful move. ${ }^{9}$ Backed by two commission reports, all parties pressed for organizational changes and tighter and less opaque responsibility structures. The SVP and the BDP (a small right-conservative party) repeated their criticism of the expensive therapy setting, blamed the minister for tolerating a soft, leftish legal practice, and advised him to resign. Moreover, they tried to convince other parties of the necessity for a parliamentary inquiry commission. The justice minister's Green Party and the SP (Social Democrats) conceded that there had been mistakes made in the treatment of Carlos. However, they opposed a parliamentary inquiry commission, defended the juvenile justice policy, and accused the conservative-right parties of inflating the controversy. The CVP (the Christian-democratic party) and the FDP (the liberal party) took an inbetween stance. They were more critical toward the minister than the 
Green Party and the SP, but they also supported the juvenile justice policy and ultimately opposed a parliamentary inquiry commission. In his parliamentary response, the minister was a bit self-critical and reinforced his intention to implement the recommendations made in the two commission reports but continued to deflect responsibility onto the administrative level. ${ }^{10}$

\section{Consequences of the Blame Game}

While the parliamentary vote against an inquiry commission finally terminated the blame game surrounding the CARLOS controversy, the justice minister could not escape its consequences. He was voted out of office in the April 2015 cantonal elections. ${ }^{11}$ Although the national parliament vetoed the SVP's motion to tighten the juvenile justice policy, there were significant organizational adaptations at the cantonal level that curtailed the autonomy of youth advocates regarding costs and the choice of therapy measures. The blame game also led to significant changes in the application of the juvenile justice policy. Data on the choice of therapy measures and statements by youth advocates suggest that the juvenile justice policy was applied more strictly in the aftermath of the blame game in order to provide opponents and the media with as few blaming opportunities as possible (Hinterleitner, 2018).

\section{Context-Sensitive Analysis of Blame Game Interactions}

It is baffling that the justice minister did not try to defend the therapy setting, despite ample opportunities to do so. The setting had proved to be the first successful therapy measure tried on Carlos and was no more expensive than therapy in a closed institution. Moreover, a successful therapy setting would have greatly reduced the likelihood of follow-up costs. Instead of referring to these arguments, the justice minister always acted as if he could fully sympathize with public outrage: first by hastily terminating the setting, and later by deflecting blame onto the youth advocate. Strong public feedback and personalized attacks by opponents can account for the minister's blame-management approach.

\section{Issue Characteristics}

Media coverage suggests that there was very strong public feedback to the CARLOS controversy. Both quality outlets and tabloids reported 
on it intensively. All media outlets adopted a scandalized tone and went on about the details of the therapy setting, as a media analysis of the controversy suggests. Even quality outlets adopted a very scandalizing and emotional tone when reporting on Carlos' 'luxury treatment' and quibbled over its details. For example, even quality outlets reported that Carlos preferred beef over cheaper types of meat and that he had used an Armani deodorant during the therapy setting (Schranz, 2015). This style of coverage clearly struck a chord with the public. Some journalists later indicated that they had been surprised by the intensity and tone of the comments to their articles. ${ }^{12}$ In recent years, acts of violence committed by juveniles in Switzerland frequently attracted public attention and sparked calls for a zero-tolerance approach to them, thereby increasing the salience of the youth crime topic in public discourse (Urwyler \& Nett, 2012, pp. 20-25). However, high salience does not imply that the mass public is properly informed about the functioning of the juvenile justice policy. In a country like Switzerland, which has a very low juvenile crime rate, the juvenile justice policy is very distant to most people's daily lives. Juvenile crime is mostly perceived through the media (Urwyler \& Nett, 2012, p. 22). By placing Carlos in a 'luxurious' therapy setting instead of in jail, the juvenile justice policy appeared to treat youth offenders as victims rather than as ordinary criminals, thus adopting a positive connotation of policy targets (Schneider \& Ingram, 1993).

This allowed opponents to portray the state's approach to fighting crime and ensuring public order as too lax. They urged incumbents to reverse course by tightening their grip on juvenile offenders and on the youth advocates that were too soft on them. One can clearly see how both the distance and the salience of the controversy allowed opponents to convincingly make this claim. On the one hand, distance allowed opponents to portray juvenile crime as a rampant problem that was allegedly a threat to public security. ${ }^{13}$ On the other hand, the salience of juvenile crime allowed for the adoption of an 'enough is enough' rhetoric that compared the treatment of Carlos with earlier instances of soft, leftish legal practice, which the state could no longer afford. $^{14}$

The blame management of incumbents suggests that they considered the CARLOS controversy to be very tricky and perilous due to strong public feedback. They deflected responsibility onto the administrative level and adopted ad hoc measures that signaled their willingness to 
keep 'freewheeling' bureaucrats in check. Despite the clear opportunity to defend the therapy setting as the right choice in this particular case, the justice minister only lightly defended it in public. Instead, he was anxious to cultivate his image as a strongman who understood the public's outrage. ${ }^{15}$ The senior youth advocate later remarked that he and the minister had considered the controversy about the therapy setting as 'not communicable'. The minister later added: "The media could never have been stopped!" 16 Overall, there are clear signs that strong public feedback, and the attacks by opponents that built on it, significantly constrained the incumbent's blame-management approach.

\section{Institutional Factors}

As mentioned in Chapter 2, the Swiss political system has a consensus government that represents (almost) all parties. Therefore, there is no fixed opposition that acts as the parliamentary opponent in a blame game. Instead, an issue-specific opposition constitutes itself anew every time a controversy occurs. There were three camps during the blame game about the CARLOS controversy. The first, the SVP and the BDP acted as opponents who wanted a tighter juvenile justice policy, a parliamentary inquiry commission, and the justice minister's resignation. The second, the Green Party and the SP opposed all these requests. Third, the FDP and the CVP acted as 'middle' parties that got something out of both opponents' and supporters' argumentations. They agreed with opponents that the executive had failed in the particular case and that organizational adaptations were needed. However, they opposed changes to the policy and a parliamentary inquiry commission. While opponents constantly blamed the justice minister for the controversy, they did not spare the supporting parties for tolerating a soft, leftish legal practice, for not putting more pressure on the justice minister, and for not supporting a parliamentary inquiry commission to further examine the controversy. The SVP also tried to discredit the middle course that moderate parties followed by stressing that the organizational adaptations in the wake of the controversy were not enough. Political incumbents benefited from the fact that the three camps held different views on what constituted an adequate policy response to the CARLOS controversy. The middle parties' position, requesting organizational adaptations but opposing a parliamentary inquiry commission, allowed the justice minister to end the blame game 
without appearing insensitive to the requests held by the parliamentary majority.

During the blame game, the justice minister was forced to endure a raft of personalized attacks. For the Swiss political system, this is quite uncommon since individual councilors are usually not promising targets for opponents. Councilors are protected by the collegiality principle, which stipulates that they decide and speak with one voice, but also that they are collectively responsible for any controversies that occur within one of the seven departments (Vatter, 2016, p. 236). At the same time, however, opponents can single out individual councilors as the political principals of their departments (Vatter, 2016, p. 238). Since the blame about the CARLOS controversy was situated at the cantonal level, where - unlike at the federal level - councilors are directly elected by the public, opponents saw the chance to damage an important Green Party politician. They associated the councilor with his party's soft stance on youth crime and even (indirectly) urged him to resign. The justice minister could thus not hide behind the council but had to actively engage in blame management. His desire to appear as a strongman must also be interpreted as an attempt to liberate himself from personalized blame attacks that portrayed him as too soft on youth crime.

Against this background, the rather low direct government involvement in youth crime policy did not carry too much weight. The justice minister had already exposed himself quite early in the blame game when he took the leading role in a joint press conference with the upper youth advocate. ${ }^{17}$ This clearly associated him with the controversy and thereby encouraged media outlets and opponents to focus their attention and attacks on the justice minister. Both strong public feedback and personalized blame attacks thus explain why the minister frantically engaged in blame management and committed to significant organizational adaptations (see Table 8 for a schematic assessment of the theoretical expectations).

\subsection{The Corporate Tax Reform Controversy (TAX)}

The proximate-nonsalient corporate tax reform controversy (TAX) case is about a corporate tax reform (hereafter CTR) adopted in 2008, which led to unexpectedly high tax losses for the government. The SP blamed the Federal Council for rating company interests higher 
Table 8 Assessment of theoretical expectations in the CARLOS case

\begin{tabular}{|c|c|c|c|}
\hline & Explanatory factor(s) & Expectation & Assessment \\
\hline \multirow[t]{4}{*}{ Opponents } & $\begin{array}{l}\text { Political interaction } \\
\text { structure (fragmented/ } \\
\text { consolidated opposition) }\end{array}$ & $\begin{array}{l}\text { E1: Fragmented opponents, consisting of } \\
\text { more than one party, are less successful } \\
\text { in crafting a cohesive blame-generating } \\
\text { strategy during the blame game than } \\
\text { consolidated opponents. }\end{array}$ & $\begin{array}{l}\text { Confirmed. Opponents do not secure a } \\
\text { majority for their policy demands since } \\
\text { the middle camp opposes them. }\end{array}$ \\
\hline & $\begin{array}{l}\text { Institutionalized } \\
\text { accountability structures } \\
\text { (conventions of } \\
\text { resignation) }\end{array}$ & $\begin{array}{l}\text { E3: Opponents facing extensive } \\
\text { conventions of resignation concentrate } \\
\text { their blaming more on the incumbent } \\
\text { politician than opponents facing } \\
\text { restrictive conventions, who can only } \\
\text { blame administrative actors. }\end{array}$ & $\begin{array}{l}\text { Rejected. At the cantonal level, the direct } \\
\text { election of councilors invites opponents } \\
\text { to attack them despite basically } \\
\text { nonexistent conventions of resignation. }\end{array}$ \\
\hline & $\begin{array}{l}\text { Institutional policy } \\
\text { characteristics (direct } \\
\text { government } \\
\text { involvement) }\end{array}$ & $\begin{array}{l}\text { E5: Opponents are better able to blame a } \\
\text { controversy on incumbents if the latter } \\
\text { are directly involved than when the } \\
\text { controversy is far removed from } \\
\text { incumbents. }\end{array}$ & $\begin{array}{l}\text { Rejected. The incumbent deliberately } \\
\text { associates himself with the controversy, } \\
\text { allowing opponents to involve the } \\
\text { incumbent despite originally low direct } \\
\text { government involvement. }\end{array}$ \\
\hline & Distant-salient controversy & $\begin{array}{l}\text { E7: Opponents strongly invest in blame } \\
\text { generation on the occasion of a distant- } \\
\text { salient controversy and attempt to } \\
\text { damage incumbents on moral grounds. }\end{array}$ & $\begin{array}{l}\text { Confirmed. Opponents strongly invest in } \\
\text { blame generation and attempt to } \\
\text { damage the incumbent on moral } \\
\text { grounds (by blaming him for violating } \\
\text { norms of justice). }\end{array}$ \\
\hline
\end{tabular}


Table 8 (cont.)

\begin{tabular}{|c|c|c|c|}
\hline & Explanatory factor(s) & Expectation & Assessment \\
\hline \multirow[t]{4}{*}{ Incumbents } & $\begin{array}{l}\text { Political interaction } \\
\text { structure (loyal/critical } \\
\text { governing majority) }\end{array}$ & $\begin{array}{l}\text { E2: Incumbents that receive support from } \\
\text { their party(ies) are more successful in } \\
\text { reframing a controversy than } \\
\text { incumbents that confront criticism from } \\
\text { their own ranks. }\end{array}$ & $\begin{array}{l}\text { Not testable. As a consensus body, the } \\
\text { Cantonal Council tries to avoid any } \\
\text { party affiliations during the blame } \\
\text { game. However, it aligns with the } \\
\text { position of the middle camp. }\end{array}$ \\
\hline & $\begin{array}{l}\text { Institutionalized } \\
\text { accountability structures } \\
\text { (conventions of } \\
\text { resignation) }\end{array}$ & $\begin{array}{l}\text { E4: Incumbent politicians that must } \\
\text { comply with extensive conventions of } \\
\text { resignation have greater difficulty } \\
\text { defending themselves during a blame } \\
\text { game than politicians that must comply } \\
\text { with restricted conventions. }\end{array}$ & $\begin{array}{l}\text { Rejected. At the cantonal level, the direct } \\
\text { election of councilors turns them into } \\
\text { blame targets despite basically } \\
\text { nonexistent conventions of resignation. }\end{array}$ \\
\hline & $\begin{array}{l}\text { Institutional policy } \\
\text { characteristics (direct } \\
\text { government } \\
\text { involvement) }\end{array}$ & $\begin{array}{l}\text { E6: Incumbents are better able to deflect } \\
\text { blame for a controversy onto } \\
\text { administrative actors if they are not } \\
\text { directly involved in the controversy } \\
\text { rather than if they are involved. }\end{array}$ & $\begin{array}{l}\text { Rejected. By deliberately associating with } \\
\text { the controversy, the incumbent renders } \\
\text { his blame-deflection attempts } \\
\text { incredible. }\end{array}$ \\
\hline & Distant-salient controversy & $\begin{array}{l}\text { E8: Incumbents take a distant-salient } \\
\text { controversy very seriously and confront } \\
\text { it by engaging in blame deflection and } \\
\text { symbolic activism. }\end{array}$ & $\begin{array}{l}\text { Confirmed. The incumbent takes the } \\
\text { controversy very seriously and } \\
\text { confronts it by engaging in blame } \\
\text { deflection and activism. }\end{array}$ \\
\hline
\end{tabular}


than the interests of the hard-working and tax-paying public. Despite strong resistance from conservative parties, the SP's blame-generation attempts secured it an advantage in the policy struggle about corporate taxation in Switzerland.

\section{Policy Struggle}

As a "small state in world markets" (Katzenstein, 1985), Switzerland is traditionally anxious to create an adequate business environment for domestic and foreign companies. While corporate taxation is seen as an important means of creating an adequate business environment, it is also an important source of revenue for the government. This makes corporate taxation a contested policy instrument every time changing economic and political circumstances, such as updated Organisation for Economic Co-operation and Development (OECD) standards, or a new Europen Union law, force Switzerland to adapt its corporate tax regime.

In the 1990s, Switzerland adopted a major CTR that sought to improve tax conditions for holding companies. This reform was already considered insufficient at the time of its adoption. Another reform was needed to abolish Switzerland's system of double taxation of dividends. Therefore, another reform process was launched at the turn of the millennium. During the Vernehmlassung, the consultative process during which political actors and stakeholders are able to comment on the planned CTR, the reform received broad support from conservative parties and the economic sector (Sager et al., 2017). ${ }^{18}$ The SP, the CVP, and the Green Party criticized the reform, stating that it would provoke 'random tax giveaways' to corporations and that it was not designed in a revenue-neutral way. ${ }^{19}$ They feared that tax losses due to the CTR would force the government to reduce social welfare expenditures. Conservative parties retorted that these concerns were unfounded since the Federal Council, Switzerland's collective executive government consisting of seven councilors, estimated that tax losses would only amount to 365-455 million Swiss Francs annually. When the CTR was adopted in 2007, the SP initiated a facultative referendum to give voters the last word about its adoption. ${ }^{20}$ In 2008 , voters accepted the CTR by a very slight margin of 50.5 percent.

Three years later, in March 2011, when several large companies declared tax-free dividends on the basis of the CTR, it became clear 
that tax losses were much larger than predicted by the Federal Council during the consultative process and the referendum campaign. The main reason for this was that the tax exemptions included in the CTR had been made retroactive, that is, companies could not only use them on commercial activities from 2008 on, but also on activities going back to $1997 .^{21}$

\section{Blame Game Interactions}

Since the so-called retroactivity clause had not been an issue of debate during the consultative process and the referendum campaign, the SP took up the issue. It accused the Federal Council of having violated the principle of voting liberty, which states that the opinion-formation process leading to a vote must be based on correct and unbiased information provided by the executive. ${ }^{22}$ The SP feared tax losses of more than 10 billion Swiss Francs over the next ten to fifteen years. The finance department, headed by the councilor Eveline Widmer-Schlumpf, admitted that revenue losses would be higher than estimated back in 2007/2008. Despite the higher than expected tax losses, the councilor rejected calls to amend the CTR. She justified her stance by highlighting the importance of legal certainty for companies: "It is particularly important that our legal system remains predictable. Confidence in the reliability of our legislation is an important [international] asset." Moreover, she carefully alluded to parliament's responsibility to discuss the reform proposals during the consultative procedure. ${ }^{23}$ Unsatisfied with this response, the SP maintained blame pressure in the following weeks and requested an extraordinary session of the National Council, the lower house of the Swiss parliament. ${ }^{24}$

During this session, ${ }^{25}$ held on April 12, 2011, the SP repeated its criticism and formulated a concrete demand: The Federal Council should either repeat the referendum or amend the CTR to compensate for the unexpected tax losses. As one SP politician put it, "[t]here has been a serious failure on the part of the Federal Council and the administration. The people voted on the wrong basis. That is unacceptable!" ${ }^{26}$ The Green Party blamed the Federal Council and the finance department for not properly informing the electorate and for valuing economic interests over democratic principles. The SVP and the FDP supported the CTR and attacked the opponent camp for inflating expected tax losses and for its 'communist agenda': "Above all, 
however, the SP is not at all interested in this corporate tax reform: the $\mathrm{SP}$ is interested in implementing its party program. As we all know, it wants to overcome capitalism." ${ }^{27}$ The supporting camp further argued that the CTR addressed important tax issues and was decisive for Switzerland's economic prosperity, stressed the importance of legal certainty, and largely avoided a discussion about voting liberty. The CVP and the BDP adopted a middle position. They criticized the executive for the controversy but also stressed the importance of legal certainty. The councilor was apt to confront the controversy in a problem-oriented way. She admitted that the voting guide had been incomplete and explained why, in her view, the referendum should not be repeated: "Democracy is only possible within the framework of the rule of law. I do not want democracy to be played off against the rule of law; it is a balancing of interests." However, she suggested that it was still possible to make amendments to the CTR in order to limit further tax losses: "I have shown you the possibilities of doing something in commercial law or tax law, if you want to." 28 The BDP, WidmerSchlumpf's party, initially indicated that it would support amendments to the CTR. However, overall, the SVP, the FDP, the CVP, and the BDP, which together constituted a comfortable parliamentary majority, rejected the demands of the SP and the Green Party.

In the following weeks, the SP, and to a lesser degree the Green Party, pulled out all the stops to reach their policy demands. They requested a ruling from the Federal Court over whether to repeat the referendum, asked for a parliamentary inquiry, and tried to win a majority in support of making amendments to the CTR in both chambers of parliament. However, all these attempts were blocked. The Federal Court criticized the Federal Council but opted against a repetition of the referendum. The conservative majority in both chambers and in the audit committee, where the decision about an inquiry is made, blocked all of the opponent camp's motions and requests.

While the blame game about the CTR controversy was effectively over, the SP already began to raise the stakes for the next policy struggle. Over the course of several years, the Federal Council had been preparing the next CTR that would comply with OECD standards. The OECD requested that Switzerland abolish tax privileges for foreign corporations. In order to avoid alienating the latter, the Federal Council intended to combine those reforms with tax privileges elsewhere. The SP linked these reform plans with the CTR controversy and 
gave the conservative majority a choice of either agreeing to compensation measures up front or facing another referendum on the new reform. ${ }^{29}$ Initially, this strategy seemed to pay off. In order to limit tax losses, the Council of States, the smaller chamber of Switzerland's federal parliament, wanted to draft a more 'defensive' reform, which it expected would have a higher likelihood of being accepted by the electorate in case the SP opted for a referendum. ${ }^{30}$ However, the conservative majority did not buckle under the pressure from the SP and finally rejected the adoption of compensation measures in March 2013.

\section{Consequences of the Blame Game}

While resignations in response to the controversy had never been an issue of debate, the policy consequences resulting from the blame game about the CTR controversy are remarkable. During the controversy, the conservative majority blocked all attempts by the SP to limit tax losses through amendments. However, there were important indirect consequences. The SP challenged the new reform through a referendum in February 2017 and won it by a large margin: 59.1 percent of voters rejected the new reform. With a 45.2 percent turnout, this referendum's turnout was significantly higher than the one about the CTR (37.7 percent). During the referendum campaign, the SP made frequent reference to the CTR, while conservative parties spoke exclusively of a 'tax reform' instead of a corporate tax reform in order to decouple the new reform from the CTR. ${ }^{31}$

\section{Context-Sensitive Analysis of Blame Game Interactions}

A context-sensitive analysis shows that opponents had a very hard time achieving immediate policy change due to moderate public feedback and their inability to pull middle parties onto their side. However, high direct government involvement in the controversy allowed opponents to anchor the impression that the Federal Council had 'played foul' with regard to the CTR into public memory and that its promises, and that of conservative parties, about negligible tax losses due to the new reforms, could not be trusted. As the clear success of the referendum suggests, blame generation in the wake of the CTR controversy benefited opponents in the next round of the policy struggle about corporate taxation in Switzerland. 


\section{Issue Characteristics}

The controversy about the CTR attracted consistent and problemcentered coverage from quality outlets, and less, although also more biting, coverage from tabloids. The complex and technical nature of this controversy limited public feedback. All media outlets spent considerable energy explaining the complex issues at the root of the tax losses to the public. Corporate taxation is traditionally a nonsalient rather obscure policy area that does not arouse public emotions. The weak interest in the CTR can also be deduced from the very low turnout to the first referendum in 2008 . With only a 37.7 percent voter participation, the referendum had the second-lowest turnout of the twenty-seven referendums held during the 48th legislative period from 2007 to 2011. Exit polls further show that voters struggled with the obscurity of the CTR. ${ }^{32}$

Nevertheless, the significant tax losses associated with the controversy are likely to have struck a chord with the public. Opponents used the losses to activate considerations of self-interest. They argued that the Federal Council had betrayed the people ('a gigantic scam') by not properly informing them about the implications of the CTR and that the support camp valued company interests higher than the interests of the hard-working and tax-paying public. ${ }^{33}$ These claims resonated widely in the media, which frequently referred to the CTR controversy as a 'billion franc debacle' or a 'fudge reform'. The Federal Council, in response, took the CTR controversy seriously. It admitted that mistakes had been made, and it later expressed its willingness to explore opportunities for reducing tax losses. At the same time, however, the Federal Council and the support camp attempted to dispel opponents' claims of personal relevance. They argued that tax losses would be much smaller than those alleged by opponents and that the whole public would benefit from the CTR through rising corporate tax income and the creation of new jobs.

\section{Institutional Factors}

Switzerland's political interaction structure played an important role in blame game interactions. Parties' attempts to position themselves in relation to the controversy resulted in three camps: an opponent camp, consisting of the SP and the Green Party, which wanted the referendum repeated or the CTR amended; a support camp, consisting of the SVP and the FDP, which opposed both of these demands; and a middle 
camp, consisting of the CVP and the BDP, which opposed a repetition of the referendum but, at least initially, was not wholly against amendments to the CTR. This constellation of viewpoints made opponents concentrate their attacks and claims on other parties. In order to get its motions through parliament, they had to draw the middle camp to their side. They did so by discrediting the support camp for its uncompromising stance and reminded it of the SVP's often used 'take the people seriously' slogan: “Those who take the people seriously will ensure a repetition of the referendum and agree with our motion today. It is especially the SVP's duty to do so. What is its slogan again? 'The people, the people, the people! The people are always right." 34 While there were also attacks on the Federal Council, they were more moderate and less aggressive. Opponents' strong focus on the support and middle camps allowed the Federal Council to remain largely out of blame game interactions and to adopt a problem-centered stance toward the controversy. Like in the CARLOS case, political incumbents aligned with the position of the middle camp, opposing the repetition of the referendum but expressing their willingness to explore possibilities of amending the CTR.

The collegiality principle was another factor that allowed the Federal Council to remain in the background and to only adopt a reduced blame-management approach. During the blame game, opponents only addressed their criticism to the Federal Council as a whole. Widmer-Schlumpf, the councilor of the finance department, was never personally attacked. Another factor that could have benefited the councilor was the fact that the CTR had been drafted before her time in office. In the media, the SP temporarily referred to the controversy as the 'Merz-lie', linking the controversy to Hans-Rudolf Merz, Widmer-Schlumpf's predecessor. It cannot be assessed whether the SP would have ignored the collegiality principle and openly attacked Merz had he still been in office.

While there were no personalized attacks on the councilor, the Federal Council could not completely steer clear of criticism for its role during the policy reform process. This was due to its clearly discernible direct involvement in the policy controversy. The Federal Council authorizes the voting guide and is responsible for the estimates and projections made by the federal administration. Direct government involvement allowed opponents to accuse the Federal Council of foul play because it allegedly violated the principle of voting liberty. The 
Federal Council saw its blame deflection possibilities constrained. Blaming the federal administration for an issue for which the political responsibility clearly lay with the Federal Council would have appeared incredible. However, since there were no hefty or personalized attacks, this constraint did not overly affect the Federal Council (see Table 9 for a schematic assessment of the theoretical expectations).

\subsection{The National Exposition Controversy (EXPO)}

The distant-nonsalient national exposition (EXPO) controversy is about a contested Swiss national exposition held in 2002. Until its delayed opening, the Federal Council repeatedly requested additional financing from the parliament in order to avoid the cancellation of the exposition. Despite receiving criticism on the occasion of these requests, the Federal Council received the funds and followed through with the exposition. ${ }^{35}$

\section{Policy Struggle}

In the 1990s, a political discussion began about holding a new national exposition in Switzerland. After several cantons and cities submitted their applications to host it, the Federal Council decided to hold the exposition (hereafter Expo.02) in the region of the three lakes of Neuchâtel, Biel, and Murten in 2001. ${ }^{36}$ After deciding on the location, the Federal Council requested a detailed feasibility study from the Verein Landesausstellung (hereafter Verein), an association of regional actors responsible for the planning, construction, and operation of Expo.02. This feasibility study concluded that it was possible to hold Expo.02 in the three-lakes region and that the financial contribution required from the federal state would amount to 170 million Swiss Francs. $^{37}$

When approving the feasibility study at the end of 1996, the Federal Council reduced the federal contribution to 130 million Swiss Francs. This reduced federal contribution can be explained by the dilemma the Federal Council found itself in when deciding about Expo.02. On the one hand, there was a broad public and political majority that wanted the Federal Council to endorse Expo.02. On the other hand, the Federal Council faced a tight federal budget, general skepticism toward huge statist interventions, and a public that, for the most part, opposed a 


\section{Table 9 Assessment of theoretical expectations in the TAX case}

\begin{tabular}{|c|c|c|c|}
\hline & Explanatory factor(s) & Expectation & Assessment \\
\hline \multirow[t]{4}{*}{ Opponents } & $\begin{array}{l}\text { Political interaction } \\
\text { structure (fragmented/ } \\
\text { consolidated opposition) }\end{array}$ & $\begin{array}{l}\text { E1: Fragmented opponents, consisting of } \\
\text { more than one party, are less successful } \\
\text { in crafting a cohesive blame-generating } \\
\text { strategy during the blame game than } \\
\text { consolidated opponents. }\end{array}$ & $\begin{array}{l}\text { Confirmed. Opponents do not secure a } \\
\text { majority for their policy demands since } \\
\text { the middle camp opposes them. }\end{array}$ \\
\hline & $\begin{array}{l}\text { Institutionalized } \\
\text { accountability structures } \\
\text { (conventions of } \\
\text { resignation) }\end{array}$ & $\begin{array}{l}\text { E3: Opponents facing extensive } \\
\text { conventions of resignation concentrate } \\
\text { their blaming more on the incumbent } \\
\text { politician than opponents facing } \\
\text { restrictive conventions, who can only } \\
\text { blame administrative actors. }\end{array}$ & $\begin{array}{l}\text { Partly confirmed. The collegiality } \\
\text { principle, together with the fact that the } \\
\text { reform had been adopted under the } \\
\text { incumbent's predecessor, restrains } \\
\text { opponents from blaming the councilor. }\end{array}$ \\
\hline & $\begin{array}{l}\text { Institutional policy } \\
\text { characteristics (direct } \\
\text { government } \\
\text { involvement) }\end{array}$ & $\begin{array}{l}\text { E5: Opponents are better able to blame a } \\
\text { controversy on incumbents if the latter } \\
\text { are directly involved than when the } \\
\text { controversy is far removed from } \\
\text { incumbents. }\end{array}$ & $\begin{array}{l}\text { Confirmed. Direct government } \\
\text { involvement allows opponents to } \\
\text { criticize the Federal Council. }\end{array}$ \\
\hline & $\begin{array}{l}\text { Proximate-nonsalient } \\
\text { controversy }\end{array}$ & $\begin{array}{l}\text { E9: Opponents invest considerably in } \\
\text { blame generation on the occasion of a } \\
\text { proximate-nonsalient controversy and } \\
\text { try to activate considerations of self- }\end{array}$ & $\begin{array}{l}\text { Confirmed. Opponents invest } \\
\text { considerably in blame generation and } \\
\text { seek to activate considerations of self- } \\
\text { interest. }\end{array}$ \\
\hline
\end{tabular}


Incumbents

Political interaction structure (loyal/critical governing majority)

\section{Institutionalized accountability structures (conventions of resignation)}

Institutional policy characteristics (direct government involvement)

Proximate-nonsalient controversy
E2: Incumbents that receive support from their party(ies) are more successful in reframing a controversy than incumbents that confront criticism from their own ranks.

E4: Incumbent politicians that must comply with extensive conventions of resignation have greater difficulty defending themselves during a blame game than politicians that must comply with restricted conventions.

E6: Incumbents are better able to deflect blame for a controversy onto administrative actors if they are not directly involved in the controversy rather than if they are involved.

E10: Incumbents take a proximatenonsalient controversy seriously and address it by mainly adopting reframing strategies and forms of activism.
Not testable. As a consensus body, the Federal Council attempts to avoid any party affiliations during the blame game. However, the Federal Council aligns with the middle camp.

Partly confirmed. Principle of collective responsibility spares councilor from personalized attacks. The fact that the reform was adopted under the incumbent's predecessor could have also played a role.

Not testable. Direct government involvement should have rendered deflection implausible but is not necessary due to lack of personalized attacks.

Confirmed. Incumbent takes the controversy seriously, engages in reframing and signals its willingness for activism (although this is blocked by the support camp). 
large federal contribution. ${ }^{38}$ Given Switzerland's far-reaching direct democratic rights, which can effectively be used as veto-instruments, it became plausible for the Federal Council to find a middle ground by decreasing the expected federal contribution to 130 million Swiss Francs. When justifying this amount, the Federal Council publicly announced that there would be no further contributions. ${ }^{39}$

In the summer of 1999, it became clear that Expo.02 could not be carried out with the initial federal contribution of 130 million Swiss Francs. Until its opening in May 2002, Expo.02 had to be saved from the brink of failure several times. The parliament rubber-stamped a total of five additional financing requests from the Federal Council. In the end, the total federal contribution amounted to 928 million Swiss Francs. The main reasons for the cost increases were management problems at the Verein and an overestimation of the potential private sponsorship. Within the Verein, there were many local actors who did not dispose of sufficient experience to plan, organize, and implement such a complex project. Moreover, the Federal Council never questioned the statements made by the Verein about the private sponsorship potential of the exposition, even though the amount of private contributions would ultimately determine the financing deficit the Federal Council would have to cover. ${ }^{40}$

\section{Blame Game Interactions}

From August 1999 on, the media and politicians from the four major parties in the National Council, the right-conservative SVP, the FDP, the CVP, and the SP, began to criticize the Federal Council's passivity in regard to the management problems at the Verein. They urged the Federal Council to assume political responsibility for Expo.02, to install new management at the Verein, and to postpone the exposition. ${ }^{41}$ The Federal Council took these requests seriously. ${ }^{42}$ It postponed the exposition to 2002 and implemented a new management structure. In order to ensure its smooth preparation, it asked the parliament for an additional loan of 250 million Swiss Francs. To justify this request, the Federal Council made hard stipulations to the Verein. It tied additional financing to a cost moratorium until the parliament would make a decision about the loan and forced the Verein to adopt several cost-saving measures. The Federal Council attacked the Verein for its poor management but framed Expo.02 as an important project whose termination would be an embarrassment 
to Switzerland. The councilor heading the economic department and responsible for overseeing Expo.02, Pascal Couchepin, took a tough stance. He called the additional loan a 'limited debacle' and framed the management problems at the Verein as a 'salutary crisis', which finally allowed the Federal Council to intervene and to sort out the problems with Expo.02. He claimed that "before the debacle, we couldn't intervene; we only had the chance to trust the people [at the Verein]. Unfortunately, in June we had to find out that the matter was not progressing. And then I honestly wished for a crisis, I wished for a crisis to get down to the root of the trouble."43

While these steps allowed the Federal Council to mute criticism for some time, it quickly turned out that the additional 250 million Swiss Francs was not enough. As mentioned earlier, the Federal Council had to ask parliament for additional money at irregular intervals until the opening of Expo.02. Each time, the Federal Council reassured the parliament that the respective contribution was needed due to unexpected developments, that it would be the last one, and that it was vital in order to save a great project from the brink of failure. These financing approvals were accompanied by an increasingly outraged parliament. The Federal Council was explicitly accused of presenting the parliament with an overmodest financing request while already covertly preparing the next one. For example, a CVP politician claimed that for "me it is also clear: Whoever said A must also say B - I only hope that we don't have to go through the whole alphabet!" ${ }^{44}$ The SVP, in particular, the (much smaller) Green Party, and later also the CVP, withheld their approval for new federal contributions. However, the other major parties grudgingly gave their approval, knowing well that the latter was needed to prevent the grounding of Expo.02 shortly before its opening. ${ }^{45}$ When Expo.02 finally opened its doors in May 2002 and developed into a huge success, criticism about the significant extra costs quickly dissipated.

\section{Consequences of the Blame Game}

The blame game surrounding the EXPO controversy did not produce significant consequences. Personnel changes only occurred at the level of the Verein. Despite a bold intervention in response to multi-partisan pressure early on in the blame game, the Federal Council went ahead 
with Expo.02 by securing parliamentary approval for five additional financing requests.

\section{Context-Sensitive Analysis of Blame Game Interactions}

The relative ease with which the Federal Council secured parliamentary approval is quite surprising. Despite a clear and openly voiced promise to keep public expenditure for Expo.02 at a very low level, by its opening, the Federal Council had been granted contributions totaling more than seven times the initial amount requested. Weak public feedback to the cost increases, fragmentation among parties, the collegiality principle, and low direct government involvement all worked to create a situation that allowed the Federal Council to secure the financing of the project.

\section{Issue Characteristics}

The first factor that benefited the Federal Council was weak public feedback to the cost increases. While there was consistent coverage of Expo.02, especially in quality outlets, most of this coverage concentrated on artistic and organizational aspects. The tone of coverage was always very problem-centered. Throughout the blame game, the media exhibited a positive stance toward the project, despite recurrent cost overruns. Even the economic-liberal Neue Zürcher Zeitung, from which a more skeptical stance toward an over expensive public project could well have been expected, described Expo. 02 in a sympathetic and not too critical way. ${ }^{46}$ Cultural policy is generally a low-salience policy area that usually only reaches a minority of the public. In Switzerland, cultural policy is especially uncontested since it is widely accepted as an instrument for creating a common national identity across language barriers and cultural differences (Bijl-Schwab, 2017). Expo.02 was no exception in this regard. Polls show that the public generally viewed the exposition favorably, while not attaching too much importance to it either. ${ }^{47}$ Moreover, the additional financing requested by the Federal Council appeared comparatively minor as it was done in a step-wise manner (see Hinterleitner, 2019 on this 'salami tactics' aspect). Therefore, opponents could neither emotionalize the controversy nor activate considerations of self-interest. They solely urged the Federal Council to assume responsibility as the political patron of the exposition. Even during the acute crisis phase, the parties that had begun 
opposing the project made problem-based claims. While they criticized the Federal Council for wasting public money, this criticism remained very general and cynical. When reacting to these allegations, the Federal Council adopted a self-confident stance and primarily applied reframing and blame-deflection strategies. The councilor, Couchepin, could speak of a 'salutary crisis' and act as a strongman in relation to the Verein; a stance he could have hardly adopted in the face of stronger public feedback.

\section{Institutional Factors}

There are two different constellations of actors in the course of the Expo.02 blame game. At first, all major parties urged the Federal Council to assume political responsibility. However, during the later phase of the blame game, the major parties divided into two camps: one that was willing to embrace the possibility of grounding Expo.02 and another camp that was not willing to take responsibility for a lastminute cancellation. This division detracted blame from the Federal Council to some degree as the parties in both camps began to direct their attention toward each other. The support camp blamed the opponent camp for its uncompromising and irresponsible stance, while the opponent camp accused the support camp of being blackmailed by the Federal Council. ${ }^{48}$

Another factor that benefited the Federal Council, and Councilor Couchepin in particular, was the collegiality principle. While Couchepin was occasionally addressed personally during parliamentary debates, the opponent camp did not single him out in their attacks. Blame was predominantly directed at the Federal Council as an institution. Finally, the Federal Council and Councilor Couchepin benefited from low direct involvement in the organization of Expo.02. Cultural policy in Switzerland is traditionally very decentralized and is primarily the task of cantons and communes (Bijl-Schwab, 2017). During the blame game surrounding Expo.02, the Verein was the actor that attracted most of the media attention and criticism from political parties. Its distance from the Verein, and the latter's autonomy in the organization of the exposition, allowed the Federal Council to credibly deflect responsibility for management problems and additional financing requests. By adopting the narrative of the salutary crisis and expressing its satisfaction over the opportunity to finally intervene at the Verein, the Federal Council indirectly suggested that beforehand its 
hands had been tied. Later on, when arguing that a particular financing request should suffice to save the project, the Federal Council frequently added that it had to trust the information provided by the Verein. Overall, the Verein was an ideal scapegoat that allowed the Federal Council to maintain the pretense that it was not originally responsible for the cost increases (see Table 10 for a schematic assessment of the theoretical expectations).

\subsection{The Swiss Blame Game Style}

In this section, I compare the CARLOS, TAX, and EXPO cases and subsequently examine a test case to derive robust and generalizable insights into the Swiss blame game style.

\section{Political Interaction Structure}

Swiss blame games exhibit a very peculiar basic form. With the political executive consisting of seven individual councilors, Switzerland has a government that represents all major parties. Therefore, the Federal Council does not face a classic opposition that would act as its natural opponent during a blame game. Instead, the cases reveal that usually only a fraction of the parties initially takes umbrage at a controversy and constitutes itself as the opponent during the ensuing blame game. Another fraction of the parties acts as the support camp that opposes the framing of the controversy and the demands of opponents. A third fraction serves as the middle camp, which takes a more moderate position vis à vis the controversy and the framing and demands coming from the other two camps. Like during routine politics (Vatter, 2016, p. 282), the camps and alliances that develop during a blame game are policy-specific. To be sure, some parties have their natural partners with regard to a particular controversy type and thus can start a blame game from the premise of a certain alliance pattern, but in the cases covered, there was still a lot of variation in camps and alliances.

The peculiar political interaction structure accounts for important blame game interactions. Due to the broad political responsiveness that the collective nature of the executive demands, it usually avoids openly allying with either supporters or opponents without having the support of the middle camp. Therefore, opponents can achieve their policy goals during a blame game by pulling the middle camp to their side. 
Table 10 Assessment of theoretical expectations in the EXPO case

\begin{tabular}{|c|c|c|c|}
\hline & Explanatory factor(s) & Expectation & Assessment \\
\hline \multirow[t]{4}{*}{ Opponents } & $\begin{array}{l}\text { Political interaction } \\
\text { structure (fragmented/ } \\
\text { consolidated opposition) }\end{array}$ & $\begin{array}{l}\text { E1: Fragmented opponents, consisting of } \\
\text { more than one party, are less successful in } \\
\text { crafting a cohesive blame-generating } \\
\text { strategy during the blame game than } \\
\text { consolidated opponents. }\end{array}$ & $\begin{array}{l}\text { Confirmed. Opponents do not secure a } \\
\text { majority for their policy demands. }\end{array}$ \\
\hline & $\begin{array}{l}\text { Institutionalized } \\
\text { accountability structures } \\
\text { (conventions of } \\
\text { resignation) }\end{array}$ & $\begin{array}{l}\text { E3: Opponents facing extensive conventions } \\
\text { of resignation concentrate their blaming } \\
\text { more on the incumbent politician than } \\
\text { opponents facing restrictive conventions, } \\
\text { who can only blame administrative actors. }\end{array}$ & $\begin{array}{l}\text { Confirmed. The collegiality principle } \\
\text { protects the councilor from } \\
\text { personalized attacks. }\end{array}$ \\
\hline & $\begin{array}{l}\text { Institutional policy } \\
\text { characteristics (direct } \\
\text { government } \\
\text { involvement) }\end{array}$ & $\begin{array}{l}\text { E5: Opponents are better able to blame a } \\
\text { controversy on incumbents if the latter are } \\
\text { directly involved than when the controversy } \\
\text { is far removed from incumbents. }\end{array}$ & $\begin{array}{l}\text { Confirmed. During the blame game, } \\
\text { the Verein takes center stage. }\end{array}$ \\
\hline & $\begin{array}{l}\text { Distant-nonsalient } \\
\text { controversy }\end{array}$ & $\begin{array}{l}\text { E11: Opponents do not invest much in blame } \\
\text { generation on the occasion of a distant- }\end{array}$ & $\begin{array}{l}\text { Confirmed. Opponents do not invest } \\
\text { much in blame generation. }\end{array}$ \\
\hline
\end{tabular}


Table 10 (cont.)

\begin{tabular}{|c|c|c|c|}
\hline & Explanatory factor(s) & Expectation & Assessment \\
\hline \multirow[t]{4}{*}{ Incumbents } & $\begin{array}{l}\text { Political interaction } \\
\text { structure (loyal/critical } \\
\text { governing majority) }\end{array}$ & $\begin{array}{l}\text { E2: Incumbents that receive support from } \\
\text { their party(ies) are more successful in } \\
\text { reframing a controversy than incumbents } \\
\text { that confront criticism from their own } \\
\text { ranks. }\end{array}$ & $\begin{array}{l}\text { Not testable. As a consensus body, the } \\
\text { Federal Council tries to avoid any } \\
\text { party affiliations during the blame } \\
\text { game. However, the Federal } \\
\text { Council receives cover from the } \\
\text { support camp for its decision to go } \\
\text { ahead with Expo. } 02 \text {. }\end{array}$ \\
\hline & $\begin{array}{l}\text { Institutionalized } \\
\text { accountability structures } \\
\text { (conventions of } \\
\text { resignation) }\end{array}$ & $\begin{array}{l}\text { E4: Incumbent politicians that must comply } \\
\text { with extensive conventions of resignation } \\
\text { have greater difficulty defending themselves } \\
\text { during a blame game than politicians that } \\
\text { must comply with restricted conventions. }\end{array}$ & $\begin{array}{l}\text { Confirmed. The councilor benefits } \\
\text { from the collegiality principle. }\end{array}$ \\
\hline & $\begin{array}{l}\text { Institutional policy } \\
\text { characteristics (direct } \\
\text { government } \\
\text { involvement) }\end{array}$ & $\begin{array}{l}\text { E6: Incumbents are better able to deflect } \\
\text { blame for a controversy onto } \\
\text { administrative actors if they are not directly } \\
\text { involved in the controversy rather than if } \\
\text { they are involved. }\end{array}$ & $\begin{array}{l}\text { Confirmed. Low government } \\
\text { involvement facilitates blame } \\
\text { deflection. }\end{array}$ \\
\hline & $\begin{array}{l}\text { Distant-nonsalient } \\
\text { controversy }\end{array}$ & $\begin{array}{l}\text { E12: Incumbents do not take a distant- } \\
\text { nonsalient controversy very seriously and } \\
\text { only scarcely engage in blame management. }\end{array}$ & $\begin{array}{l}\text { Partly confirmed. The political } \\
\text { incumbent takes multiparty } \\
\text { pressure seriously, but later, only } \\
\text { scarcely engages in blame } \\
\text { management. }\end{array}$ \\
\hline
\end{tabular}


This explains why opponents frequently concentrate their blaming efforts on the support camp. By discrediting the position of the support camp, they increase the likelihood that the middle camp will ally with them and not with the support camp. True to the motto, 'when two people quarrel, a third rejoices', political incumbents benefit from this peculiar type of party-centered blaming. The basic form of Swiss blame games puts political incumbents in a quite comfortable position since a significant share of the blame pressure generated by opponents is directed at the support or middle camp and not primarily at them. Moreover, because there are three camps during a blame game, there is a higher likelihood that a moderate request for policy change will be made by one of the parties. Political incumbents can act on moderate requests and thereby express their willingness to cooperate in addressing the controversy, while simultaneously rejecting more far-reaching demands.

\section{Institutionalized Accountability Structures}

The Swiss-specific collegiality principle presents another institutional factor that accounts for the comparatively low number of attacks directed at political incumbents. The collegiality principle implies that councilors are collectively responsible for controversies that concern one of the seven federal departments. Moreover, since the parliament cannot dismiss individual councilors from office outside of regular elections (Vatter, 2016, p. 236), it is highly unlikely that councilors will resign during a blame game. Almost absent conventions of resignation make councilors an unattractive target for opponents. It is possible for parties to criticize individual councilors due to their departmental responsibility, but as the TAX and EXPO cases suggest, most criticism is directed at the executive as an institution. Individual councilors are not singled out. The absence of personalized attacks allows incumbents to adopt a problem-centered stance and, for the most part, remain out of blame game interactions. However, the CARLOS case shows that there is a slightly different dynamic at the cantonal level, where councilors are directly elected by the public. This changes opponents' incentive structure since damaging the reputation of a councilor during a blame game can decrease his or her prospect for reelection. In the case of personalized attacks from opponents, incumbents may be forced to set aside their impartiality and more intensively engage in blame management. 


\section{Institutional Policy Characteristics}

Direct government involvement in a policy controversy is an important mediating factor in the Swiss political system. On the one hand, the degree of direct government involvement influences the ease with which opponents can establish a connection between incumbents and a policy controversy and whether they can credibly blame incumbents for it. On the other hand, the degree of government involvement influences whether political incumbents can add blame deflection to their strategy mix. While high direct involvement, like in the TAX and CARLOS cases, renders blame deflection incredible, low direct government involvement, like in the EXPO case, increases the likelihood that political incumbents can keep their distance from a controversy by deflecting blame onto the administrative level.

\section{Test Case: March on Bern Security Controversy (MOB)}

In this section, I test the findings against a fourth case to refine our understanding of Swiss blame games. The proximate-salient March on Bern security controversy (MOB) is about uncontained riots in the city of Bern in the run-up to the 2007 federal elections, which triggered a blame game in the city parliament. As a result, conservative parties urged the executive to abandon Bern's laissez-faire security policy.

\section{Policy Struggle}

On October 6, 2007, two weeks before the federal elections, the rightconservative SVP organized a grandiose preelection demonstration in the city of Bern. The left-green camp interpreted the demonstration as conservative provocation during a very heated and controversial electoral campaign. By calling it the 'March on Bern', the left-green camp likened the SVP demonstration to Mussolini's march on Rome in 1922. The municipal council (the executive government of the city of Bern) subsequently forbid an independent committee to organize a simultaneous counterdemonstration for security reasons. When the committee continued with the demonstration despite the prohibition, the municipal council, and with it the left-green camp, which constituted a majority in the city council (the parliament), tolerated this stance as part of the de-escalation strategy generally applied by the city of Bern police forces. The de-escalation strategy was prescribed to avoid clashes with demonstrators in the 
capital whenever possible. On the demonstration day, the counterdemonstration was taken over by the left-extremist group, 'Black Block', which eventually clashed with the SVP demonstration. The police was unable to prevent the clash nor contain the subsequent riots, which frightened the population of Switzerland's capital city, resulted in more than twenty injured, and caused widespread property damage. The riots attracted national and international media interest. ${ }^{49}$ After the riots, it quickly became clear that the police had underestimated the threat of a clash and had thus been ill-prepared to manage the situation. In the opinion of the conservative parties, the riots were a consequence of a laissez-faire security policy that was unable to protect the public from extremists. Consequently, they claimed that an adequate response could only consist of much tougher demonstration regulations and the termination of Bern's de-escalation strategy. ${ }^{50}$

\section{Blame Game Interactions}

To emphasize their points of view in the ensuing debate in the city council on October 18, the SVP and the FDP largely blamed the leftgreen camp for having supported the counterdemonstration instead of clearly distancing themselves from left extremists: "Of all people, Daniele Jenni and his comrades-in-arms, who otherwise stand up at every opportunity for freedom of opinion and assembly and for the use of public space, are responsible for these riots." ${ }^{51}$ They also criticized the executive for underestimating the concrete threat and for riding out the issue by commissioning a report. However, criticism toward the executive was much less pronounced than toward left-green parliamentarians and often only voiced indirectly. Opponents also refrained from personally attacking the security councilor. The only personalized attacks that occurred in this blame game were those directed toward individual parliamentarians from the left-green camp who had actively supported the counterdemonstration. ${ }^{52}$

The left-green camp squarely opposed the policy requests proposed by the conservative camp. Although self-critical to some degree, it mainly blamed the conservative camp for its provocation and claimed that it was co-responsible for the riots: "The politics of the SVP ... laid the bad ground for the riots." ${ }^{53}$ While carefully expressing regret about the executive government's decision not to authorize both demonstrations, the left-green camp's stance toward the executive was openly supportive. It endorsed the executive's move to thoroughly investigate the controversy 
before drawing conclusions and asked it to fend off hasty calls from conservatives to tighten demonstration regulations. The middle camp, consisting mainly of Cristian-democratic parties, assigned blame to both the conservative and the left-green camp, while also stressing the need for thorough investigations. However, there were also voices that asked for a harder hand from the executive. ${ }^{54}$

The municipal council was eager to express its regret over the riots, readily assumed political responsibility, and signaled its willingness to learn from its mistakes. It also justified its nonintervention into police matters and commissioned an inquiry report into the events. Moreover, it expressed the possibility for smaller changes to demonstration regulations. Overall, the executive was eager to take a neutral position, labeling itself as explicitly 'above party politics'. ${ }^{55}$ After the parliamentary debate, the controversy flared up again briefly with the December 2007 publication of the report commissioned by the municipal council. It concluded that the passive role of the executive government created a leadership vacuum. This conclusion was greeted by the latter as a welcome learning opportunity. ${ }^{56}$

\section{Consequences of the Blame Game}

The blame game produced a special kind of personal consequence. Although opponents never requested the security councilor's resignation during the blame game, his own party, the FDP, did not nominate him again for the upcoming elections in January 2008. During and after the blame game, the conservative camp made several attempts to tighten existing demonstration regulations. However, the left-green parliamentary majority blocked all attempts to do so, including those that the municipal council had expressed its approval for.

\section{Test of Preliminary Findings and Summary}

In the following, I assess whether the political interaction structure, institutionalized accountability structures, and institutional policy characteristics influenced this blame game in ways congruent with the previous findings.

\section{Political Interaction Structure}

The blame game surrounding the MOB controversy has a basic form that is very similar to the three previously analyzed blame games. From 
the beginning, conservative parties constituted themselves as a controversy-specific opposition that requested policy change from the executive and the parliamentary majority. The left-green camp firmly opposed any policy change, and the middle camp took a more moderate stance. Overall, there were three camps among which the majority of blame game interactions occurred. The statements by parliamentarians during the blame game confirm that the majority of blame attacks focused on parties, not the executive. There is also clear evidence that the latter benefited from the blaming orientation of parties. Among the cacophony of interpretations of the controversy and suggestions for remedial action proposed by parties, the executive found explicit support for its chosen strategy. Meanwhile, it played for time and awaited the results of the commissioned report before reacting to the conservative camp's policy requests.

\section{Institutionalized Accountability Structures}

As in the TAX and EXPO cases, we can discern the strong influence of the collegiality principle. While the security councilor received substantial negative press, parliamentarians did not single him out during the blame game. Criticism was overwhelmingly directed at the executive as a whole. This allowed the councilor to adopt a rather neutral and problem-oriented stance during the blame game. The security councilor did not engage in much blame management. Nevertheless, the almost complete absence of personalized attacks on the security councilor may also have had to do with his party affiliation. Had the councilor, as in the CARLOS case, belonged to the left-green camp, more personalized attacks could have occurred. Overall, we can conclude that the collegiality principle is not an impermeable blame shield under all circumstances. At the cantonal level, or in the case of councilors' specific party affiliations, individualized criticism may occur.

\section{Institutional Policy Characteristics}

Another factor that benefited the executive was its low direct involvement in police matters. During the blame game, the executive government preferred to keep its distance from the controversy and repeatedly emphasized the important and widely accepted guiding principle of its nonintervention in operational matters. Although this strategy was criticized in the December report, it was accepted by large parts of 
parliament during the blame game and thus worked to avoid an overly strong association between the security councilor and the controversy.

\section{Summary}

The Swiss political system features blame games characterized by interparty conflict that largely spares the politically responsible executive from participating in blame game interactions. This is very different from the more government-opposition centered blame games that occur in parliamentary systems. Opponents cannot usually force incumbents to resign during a blame game. They can only attempt to reach their policy goals. To do so, they concentrate on forging a 'pressure majority' in parliament. A pressure majority, consisting of several parties that acknowledge the need for policy change in response to a controversy, brings opponents closer to their policy goals. Due to its collective and nonpartisan nature, the executive government is eager to express its cooperation with as many parties as possible and is thus unlikely to completely ignore the policy requests of a significant share of the party landscape. A pressure majority, therefore, greatly increases the likelihood that the executive will act in the interest of opponents. Interparty conflict creates a comfortable situation for political incumbents. They are less likely to be put under fire, do not have to engage in intensive blame management, and can assume a rather neutral role during a blame game. Taken together, the Swiss political system is conducive to producing rather unaggressive, problem-centered blame game interactions. These findings align with research on how the Swiss political system processes policy problems (Campbell \& Hall, 2017). With its culture of social partnership, Switzerland has developed institutions that enable decision-makers to quickly address problems while keeping political conflict within bounds. 


\section{Mapping the Influence of Institutional Factors}

The previous chapters covered blame games in the UK, Germany, and Switzerland that varied considerably on a number of dimensions. Some blame games involved heated interactions that put political incumbents under considerable pressure, others mainly focused on the actions or omissions of administrative actors. In some blame games, incumbents could draw on considerable support from the governing majority, during others, they stood alone against criticism and blame. Opponents were sometimes united in their stance toward the government and coordinated their attacks, sometimes they followed their own particular agendas. In the preceding chapters, I derived important insights on the blame game style that characterizes each country.

Chapter 3 found that the UK political system makes it very difficult for opponents to reach their reputational and policy goals during a blame game. All the relevant institutional factors in the UK system are configured in favor of incumbents. Ministers constitute very strong blame shields for the government of the day, as they are usually only in office briefly and cannot be held personally accountable for a controversy due to very restrictive conventions of resignation. The administration bias injected by forms of agencification and reinforced by the work of parliamentary committees and their reports ensures that controversies often appear far away from the central government. The configuration of institutional factors in the UK system allows incumbents to ride out or to protract a controversy and leave the underlying policy problem(s) unaddressed. In the CSA, METRONET, DOME, and HCT cases, strong institutional blame protection created a relatively safe situation for incumbents. Overall, the UK blame game style is characterized by rather unaggressive and routinized interactions between the government and opponents.

Chapter 4 exposed a different blame game style in Germany. Institutional factors in the German political system are conducive to creating rather aggressive blame games in which political incumbents 
take center stage. The main reasons for this blame game style are extensive conventions of resignation and the opportunity to retrieve salient information about a controversy through the appointment of an inquiry commission. Both institutional factors are powerful tools that opponents can use to hold political incumbents accountable and to force them into heated blame game interactions. Unlike in the UK system where institutional factors comfortably protect political incumbents, incumbents in the German system often experience pressure to resign. Consequently, blamed incumbents must actively engage in blame management and may be forced to give in to opponents' policy demands. However, not all institutional factors are disadvantageous to political incumbents. In the NSU, BER, DRONE, and NITROFEN cases, incumbents benefited from an active and loyal governing majority and fragmentation among opponents. Whether the overall institutional configuration is more favorable to opponents or to incumbents largely depends on the degree of government involvement in a policy controversy. Overall, the German blame game style is characterized by aggressive and incumbent-centered interactions.

Chapter 5 showed that Switzerland features a blame game style that is very different from those of parliamentary systems. The Swiss political system features blame games that are characterized by interparty conflict that largely spares the politically responsible executive from participating in blame game interactions. This is very different from the more government opposition-centered blame games that occur in parliamentary systems. The main reason for this surprising pattern is that opponents cannot usually force incumbents to resign during a blame game. Opponents can only attempt to reach their policy goals. The CARLOS, TAX, EXPO, and MOB cases showed that in order to do so, opponents try to forge a pressure majority in parliament. A pressure majority consists of several parties that acknowledge the need for policy change in response to a controversy. Due to its collective and nonpartisan nature, the executive government is eager to express its cooperation with as many parties as possible and is thus unlikely to completely ignore the policy requests of the majority. A pressure majority, therefore, greatly increases the likelihood of the executive acting in the interest of opponents. Interparty conflict creates a comfortable situation for political incumbents. They are less likely to come under pressure, do not have to engage in intensive blame management, and can assume a rather neutral role during a blame game. Taken together, 
the Swiss political system exhibits a rather unaggressive, problemcentered blame game style.

In the following, I look at these similarities and differences systematically by comparing how the political interaction structure, institutionalized accountability structures, and institutional policy characteristics influence blame game interactions in the UK, German, and Swiss political systems. Overall, these comparisons suggest that institutional factors explain the basic form or setup of a blame game, determine gateways for blame attacks and barriers, and create a distinctive distribution of power between opponents and incumbents.

\subsection{Political Interaction Structure}

The institutionalized rules that structure interactions between political actors in democratic political systems during routine times also notably influence the basic structure of blame game interactions. Namely, they determine the coalitions that actors form and how those coalitions position themselves vis-à-vis each other. In each of the three political systems, one can observe a distinctive basic structure of blame game interactions. The UK political system exposes and pits the executive against the parliament. The German political system likewise exposes the executive but also provides it with strong support from the parliamentary majority. The Swiss cases revealed an altogether different basic structure in which some parties become opponents rather flexibly and primarily attack supporting parties to forge a pressure majority in parliament. As a result, political incumbents often fade into the background of blame game interactions. The political interaction structure determines who participates in a blame game, whether they participate as an opponent or a supporter, and whether political incumbents are forced to enter the fray or can remain at the sidelines.

\subsection{Institutionalized Accountability Structures}

The accountability structures enshrined in democratic political systems provide important gateways for blame attacks from opponents and blame barriers for incumbents by detailing the circumstances for which political incumbents can be held responsible. For opponents, these structures determine whom they can credibly blame for a controversy (political incumbents or administrative actors and entities) and whether they can 
blame the government as a whole or if they can single out individual politicians. In the UK and Swiss systems, accountability structures render it far more difficult for opponents to credibly blame the government or individual ministers/councilors than in the German system. This is why there are far more personalized attacks on political incumbents in the German system than in the UK and Swiss systems. Importantly, opponents also try to personalize a blame game when they are not after the resignation of incumbents but primarily want to change the trajectory of a policy. An incumbent under pressure is more likely to give in to policy demands. From the incumbents' perspective, accountability structures constitute more or less permeable blame barriers from their opponents' attacks. The more restrictive such accountability structures are, the less incumbents must do in terms of blame management when a controversy occurs. Incumbents that cannot be put under pressure are unattractive blame targets. Accountability structures in the UK and Swiss systems often allow incumbents to remain out of a blame game and avoid potentially threatening interactions with opponents. Accountability structures in the German system are less favorable to incumbents, as they often force them to engage in extensive blame management.

\subsection{Institutional Policy Characteristics}

The direct involvement of the government in a concrete policy issue is an important mediating factor that can tip the scales in favor of opponents or incumbents during a blame game. In modern and complex political systems, which often exhibit low direct government involvement, political incumbents are frequently far removed from policy controversies. This aggravates opponents' attempts to associate political incumbents with a controversy. Personalized blame attacks appear incredible in cases of low government involvement. Incumbents, on the other hand, possess more (credible) blame deflection possibilities when a controversy is far removed from them than when it is in a policy area where they are directly involved.

A comprehensive look at institutional factors and their combinations across political systems reveals the wide variety of ways that they produce incentives and constraints for the actors playing the blame game. Some institutional factors, such as the collegiality principle in Switzerland, or blurred ministerial responsibility in Germany, are idiosyncratic to a particular political system and thus yield particular 
effects on blame game interactions. Other institutional factors are similarly present across political systems but their causal relevance for the blame game differs across systems. The fragmentation in and between the sets of actors playing the blame game is more relevant in the Swiss than in the German system due to the importance for opponents to form a pressure majority in the Swiss system. Similarly, a parliamentary majority is more important during German blame games than during UK ones. In the latter system, incumbents do not need the support of the governing majority due to the ample blame protection offered by other institutional factors.

These observations highlight the interaction effects between institutional factors. Institutional factors combine to produce certain gateways for blame attacks and barriers against them. In the UK political system, restrictive conventions of resignation and generally low government involvement work together to create strong blame barriers for political incumbents. In the German system, blame barriers are more permeable because extensive conventions of resignation and the possibility of appointing an inquiry commission provide opportunities to put ministers under pressure. In Switzerland, strong fragmentation and the collegiality principle allow incumbents to keep out of blame game interactions. In addition to interaction effects, we also observe equifinality between different combinations of institutional factors. Equifinality means that different combinations of institutional factors lead to the same type of actions during a blame game (Schneider \& Wagemann, 2012). Namely, the cases reveal that incumbents sometimes manage to adopt a statesmanlike or 'above politics' position toward a controversy. In the three political systems, incumbents can adopt such a position for different reasons. In the Swiss system, this outcome occurs when there are distracted opponents who focus their blaming on the parties who support the executive. In the German system, a parliamentary majority acting as an attack device provides the incumbent with the reprieve needed to adopt an above politics position. Finally, in the UK system, strong blame protection from restrictive conventions of resignation and generally low government involvement facilitate the adoption of a statesmanlike position. Likewise, in both the UK and the Swiss political systems, opponents often spare political incumbents from blame. In the UK system, opponents are unable to do otherwise because restrictive conventions of resignation, frequent ministerial reshufflings, and generally low government involvement put ministers out of reach. In the Swiss system, institutional factors provide blame gateways for opponents but 
using them without securing a pressure majority in parliament would lead to nothing. Hence, there is functional equivalence of institutional factors as regards their effects on blame game interactions.

By looking at the influence of institutional factors as a whole, we see that they tend to produce unequal distributions of power between opponents and incumbents (Moe, 2005). In all three systems, opponents have a tough act to follow during blame games. This suggests that political systems are to some degree conflict-stable. They are not easily thrown off track by the political quarrels that they must digest at irregular intervals. Blame games, it seems, exhibit a status quo bias that is similar to that at work in democratic politics more generally (Hacker et al., 2015). Nevertheless, we see that the institutional terrain of a political system determines which goals opponents can reasonably pursue during a blame game. By emitting incentives and constraints, institutional factors decisively influence the type of payoff opponents can reasonably expect for generating blame. In the UK system, it is very difficult for opponents to pursue both reputational and policy goals. In the German system, opponents can pursue both reputational and policy goals. And in the Swiss system, policy goals are much more within reach than reputational goals.

While institutional factors determine important parameters of blame game interactions, they do not tell us how opponents and incumbents communicate with the public during a blame game. Institutional factors may tell us why opponents direct their attacks at the administrative level, but they do not tell us how exactly opponents blame administrative actors. Likewise, institutional factors inform us why incumbents can adopt a particular attitude toward a controversy, but this does not tell us what they expect from this attitude and what they intend to express to the public by adopting it. To account for these important aspects of blame game interactions, the next chapter lays a different analytical grid over the cases by examining the influence of issue characteristics on blame game interactions. 


\section{Mapping the Influence of Issue Characteristics}

This chapter assesses how different combinations of issue characteristics influence the blame game interactions between opponents and incumbents. It analyzes and compares blame game interactions in light of distant-salient, proximate-nonsalient, and distant-nonsalient policy controversies. Each of the following three sections includes comparisons of three in-depth cases and a test case exhibiting a similar configuration of issue characteristics to verify and refine the results obtained from the comparisons. As outlined in Section 1.4, the three test cases are situated in the US political system to generate maximum variation on the explanatory factors that are not currently in the comparative focus. This arrangement enhances the generalizability of the findings. The chapter concludes with a comparison across controversy types.

\subsection{Distant-Salient Blame Games}

I first examine how opponents and incumbents reacted to and tried to work with public feedback to distant-salient controversies in order to reach their goals during blame games. As shown in the in-depth case studies in Chapters 3-5, public feedback to the CSA controversy, the NSU controversy, and the CARLOS controversy was strong and mainly based on moral considerations. I expected that strong public feedback to a distantsalient controversy would prompt opponents to heavily invest in blame generation and to attempt to damage incumbents on moral grounds. Incumbents, in turn, were expected to take the controversy very seriously and to confront it by engaging in blame deflection and symbolic activism.

\section{Opponent Behavior in Response to Distant-Salient Controversies}

Opponents' public statements in the distant-salient CSA, NSU, and CARLOS cases share interesting similarities. They leverage emotions 
in order to attract the public's attention and to simultaneously create moral pressure so that incumbents take action. By referring to the intolerable fate of children and lone parents under the current policy scheme (CSA), accusing the government of failing to protect migrants and their families (NSU), or portraying juvenile crime as a rampant problem that threatens public security (CARLOS), opponents alerted the public of the existence of a severe problem that required their attention and moral concern. The emotions that opponents leveraged for this purpose were either positive or negative, depending on the connotation of the policy target population (Schneider \& Ingram, 1993). Lone parents and their children and the families of victims were portrayed to be suffering and in desperate need of help while juvenile offenders were portrayed as an undeserving target group in need of harsher punishment.

At the same time, opponents argued that political incumbents had a moral responsibility to address the controversy. By equating political responsibility with moral responsibility, opponents sought to establish a moral connection between incumbents and the controversy (Goodhart, 2017). In the CSA case, opponents repeatedly accused the Blair government of failing families and children and claimed that the latter would suffer if the Blair government continued to leave the controversy unaddressed. In the NSU case, opponents repeatedly argued that political responsibility needed to be assumed out of respect for victims and their families. In the CARLOS case, opponents claimed that tolerating a soft, 'leftish' legal practice violated generally accepted norms of justice.

During the blame games, opponents frequently attempted to debunk the (usually numerous) ad hoc measures that incumbents introduced in response to a controversy as insufficient, reputation-driven activism, presenting this as proof that incumbents did not live up to their moral responsibility to address the controversy. Opponents in the CSA case criticized incumbents for only announcing gimmicks and reviews and called the Blair government's reform plans for the child maintenance system a huge disappointment to families. Opponents in the NSU case accused incumbents of not being fully committed to the investigations. The government only acted by founding ever new and obscure commissions. In the CARLOS case, opponents criticized the executive's ad hoc measures to improve control over youth advocates as too lax, and they claimed that investigations into the therapy setting for 'Carlos' were insufficient. Overall, there is clear and abundant evidence that 
opponents worked with the salience of a controversy to attract the attention of the public and to damage incumbents on moral grounds. However, only in the CARLOS case is there concrete evidence that opponents also systematically exploited the wider public's distance to the controversy by portraying youth crime as a much bigger problem than it actually was in Switzerland. In the other two cases, it was simply difficult for opponents to exaggerate the salience of the controversy.

A look at the amount of blame opponents generated in the three blame games suggests that the distance and the salience of the respective controversies does not fully account for this parameter of opponent behavior. While opponents in the CARLOS case heavily engaged in blame generation, the other two cases provide a picture that is less clear. In the CSA case, the Tories did not initially invest much in blame generation because lone mothers were not an important voter group for them and because they had been involved in the setup of the flawed child maintenance system. In the NSU case, the SPD kept relatively quiet because some of the murders had happened while it had been in the government and because the severity of the controversy prevented it from exploiting the controversy too visibly. Hence, other factors must be considered to explain the amount of blaming that opponents undertake during a blame game.

\section{Incumbent Behavior in Response to Distant-Salient Controversies}

In the CSA, NSU, and CARLOS cases, political incumbents were eager to acknowledge the existence of a problem and expressed their willingness to take the problem seriously. In their public statements, they conveyed the idea that they were in emotional harmony with citizens. Depending on the dominant feeling in society and the dominant attitude toward the policy target population, they exhibited either a caring or an angry attitude. In the CSA case, political incumbents never downplayed the adverse impact of the child maintenance system on lone mothers and their children. Instead, they commiserated with them and repeatedly expressed their indignation toward 'errant fathers' who did not pay maintenance for their children. In the NSU case, the government expressed its bewilderment at the terror acts, apologized to the victims' families, and promised to learn from the failure of the investigation. In the CARLOS case, the minister of justice anxiously cultivated his image as a strongman willing to be tough on juvenile offenders and on the 
youth advocates who coddled them. Just as opponents flexibly leveraged either negative or positive emotions, incumbents were eager to match their attitude toward the controversy to the dominant feeling in society.

To lend weight to their 'attitude reports', incumbents reassured the public that they had the controversy under control and that they would do everything in their power to properly address it. In the CSA case, the government portrayed its reform plans as a radical shake-up of the flawed child maintenance system. Incumbents in the NSU case repeatedly confirmed their interest in the inquiry into the investigation failure and ensured their continuing commitment to comprehensively reforming the investigation apparatus. The incumbent in the CARLOS case also adopted a raft of ad hoc measures to keep 'freewheeling' youth advocates in check.

A look at the presentational strategies incumbents adopt in light of a distant-salient controversy reveals that blame deflection is the order of the day while reframing attempts are almost invisible. In all three cases, political incumbents repeatedly shifted blame downward onto the administrative level or onto the previous government. There are only limited reframing attempts in the CSA case where incumbents cautiously emphasized the performance improvements brought about by the reforms, and in the CARLOS case, where incumbents only lightly defended the therapy setting for Carlos. The especially strong evidence in the CARLOS case that incumbents had pondered the use of a reframing strategy but then opted against it because they considered that the controversy was not 'communicable' suggests that incumbents do not dare to reframe distant-salient controversies. This is an interesting finding given that one could expect that the distance of the controversy to the wider public would offer greater reframing possibilities. Instead, it seems that during a blame game in which a salient issue is processed, incumbents do not want to stand on the wrong side of the issue. Overall, incumbents have a surprisingly similar strategy profile across the three cases, which is firmly in line with the theoretical expectations. Incumbents take a distant-salient controversy very seriously and confront it by engaging in activism and blame deflection.

\section{Test Case: Veterans Health Administration Operation Controversy}

In order to refine our understanding of how blame game actors react to and work with this controversy type, the following section tests these 
findings against a fourth case that is also distant-salient. The Veterans Health Administration Operation (VHA) controversy is about poor care standards at a veteran hospital, which led to a blame game for the Obama administration in 2014.

\section{Policy Struggle}

The VHA controversy became known nationally in April 2014, when $\mathrm{CNN}$ reported on practices to hide long wait times for veteran patients at a hospital in Phoenix. The CNN report suggested that these practices could have led to up to forty veterans dying while waiting for care. The controversy had already simmered in the local media for some time, but the controversy was only catapulted onto the national agenda, where both quality papers and tabloids intensively and emotionally covered it, following the CNN report. ${ }^{1}$ Republicans quickly used the controversy as an occasion to attack the Obama administration for its 'big government' approach and Obama's overt inability to "properly manage the leviathan government that he helped create." 2

\section{Blame Game Interactions}

In reaction to the CNN report, Republicans began to assign blame to the Department of Veterans Affairs (VA) and its secretary, Eric Shinseki. Some Republicans urged the VA secretary to resign early on and criticized the department for stonewalling. ${ }^{3}$ When the VA secretary announced the resignations of local VA officials and an inquiry into the matter led by the inspector general, Republicans condemned this as an insufficient reaction to a serious problem. Shinseki had portrayed an unrelated resignation of a VA official as a reaction to the controversy a move Republicans, after they had found out about the true background of the resignation, called "the pinnacle of disingenuous political doublespeak." 4 They claimed that 'true' accountability and an independent inquiry were needed instead. Since President Obama did not immediately become personally involved but rather let his VA secretary initially do the crisis management, Republicans criticized him for not reacting quickly enough and for taking the controversy too lightly. ${ }^{5}$

The VA secretary immediately reacted to the allegations by calling them "absolutely unacceptable," if true. ${ }^{6} \mathrm{He}$ declared that he was taking the controversy very seriously, announced the launch of an inquiry led by the inspector general, and suspended several local 
officials. ${ }^{7}$ However, Shinseki also asked for time to examine the allegations in detail and pointed to the overall good quality of veteran care. ${ }^{8}$ As Republicans consistently maintained the blame pressure and increasingly focused on Obama, the latter was also forced to react to the controversy. The president sent one of his personal advisers to help investigate the practices at the Phoenix hospital and to find the underlying cause of the allegations. Obama took a tough stance on the controversy, proclaiming that he was "madder than hell" about what had happened. ${ }^{9} \mathrm{He}$ also justified his delayed reaction by arguing that he had only learned about the controversy from the national media. When on May 28 the inspector general published the first inquiry results that confirmed widespread manipulations of waiting lists at the Phoenix hospital, Obama finally decided, amid widespread calls from Republicans, to dismiss the VA secretary.

\section{Consequences of the Blame Game}

After Shinseki's resignation, opponents and the administration were both eager to express their determination to further evaluate the controversy and to propose solutions. Congress finally agreed on a huge increase in funding to overhaul the VA's health care system, passed new legislation expanding veterans' access to care, and eased the ability to fire VA executives. ${ }^{10}$

\section{Test of Preliminary Findings and Summary}

In the remainder of this section, I assess whether opponent and incumbent behavior in the blame game surrounding the VHA controversy is in line with the behavioral patterns observed in the in-depth cases.

\section{Opponent Behavior}

In their intensive and consistent blame attacks on the VA secretary, and the Obama administration as a whole, opponents relied heavily on the use of emotions to attract the attention of the public. They repeatedly spoke of "our" veterans, whom "we, as a country," had let down. According to opponents, this was a controversy that concerned everyone, as there exists a collective duty to care for those who fought and sacrificed for the nation. Opponents took the same position to create moral pressure for the government to address the controversy. They equated political with moral responsibility by arguing that the 
government had a "sacred obligation" to care for veterans. By not providing adequate and timely care for veterans, the government had violated a "solemn vow." 11

One can also discern clear attempts by opponents to debunk the government's crisis management as reputation-driven activism. The call for an independent inquiry, the accusation of stonewalling, or the labeling of the unrelated resignation of a top official as a form of "semantic hair splitting," are clear assertions by opponents that the government did not live up to its moral responsibility. How much emphasis opponents put on portraying the government as uncommitted and aloof can also be read from their criticism of Obama's relatively late personal intervention. ${ }^{12}$ Overall, in this blame game, one can observe opponent behavior that is strongly in line with the predictions derived from the three in-depth cases.

\section{Incumbent Behavior}

A similar picture emerges when validating the predictions regarding incumbent behavior. In line with the other distant-salient cases, the VA secretary did not wait long to position himself in regard to the controversy and expressed a caring attitude. Both the VA secretary, and later the president, repeatedly claimed that they took the controversy very seriously. They were both eager to express a compassionate attitude toward veterans and outdid each other in expressing their anger about waiting time manipulations. While the VA secretary reported that the allegations made him "mad as hell," the president proclaimed to be "madder than hell." ${ }^{13}$ How important it was for incumbents to signal a caring attitude during the VHA controversy blame game can also be gleaned from the mocking of the VA secretary by Comedy Central's Jon Stewart. Stewart suggested that the VA secretary was not truly emotionally involved in the issue, telling him that "your 'mad as hell' face looks a lot like your, 'Oh, we're out of orange juice face." 14 To substantiate its commitment, the government also adopted a raft of ad hoc measures, such as the commissioning of several inquiries, repeated firings of VA officials, and announcements that it would provide affected veterans with immediate care.

Another similarity in incumbents' strategy profile is their overt use of blame deflection. It is surprising, however, that incumbents also carefully engaged in reframing. The VA secretary prudently emphasized the high overall satisfaction with veteran care and the previous achievements under the Obama administration in that policy area. Hence, we 
must nuance the finding that incumbents, confronted with a distantsalient controversy, never brace themselves against blame but only seek refuge in blame deflection. A look at the specific reframing activities in the VHA case, and also at the careful reframing attempts in the CSA and CARLOS cases, suggests that incumbents can apply some reframing activities while they avoid others. Namely, incumbents may try to put a distant-salient controversy into perspective by shifting public attention toward positive achievements or developments in related areas, or by announcing that they will wait with their final verdict about a controversy. ${ }^{15}$ However, what incumbents do not do when confronted with a distant-salient controversy is play it down or take it lightly. Overall, in regard to incumbent behavior, one can state that the predictions derived from the in-depth case studies are largely corroborated by the president and his secretary's behavior during the VHA controversy.

\section{Summary}

Opponents who generate blame for a distant-salient controversy work with emotions in order to moralize the controversy and put political incumbents under pressure. They are eager to portray incumbents' responses to a controversy as morally inadequate. Incumbents, in turn, when confronted with a distant-salient controversy, quickly position themselves, assume an attitude that matches the dominant feeling in society, and adopt various ad hoc measures to demonstrate activism. They also engage in blame deflection and only carefully reframe the controversy.

\subsection{Proximate-Nonsalient Blame Games}

This section seeks to answer how opponents and incumbents reacted to and tried to work with public feedback to proximate-nonsalient controversies. As shown in the in-depth case studies, there was moderate public feedback to the METRONET, BER, and TAX controversies. I formulated the expectation that moderate public feedback to a proximate-nonsalient controversy would prompt opponents to invest considerably in blame generation and to try to activate considerations of self-interest among the wider public. Moreover, I expected that incumbents would take a proximate-nonsalient controversy seriously and mainly address it by adopting reframing strategies and forms of activism. 


\section{Opponent Behavior in Response to Proximate-Nonsalient Controversies}

A comparison of opponents' public statements in the three cases suggests that proximate-nonsalient controversies largely deprive opponents of the opportunity to leverage emotions to attract the attention of the public and to put moral pressure on incumbents. To be sure, opponents made use of deft words to call attention to a controversy, calling it either a 'disaster', a 'fiasco', a 'scandal', a 'debacle', or a 'scam'. However, it is not necessarily clear from the outset whether or not a proximatenonsalient policy controversy will actually constitute a venerable political scandal. In the METRONET case, for instance, it was far from obvious that the failure of the PPP constituted a scandal. Opponents had to first establish this as a fact during the controversy by, among other things, making the incumbent publicly admit that the whole issue was a scandal. This is in marked difference to a distant-salient controversy, whose severity opponents need not establish in the first place but can take for granted during the blame game.

The cases reveal an interesting strategy of how opponents attempt to overcome this disadvantage. Instead of leveraging emotions, they leverage the controversy's proximity to the public in order to convince it that the controversy is relevant to them and to simultaneously draw incumbents into the blame game. In the METRONET case, opponents promised the public that they would try everything in their power to inhibit the passing of financial losses onto passengers in the form of price hikes or through job or pension losses. Moreover, they condemned the huge bill "forced upon Londoners." Similarly, in the BER case, opponents emphasized the massive impact of the delayed and over-expensive airport project on the cash-strapped household of the city of Berlin. In the TAX case, opponents also repeatedly claimed that the company tax breaks had been made on the back of the hard-working and tax-paying public. These claims of personal relevance portrayed citizens as economic actors who suffered material losses from a controversy. According to this line of argumentation, citizens are forced to pay for the controversy through higher taxes or prices for services, job or pension losses, or endure poor public services in other areas that can no longer be financed.

Claims of personal relevance formed by opponents can also take a different form. In the three cases, opponents also emphasized that the actions of incumbents had deprived citizens of the rights that they 
are entitled to as members of a democratic political system. In the METRONET case, opponents tried to turn the flawed PPP into a safety issue by connecting it to an increase in the number of tube accidents, arguing that the government had sacrificed passenger safety in favor of efficiency. In the BER case, opponents argued that incumbents and their behavior with regard to the airport had humiliated the citizens of Berlin. Moreover, in the TAX case, opponents argued that incumbents had betrayed Swiss citizens by not properly informing them about the implications of the tax reform and that incumbents would favor company interests over citizen interests. By emphasizing a betrayal aspect, opponents attempted to inject an element of unfairness into their respective blame game, thus bringing an inherently nonsalient controversy closer to a salient one.

While claims of personal relevance constitute a different path through which opponents try to attract the attention of the wider public and put pressure on incumbents, they also entail a specific way to place policy goals on the agenda. Unlike in the distant-salient cases, where opponents argued that incumbents had a moral responsibility to change policy, opponents wrapped their policy goal(s) in problem-centered claims. They urged incumbents to immediately limit or atone for the damage revealed by the controversy by renationalizing operations to guarantee safe and reliable services (METRONET), by compensating for the financial losses of affected companies and citizens (BER), or by limiting tax losses by making amendments to the reforms (TAX).

Overall, there is strong evidence that opponents make claims of personal relevance when generating blame for a proximate-nonsalient controversy. The same cannot be said for the amount of blame generation. While there is considerable blame generation in the BER and TAX cases, the METRONET case does not follow this pattern. The Tories in particular did not invest much in blame generation because they were not categorically against PPPs. As for distant-salient controversies, issue characteristics alone cannot account for the amount of blame generated by opponents.

\section{Incumbent Behavior in Response to Proximate-Nonsalient Controversies}

In the three in-depth cases regarding proximate-nonsalient controversies, incumbents admitted to the existence of a serious problem and 
signaled their willingness to address it. However, and much unlike distant-salient blame games, incumbents exhibited a confident stance when addressing a proximate-nonsalient controversy. In the METRONET case, the government rejected criticism of its PPP policy, confidently claimed that it would find a new buyer of Metronet's debts, and did not shy away from attracting further criticism by awarding the owners of Metronet with new PPP contracts, despite earlier statements to the contrary. In the BER case, we can also observe the peculiar mix of admitting the existence of a problem and of confidently addressing it. Moreover, in the TAX case, the government firmly maintained its point against a repetition of the tax reform referendum due to the importance of legal certainty for companies and, in the early phases of the blame game, it also rejected amendments to the reforms. We can clearly observe that the incumbents in the three cases did not adopt an attitude that was in line with the dominant feeling in society. Rather, they dared to impose their will and view on the controversies.

This confident stance also manifested itself in moderate levels of activism during the blame games. Contrary to what I expected, the cases do not provide clear evidence that incumbents engaged in activism to quickly eliminate the negative consequences emanating from a proximate controversy. In the METRONET case, for example, incumbents were exonerated by promising to learn from the controversy. In the TAX case, the Federal Council could have done more at the beginning of the blame game to signal its responsiveness to the claims of opponents but did not. Three interrelated factors can account for a lack of activism on the part of incumbents. First, there may be generally less pressure to act during a nonsalient controversy than during a salient one. Second, the ample use of reframing, which also serves to defend the policy contested by opponents (see later), may allow incumbents to reduce their substantive responses to the controversy. And third, the degree to which incumbents must accommodate opponents with their policy demands also depends on various institutional factors. Overall, I must qualify the expectation that incumbents exhibit high degrees of activism toward proximate-nonsalient controversies under all conditions.

With regard to presentational strategies, one can discern that incumbents deflected blame onto various entities such as private companies (METRONET and BER), administrative actors (BER), or onto parliament (TAX). Moreover, incumbents intensively engaged in reframing. In marked contrast to distant-salient blame games, the reframing 
activities observed in the cases were not only intended to distract from the controversy, or put it into a larger problem context. Instead, they targeted the controversy itself, that is, incumbents explicitly tried to dispel or relativize the claims of personal relevance that had been made by opponents. On the one hand, incumbents downplayed the material losses emphasized by opponents. On the other hand, they emphasized the multiple benefits a policy granted despite the problem(s) exposed by the controversy. In the METRONET case, incumbents defended PPPs and argued that they presented good value for money. In the BER case, the mayor repeatedly argued that the delays and extra costs for the airport would be offset by positive economic effects. And in the TAX case, the Federal Council and the support camp argued that tax losses were much smaller than portrayed by opponents and that the public would instead benefit from rising corporate tax income and the creation of new jobs. This evidence suggests that, unlike in distant-salient cases, incumbents contend with opponents over what a controversy or the policy it stands for - means to the public as a whole. Overall, one can conclude that incumbents take a proximate-nonsalient controversy seriously but, at the same time, exhibit a confident stance toward it. They concentrate on contesting opponents' claims of personal relevance by reframing the policy controversy and its implications.

\section{Test Case: Flu Vaccine Provision Controversy (FLU)}

In the following, I test the earlier findings against a fourth proximatenonsalient case to obtain a more definitive picture of how blame game actors react to and work with this controversy type. The Flu Vaccine Provision (FLU) Controversy is about a vaccine shortage in the USA, which developed into a blame game for the Bush administration before the 2004 presidential elections.

\section{Policy Struggle}

The FLU controversy began on October 6, 2004, when the US Department of Health and Human Services announced that Chiron, an American biotech company, and one of its two major vaccine suppliers, would be unable to supply flu shots due to contamination problems in one of its factories in Liverpool, UK. Since the authorities could not adequately compensate for this loss of production by buying from other providers, the contamination problems resulted in 
a massive shortfall of the vaccine for the 2004-2005 influenza season. Experts quickly furnished opponents with a prime occasion for blaming the government for an 'utterly predictable' public health fiasco. They argued that a frail system, based on too few suppliers, was a main reason for the shortage. Experts called for a more diversified supplier base and, for this purpose, asked the government to take measures to encourage more companies to stay in the vaccine market. ${ }^{16}$ Another bone of contention was that the Food and Drug Administration, an agency of the Department of Health and Human Services, had been aware of the production problems at Chiron's Liverpool plant for at least a month before the announcement. Instead of preparing for the worst case, the Food and Drug Administration had trusted Chiron's claim that the problems could be fixed in time and would not significantly affect the vaccine supply. ${ }^{17}$ Both the undiversified supplier base and the Food and Drug Administration's slow reaction to the production problems provided fertile ground for Democrats to blame the Bush administration before the November 2004 presidential elections.

\section{Blame Game Interactions}

The main opponent in this blame game, the Democratic presidential candidate John Kerry, used the vaccine shortage as a symbol for President Bush's "dangerous indifference" to health care questions and accused him of being "out of touch with people's daily lives." 18 He blamed the Bush administration for not reacting in time and for acting surprised instead of telling the truth early on. Moreover, Kerry hinted at the government's general inability to protect US citizens from threats, rhetorically asking "If you can't plan to have enough of that vaccine, what are they doing with respect to other things that could potentially hurt America in terms of bioterrorism, chemical terrorism, other kinds of things?" 19 Other Democrats, among them Edward Kennedy from Massachusetts, stressed that citizens deserved to know the truth about the Food and Drug Administration's actions and responsibility with regard to the vaccine shortage. Kennedy in particular criticized that the government was putting "a happy face on a disaster." 20

The Bush administration quickly reacted to the shortage, and the Department of Health and Human Services' secretary called Chiron's announcement disappointing news that meant "a serious challenge to our vaccine supply for the upcoming season." ${ }^{21}$ The 
secretary confessed that US authorities had been surprised by the extent of Chiron's production problems. When questioned about the Food and Drug Administration's actions during the controversy, its acting commissioner strongly rejected criticism, arguing that "We followed standard procedures and this is the way we have always done it." 22 President Bush also claimed that "We took the right action." ${ }^{23}$ The Bush administration not only defended the actions of the Food and Drug Administration but went further by attacking the Kerry camp for "incredible hypocrisy" and the application of scare tactics. ${ }^{24}$ It contested Kerry's problem analysis, arguing instead that a broken medical malpractice liability system, for which Democrats were responsible, lay at the root of the vaccine shortage. The Bush administration was also eager to spread optimism and show its control of the controversy. It repeatedly emphasized that the shortage "is not a crisis" and that existing flu shots would be "enough to keep America safe." 25 Moreover, Bush claimed that flu shots could be imported from Canada and Germany to increase supply. During the whole blame game, the Bush administration invested a great deal into effective crisis management, which was supplied and coordinated by its Centers for Disease Control. The latter drew up a plan to effectively and fairly distribute the remaining flu shots to priority citizens, explored the possibility of splitting doses to vaccinate more people, and exhibited a tough stance on price gougers. ${ }^{26}$

\section{Consequences of the Blame Game}

After the elections, investigations by Congress, the Department of Health and Human Services, and the Justice Department, as well as skirmishes between Democrats and the Food and Drug Administration, went on for a while. Aided by a relatively mild flu season, the controversy never regained the public attention it had received prior to the elections. ${ }^{27}$ In the end, it led neither to resignations nor to immediate policy consequences.

\section{Test of Preliminary Findings and Summary}

In the following, I test whether opponent and incumbent behavior in the blame game surrounding the FLU controversy is in line with the behavioral patterns observed in the in-depth cases. 


\section{Opponent Behavior}

One clearly sees that opponents primarily tried to exploit the proximity of the FLU controversy to attract the attention of the public and to put pressure on incumbents. Opponents claimed that the Bush administration had lied to the public about the content and amount of information it possessed about vaccine production problems and that the Bush administration was unable to protect citizens from biological threats. These claims sent a clear message of personal relevance to citizens and suggested that citizens had been deprived of their right to be properly informed about an important issue and of the right to feel secure. A radio advertisement from the Kerry campaign nicely illustrates how opponents aimed to catch the attention of the wider public by making claims of personal relevance: "If you're an elderly man or woman, if you're a young child, if you're a pregnant woman, George Bush and the Republicans have this to say on health care: Don't get sick." ${ }^{28}$ The New York Times also grasped how much the Democrats emphasized proximity during this controversy, remarking that "the Fear Room at Kerry campaign headquarters is on a hair trigger to turn any breaking news into a personal threat." 29

A noteworthy difference to the previously analyzed cases is that the opponents in this blame game did not propose concrete policy proposals that would correct the 'rights violations' by incumbents. Instead, opponents predominantly used the controversy as a symbol for bad health care performance by the government and as an occasion to damage the government before the elections. This suggests that opponents may not always have an interest in tying their policy requests to claims of personal relevance. Overall, in this blame game, one can observe opponent behavior that is largely in line with the predictions derived from the in-depth cases.

\section{Incumbent Behavior}

The FLU case also allows me to corroborate several of the predictions relating to incumbent behavior. As in the in-depth cases, incumbents quickly acknowledged the existence of a problem and signaled their commitment to address it. In doing so, incumbents exhibited a very confident stance. Both public officials and politicians strongly defended their actions. Moreover, they contested the 'problem analysis' presented by opponents and confidently attacked them for being hypocritical and for scaring citizens. 
While there are careful and rather indirect blame deflection attempts onto Chiron and the British authorities that had imposed a production ban on Chiron's Liverpool factory, incumbents concentrated more on reframing the controversy. The Bush administration repeatedly emphasized that it had the vaccine shortage under control, that the shortage was not a crisis, and expressed its optimism that the number of flu shots could be increased by splitting doses and buying shots from other countries. When defending the crisis management of his administration during a presidential debate, President Bush left the Food and Drug Administration, which was the agency most criticized by opponents, completely unmentioned while concentrating on the mostly successful crisis management by the Centers for Disease Control. Finally, the Bush camp also emphasized that it had invested much more into influenza preparedness than previous Democratic administrations. Taken together, these reframing attempts clearly intended to qualify the claims of personal relevance made by opponents. According to incumbents, the government was able to provide security, had never lied to citizens, and had acted correctly.

When it comes to substantive responses, there is no evidence that the government deliberately remained inactive. Instead, it seems that the government did everything possible to address the controversy. Hence, I cannot verify the claim that the increased use of reframing allows incumbents to reduce their substantive efforts to address a controversy. Overall, I conclude that incumbent behavior is largely in line with the predictions derived from the in-depth cases.

\section{Summary}

The analysis makes me conclude that opponents who blame incumbents for a proximate-nonsalient controversy mainly rely on claims of personal relevance to attract the attention of the public and to put pressure on incumbents. Incumbents having to address a proximatenonsalient controversy admit the existence of a significant problem and signal their willingness to address it. However, in doing so, they exhibit a confident stance, defending their actions and strongly engaging in reframing activities.

\subsection{Distant-Nonsalient Blame Games}

In this section, I examine whether and how the actors playing a blame game tried to work with and reacted to public feedback to distant- 
nonsalient controversies. As shown in the in-depth case studies, public feedback to the DOME, DRONE, and EXPO controversies was weak. Accordingly, I formulated the expectation that opponents would not invest much in blame generation on the occasion of a distant-nonsalient controversy. I also expected that incumbents would not take a distantnonsalient controversy very seriously and would only half-heartedly engage in blame management.

\section{Opponent Behavior in Response to Distant-Nonsalient Controversies}

The blame-generation attempts of opponents in the three distantnonsalient blame games share two important characteristics: the absence of emotions and convincing claims of personal relevance. While opponents employed harsh words like 'scandal' (DOME), 'financial fiasco' (DRONE), or 'moneysink' (EXPO) to attract the attention of the public, they could not do much more than this. In the DOME case, opponents could only criticize the government for money waste. However, the extra money that the government put into the exposition was relatively modest and thus did not lend itself to convincing claims of personal relevance. Opponents could only couch their attacks in truisms like 'When you put your money on the wrong horse, you stop betting on it.' In the DRONE case, opponents criticized the failed procurement project in a routinized way, arguing that the government continued a sad tradition of the German military. In the EXPO case, attacks by opponents were never harsh and, during later phases of the blame game, when the government brought ever new financing requests, became overtly cynical. Taken together, the public statements suggest that in the absence of opportunities to leverage powerful emotions or to make convincing claims of personal relevance, opponents can only use deft but eventually empty words to attract the attention of the public and to put pressure on incumbents.

While these observations are in line with theoretical expectations, the DOME and DRONE cases provide further, indirect, evidence that distant-nonsalient controversies are far from ideal for blamegeneration purposes. In both cases, opponents were quick to concentrate their attacks on the personal involvement of incumbents once they were provided an opportunity to do so. In the DOME case, opponents urged the Millennium minister to resign because he had allegedly 
ignored warnings about the Dome's solvency. Similarly, after the opponents in the DRONE case had seen a chance to personalize the controversy by convicting the minister of personal wrongdoings, they stepped up their blame-generation efforts and personally attacked the minister. At the same time, however, the controversy as such faded into the background. Opponents had completely organized the blame game around the question of what the minister had known at what time and whether this was a reason to resign. While this confirms the insight gained from the other controversy categories that the amount of blame generation does not solely depend on issue characteristics, it also suggests that opponents are aware of the apparent unfruitfulness of distant-nonsalient controversies for blame-generation purposes. In sum, the evidence suggests that opponents do not invest much in blame generation and merely pay lip service to a distant-nonsalient controversy in the absence of factors that could facilitate the personal involvement of incumbents.

\section{Incumbent Behavior in Response to Distant-Nonsalient Controversies}

In the three in-depth case studies, incumbents took their time to react to and position themselves toward the controversy. In the DRONE case, the minister remained very passive until he was accused of personal wrongdoings. He waited for quite some time to inform parliament about the cancellation of the procurement of the drones, ignored initial criticism, and barely addressed the controversy in a parliamentary debate. Similarly, in the EXPO case, the Federal Council ignored the management problems at the Verein for quite a while until all major parties prompted it to assume political responsibility. Only in the DOME case, where the government was directly involved in the policy issue right from the start, was it very difficult to remain passive.

One can also discern that as soon as the controversies could not be ignored any longer, incumbents confidently addressed them. In the DOME case, Blair and his minister admitted that mistakes had been made in the planning of the exposition but never apologized for them. Instead, they attacked the media for bashing the Dome. In the DRONE case, the minister confidently addressed the controversy by promising information in the near future and defended the use of drones. After it had become clear that the allegations against him could not be 
substantiated, he once again exhibited a very confident stance. In the EXPO case, the incumbent even framed the controversy as a "salutory crisis" that finally allowed him to set things straight - a stance he could hardly afford in the case of a salient or proximate controversy. This evidence suggests that incumbents exhibit an even more confident stance toward distant-nonsalient controversies than toward proximate-nonsalient ones. Generously admitting mistakes, presenting oneself as the savior during a crisis for which one is ultimately responsible, or attacking the media for misrepresenting a controversy, are behavioral patterns that suggest that incumbents feel very safe during blame games about distant-nonsalient controversies. A sense of security helps to explain why the incumbents in the three cases did not do more than was absolutely necessary to address the controversies. In the DRONE case, for instance, the minister only promised ad hoc improvements after opponents began to accuse him of lying. Likewise, in the EXPO case, the government only became active after all major parties pressed for stronger political involvement at the Verein.

With regard to presentational strategies, the cases suggest that incumbents, like during proximate-nonsalient blame games, occasionally deflect blame onto administrative actors or onto previous governments. However, they predominantly relied on reframing strategies when addressing a distant-nonsalient controversy. While incumbents in the DOME and EXPO cases defended the respective expositions against their critics, in the DRONE case, the minister defended the use of drones for military purposes. Incumbents obviously did not shy away from the discourse about a distantnonsalient controversy. Moreover, their public statements show that incumbents have a freer hand in reframing a distant-nonsalient controversy because they do not need to dispel claims of personal relevance. In other words, their reframing attempts do not need to accommodate negative consequences for the wider public. Overall, one sees that incumbents combine a passive but very confident stance with ample reframing activities.

\section{Test Case: Solyndra Loan Provision Controversy (SOLYNDRA)}

In this section, I test the earlier findings against a fourth case from the distant-nonsalient category. This allows me to refine our understanding 
of how blame game actors react to and work with feedback to distantnonsalient controversies. The SOLYNDRA controversy is about a solar panel manufacturer that defaulted on a US government loan in 2011. Republicans used the default to blame the Obama administration for its green energy policy.

\section{Policy Struggle}

In 2009, the Obama administration granted a US\$535 million loan guarantee to Solyndra, a California-based solar panel manufacturer. The loan guarantee was granted as part of a recently extended loan guarantee program administered by the US Department of Energy. After taking office in February 2009, President Obama signed the American Recovery and Reinvestment Act into law. It provided for considerable investments into green energy to stimulate the economy in response to the economic crisis. Two years later, in late August 2011, Solyndra filed for bankruptcy. ${ }^{30}$ For Republicans, the bankruptcy was a welcome event to criticize the Obama administration's green energy policy and to condemn its costly and futile interventions into the economy to create jobs. Republicans were very much tempted to tie Obama and his closest advisers to the controversy, as the president had visited Solyndra one year earlier and had portrayed the company as a "testament to American ingenuity and dynamism." 31

\section{Blame Game Interactions}

After the bankruptcy announcement, Republicans began to frame Solyndra as a "model of poor government investment" and quickly came up with the allegation that the Department of Energy had only approved the loan because a wealthy donor to the Obama campaign was also an investor in Solyndra. ${ }^{32}$ While these attacks suggested that this controversy was an instance of 'crony' capitalism right from the start, they initially targeted Obama's 'interventionist' stance in rather general terms rather than bluntly accusing his administration of corruption. Republicans, although emphasizing the loss of taxpayer money in times of fiscal stress, concentrated on portraying Obama as a 'failed venture capitalist'. ${ }^{33}$ After e-mail releases began to suggest that the Department of Energy had fast-tracked loan guarantee reviews for political reasons, Republicans intensified their blaming to drive the controversy into a full-blown scandal. They pressed the Obama administration to suspend loan handouts to clean energy companies and 
stepped up their investigation efforts through committees, hoping to unequivocally show that the Obama administration had acted corruptly in the Solyndra case. ${ }^{34}$

In reacting to Republicans' allegations, the government adopted a clearly discernible strategy mix and followed it even after Republicans formulated clear-cut corruption allegations. President Obama, his advisers, and the Department of Energy secretary called the loan default an unfortunate event, but not a mistake, because occasional defaults were an unavoidable part of a risky and innovationgenerating loan program. Accordingly, they refused to apologize for past actions. ${ }^{35}$ The Obama administration also engaged in heavy reframing activities. It argued that Solyndra had already applied for a loan guarantee under the Bush administration and that the Obama administration had only finished the application procedure in a sound and legal way. ${ }^{36}$ The Obama administration also stressed the fact that changing market conditions, especially the increased competition from China, had caused the bankruptcy of Solyndra. Moreover, it expressed optimism that part of the federal investment could still be recovered in the ensuing bankruptcy reorganization. Overall, the Obama administration heavily contested that the Solyndra loan default constituted a scandal at all. Consequently, it also did not accuse Solyndra of having done anything wrong. ${ }^{37}$ Throughout the blame game, the Obama administration held on to the loan program. The Department of Energy even issued two large loan guarantees to solar companies only a few days after Solyndra's bankruptcy. Moreover, the administration announced its plan to hand out further US\$9.2 billion in guarantees until the end of September 2011. ${ }^{38}$

\section{Consequences of the Blame Game}

Further e-mail releases in the course of investigations prompted the Republican House majority to drag the controversy on for some time. ${ }^{39}$ However, as those e-mails did not allow Republicans to substantiate their corruption allegations, the blame game ended without producing noteworthy consequences. There were no resignations related to the controversy and the Obama administration announced that it intended to maintain its loan guarantee program unchanged. ${ }^{40}$ The New York Times eventually remarked that the "circus of broad accusations" staged by the Republicans had not succeeded in inflating the controversy or in tarnishing the Obama administration. ${ }^{41}$ 


\section{Test of Preliminary Findings and Summary}

In the remainder of this section, I assess whether opponent and incumbent behavior in the blame game surrounding the SOLYNDRA controversy is in line with the behavioral patterns observed in the three in-depth cases.

\section{Opponent Behavior}

By analyzing opponents' public statements, it is possible to discern a significant change in the level of blaming throughout the course of this blame game. While Republicans immediately blamed the Obama administration for unsuccessfully meddling in the economy, they only stepped up their blaming efforts when they got hold of e-mails that suggested that the Obama administration had acted corruptly in the Solyndra case. Also, media outlets duly noted that Republicans were "escalating political furor" and were "broadening their attacks" when the corruption issue had become salient. ${ }^{42}$ Very similarly to the DRONE case, it was mainly the prospect of damaging Obama, or one of his closest advisers, and not the controversy itself that prompted Republicans to step up their blame-generation efforts.

It is also apparent that Republicans had difficulties leveraging emotions or personal relevance during this blame game. Picturing the president as a failed venture capitalist may constitute a scathing reproach, especially in the US context, but it hardly leverages emotions that attract the attention of the public. Also, the occasional indications from Republicans that the Obama administration had wasted US $\$ 0.5$ billion of taxpayer money during times of fiscal stress rang hollow in the face of a loan program that was supposed to invest many times over into clean energy. This lack of leverage helps to explain why Republicans were eager to shift the debate from money waste and failed state interventionism to personal involvement and corruption.

Nevertheless, Republicans were not reluctant to blame the government, even before corruption allegations became salient. This suggests that distance and low salience alone cannot fully account for the amount of blaming in this case. For example, the Republicans' strong ideational opposition to state interventionism could account for their willingness to blame Democrats, even in the case of a distant-nonsalient controversy. Taken together, the blaming activities of opponents are mainly in line 
with those observed in the three in-depth cases, especially if one isolates the influence of the rather idiosyncratic corruption allegations.

\section{Incumbent Behavior}

Incumbents' public statements reveal a very consistent and clear strategy profile. Throughout the blame game, incumbents contested whether the loan default was a controversial event at all, refused to call the investment decision a mistake, and accordingly, did not apologize for it. Incumbents were also able to apply reframing strategies without deflecting blame onto others. This is a noteworthy finding, since the Obama administration could have blamed Solyndra for misleading the federal authorities or officials who had gotten into a predicament due to the e-mail releases. Instead, the Obama administration defended the loan decision made two years before, portrayed the default as an unfortunate, although normal, occurrence, and spread optimism that significant parts of the loan could eventually be recovered. Moreover, the administration calmly and firmly held on to its view that all procedural requirements had been met, that there had not been undue political meddling, and that corruption allegations were unsubstantiated. Finally, incumbents did not actively address the controversy, let alone give in to the demand of opponents to stop the loan guarantee program. Instead, incumbents kept issuing loans to solar companies and expressed their determination to continue with the loan guarantee program.

The only prediction that cannot be substantiated is that incumbents take their time when reacting to a distant-nonsalient controversy. When Republicans began their criticism, the Obama administration immediately retorted. Hence, I must qualify the prediction that the distance and low salience of a controversy alone can account for incumbents' reaction speed to the controversy. Overall, one can conclude that incumbent behavior is mostly in line with the predictions derived from the three in-depth cases.

\section{Summary}

The analysis suggests that opponents who blame incumbents for a distant-nonsalient controversy do not usually invest much in blame generation in the absence of factors that promise to damage the reputation of incumbents. Distant-nonsalient controversies do not lend themselves to the leveraging of emotions or personal relevance. Incumbents 
that have to deal with distant-nonsalient controversies thus confidently confront opponents, reframe their attacks, and do not usually issue substantive responses. In the next section, I compare and summarize the results obtained from the analysis of the different combinations of issue characteristics on blame game interactions.

\subsection{Issue Characteristics and Their Influence on Blame Game Interactions}

The analyses and comparisons carried out in the nine in-depth cases and in the three test cases reveal that issue characteristics influence important parameters of opponent and incumbent behavior. While institutional factors influence the basic form of a blame game, provide gateways for and barriers to blame attacks, and determine the power distribution between opponents and incumbents, these contextual factors omit the question of what exactly blame game actors say and do to influence the public and attack the other side. In other words, the content of blame game interactions is left largely unexplained by institutional factors. The previous three sections show that issue characteristics fill this gap. Issue characteristics influence whether and how opponents can signal the severity of a controversy to the public and how they can put incumbents under pressure to meet their policy demands. Moreover, issue characteristics influence how incumbents position themselves with regard to a controversy and determine the strategy mix they employ to manage blame.

\section{Opponent Behavior}

Regardless of the controversy type, opponents abundantly use deft words to tag a controversy. Tags like 'terrible failure', 'huge scandal', or 'horrible shambles' belong to the same type of 'baseline rhetoric' that opponents adopt to attract the public's attention. The message opponents send by adopting this rhetoric is a simple one: "Hey, look, this is unlike routine political business, something is going terribly wrong here!" Another similarity across controversy types is that opponents attempt to kill two birds with one stone with their public statements during a blame game: They seek to attract the attention of the public and to put pressure on incumbents to enter a blame game and to address the underlying controversy. It is here where issue 
characteristics become decisive. Issue characteristics determine the ways in which opponents pursue these mutually reinforcing goals.

\section{Attracting the Attention of the Public: Emotions, Personal Relevance, or Merely Deft Words}

In the case of a distant-salient controversy, attracting the attention of the public is a relatively easy task for opponents. A salient controversy is inherently contentious and attracts the attention of the public as soon as it hears about it. On top of simply pointing the public to a distantsalient controversy, opponents usually fuel public feedback by stressing the emotional content of the controversy, like norm violations or suffering on the part of citizens. In the absence of salience, attracting public attention is more difficult. Opponents must then go the extra mile to try to convince the public that a controversy merits close attention. This is where proximity becomes relevant. Proximity allows opponents to approach citizens as deprived subjects. Opponents formulate claims of personal relevance that relate to material losses and/or to the violation of rights, such as the right to be properly informed by the government about certain issues or the right to enjoy protection from particular threats. In both distant-salient and proximatenonsalient cases, political opponents are often joined by vocal social actors in their blame-generation efforts. This aspect lends additional weight and credibility to the blame-generation efforts of political opponents. In distant-nonsalient cases, on the contrary, political opponents have a hard time convincing the public that a controversy merits their attention. It is in these cases where the baseline rhetoric of deft words rings most hollow.

\section{Putting Pressure on Incumbents: Moral Obligation, Debt Obligation, or Bad Job}

The in-debt cases revealed that political systems exhibit various institutional factors that combine to form functionally equivalent blame barriers that protect incumbents. This is a complication opponents attempt to overcome by establishing a causal connection between the incumbent and the controversy. How opponents attempt to make this connection and whether or not they succeed, depends, to a significant degree, on issue characteristics. In the case of a distant-salient controversy, opponents primarily leverage emotions to tie incumbents to a controversy. The causal connection opponents strive to create takes 
the form of a moral obligation that incumbents must address. No matter how far away from the incumbent this controversy might be in institutional terms, as the politically responsible actor, the incumbent, must assume this responsibility by engaging with the controversy and eventually accepting its consequences. Accordingly, opponents frequently debunk incumbents' attempts to address a distant-salient controversy as a morally reprehensible form of reputation-driven activism. In sharp contrast to the latter, opponents present their policy demands as the morally adequate solution to the problems at the root of the controversy. In case of a proximate-nonsalient controversy, the causal connection opponents seek to establish takes the form of a debt obligation. Incumbents who 'betrayed' the public by depriving it of money, services, or democratic rights, should 'pay back' what they owe by meeting the policy demands of opponents. In the case of a distant-nonsalient controversy, opponents have difficulty establishing a causal connection between incumbents and the controversy since they can leverage neither emotions nor obligations before the wider public. It is in these cases where opponents have the biggest difficulty forcing incumbents to admit that a controversy actually constitutes a 'scandal' or 'crisis'. Opponents usually only half-heartedly blame incumbents, basically accusing them of doing a 'bad job' in some way.

Issue characteristics cannot fully explain the amount of blaming undertaken by opponents during a blame game. While the cases suggest that salience increases the amount of blame generation opponents undertake, they also reveal that there are other factors that also influence this parameter of opponent behavior. Subsequently, I briefly outline five additional factors that can help to account for this parameter of opponent behavior. First, as the CSA case suggests, prior involvement in a policy issue on the part of opponents may hamper the overall amount of blame generation during a blame game. Opponents' prior involvement is not unusual given regular changes in government and the often considerable time spans between the adoption of a policy and the point when it becomes controversial. Opponents who carry part of the policy responsibility because they were involved in its adoption risk appearing hypocritical if they blame the government of the day for its failure. For incumbents, 'inherited' policy controversies create wiggle room, allowing them to buy time and providing them with an additional blame-deflection possibility. Nevertheless, as the CSA case in 
particular suggests, this advantage diminishes during a blame game if incumbents are unable to solve the 'inherited' controversy. I expect the influence of prior involvement in a policy issue to be strongest in political systems where opponents are rather consolidated, given that the likelihood is higher that a large share of opponents is constrained by prior involvement.

Second, when incumbents have personally associated with a policy, like in the BER case, opponents are tempted to increase the amount of blame generation. A personal association provides opponents with the opportunity of transforming a policy controversy into a venerable personal scandal during which the resignation of political incumbents becomes possible. In general, blame games that contain multiple blameworthy events provide opponents (and incumbents) with more framing opportunities (e.g., they can decide whether to portray an issue as a financial issue, a moral issue, etc.). During such blame games, opponents can be expected to emphasize the most blameworthy aspect(s) of a policy controversy, while incumbents will emphasize the least blameworthy aspect(s). A consequence of these orientations is that, when a 'new' event emerges during a blame game (like the discovery of a personal involvement of the incumbent), blame game actors will change their strategy mix.

Third, as the DRONE and the SOLYNDRA cases suggest, upcoming elections may prompt opponents to invest considerably in blame generation even in the case of controversies that promise only weak public feedback. In the run-up to elections, opponents cannot be picky by sparing their blame for more promising controversies; they may be forced to 'clutch at straws'.

Fourth, blame generation may be more intensive than issue characteristics alone suggest in cases where a policy controversy becomes emblematic of a larger political conflict. In such cases, opponents can be positive that their ranting and raving will resonate widely. In the DOME case, for example, media and political interest in the controversy was out of proportion because the Millennium exhibition had become a symbol for discussing the 'New Labour' phenomenon. Without this function of the DOME controversy, opponents would have almost certainly invested less in blame generation, and Mark Knopfler would not have written the song 'Silvertown Blues' about it. 
Finally, there should be a difference between whether opponents generate blame for a controversy that lies in the past, like in the DRONE case, or for an ongoing controversy, like in the BER case. Only the latter provide opponents with recurrent occasions for blame generation. ${ }^{43}$ While these explanatory factors can be causally relevant in particular cases, their influence on the overall blame game should not be overestimated. The method of comparative historical analysis, with its focus on longer time spans, allowed me to isolate the influence of these additional factors. In the cases examined, their influence was usually limited in time and greater blame generation did not lead to stronger public feedback.

Overall, while issue characteristics are not cast in stone, my analysis suggests that there are also limits to their malleability through communicative strategies, such as calculated overcommunication. In other words, issue characteristics do not 'lose their bite' even if political actors are hell-bent on ignoring them. The reason is that, in addition to opponents, there are other actors, like the media and the public, that hold prefabricated opinions about controversy types. For example, even in cases where opponents excessively repeat (Hansson, 2015) that a controversy is a scandal, issue characteristics have an important influence on their success prospects. In sum, one can clearly observe how opponents actively work with and are constrained by issue characteristics when focusing the public's attention on a controversy and putting pressure on incumbents.

\section{Incumbent Behavior}

The comparison of blame game interactions against the background of different controversy types reveals that issue characteristics influence two specific dimensions of incumbent behavior: their positioning toward a controversy and their concrete strategy mix.

\section{Positioning toward the Controversy: Humble or Confident}

When engaging in a controversy, incumbents are eager to express a specific attitude to the public. Once confronted with a distantsalient controversy, incumbents adopt an attitude that is in line with the dominant feeling in society. Depending on the specific controversy, this can encompass a compassionate or a rather angry attitude. When incumbents have to address a proximate-nonsalient controversy, they 
acknowledge the existence of a problem and express that they take this problem very seriously, but they simultaneously exhibit a rather confident stance. In response to a distant-nonsalient controversy, incumbents exhibit a very relaxed and confident stance.

\section{Strategy Mix: Blame Deflection, Reframing, or Activism}

Incumbents not only adopt a controversy-specific attitude, they also apply a controversy-specific strategy mix to manage blame. A first notable finding is that incumbents apply blame-deflection strategies irrespective of specific issue characteristics. At first sight, this is not very surprising because in complex policy areas, responsibility and blame deflection is usually a strategy that is easy for politicians in charge to use. A closer look at the cases, however, reveals that during salient controversies, incumbents deflect blame more intensively than during nonsalient controversies. Two reasons can account for this difference. First, incumbents face comparatively more pressure for salient controversies and only possess limited possibilities for reframing a salient controversy (see later). This makes blame deflection the only presentational strategy available to incumbents (see also Hinterleitner, 2018). Second, blame deflection and reframing can be contradictory in cases where incumbents deny the existence of a problem. Denying a problem suggests that the blame assigned by opponents is not justified at all. Hence, when incumbents apply this reframing strategy, they cannot simultaneously deflect blame because blame deflection implicitly acknowledges that someone caused a problem for which blame must be allocated.

Issue characteristics also influence whether and how incumbents attempt to reframe a controversy and how active they are in addressing it. Confronted with a distant-salient controversy, incumbents are eager to avoid getting their fingers burned by attempting to reframe it. Trying to reframe a distant-salient controversy encompasses the danger of standing on the wrong side of the controversy and is not compatible with the emotionally harmonized attitude incumbents exhibit in the face of such controversies. This is why one only observes very careful reframing attempts that never contest the existence of a problem per se. Instead, incumbents usually engage in frantic activism to signal their commitment to addressing the controversy. Anxious to secure their continuing involvement with the controversy, they usually produce 
a steady stream of inquiries, measures, amendments, or initiatives intended to tackle the problem at the root of the controversy.

Incumbents are much more inclined to reframe nonsalient controversies. In the case of a proximate-nonsalient controversy, this reframing is especially targeted at the controversy's negative effects on the wider public. Incumbents usually argue that a controversy and its consequences are much less negative than portrayed by opponents or is outweighed by multiple benefits. Surprisingly, activism was even limited in proximate-nonsalient controversies, for which I expected opponents to have a more active stance (this will be addressed later).

Confronted with a distant-nonsalient controversy, incumbents have a freer hand in reframing a controversy, often contesting whether the latter constitutes a problem or crisis at all. It is in these cases that incumbents sometimes even dare to switch from blame management to credit claiming. As Leong and Howlett (2017) state, the link between these concepts deserves more theoretical and empirical attention. At some point, a very confident blame-management approach can turn into some form of credit claiming. The study of the distant-nonsalient controversies suggests that 'favorable' issue characteristics allow incumbents to strongly reframe a controversy and thereby also switch from blame management to credit claiming.

Just like issue characteristics cannot fully account for the amount of blame generation by opponents, they also cannot solely explain the degree of activism by incumbents. Instead, institutional factors seem to be decisive, too. Institutional factors that comfortably protect incumbents (METRONET, CTR), or a policy problem that limits the opportunities for activism (BER) are also important in determining the degree of activism adopted by incumbents. With this limitation in mind, one can derive stylized patterns of incumbent behavior with regard to different controversy types. With regard to a distant-salient controversy, incumbents adopt a humble attitude, intensively deflect blame, only very carefully reframe the controversy, and strongly engage in activism. With regard to a proximate-nonsalient controversy, incumbents adopt a confident attitude, only carefully deflect blame, intensively reframe the controversy by dispelling claims of personal relevance, and only weakly engage in activism. With regard to a distant-nonsalient controversy, incumbents adopt a very confident attitude, only carefully deflect blame, if at all, intensively reframe the controversy, and only weakly engage in activism. 
Overall, it is best to consider the previously derived behavioral patterns as 'more or less' statements rather than as deterministic 'either/or' statements because blame games may contain public statements that contradict them. For example, in the distant-nonsalient SOLYNDRA case, opponents made claims of personal relevance by suggesting that the loan default constituted a waste of precious taxpayer money and that citizens had a right to know what had really been going on during the loan approval procedure. While those claims were few and not prominently voiced, they nevertheless slightly contradict my conclusion that opponents only make claims of personal relevance in case of proximate-nonsalient controversies. 'Unexpected' behavior of this sort may result from interaction effects with institutional factors, such as direct government involvement in a controversy or from misperceptions on the part of blame game actors. Both interaction effects and misperceptions will be accounted for in the remaining chapters of this book. 


\section{A Typological Theory of Blame Games and Their Consequences}

The two groups of explanatory factors contained in the theoretical framework - institutional factors and issue characteristics - influence blame game interactions in important ways. The previous chapters demonstrate that there are important interaction effects between institutional factors and issue characteristics. For example, whether or not incumbents deflect blame depends both on the availability of scapegoats in a particular institutional context and on the strength of public feedback to a particular controversy type, as incumbents only deflect blame if public pressure forces them to do so. Given that blame deflection implicitly acknowledges that someone caused a problem for which blame must be allocated, incumbents are usually eager to contest the existence of a problem for as long as possible. Another example is the degree of activism adopted by incumbents, which depends on both the strength of public feedback and on the shape of institutional blame barriers.

In this chapter, I will look at these interaction effects in more detail. To obtain a comprehensive picture of blame games, I will examine how institutional factors and issue characteristics combine to produce blame game consequences. This examination begins by reconsidering the role of citizens during blame games. Akin to the spectators of a boxing match, citizens observe a blame game with more or less interest and passion, they eventually take sides with one of the combatants, and they form an opinion on who they believe should win. As we have seen, the public's attitude toward a blame game influences blame game interactions in important ways. But whether and how this attitude leaves an imprint on the consequences of the blame game is a different question. In a perfectly democratic world, we would expect that strong public feedback translates into extensive blame game consequences that are largely in line with the preferences of the majority of the public on that particular controversy. Weak public feedback would 
mean only minor consequences because the majority of the public would not see a need for significant changes. However, we have reason to expect that political systems do not just 'pass through' public feedback, but weaken, divert, or altogether stall it during blame games.

In order to better understand the transmission of citizen preferences during blame games, one must assess whether and how public feedback to a particular controversy leads to blame game consequences. In other words, one needs to analyze interaction effects between institutional factors and issue characteristics to understand how public feedback translates into reputational and/or policy consequences. To answer these questions, I construct a typological theory of blame games and their consequences (Collier et al., 2012; George \& Bennett, 2005). A typological theory develops "contingent generalizations about combinations or configurations of variables that constitute theoretical types" (George \& Bennett, 2005, p. 233). A typological theory helps to handle and structure a complex empirical reality and allows me to move up the ladder of abstraction and consider blame games and their consequences in their entirety after a dense empirical analysis that focused on establishing the influence of individual contextual factors on blame game interactions.

\subsection{Constructing a Typological Theory}

To begin with, I use the strength of public feedback and the extent of consequences to construct a property space consisting of four blame game types (see Table 11). Blame games can exhibit weak public feedback and limited consequences, strong feedback and limited consequences, weak feedback and extensive consequences, and strong feedback and extensive consequences. In a second step, I categorize

Table 11 Relationships between public feedback and blame game consequences

\begin{tabular}{lll}
\hline & Limited consequences & Extensive consequences \\
\hline Weak public feedback & $\begin{array}{c}\text { METRONET, DOME, } \\
\text { EXPO }\end{array}$ & DRONE, TAX, BER \\
Strong public feedback & CSA & NSU, CARLOS
\end{tabular}


the nine blame games studied in detail along those dimensions to assign them to one of the four blame game types. ${ }^{1}$ To do so, I establish empirical thresholds that allow me to distinguish weak from strong feedback and limited from extensive consequences. The procedure that I apply here is called 'pragmatic compression' or the "collapsing [of] contiguous cells if their division serves no useful theoretical purpose" (Elman, 2005, p. 300). From a broader perspective, what ultimately interests me is whether or not a blame game was a venerable political scandal, whether it was just a hiccup in the trajectory of a public policy, or whether it significantly altered its trajectory. The dichotomization focuses on these broader issues, and it captures the aspects of the empirical reality that are relevant at this point in the analysis (but not more in order to avoid complicating it).

Obviously, these dichotomizations lead to a loss of information and involve tricky decisions (Ragin, 2008). For example, I need to consider temporal factors such as looming elections or unusual personal involvement, which lead opponents to more heavily invest in blame generation and that, consequently, may lead to stronger feedback than a particular controversy type alone would suggest. Similarly, I must consider that some controversies are so intricate that incumbents cannot boldly address them, even if they want to. In these cases, the consequences of a blame game are not only produced by the interplay of issue characteristics and institutional factors, but they also depend on other controversy-related factors. However, extensive case knowledge allows me to transparently address these measurement problems. Reducing the risk of mistaken inferences by relying on detailed within-case evidence is seen as a decisive advantage of typological theorizing over purely comparative approaches (George \& Bennett, 2005, p. 254).

To distinguish weak from strong public feedback, I draw on the measurements conducted in the case studies in Chapters 3-5. An overview of these measurements and the categorizations that result therefrom can be found in Table A3 in the Appendix. The case studies reveal that public feedback to distant-salient blame games (CSA, NSU, CARLOS) is significantly stronger than feedback to distantnonsalient blame games (DOME, DRONE, EXPO). Accordingly, I assign the three distant-salient blame games to the 'strong feedback' category and the distant-nonsalient blame games to the 'weak feedback' category. I also assign proximate-nonsalient blame games to the 'weak feedback' category since the feedback measured in the 
METRONET, BER, and TAX cases was still rather moderate and the difference in feedback intensity compared to distant-salient blame games was much larger than the difference to distant-nonsalient ones.

To distinguish blame games without consequences from rather consequential blame games, we must contrast the types and degrees of consequences found in the nine cases. Measurement details for each case can be found in Table A4 in the Appendix. The two main categories of blame game consequences are reputational consequences and policy consequences. Reputational consequences encompass the resignations of actors somehow involved in the controversy, ranging from incumbent politicians to administrative actors. While the resignations of political incumbents could only be observed in the CARLOS and BER cases, resignations of administrative actors were more widespread. I weigh political resignations higher than administrative resignations. One of opponents' main goals during blame games is to put political incumbents under pressure (either to bring them to resign or to give in to their policy demands). While bureaucratic resignations can be portrayed by incumbents as mere hiccups in the administrative regime, political resignations reveal that incumbents had to assume political responsibility for a policy controversy, and they also satisfy a feeling of vindication among the affected public (interpreted as a form of 'responsiveness' to the public's demands). Policy consequences encompass changes and adaptations to the policy at the heart of the controversy. The case studies revealed that blame games do not usually lead to sweeping policy change. Put differently, opponents rarely reach all their policy goals during a blame game. However, as observed in the TAX and DRONE cases, blame games can exhibit more subtle policy consequences. Even if opponents' blame generation does not lead to immediate policy change, it may still anchor a controversy in collective memory. Opponents can then draw on collective memory to generate public feedback during a subsequent round of conflict. The previous controversy thereby serves as an anchor that influences subsequent public reactions (Tversky \& Kahneman, 1974). In other words, blame generation may lay the groundwork for stronger public feedback in the future and thereby paves the way for lagged policy consequences. Therefore, I treat cases that have consequences resulting from an anchoring effect as blame games with extensive consequences. Moreover, I treat the relationship between reputational and policy consequences as one of 'arithmetic addition', that is, the aggregate 
level of reputational and policy consequences determines whether consequences are 'limited' or 'extensive' (Goertz, 2006). This approach is warranted because, depending on the particular controversy, the public may not only be interested in policy consequences but also in the punishment of incumbents.

Overall, the variation in consequences across cases suggests that we must set a rather low threshold for distinguishing blame games with limited consequences from blame games with relatively extensive consequences. Even by setting a low threshold, however, there are clear cases of blame games with very limited consequences in the sample, namely the CSA, METRONET, DOME, and EXPO cases. At the other end of the spectrum, we have clear cases of blame games that have extensive reputational and/or policy consequences, namely the NSU, DRONE, CARLOS, and TAX cases. The only case that is trickier to assign is the BER case. The idiosyncratic nature of the policy problem at the heart of this blame game made it impossible for incumbents to boldly address the problem. When the blame game started, it was already too late for incumbents to terminate the construction of the airport or to significantly adapt its implementation structure due to contractual commitments. Hence, we ultimately do not know whether incumbents deliberately opted against bold policy change or whether they wanted to boldly address the controversy but were unable to do so. Three reasons make me treat the BER case as a blame game with extensive consequences. First, several public managers had to resign. Second, the controversy ultimately cost the mayor his political career. And third, evidence suggests that incumbents did everything in their power to open the airport as soon as possible.

\subsection{Political Systems and How They Manage Policy Controversies}

A look at the distribution of cases across the cells in Table 11 reveals an important insight. All four blame game types are empirically present in the case sample. This means that there is no perfect match between strong public feedback and extensive consequences on the one hand, and weak feedback and limited consequences on the other. Instead, the relationship between public feedback and blame game consequences is more complicated. Table 11 reveals that there are blame games where feedback is limited but that produce extensive consequences (BER, 


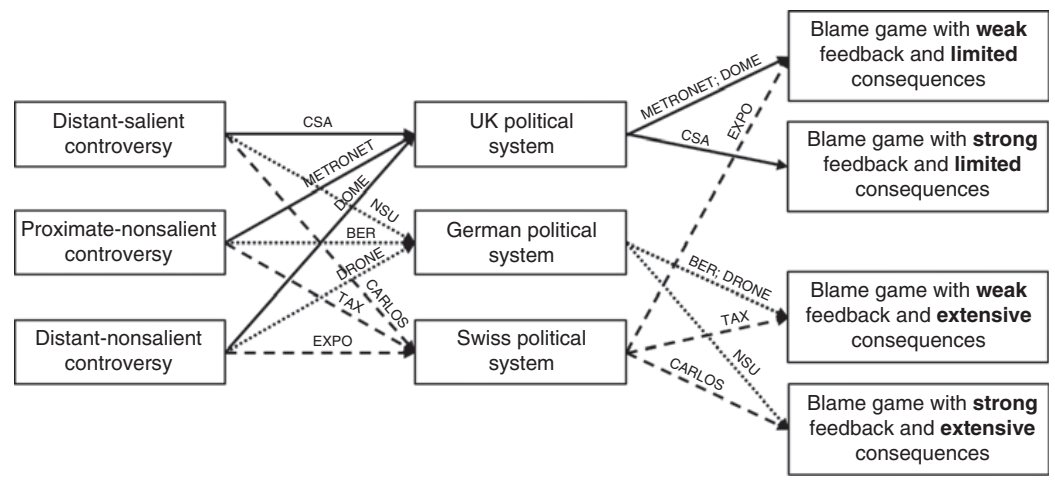

Figure 3 Causal diagram of the typological theory

DRONE, TAX), and that there is a blame game in the sample where feedback is strong but consequences are limited (CSA). This suggests that there must be interaction effects at work between a controversy (and the public feedback to it) and the institutional system in which it is processed that lead to rather counterintuitive blame game types.

To expose the interaction effects that produce the four blame game types, I adopt a more procedural perspective, transforming this typology into a causal diagram, as pictured in Figure 3 (George \& Bennett, 2005, chapter 11). On the right side of Figure 3, there are the outcome boxes, one for each of the four blame game types found in the sample and pictured in Table 11. On the left side, there are three boxes capturing the three controversy types. In the middle are three boxes representing the three political systems in which blame games were studied in detail. The three controversy boxes and the three political system boxes stand for the six explanatory variables encompassed in the theoretical framework. ${ }^{2}$ The political system boxes are situated in the middle to express the idea that a controversy is managed or processed by a political system before it leads to specific consequences.

The causal diagram reveals that the shape of the political system mediates the relationship between public feedback and blame game consequences. All of the controversy types that pass through the UK political system result in blame games with limited consequences. This means that the UK political system stalls public feedback, even in cases where the latter is strong (as the CSA case suggests). The UK political system seems like a tube that remains clogged, even if filled with 
considerable public feedback. The main reason for this outcome is the very strong blame barriers that the UK political system provides to incumbents. Restrictive conventions of resignation, frequent ministerial reshufflings, and generally low government involvement make it almost impossible for opponents to get hold of political incumbents. The comfortable blame protection resulting from these barriers makes reputational consequences unlikely and reduces incumbents' incentives to quickly and boldly address a policy controversy. These observations suggest that the UK political system is rather impervious to public feedback during blame games. Even if the majority of the public sees a need for consequences, it is unlikely that consequences will come about during blame games due to the system's particular configuration of the political interaction structure, accountability structures, and institutional policy characteristics. This finding is quite at odds with the widely held high esteem for Britain's political debate culture. Debates in the UK political system may be witty and sharp, but, at least with regard to policy controversies, they often only produce hot air.

The German political system gives the opposite 'treatment' to policy controversies during blame games. In the sample, all controversy types, irrespective of whether they exhibited strong or rather weak public feedback, led to blame games with extensive consequences. This implies that in the German political system, public feedback can be amplified through the interactions of blame game actors. Even in cases where the public watches a blame game rather indifferently and does not show too much interest in its consequences, the combatants are likely to really struggle with each other. The main reason for this surprising outcome is the strong 'executive focus' in German blame games. The German political system provides opponents with ample opportunities to pressure incumbents to address a policy controversy. The extensive conventions of resignation and the opportunity to grill incumbents before an inquiry commission allows opponents to create the impression of an 'entangled' executive, even in controversies that only attract weak feedback. An 'entangled' executive is much more likely to suffer reputational damage or give in to policy demands than an executive on top of events. This explains why blame games can exhibit extensive consequences even in cases where public feedback is rather weak. It must be noted, however, that a strong 'executive focus' is not a necessary requirement for extensive blame game consequences 
in the German political system. As the NSU case suggests, strong public feedback can lead to extensive blame game consequences even in cases where blame game interactions predominantly focus on administrative actors and entities. Hence, the German system has at least two mechanisms through which controversies can lead to extensive consequences. We can therefore conclude that the German political system is much more responsive to public feedback during blame games than the UK political system.

The Swiss political system lies somewhere between the UK and German political systems in terms of responsiveness to public feedback. The three controversies processed by the Swiss political system either had limited or extensive consequences. Interestingly, and in line with the patterns revealed for controversies processed by the German political system, strong public feedback is not a necessary requirement for extensive consequences in the Swiss political system (as the TAX case demonstrates). This suggests that public feedback in the Swiss political system can also be amplified through blame game interactions. However, since the consequences qualified as 'extensive' in the TAX case have to do with an anchoring effect while immediate policy consequences were thwarted by the parliamentary majority, we can conclude that the Swiss system leads to less feedback amplification than the German political system. Therefore, the strength of public feedback and the extent of blame game consequences are comparatively most congruent in the Swiss political system: Weak public feedback leads to limited consequences (EXPO) and strong public feedback to extensive consequences (CARLOS). Political combatants in the Swiss system are very responsive to the attitudes of their spectators. They are committed to fight if the public wants them to, and they switch into training mode if the public watches the blame game rather indifferently. The main reason for the proportionality between public feedback and blame game consequences lies in opponents' attempts to forge a 'pressure majority' during blame games. Since reputational goals are largely out of reach for opponents in the Swiss system, they concentrate on reaching their policy goals. The stronger the public feedback, the higher the likelihood that opponents succeed in forging a 'pressure majority' that will be heard by the collective executive government. Hence the congruence between strength of feedback and extent of consequences. These observations reveal that the Swiss political system is very responsive to public feedback during blame games. 
Overall, the typological theory reveals that political systems do not just 'pass through' public feedback but give it a decisive twist during blame games. Blame game interactions either stall public feedback (as in the UK political system), amplify it (as in the German political system), or process it in a relatively unchanged manner (as in the Swiss political system). Each political system has its own peculiar way(s) of managing policy controversies. In doing so, some are more responsive to the preferences of the public than others. Put differently, whether or not blame games act as a well-functioning mechanism for transmitting citizen preferences depends on the institutional system in which blame games are played out. The finding that political systems are varyingly responsive to public feedback when they manage policy controversies during blame games has important implications for our understanding of politics and democracy under pressure. These implications will be drawn out in the concluding chapter. 


\section{Blame Games and Their Implications}

for Politics and Democracy under Pressure

Blame games are distinct political events that protrude from routine political processes. This book develops a theoretical framework for explaining blame game interactions and their consequences. By applying the framework to fifteen blame games, situated in various political systems and issue contexts, it creates a comprehensive understanding of these distinct political events. As microcosms of conflictual politics, the careful study of blame games offers crucial insights into how democratic political systems change and function when they switch into 'conflict mode'. The present chapter begins by summarizing the results derived from the empirical analysis. It then assesses the explanatory potential of the framework, its applicability across space and time, and considers avenues for future research on blame games. Finally, the chapter will draw out a number of insights from the study of blame games that help to improve our understanding of politics and democracy under pressure.

\subsection{What This Book Has to Say about Blame Games}

Blame games are context-sensitive 'embedded' political events. Understanding them requires the consideration of the institutions that preset the space in which political conflict management occurs, the issue characteristics of the policy controversies at the root of blame games, and interrelations between these groups of factors. In the following, I will briefly summarize the most important results of the empirical analysis.

\section{The Imprint of Institutions}

The empirical analysis shows how institutional factors - ranging from hard-wired formal institutions to conventions and policy characteristics emit incentives and constraints on blame game actors. The structures 
around routine political interactions, institutionalized accountability structures, and institutional policy characteristics combine in peculiar ways in a political system to influence the behavior of opponents and incumbents. These institutional factors explain the basic setup of a blame game, that is, how political actors position themselves toward a controversy. Moreover, they provide blame gateways to opponents and blame barriers to incumbents. Blame gateways determine whom opponents can hold responsible and credibly attack. Blame barriers, by reducing or deflecting the blame coming from opponents, create space for incumbents to maneuver and thus determine how actively they must engage in blame management. Together, institutional factors influence the power distribution between opponents and incumbents and determine the goals these actors can reasonably pursue during a blame game.

Institutional factors in the UK political system render it difficult for opponents to reach their reputational and policy goals. Ministers, who are usually only briefly in office and are not personally responsible for a controversy, constitute very strong blame shields for the government of the day since, in the absence of personal wrongdoings, they cannot be brought to resign. The 'administration bias', injected by forms of agencification and reinforced by the work of parliamentary committees, ensures that the ministerial blame shield is often not even checked for its resilience during a blame game because media attention and opponent attacks overwhelmingly focus on administrative actors and entities. Incumbents can thus remain rather passive during a blame game, tolerate occasional criticism from the governing majority, and develop strong incentives to leave a policy controversy unaddressed. Overall, institutional factors in the UK political system clearly benefit incumbents during blame games.

Institutional factors in the German political system are conducive to creating a rather aggressive blame game that centers on political incumbents. Extensive conventions of resignation and opportunities to retrieve salient information about a controversy by appointing an inquiry commission are powerful tools for opponents to hold political incumbents accountable and to force them into heated blame game interactions. Consequently, blamed incumbents must actively engage in blame management and may be forced to act in the interest of opponents. However, political incumbents also benefit from institutional factors. An active and loyal governing majority and fragmentation among opponents are assets. Whether the overall institutional 
configuration is more favorable to opponents or to incumbents largely depends on the degree of government involvement in a policy controversy. When government involvement is high, incumbents are likely to be at a disadvantage because they cannot keep out of heated blame game interactions with opponents. Conversely, when government involvement in a controversy is low, institutional factors combine to generate a relatively comfortable environment for incumbents.

The Swiss political system features blame games that are characterized by rather unaggressive interparty conflict that spares the politically responsible executive from a large share of the blame. This conflict form is significantly different from the government opposition conflict that characterizes parliamentary systems. Because opponents cannot usually bring incumbents to resign, they concentrate on achieving their policy goals and, for this purpose, attempt to forge 'pressure majorities' in parliament. A pressure majority consists of several parties that acknowledge the need for policy change in response to a controversy. Successfully forging a pressure majority greatly increases the likelihood that the collective executive government will act in the interest of opponents. Due to its collective and nonpartisan nature, the Swiss government is eager to signal its cooperation with as many parties as possible, thus making it very sensitive to the parliamentary majority's stance during a blame game. Interparty conflict creates a comfortable situation for political incumbents. They do not have to engage in intensive blame management and can assume a rather neutral role during a blame game, even in cases where the fault for a controversy clearly lay with the executive.

Overall, these findings shed light on an aspect of institutions that E. E. Schattschneider (1975) and Albert Hirschman (1994) emphasized long ago. Institutions determine the routinized ways in which democratic political systems manage, or 'digest', their policy conflicts. Examining how institutional factors influence blame game interactions amounts to exposing the institutionalized forms of conflict management that democratic political systems have developed to deal with policy controversies.

\section{Blame Games in Front of an Audience}

While institutional factors determine the broad contours of blame game interactions in a political system, each system leaves room for blame game actors to address controversy types in specific ways. The 
empirical analysis demonstrates how issue characteristics influence the content of blame game interactions. The salience of a controversy and its proximity to the wider public influence whether and how opponents can signal the severity of that controversy to the public and how they can put incumbents under pressure in order to meet their policy demands. Salience and proximity also influence how incumbents position themselves in the face of a controversy and largely account for the concrete strategy mix they employ to manage blame.

Opponents who generate blame for a distant-salient controversy use emotions to attract the public's attention and argue that political incumbents have a moral obligation to address the controversy. Accordingly, they often dismiss incumbents' responses to the controversy as morally inadequate. For incumbents, a distant-salient controversy is a prickly affair. They have to quickly position themselves toward a distant-salient controversy, assume a humble attitude that matches the dominant feeling in society, and adopt various ad hoc measures to demonstrate activism. While incumbents are afraid of reframing the controversy, they intensively engage in blame deflection.

Opponents that blame incumbents for a proximate-nonsalient controversy mainly rely on claims of personal relevance in order to attract the attention of the public and argue that incumbents have a 'debt obligation' to address the controversy. Incumbents who 'betrayed' the public are called on to pay back what they owe by meeting opponents' policy demands. Incumbents, in turn, have to admit the existence of a significant problem and express their willingness to address it. However, in doing so, they can afford to exhibit a confident stance. They defend their actions and strongly engage in reframing activities.

Opponents who blame incumbents for a distant-nonsalient controversy do not usually invest much in blame generation in the absence of factors that promise to damage incumbents' reputation, such as an incumbent's unusual personal involvement in a policy controversy. Distant-nonsalient controversies do not lend themselves to the leveraging of emotions or of personal relevance. Opponents therefore only accuse incumbents of doing a 'bad job' in some way. Incumbents, in turn, can address a distantnonsalient controversy in a very confident way. They intensively reframe opponents' attacks, often even contesting the existence of a problem, and do not usually issue substantive responses.

Overall, the case studies reveal that opponents and incumbents adopt specific behavioral patterns vis à vis different types of policy 
controversies. Opponents and incumbents are aware that they interact in front of an audience that is varyingly predisposed to pay attention to their interactions, and they actively work with issue characteristics to reach their goals. A thorough understanding of blame game interactions requires the consideration of the relationship between the audience and the actors playing the blame game.

\section{A Comprehensive View of Blame Games: How Democratic Political Systems Manage Their Policy Controversies}

The last part of the empirical analysis looks at how institutional factors and issue characteristics interact to produce reputational and/or policy consequences. Based on a typological theory of blame games and their consequences, I show that political systems do not just 'pass through' policy controversies (and the public feedback attached to them). Instead, system-specific blame game interactions give them a decisive twist. Depending on the configuration of institutional factors, blame game interactions stall public feedback, amplify it, or process it in a relatively unchanged manner. The UK political system even stalls strong public feedback because blame barriers significantly reduce incumbents' incentives to quickly and boldly address a policy controversy. Blame game interactions in the German political system can amplify even weak public feedback because institutional factors allow opponents to easily put incumbent politicians under pressure. This dynamic creates a strong executive focus during the blame game that forces incumbents to address a policy controversy. In the Swiss political system, the strength of public feedback and the extent of blame game consequences are comparatively the most in line because institutional factors prompt opponents to focus on creating a 'pressure majority', that is, a parliamentary majority that favors policy change, whose successful creation depends heavily on the strength of public feedback.

\section{The Explanatory Potential of the Framework}

The empirical analysis presented in this book shows that blame game interactions are highly responsive to the institutional terrain in which they take place and to the audience in front of which they occur. Due to the infinitely complex nature of political events like blame games, there can always be blame game interactions that diverge from these 
patterns and similarities in one way or another. Nevertheless, the framework developed in this book, together with the compound research design, allows me to derive robust and generalizable blame game styles. As the fifteen blame games demonstrate, these blame game styles apply to a wide variety of policy controversies that democratic political systems frequently confront. The political management of failed infrastructure projects, procurement or food scandals, security issues, or flawed policy reforms proceed in ways that are largely explicable by reference to institutional factors and issue characteristics. Given the many controversies that each political system (and the actors operating in it) must process year in and year out, one cannot expect that every controversy is uniquely confronted. And yet, it is pretty surprising that a handful of institutional factors and issue characteristics can account for the large contours of a wide variety of policy controversy-induced blame games and their consequences. The analysis shows that other controversy aspects that one could consider decisive, such as whether a blame game cross-cuts or aligns with electoral cleavages or whether or not it involves a vocal opponent at the local level, are of secondary importance when it comes to the processing of policy controversies during blame games.

Crucially, the theoretical framework can tell us why some policy controversies develop into 'high stakes' blame games while other controversies are followed by 'below the radar' blame games that are only noticed indifferently. This is a decisive contribution to the literature on policy failures, political scandals, and media 'feeding frenzies', which often overlooks the question of why a controversy develops into a fullblown scandal (e.g., Barker, 1994; Sabato, 2000) or struggles to capture complex scandalization processes (Allern \& von Sikorski, 2018). A comprehensive understanding of political conflict management requires considering instances of conflict management that proceed smoothly and those that are suppressed. The theoretical framework thus helps to make sense of a democratic conundrum: why venerable political scandals that attract strong attention from political actors, media, and the public do not necessarily produce significant consequences. The framework in this book replaces a simplistic view of the relationship between the level of public interest in a blame game and the extent of its consequences with a more accurate (and complex) picture of blame games and their consequences. 
A theoretical framework that explains the political processing of a wide variety of policy controversies can illuminate the important political decisions and policy developments that occur during this processing - decisions and developments that are likely to go by the board if one only looks at policy conflicts from a very high level of generality. Many of these decisions and developments have implications that go beyond the particular blame games that triggered them. First, the framework allows for the identification of the conditions under which governments can leave severe and long-lasting policy problems unaddressed without facing any consequences. If publics do not care too much about the policy problem, like in the Swiss EXPO case, or if incumbents are isolated from blame, like in the UK political system, incumbents can afford to look elsewhere.

Second, and related, the framework also helps one to grasp why governments can stick to a policy even though the latter frequently fails and wastes huge amounts of taxpayers' money. Despite obvious and persistent failure, UK governments could afford to put off comprehensively reforming the child support system. The UK blame game style identified in this book goes a long way to explaining the persistence of arguably one of the most long-lasting policy failures in the history of the UK. As the CSA case exemplifies, in situations where strong blame barriers comfortably protect incumbent politicians from blame and criticism, there are only weak incentives to get the policy back on track.

Third, the framework provides insights into how even policies that work well can become politicized and be portrayed as utter failures. The Swiss blame game about the treatment of the youth offender named 'Carlos' is a case in point. Opponents were able to portray the therapy setting of the youth offender as over-expensive and wrong even though it had worked well and policy experts widely agreed that the Swiss juvenile justice policy was very effective. Confronted with distant-salient policy controversies, political opponents and media actors often go haywire and make a problem much bigger than it is.

Fourth, the framework recognizes that blame that gets anchored in public memory can have an impact on subsequent policy struggles. Even though opponents in the German DRONE case were unable to bring the incumbent minister to resign or to thoroughly reform the procurement practice of the German military, the blame game about the failed drone procurement made his successor unequivocally position herself against 
procurement failures and initiate a long deferred reform process. By anchoring a policy problem in public memory, blame games can leave a long-term imprint on policy trajectories.

Finally, the framework provides insights into why political decisionmakers, out of fear from blame, become complacent and submissive actors. In the Swiss blame game about the adequate treatment of severe youth offenders, incumbents indicated that they felt unable to brace themselves against the frantic attacks from opponents and the biting media coverage even though there was no clear policy failure and the policy for which they were responsible was actually successful. The CARLOS case thus exemplifies how incumbents often seem unable or unwilling to find the courage to stand up for policies that they deem worthwhile during particularly heated blame games.

\section{Generalizing across Space and Time}

The theoretical framework developed and tested in this book is tailored to explaining blame games in response to policy controversies. Policy controversies are at the heart of political struggle in modern, policyheavy political systems. However, I claim that the framework can also help to understand other types of blame games and their consequences. As explained in Chapter 2, a wide variety of events can trigger political blame games, among them the personal wrongdoing of political actors, external threats, like natural catastrophes or foreign policy crises, and deliberate government decisions that impose losses on citizens. Institutional factors and issue characteristics should also help to explain the blame game interactions that follow in the wake of these controversial events. Like the blame game interactions that occur in response to policy controversies, blame games that occur in the aftermath of personal wrongdoing or external threats represent instances of political conflict management that occur in front of an audience. Nevertheless, I suspect that some tweaking and fine-tuning of the framework will be required to satisfactorily explain other types of blame games.

To account for blame game interactions in the wake of personal scandals, it is also important to consider the norms of political conduct that define blameworthy political behavior. These norms influence the amount of blame that opponents generate and predetermine the blame management approach that incumbents can pursue. With regard to 
external threats, such as foreign policy crises or natural catastrophes, salience and proximity could be less of an issue for incumbents than when they are confronted with a domestic policy controversy. Both foreign policy crises and natural catastrophes often produce a 'rallyround-the-flag' effect that temporarily mutes public blame (Boin et al., 2008). This provides incumbents with valuable time to address the external threat and publicly frame it according to their needs. Also, when it comes to blame games in the wake of a loss-imposing government decision, such as pension cuts, political incumbents dispose of more room to maneuver than when addressing an unanticipated policy controversy. In stark contrast to unexpected policy controversies, political incumbents can usually prepare for a blame game about a lossimposing decision by engaging in anticipatory forms of blame avoidance (Hinterleitner \& Sager, 2017). For example, governments can often time an unpopular decision to make sure that losses do not become a major issue during elections or simply disappear behind other attentionabsorbing events (Pal \& Weaver, 2003). Timing unpopular decisions, making hidden cuts, or spreading losses broadly are strategies incumbents can employ when they have to retrench the welfare state (Hinterleitner \& Sager, 2019; Wenzelburger, 2011; van Kersbergen \& Vis, 2015). These strategies illustrate that when it comes to the 'politics of pain', incumbents can usually rely on a larger spectrum of blamemanagement strategies than during blame games about unexpected policy controversies. Finally, there are blame game triggers whose public evaluation is particularly ambiguous. The blame games examined in this book were all triggered by events that were clearly controversial in one way or another. In cases where the actors playing the blame game fiercely disagree as to whether a controversial event is actually controversial, incumbents should often not only play defense, but they should also be able to attack political opponents for starting a fire where a cool head is needed. It is in these cases that political opponents can often switch from blame management to credit claiming (Leong \& Howlett, 2017). These reflections suggest that for the framework to be applicable to other types of blame games, additional contextual factors would have to be considered and the relative explanatory potential of institutional factors and issue characteristics would have to be reassessed.

It should also be possible to apply the framework in non-Western political settings, again with some tweaking and fine-tuning. For political blame games to develop at all, there needs to be an accountability 
regime in place that allows political opponents or societal actors to hold incumbents accountable and to assign blame for that purpose (Bovens, 2007; Olsen, 2015). Without such a regime, incumbents could simply ignore blame or suppress blame makers. However, intercultural differences also need to be considered. For instance, there are important intercultural differences between conventions of assuming or denying responsibility for political actions and policy controversies. While in South Korea or Japan public apologies and admissions of responsibility are prevalent, in many Western political systems, they are tactics of last resort that incumbents only employ after all other blame-management strategies have been exhausted (Hood et al., 2009). Intercultural differences of this kind are very likely to inject specific dynamics into blame game interactions.

Finally, there is the question of how stable the blame game styles identified in this book are over time. Although institutionalized forms of conflict management are unlikely to change overnight, there are several reasons to expect that they are not as stable as other types of institutions and institutionalized practices. An obvious reason for changing blame game styles are shifting party landscapes. Many parliamentary systems currently witness the emergence of new parties. As systems change from two major parties to several smaller ones, the typical coalition dynamics that characterize blame game interactions in a political system are likely to switch.

Another reason for instability over time is the erosion of democratic norms. As microcosms of conflictual politics, blame games contain political interactions that often go against democratic norms. At a more general level, many democracies are currently characterized by a normeroding politics. Extreme statements and actions that violate democratic norms, like respect for political opponents, acceptance of election outcomes, or restraint in the exercise of political power, have become widespread within a surprisingly short amount of time (Levitsky \& Ziblatt, 2018; Lieberman et al., 2019). Former US president Barack Obama captured these dynamics in a speech in South Africa: "We see the utter loss of shame among political leaders where they're caught in a lie and they just double down and they lie some more. It used to be that if you caught them lying, they'd be like, 'Oh, man' - now they just keep on lying." As democratic norms importantly influence the patterns and conventions of responsibility attribution and admission in a political system, changes in these norms are likely to affect blame game styles. 
A final possible reason for the instability of blame game styles over time is changing media systems. With the advent of social media has come the possibility that media systems fractionalize into filter bubbles and echo chambers. This would mean that blame games would no longer play out in front of one (major) audience but in front of multiple audiences that opponents and incumbents would have to address differently. Moreover, social media may help politicians to better sense the public's attitude toward a policy controversy, to predict its reaction, and to draft more effective blame-generation and blame-management strategies accordingly. One could also expect that the pervasion of social media could make blame game interactions 'faster', since traditional media outlets (as catalysts and transmitters) would be bypassed. Whether this is positive for incumbents (because specific blame games would become shorter and disappear from the news sooner) or negative (because blame game dynamics would become increasingly uncontrollable) is a question for future research. Overall, while certainly a fruitful exercise, there are reasons to be careful when applying the framework developed in this book to other types of blame games, political systems, and time periods.

\section{Avenues for Future Research on Blame Games}

The interesting and novel results obtained from the empirical analysis are a testament to the framework's significant explanatory potential. Nevertheless, it is not very surprising that three groups of institutional factors and two issue characteristics cannot fully account for every aspect of a complex blame game. Particularly when considering the amount of blame generation by opponents and the degree of activism by incumbents, I had to consider additional contextual factors. This suggests that one can achieve an even better understanding of blame games by painting a more detailed picture of the context in which blame game actors are positioned.

Another avenue to a deeper understanding of blame games would be to open up causal space for 'nonrational' behavior, that is, to also consider ideational and psychological explanations of opponent and incumbent behavior (Hay, 2011; Parsons, 2007). The framework developed in this book does not consider nonrational behavior because it is based on a structural and an institutional logic (Parsons, 2007). First, it treats institutions as fixed structures that make opponents and 
incumbents act in certain ways by influencing the incentives and expected pay-offs of particular blame-generation and blamemanagement strategies (the structural logic). Second, the framework treats issue characteristics as 'institutions' with which actors work to reach their goals during blame games (the institutional logic). As explained in Chapter 2, treating issue characteristics as institutions highlights the fact that blame game actors can manipulate issue characteristics to a certain degree during blame games. Political institutions, on the other hand, are treated as unalterable structures that actors must take as given during a blame game. Conceiving the influence of institutional factors and issue characteristics in this way implies objective rationality on the part of opponents and incumbents since they are expected to react "regularly and reasonably to external constraints" (Parsons, 2007, p. 13). Treating political elites as rational decisionmakers is reasonable because it allows for relatively parsimonious explanations of their actions.

Nevertheless, although there is research arguing that political elites are comparatively more rational than ordinary people since they base their decisions on abundant experience (Hafner-Burton et al., 2013), politicians also suffer from decision-making biases. Considering these biases in the study of blame games could allow one to craft more realistic explanations of specific blame-generation and blamemanagement approaches. This would require 'operationalizing' the decision-making biases exposed by researchers (Linde \& Vis, 2017; Sheffer \& Loewen, 2019; Sheffer et al., 2018) in the context of blame game interactions. For example, one could expect that incumbents' overconfident attitude during a blame game that currently attracts only weak public feedback is not due to their rational assessment of the level of current feedback but can be explained by incumbents' underestimation of the possibility that the blame game could develop into a full-blown and dangerous scandal. In the following, I briefly discuss three (groups of) factors that could be considered in future research on blame games.

\section{Incumbents' Decision to Engage}

The case studies reveal that the proximity of a controversy to incumbents is an important explanatory factor of blame game interactions. In the case of their direct involvement, incumbents are likely to receive more blame from opponents since the latter can more easily tie the controversy 
to incumbents and turn it into a personal scandal. Therefore, it would be rational for incumbents to identify potentially controversial policies in advance and keep as much distance from them as possible (Hinterleitner \& Sager, 2017; Leong \& Howlett, 2017). This should even apply to policies that promise to allow for credit claiming, as incumbents are loss averse and therefore prefer avoiding blame over claiming credit (Weaver, 1986). Contrary to these expectations, the cases clearly show that there are instances in which incumbents deliberately choose to engage with potentially controversial policies. This 'nonrational' behavior may be due to miscalculations of the reputational risks attached to a policy, to a decision calculus in which credit claiming trumps blame avoidance, or to a strong 'ideational' attachment to a policy that induces incumbents to consciously put their reputation at risk. Future research should thus address the question of why and under which conditions political decision-makers opt to associate with a potentially risky policy issue or decide to stay away from it.

\section{Resources Such as Intelligence, Argumentative Skills, or Popularity} In the case studies, I do not analyze the resources available to the actors playing the respective blame games. An important such resource is a political incumbent's popularity when entering a blame game. While the BER case suggests that even a popular politician can get worn down by an intricate policy problem, I did not consider his popularity as an asset that influenced how successfully he managed blame, and how long he could withstand the attacks of his opponents. Popularity among constituents could be conceived as a blame shield that allows incumbents to withstand blame attacks for longer. Considering assets such as popularity, intelligence, or argumentative skills could lead to a better understanding of why some blame-generation or blame-management approaches are more successful than others (Boin et al., 2010; Hinterleitner \& Sager, 2017). Moreover, they could account for slight differences in blame generation or blame management within the same institutional and issue context. Opponents that exhibit plenty of these resources should be able to more quickly grasp the blame-generating potential of a controversy or more effectively exhaust the feedback potential of a controversy. Incumbents who can draw on these resources can be expected to be better able to credibly manage blame and select the blame-management approach that fits best with regard to a particular controversy. 


\section{Ideas about Policies and Norms of Decency}

Another group of explanatory factors are the ideas that actors may hold about particular policies and the norms that may bind them when engaging in blame game interactions. On the one hand, opponents who have an ideational attachment to a policy may increase blame generation beyond the level warranted by issue characteristics. In the SOLYNDRA case, for example, ideational attachment to free markets could account for the Republicans' ongoing attacks of Obama's green energy program, even though the bankruptcy of the solar company clearly constituted a distant-nonsalient controversy. On the other hand, incumbents ideationally attached to a policy may choose to fervently defend it even though this might be foolish from a reputational point of view. Moreover, norms of decency may prevent opponents from too heavily exploiting a severe controversy for reputational or policy purposes. For instance, norms of decency might provide an additional explanation (next to the federal government's low involvement in the controversy) of opponents' relative restraint in exploiting the distantsalient NSU controversy for their political purposes.

However, there are also reasons to expect that norms and ideas are often subordinate to material considerations when it comes to explaining heated blame game interactions. In situations where actors face blame, they frequently prioritize material interests over ideational motives, as "blame avoiding behavior in situations that mandate such behavior is a precondition for pursuing other policy motivations in situations that do not compel that behavior" (Weaver, 1986, pp. 377-378). Overall, I claim that the theoretical framework introduced in this book goes a long way to comprehensively account for blame game interactions and their consequences. At the cost of analytical parsimony, accounts of blame game interactions can of course be further refined by considering both additional contextual factors and psychological and ideational explanations.

\subsection{The Study of Blame Games and Its Wider Implications}

Blame games are important political events because they are one of the primary ways through which democratic political systems manage their policy controversies. And yet, the study of blame games does more than inform readers about how democracies come to terms with their policy problems. As microcosms of conflictual politics, the study of blame 
games yields valuable insights that help us make sense of the more conflictual style of politics that modern democratic political systems currently experience on a wider scale.

As the empirical analysis makes clear, political interactions are very conflictual when political systems address their policy controversies during blame games. Political actors frequently attack their opponents, portray them as incompetent or guilty, exaggerate a controversy, and adopt an uncompromising stance. During blame games, political actors often bend the norms of democratic conduct. Recent political developments, from Trumpism in the USA, to Brexit-politics in the UK, to extremist right parties and populist movements all over Europe, suggest that conflictual politics are no longer an exception but tend to become the rule. Phenomena such as polarization, populism, blame generation, negative messaging, or attack politics are all manifestations of a widespread tendency toward intensified and more conflictual interactions between political actors (e.g., Hetherington, 2009; Hinterleitner, 2018; Mudde \& Rovira Kaltwasser, 2013; Nai \& Walter, 2015; Tushnet, 2003; Weaver, 2013, 2018).

In times when problems are often complex (Adam et al., 2019) and public budgets are in dire straits (Blyth, 2013), it is not very surprising that political actors struggle to satisfy public demands and, therefore, fight harder over available resources. If political conflicts are less and less characterized by positive-sum relationships, one man's gain becomes another man's loss. Despite these more difficult circumstances, there is no reason to expect that citizens will demand less from their leaders (Flinders, 2014). Politics still is, and will remain in the near future, a means of problem solving on citizens' behalf. As long as there are problems, citizens want their leaders to address them. But demanding citizens that cannot be pleased all the time tend to become dissatisfied with their leaders. This increases the incentives for political actors to play hardball and engage in a discourse that channels citizens' dissatisfactions. In short, the rise of conflictual politics is the result of political, economic, and societal circumstances that put political actors under pressure and accordingly prompt them to adopt different means to win votes and gain control over policies - means that are less promotive of political compromise and deal making.

It is surely tempting to assert that more conflictual politics has always been with us and that conflictual politics is nothing unusual (see Shea \& Sproveri, 2012). Just as a football match in which players foul all the 
time is still a football match, conflictual politics may still just be politics. However, the sheer scale of conflictual politics in Western democracies in recent years suggests otherwise. Moreover, by taking the long view, one comes to appreciate that democratic political systems, slowly but steadily, seem to use up the 'surplus of consensus' that characterized their trajectories during the decades that followed World War II. Earlier work, especially by Otto Kirchheimer (1957) and Robert Dahl (1965), shows that, back in the 1950s and 1960s, students of politics were aware of the fact that the postwar era had heralded a politics that was markedly different from earlier times. The time during which most of our (still dominant) theories of politics emerged was characterized by a "growing extent of agreement among political actors" on both policy and system issues (Mair, 2007, p. 6). Newly appreciating the exceptionality of this 'surplus of consensus' makes us aware of the fact that there is not just one invariant type of politics but that politics comes in different variants; some of them more conflictual than others. I claim that blame games help to make sense of the more conflictual variant. In the remaining pages of this book, I elaborate on what blame games suggest about politics and democracy under pressure.

\section{Blame Games and Their Implications for Politics under Pressure}

Political science, by and large, is not attuned to the thought that political systems work under varying degrees of conflict or that their politics heat up or cool down in response to the challenges they face. Political science usually conceives of political systems and their workings in a more static way, or conceptualizes them with regard to an important function. Bryan D. Jones and Frank Baumgartner's (2007) conceptualization of political systems as information management systems is a case in point. Most contemporary political science work, just like the diverse literature on problem processing (e.g., Hoppe, 2011; Richardson, 2014), adopts a static perspective on how political systems manage their controversies and address their conflicts. Since there is no explicit distinction between more and less conflictual politics in this research, there is the temptation to rely on a form of subliminal 'concept stretching', that is, the assumption that conflictual politics are not much different from normal politics and that our approaches for explaining the latter also work in case of the former. 
This book shows that this assumption would be wrong: Conflictual forms of politics require distinct explanatory approaches. The theoretical framework developed and tested in this book contains explanatory factors that are not congruent with those commonly used to analyze political systems and their politics and policymaking styles, and the combinations in which these factors occur across political systems do not fit neatly into established categorizations (e.g., Lijphart, 2012). I argue that the factors known to structure normal politics, like the traditions of negotiated decision-making in Germany or the centralization of the UK system, do not necessarily help to make sense of conflictual politics; or they play a different role for conflictual politics. For example, the counterintuitive finding that blame games in the UK are less aggressive and consequential than those in Germany is at odds with conventional wisdom on the UK's venerable conflict culture and on the German system's consensual underpinnings. The blame game styles of these countries do not fit into existing categorizations. Likewise, while the formation of coalitions and majorities is important for both normal and conflictual politics, during the latter, small parties often assume a more important role than their size alone would suggest. The empirical analysis showed that smaller parties often manage to punch above their weight during blame games due to the media's interest in poignant statements. Again, conventional knowledge about normal politics cannot account for this aspect of (conflictual) blame game interactions.

Next to reconsidering and rearranging existing categorizations, it will also be necessary to consider additional factors in the study of conflictual politics. For instance, future research needs to more closely examine the characteristics of democracies that influence the distribution and attribution of responsibility, both within a political system as a whole and within particular policy areas. As an important part of the institutional terrain, policies decisively influence who can be held responsible and who can be forced to act. For example, controversies that occur in a policy area that has experienced widespread agencification reforms are processed differently than controversies that occur in a policy area where governments are more directly involved. When it comes to the study of more conflictual politics, one is well advised to recall E. E. Schattschneider's famous quote that "[n]ew policies create a new politics" (1935, p. 288). Some policy arrangements are more conducive to creating conflictual politics than others. 
A second crucial implication for politics under pressure, which follows from the study of blame games, is an updated understanding of political elites and the goals for which they strive. In order to capture what political elites are really up to under conflictual conditions, we must simultaneously consider them as vote seekers and as policy seekers. As policy has become the main instrument through which the state governs, political conflicts increasingly revolve around policy (Orren \& Skowronek, 2017; Pierson, 2007b). Policy thereby automatically assumes greater importance in the decision-making of political elites. As Jacob Hacker and Paul Pierson put it (2014), in a conflictual democracy, gaining the 'prize of policy' is tantamount to gaining power. The greater importance of policy by no means implies that vote and reputation seeking become unimportant for political elites. In more conflictual times, a positive reputation constitutes an important blame shield for politicians (Hinterleitner \& Sager, 2018). However, the blame games studied in this book suggest that the goals actors decide to pursue during policy conflicts are controversy-specific and influenced by the shape of the political system. Sometimes, reputational goals are within reach and thus pursued, sometimes policy goals are more important.

This is a crucial insight that remains overlooked by the wide and diverse literature on elite decision-making, which, for the most part, conceives political elites as reputation-conscious, vote-seeking political actors (Busuioc \& Lodge, 2016). While this literature successfully uses behavioral insights to enrich our understanding of the processes through which political elites reach their decisions (Hafner-Burton et al., 2013, 2017; Linde \& Vis, 2017; Vis, 2011), it has yet to broaden its focus with regard to the substantive goals that political elites pursue, that is, whether they pursue reputational and/or policy goals in a particular situation. Developing insights about the conditions under which political elites seek reputational and/or policy goals is imperative for understanding more conflictual political interaction.

An updated understanding of political elites' strategic behavior under pressure also serves a normative purpose. Unlike Bertold Brecht suggests in his play, Life of Galileo, it is not only difficult for "peoples to calculate the moves of their rulers": Evaluating them is also difficult. In times of heightened political conflict, however, critical evaluations are essential. Political elites play a crucial role in the erosion of democratic norms and in the exacerbation of democratic disaffection (Boswell et al., 2018; 
Levitsky \& Ziblatt, 2018). They can give in to populist temptations, for example, by inflating an issue, by calling for the resignation of an opponent (even in a situation where this is utterly excessive), by riding out an issue, or by brushing aside problem-oriented questions. In many situations, however, political elites can also resist doing so.

The study of blame games helps us to make realistic and fair evaluations about the actions of political elites by zooming in on the institutional and issue context in which they have to operate. The study of blame games allows us to assess political elites' room to maneuver in a controversial situation, the goals they pursue, and the strategies they employ. Answers to these questions are important preconditions for understanding and evaluating elite behavior. In times of widespread antiestablishment feelings and politics, context-sensitive assessments of elites' room to maneuver are essential for creating realistic expectations of them. By systematically considering what elites can do in particular contexts, we can come to normative judgments about good or bad elite behavior that "deal in facts" (Gerring \& Yesnowitz, 2006, p. 108). Basing our evaluations of elite behavior on a realistic assessment of context is an interesting opportunity for connecting the 'positive' study of blame games with normatively valued issues.

\section{Blame Games and Their Implications for Democracy under Pressure}

Just as we need an updated understanding of what occurs in the political sphere under more conflictual conditions, we need to reconsider the role of citizens in a conflictual democracy. Traditional political science scholarship usually equates the 'citizen' with the 'voter'. Assessing the influence of citizens on politics and policy in representative democracies usually amounts to examining vote choice. What David Mayhew (1974) termed the 'electoral connection' is the primary transmission mechanism through which citizens communicate with the political sphere. This book shows that citizens not only exert causal influence on politics and policy in their role as voters but also in their role as spectators of policy conflicts. The way citizens watch a blame game has an important influence on its consequences. Blame games thereby act as another transmission mechanism between citizens and politics. Citizen preferences in the form of public feedback to a controversy are processed by the political system by means of blame 
game interactions and lead to consequences that are more or less in line with citizen preferences. As we have seen, a lot of communication and information exchange between citizens and the political sphere occurs during blame games. On the one hand, blame games are testing grounds for political elites to discover whether and how much the public cares about particular parts of the policy infrastructure. On the other hand, blame games are opportunities for citizens to learn and form an opinion about a particular policy issue. Whether to invest in unmanned warfare, how to treat youth offenders, or whether to propel industrial change through governmental intervention are only some of the policy issues that citizens are confronted with in their role as spectators of blame games. While the blame game mechanism may interrelate with elections, it is nevertheless distinct. A policy controversy can develop into a blame game that alters the policy infrastructure without ever being treated in elections. Moreover, voters and spectators of policy conflicts do not necessarily overlap. Citizens, in their role as spectators of policy conflicts, may generate a specific mood that affects subsequent elections, but they may still decide not to take part in them.

A crucial insight here is that there are varieties of blame game transmission mechanisms across democratic political systems. As my typological theory of blame games and their consequences shows, political systems do not just 'pass through' public feedback, but they amplify, weaken, or altogether stall it during a blame game. While this book only analyzes three political systems in detail, the insights gained from their comparison are sufficient to conclude that some political systems are more responsive to citizen preferences during blame games than others. My analysis suggests that the UK political system exhibits a blame game mechanism that is much less responsive to the demands of citizens than the blame game mechanisms of the German and Swiss political systems. These insights call for more research on varieties of blame game transmission mechanisms.

If one accepts the finding that blame games are an additional transmission mechanism that connects citizens with politics and policy, then we must broaden our view of how democracies secure, or fail to secure, responsiveness to citizen preferences. Democratic responsiveness, in the words of G. Bingham Powell (2004, p. 91), is "what occurs when the democratic process induces the government to form and implement policies that the citizens want." In examining the connections between 
citizen preferences and policy outcomes, the existing literature on the topic has not yet looked at the blame game channel but almost entirely focuses on elections (e.g., Hobolt \& Klemmensen, 2007; Kang \& Powell, 2010; Powell, 2011; Wlezien \& Soroka, 2012). A reassessment of democratic responsiveness under more conflictual conditions must incorporate the insight that citizens, confronted with the overcrowded, controversy-laden political agendas of their political systems, do not only express their preferences as voters, but also through their role as spectators of blame games. This reassessment also provides us with a broader basis on which to assess the health of democracies. For Albert Hirschman (1994), it was vital to understand institutionalized forms of conflict management, as they are constitutive for the survival of democracies. A democracy that does not properly manage its conflicts risks being poisoned by them. This book shows that political conflict management not only occurs on a regular basis when citizens come to the ballot box but also when citizens watch seemingly routine and minor political quarrels, like the one about the chaotic launch of the healthcare .gov website or that about the Swiss 'lobbying affair'. 


\section{Appendix}

\section{The Institutional Terrain in the Analyzed Political Systems}

The institutional factors outlined in Chapter 2 vary considerably across the UK, German, Swiss, and US political systems (see Table A1 for an overview). The different shapes and combinations of institutional factors across these systems should produce major differences in blame game interactions and, therefore, constitute ideal institutional settings for examining and comparing how democracies manage policy controversies. The UK system features a relatively consolidated opposition consisting of a maximum of two parties, a quite critical governing majority, in which 'backbenchers' frequently voice criticism against the government, restricted conventions of resignation for ministers, and generally low direct government involvement in policy issues. In the UK, blame generation by opponents should mainly focus on administrative actors and entities because ministers are hard to get hold of. Incumbents, in turn, should not have much of a problem with critical backbenchers because the overall blame directed at them should be low and because they should possess ample blamedeflection possibilities in policy sectors with low direct government involvement. Germany exhibits a fragmented opposition, a loyal governing majority, relatively extensive conventions of resignation, and generally high direct government involvement. In Germany, opponents, while being less consolidated than their UK peers, are likely to focus their blame-generation efforts on incumbent ministers. Although incumbents receive support from a loyal governing majority, they should have greater difficulty defending themselves during a blame game due to extensive resignation conventions and generally high direct government involvement. Switzerland has a consensus government that represents (almost) all parties. During a blame game, some of these parties constitute a fragmented and 
Table A1 Institutional factors and their shape across political systems

\begin{tabular}{|c|c|c|c|}
\hline & Political interaction structure & Institutionalized accountability structures & Institutional policy characteristics \\
\hline & $\begin{array}{l}\text { Organization of opposition; } \\
\text { stance of governing majority }\end{array}$ & Conventions of resignation & Direct government involvement* \\
\hline UK & $\begin{array}{l}\text { Relatively consolidated } \\
\text { opposition (max. two } \\
\text { parties); critical/passive } \\
\text { governing majority }\end{array}$ & $\begin{array}{l}\text { Ministerial responsibility: ministers } \\
\text { responsible for department but resignation } \\
\text { only in case of personal fault } \rightarrow \text { very } \\
\text { restrictive conventions of resignation }\end{array}$ & $\begin{array}{l}\text { Low government involvement } \\
\text { (due to widespread } \\
\text { agencification) }\end{array}$ \\
\hline Germany & $\begin{array}{l}\text { Fragmented opposition; loyal } \\
\text { governing majority }\end{array}$ & $\begin{array}{l}\text { Departmental principle: ministers are only } \\
\text { accountable to chancellor, not to } \\
\text { parliament } \rightarrow \text { extensive conventions of } \\
\text { resignation }\end{array}$ & $\begin{array}{l}\text { High government involvement } \\
\text { (due to limited agencification) }\end{array}$ \\
\hline Switzerland & $\begin{array}{l}\text { Issue-specific, very fragmented } \\
\text { opposition; issue-specific, } \\
\text { relatively loyal majority (due } \\
\text { to consensus government) }\end{array}$ & $\begin{array}{l}\text { Departmental principle: councilors responsible } \\
\text { for preparation and implementation of } \\
\text { collectively made decisions } \rightarrow \text { almost absent } \\
\text { conventions of resignation }\end{array}$ & $\begin{array}{l}\text { High government involvement } \\
\text { (due to limited agencification) }\end{array}$ \\
\hline USA & $\begin{array}{l}\text { Consolidated opposition (one } \\
\text { party); critical/passive } \\
\text { governing majority (due to low } \\
\text { party discipline and the } \\
\text { possibility of divided } \\
\text { government) }\end{array}$ & $\begin{array}{l}\text { Secretaries serve at the pleasure of the president } \\
\rightarrow \text { conventions of resignation generally } \\
\text { rather extensive, but ultimately dependent } \\
\text { on leadership style of the president }\end{array}$ & $\begin{array}{l}\text { Low government involvement } \\
\text { (due to widespread } \\
\text { agencification) }\end{array}$ \\
\hline
\end{tabular}

Note: Direct government involvement is, strictly speaking, a policy-specific characteristic. Therefore, at the system level, only tendencies regarding the value of this factor can be formulated. Accordingly, the government's direct involvement should be less pronounced in the UK and the USA since these countries have embarked on agencification reforms more heavily than countries like Germany or Switzerland (Verhoest et al., 2012). 
Table A2 Keywords used to identify relevant media coverage

\begin{tabular}{ll} 
Case & Keywords \\
\hline CSA & Child Support Agency; CSA \\
METRONET & $\begin{array}{c}\text { Metronet; tube lines; PFI } \\
\text { DOME }\end{array}$ \\
NSU & Nillennium Dome; the dome; millennium exhibition \\
& $\quad$ sozialistischer Untergrund \\
BER & BER; Flughafen Berlin Brandenburg; BBI (Berlin \\
& $\quad$ Brandenburg International) \\
DRONE & Euro Hawk; Euro-Hawk; Drohnenaffäre \\
CARLOS & Carlos \\
TAX & Unternehmenssteuerreform \\
EXPO & Expo.01; Expo.02; Expo 01; Expo 02; Landesausstellung \\
HCT & Mid Staffs; Mid Staffordshire NHS; David Nicholson \\
NITROFEN & Nitrofen \\
MOB & Marsch auf Bern; Ausschreitungen; Krawalle \\
VHA & veterans affairs, veterans scandal \\
FLU & vaccine; flu \\
SOLYNDRA & Solyndra
\end{tabular}

issue-specific opposition, while the other parties act as an issuespecific, relatively loyal parliamentary 'majority'. The Swiss parliament cannot bring federal councilors to resign outside of regular elections, and there is high direct government involvement in many policy sectors. In this institutional setting, opponents are unlikely to act cohesively and should not blame individual councilors. Incumbents, in response, are likely to have little difficulty staying out of a blame game. Finally, the US system features a consolidated opposition consisting of one party, a rather passive governing majority, rather extensive resignation conventions for secretaries, however this ultimately depends on the leadership style of the president, and generally low direct government involvement in many policy sectors. 


\section{Public Feedback and Blame Game Consequences}

Table A3 Overview of public feedback intensity in the in-depth cases

\begin{tabular}{|c|c|c|c|c|}
\hline & $\begin{array}{l}\text { Intensity of } \\
\text { coverage }\end{array}$ & Tone of coverage & Peculiarities & $\begin{array}{l}\text { Feedback } \\
\text { intensity }\end{array}$ \\
\hline CSA & $\begin{array}{l}\text { Intensive coverage } \\
\text { across the } \\
\text { board (coverage } \\
\text { constantly } \\
\text { increases until } \\
\text { 2006) }\end{array}$ & $\begin{array}{l}\text { Widespread emotional coverage that } \\
\text { concentrates on shocking examples (the } \\
\text { controversy is frequently referred to as } \\
\text { the 'Child Shambles Agency'; } \\
\text { a 'national tragedy', or an 'unmitigated } \\
\text { nightmare'), although there is problem- } \\
\text { centered coverage in quality outlets }\end{array}$ & & Strong \\
\hline METRONET & $\begin{array}{l}\text { Consistent } \\
\text { coverage in } \\
\text { quality outlets } \\
\text { and almost no } \\
\text { coverage in } \\
\text { tabloids }\end{array}$ & $\begin{array}{l}\text { Quality coverage is mainly problem- } \\
\text { centered (illuminating the opaque and } \\
\text { complex nature of the controversy), } \\
\text { although quality outlets also tie the } \\
\text { controversy to Brown and cover the } \\
\text { issue within the larger problem-context } \\
\text { of public-private partnerships }\end{array}$ & $\begin{array}{l}\text { Polls show that the controversy has } \\
\text { no negative effect on Brown's } \\
\text { approval ratings }\end{array}$ & Weak \\
\hline DOME & $\begin{array}{l}\text { Intensive } \\
\text { coverage, even } \\
\text { in tabloids }\end{array}$ & Agitated, inflated coverage & $\begin{array}{l}\text { Three reasons suggest that media } \\
\text { coverage overestimates public } \\
\text { feedback: (1) quite a large share of } \\
\text { the coverage deals with artistic } \\
\text { aspects and not so much with the } \\
\text { controversy (this can also be }\end{array}$ & Weak \\
\hline
\end{tabular}


Table A3 (cont.)

\begin{tabular}{|c|c|c|c|c|}
\hline & $\begin{array}{l}\text { Intensity of } \\
\text { coverage }\end{array}$ & Tone of coverage & Peculiarities & $\begin{array}{l}\text { Feedback } \\
\text { intensity }\end{array}$ \\
\hline & & & $\begin{array}{l}\text { gleaned from the high media } \\
\text { interest prior to the controversy); } \\
\text { (2) polls suggest that the media is } \\
\text { much more critical toward the } \\
\text { Dome than the general public; (3) } \\
\text { the media treats the Dome as } \\
\text { a symbolic issue that allows for } \\
\text { the discussion of the New Labour } \\
\text { phenomenon }\end{array}$ & \\
\hline NSU & $\begin{array}{l}\text { Intensive coverage } \\
\text { across the board } \\
\text { of this } \\
\text { unprecedented } \\
\text { and delicate } \\
\text { investigation } \\
\text { failure (given } \\
\text { Germany's } \\
\text { history) }\end{array}$ & $\begin{array}{l}\text { Very emotionalized and scandalized } \\
\text { coverage, even in quality outlets, } \\
\text { however, also problem-centered } \\
\text { coverage in quality outlets of single } \\
\text { slip-ups and placement of the } \\
\text { controversy in a larger problem- } \\
\text { context (racism, antisemitism, right- } \\
\text { wing terrorism) }\end{array}$ & & Strong \\
\hline BER & $\begin{array}{l}\text { Consistent } \\
\text { coverage in } \\
\text { quality outlets, } \\
\text { but also }\end{array}$ & $\begin{array}{l}\text { Mainly problem-centered coverage in } \\
\text { quality outlets (detailed reconstruction } \\
\text { of problems, discussion of } \\
\text { consequences for passengers, }\end{array}$ & & Weak \\
\hline
\end{tabular}


significant

coverage in

tabloids

DRONE Quite intensive coverage, but mainly in

quality outlets companies, etc.); only later is there more person-centered and cynical coverage (due to strong exposure of Wowereit); the local tabloid is only different in that it focuses more on Wowereit and frequently appeals to incumbents

Coverage at times scandalizing
Three reasons suggest that media coverage overestimates public feedback: (1) most of the coverage relates to the minister's personal involvement (did he lie?; what did he know?), while the actual controversy fades into the background; (2) due to upcoming elections, opponents invest more in blame generation than expected (and this is taken up by quality outlets); (3) polls show that the public never shows great interest in the controversy: While the minister's popularity temporarily suffers, there is never a majority that wants him to resign (even journalists acknowledge that this controversy is not very interesting for the wider public) 
Table A3 (cont.)

\begin{tabular}{|c|c|c|c|c|}
\hline & $\begin{array}{l}\text { Intensity of } \\
\text { coverage }\end{array}$ & Tone of coverage & Peculiarities & $\begin{array}{l}\text { Feedback } \\
\text { intensity }\end{array}$ \\
\hline CARLOS & $\begin{array}{l}\text { Intensive } \\
\text { coverage across } \\
\text { the board }\end{array}$ & $\begin{array}{l}\text { Scandalizing and emotional coverage } \\
\text { including reports on many delicate } \\
\text { details about the therapy setting }\end{array}$ & $\begin{array}{l}\text { Other evidence for strong mass } \\
\text { feedback: Furious social media } \\
\text { comments, The Blick's 'most read' } \\
\text { rankings, and journalists' own } \\
\text { reporting about heavy public } \\
\text { feedback to their coverage }\end{array}$ & Strong \\
\hline TAX & $\begin{array}{l}\text { Consistent } \\
\text { coverage in } \\
\text { quality outlets } \\
\text { and only } \\
\text { limited tabloid } \\
\text { coverage }\end{array}$ & $\begin{array}{l}\text { Mainly problem-centered and } \\
\text { equilibrated coverage in quality outlets } \\
\text { (numerical examples to explain } \\
\text { complex controversy), but more } \\
\text { 'biting' coverage can also be found }\end{array}$ & & Weak \\
\hline EXPO & $\begin{array}{l}\text { Not much } \\
\text { controversy- } \\
\text { related } \\
\text { coverage }\end{array}$ & $\begin{array}{l}\text { Very problem-centered; throughout the } \\
\text { controversy, media (also tabloids) } \\
\text { exhibit a positive stance toward the } \\
\text { project despite recurring cost overruns }\end{array}$ & $\begin{array}{l}\text { A poll reveals that the wider public } \\
\text { does not attach too much } \\
\text { importance to the cost increases }\end{array}$ & Weak \\
\hline
\end{tabular}


Table A4 Overview of blame game consequences in the in-depth cases

\begin{tabular}{|c|c|c|c|c|}
\hline & Reputational consequences & Policy consequences & Peculiarities & $\begin{array}{l}\text { Extent of overall } \\
\text { consequences }\end{array}$ \\
\hline CSA & Only public managers resign & $\begin{array}{l}\text { No bold policy change, only } \\
\text { patch-ups }\end{array}$ & & Limited \\
\hline METRONET & $\begin{array}{l}\text { No reputational } \\
\text { consequences; not even } \\
\text { politicians within the } \\
\text { transport department come } \\
\text { under pressure; no negative } \\
\text { effect on Prime Minister } \\
\text { Brown's approval ratings } \\
\text { (despite exposure as } \\
\text { 'architect' of PPPs) }\end{array}$ & $\begin{array}{l}\text { Minor changes voluntarily } \\
\text { implemented by the } \\
\text { Department of Transport } \\
\text { (following some } \\
\text { commission } \\
\text { recommendations), but no } \\
\text { major policy change as the } \\
\text { Labour government presses } \\
\text { on to use PPPs }\end{array}$ & $\begin{array}{l}\text { The 'nationalization' of } \\
\text { Metronet and Tube Lines } \\
\text { does not contradict this } \\
\text { finding, since there is } \\
\text { ample evidence that the } \\
\text { government would have } \\
\text { stuck to the private } \\
\text { solution had they found } \\
\text { a bidder for the } \\
\text { partnerships }\end{array}$ & Limited \\
\hline DOME & $\begin{array}{l}\text { No consequences for } \\
\text { politicians (Falconer's } \\
\text { career continued } \\
\text { unscathed), only public } \\
\text { managers resign (but not } \\
\text { framed as form of blame } \\
\text { deflection); although media } \\
\text { outlets and opponents do }\end{array}$ & $\begin{array}{l}\text { Government pulls through } \\
\text { instead of prematurely } \\
\text { closing the Dome }\end{array}$ & & Limited \\
\hline
\end{tabular}


Table A4 (cont.)

\begin{tabular}{|c|c|c|c|c|}
\hline & Reputational consequences & Policy consequences & Peculiarities & $\begin{array}{l}\text { Extent of overall } \\
\text { consequences }\end{array}$ \\
\hline & $\begin{array}{l}\text { their best to tarnish the } \\
\text { Labour government's image } \\
\text { by connecting it to the } \\
\text { Dome, it suffers no losses in } \\
\text { the upcoming } 2001 \text { general } \\
\text { elections }\end{array}$ & & & \\
\hline NSU & $\begin{array}{l}\text { Five presidents of federal or } \\
\text { national intelligence } \\
\text { services resign or are fired; } \\
\text { politicians - both at the } \\
\text { state and federal level - do } \\
\text { not resign }\end{array}$ & $\begin{array}{l}\text { Extensive reform of } \\
\text { information exchange } \\
\text { between federal- and state- } \\
\text { level administrative entities; } \\
\text { anti-terror database; } \\
\text { reorganization of the } \\
\text { Bundesamt für } \\
\text { Verfassungsschutz }\end{array}$ & $\begin{array}{l}\text { The fact that politicians do } \\
\text { not resign is due to the very } \\
\text { strong 'administrative } \\
\text { focus' of the blame game } \\
\text { (and thus an effect of } \\
\text { institutional factors) }\end{array}$ & Extensive \\
\hline BER & $\begin{array}{l}\text { Several public managers have } \\
\text { to resign; Wowereit semi- } \\
\text { voluntarily steps down (it is } \\
\text { unlikely that he could have } \\
\text { stayed in office for much } \\
\text { longer) }\end{array}$ & $\begin{array}{l}\text { No bold policy change (in the } \\
\text { form of far-reaching } \\
\text { adaptations to the } \\
\text { implementation structure or } \\
\text { the termination of the } \\
\text { project) }\end{array}$ & $\begin{array}{l}\text { The idiosyncratic nature of } \\
\text { the policy problem made it } \\
\text { difficult for incumbents to } \\
\text { do more to boldly address } \\
\text { the problem; when the } \\
\text { blame game started, it was } \\
\text { already too late for } \\
\text { incumbents to adapt or } \\
\text { terminate the project; }\end{array}$ & Extensive \\
\hline
\end{tabular}


three reasons suggest that the blame game caused extensive consequences: (1) several public managers had to resign; (2) controversy ultimately cost the mayor his political career; (3) evidence suggests that incumbents did everything in their power to open the airport as soon as possible

Extensive minister's reputation

Activism by the minister and measures adopted by his temporarily suffers in the successor lead to significant polls)

\section{CARLOS Youth advocate resigns,} incumbent councilor voted out of office (cantonal peculiarity)

changes in the procurement system (controlling and report system; transparency initiative); a considerable anchoring effect is observable

Organizational adaptations; cost control measures; changes to policy practice (due to a strong anchoring effect) 
Table A4 (cont.)

\begin{tabular}{|c|c|c|c|}
\hline & Reputational consequences & Policy consequences & $\begin{array}{l}\text { Extent of overall } \\
\text { consequences }\end{array}$ \\
\hline TAX & $\begin{array}{l}\text { No reputational consequences } \\
\text { (resignations at the federal } \\
\text { level in Switzerland are very } \\
\text { unlikely) }\end{array}$ & $\begin{array}{l}\text { Despite no immediate policy } \\
\text { change, a strong anchoring } \\
\text { effect is observable } \\
\text { (concessions to the left to } \\
\text { avoid referendum; left } \\
\text { profits from conflict } \\
\text { anchoring in the next round } \\
\text { of the policy struggle) }\end{array}$ & Extensive \\
\hline EXPO & $\begin{array}{l}\text { Personal changes at the } \\
\text { 'Verein', no resignations at } \\
\text { the political level }\end{array}$ & $\begin{array}{l}\text { While the government boldly } \\
\text { intervenes to change the } \\
\text { leadership of the 'Verein', } \\
\text { the government clearly } \\
\text { holds its course during the } \\
\text { blame game (does not } \\
\text { terminate the Expo despite } \\
\text { recurring cost overruns; } \\
\text { does not change } \\
\text { implementation structure) }\end{array}$ & Limited \\
\hline
\end{tabular}




\section{How Political Systems Manage Their Policy Controversies}

1. I did not conduct interviews with blame game actors because I am primarily interested in what blame game participants say and do during the actual blame game. To know what they think would certainly be interesting, but it is not a necessary requirement for the analysis of blame game interactions and their consequences. Moreover, I suspect that interview data would be useless for the most part as interviewees are driven by a very strong urge for social desirability when it comes to explaining their roles and actions during a blame game. Another reason against noncontemporaneous interviews is that memories on tactical issues are likely to fade quickly and that these memories are more likely to be influenced by outcomes than by what calculations interviewees were making at the time (Berry, 2002).

2. This is why I opted against counting the number of newspaper articles during a blame game. The second reason for a qualitative assessment is its flexibility, meaning that salience and proximity can be determined and compared across very different policy controversies.

3. UK newspapers: The Daily Telegraph, The Guardian, The Sun; German newspapers: Die Welt, Süddeutsche Zeitung, Bild; Swiss newspapers: Neue Zürcher Zeitung, Tages-Anzeiger, Blick; US newspapers: The Wall Street Journal, The New York Times, USA Today. I retrieved relevant articles from these newspapers mainly via the Factiva database. I used several controversy-specific keywords in each case to identify all relevant articles in the newspapers selected (see Table A2 in the Appendix). The time span during which I searched for articles starts significantly before the start of the blame game and extends beyond the end of blame game interactions until articles related to the blame game could no longer be found (the concrete time span varies considerably from case to case). Moreover, I occasionally consulted newspaper articles from other outlets in case they could provide further insights into a case.

4. Considering these different newspapers also controls for political parallelism, that is, for a situation in which only one political camp shows strong interest in a controversy while other camps largely ignore 
it, and for poor reporting by journalists; two aspects of media coverage that may distort and misrepresent the relationship between blame game actors and the public.

5. While considering social media would have been interesting, I opted against it for practical reasons. Analyzing social media would have been very challenging because of social media bubbles (and only possible for blame games that occurred after 2008-2010 - Twitter, Facebook, and so on only became widely used around that time). The analysis of television would also have been interesting because it would have allowed me to better assess politicians' attitudes toward a blame game (which is not only expressed in public statements but also in facial expressions and gestures). However, I argue that the detailed consideration of print media allows for a sufficiently clear picture of blame game actors' attitudes.

\section{Blame Games in the Political Sphere}

1. From here on, I will simply refer to them as 'blame games'.

2. Of course, this does not preclude the possibility that certain blame game (inter)actions change institutions in the longer run, for example, by eroding conventions (see Hall, 2016). I will discuss this possibility in the concluding chapter.

3. In my framework, policies influence blame games in two ways. First, as part of the institutional landscape, they emit incentives and constraints on the actors in a blame game. Second, they have interpretive effects on mass publics (Pierson, 1993), which will be accounted for in the section on issue characteristics.

4. In Switzerland, the executive consists of a collective government of seven federal councilors (the 'Federal Council'), each of which heads a department.

5. The public is thus exposed to two distortions when it comes to watching a blame game: the communication attempts by blame game actors and their reproduction by the media (Iyengar, 1990).

6. While journalists are trained to construct scandal narratives, I argue that their leeway in influencing the public's stance (or feedback) is constrained by issue characteristics. As both watchdog and scandalization machine, the media intensively covers policy controversies that are either very severe or have significant scandalization potential (both of these aspects significantly depend on issue characteristics).

7. The phenomenon of political parallelism has to be considered when assessing the general public's reaction to a blame game. If one considered only one quality outlet, there would be the danger of either over- or under-stating public feedback (see Section 1.4). 


\section{Blame Games in the UK}

1. E.g., the media reported about a father who killed himself and his four children after receiving a high payment request from the CSA. A member from an anti-CSA movement claimed that this incident, while tragic and sad, was not unusual: "There are bound to be tragic cases because of the complete and utter incompetence of the CSA." See "Debts drove father to kill himself and children," The Independent, December 19, 1995.

2. "Labour eyes child agency," The Guardian, April 25, 1997.

3. "CSA sums still wrong," The Guardian, July 15, 1998.

4. "Ministers talk tough on CSA plans," The Guardian, June 28, 1999.

5. "Families suffer as thousands of cases ignored," The Guardian, March 11, 1998.

6. "Child Shambles Agency," The Sun, November 10, 2004.

7. "Chief quits with CSA 'on brink of collapse," The Daily Telegraph, November 18, 2004.

8. "CSA chief goes amid computer chaos: Blair admits that child support failures are unacceptable," The Guardian, November 18, 2004.

9. "Crisis at the CSA highlights failure on a tragic scale," The Daily Telegraph, September 9, 2005.

10. "CSA is fundamentally flawed, Blair tells MPs," The Guardian, November 17, 2005.

11. “Chap support agency," The Guardian, November 29, 2005.

12. House of Commons Hansard Debates, January 17, 2006.

13. "Anger at plans for yet another review of Child Support Agency," The Guardian, February 9, 2006.

14. The National Audit Office is an independent parliamentary body that audits government departments.

15. "Watchdog dismisses CSA funds as waste of money," The Guardian, June 30, 2006.

16. "New CSA to have more powers over errant parents," The Guardian, July 25, 2006.

17. "Agents of disorder," The Guardian, March 17, 1998.

18. E.g., "Chief quits with CSA 'on brink of collapse,"” The Daily Telegraph, November 18, 2004; "Computer bungle 'will hit the poor," The Guardian, August 14, 2002.

19. "Pay up now, Blunkett warns errant fathers," The Guardian, September 27, 2005.

20. Committee of Public Accounts, "Child Support Agency: Implementation of the Child Support Reforms,” Thirty-seventh Report of Session 2006-2007, July 5, 2007. 
21. “CSA blew Pounds 800m," The Sun, June 30, 2006.

22. "We've done remarkable work at CSA," The Sun, November 18, 2004.

23. House of Commons Hansard Debates, January 17, 2006.

24. Alan Milburn, Secretary of State for Health, September 1999, quoted in Flinders (2005, p. 215).

25. Louise Butcher, "London Underground PPP: background," House of Commons Library Standard Note, January 16, 2012.

26. Andrew Stevens, "London's transport network suffers from underinvestment and muddled strategy," August 5, 2007. Available at: www.citymayors.com/transport/london-transport.html.

27. The Transport Committee is a parliamentary body that scrutinizes the Department for Transport.

28. Transport Committee, "The Performance of the London Underground," Sixth Report of Session 2004-2005, March 9, 2005, p. 3.

29. Butcher, 2012, ibid.

30. "Tories call for auditor to investigate PPP after Metronet collapse: Brown 'was given many warnings of problems,'” The Guardian, July 20, 2007.

31. Butcher, 2012, p. 13, ibid.

32. Transport Committee, "The London Underground and the PublicPrivate Partnership Agreements," Second Report of Session 2007-2008, January 25, 2008.

33. Ibid.

34. Ibid.

35. "Tube Lines ready to pick up the pieces of one Metronet contract," The Guardian, July 23, 2007.

36. "Corruption claim in tube contract collapse: Transport secretary rejects MPs' call for public inquiry," The Guardian, November 8, 2007.

37. Transport Committee, Second Report of Session 2007-2008, January 25, 2008.

38. Butcher, 2012, p. 11, ibid.

39. Butcher, 2012, p. 12, ibid.

40. National Audit Office, "The failure of Metronet," June 5, 2009.

41. Transport Committee, "Update on the London Underground and the Public-Private (PPP) Partnership Agreements," Seventh Report of Session 2009-2010, March 17, 2010.

42. Ibid., p. 5.

43. "PFI will ultimately cost $£ 300$ bn," The Guardian, July 5, 2012.

44. "Revealed: Tube crisis as firms fined pounds $32 \mathrm{~m}$," The Guardian, December 29, 2003.

45. E.g., "Brown should be much further ahead," The Daily Telegraph, September 6, 2007. 
46. "Brown bounces to strongest Labour lead over Cameron," The Daily Telegraph, July 15, 2007.

47. This is in stark contrast to The Sun's coverage of the CSA controversy. In 2006 alone (a year that saw intensive blame game interactions), it published fifty-two articles on the CSA controversy.

48. "Metronet: Learning lessons from the wreckage," The Guardian, February 9, 2008.

49. Transport Committee, Second Report of Session 2007-2008, January 25, 2008, pp. 24-27.

50. "Down the Tube," The Sun, July 17, 2007.

51. Transport Committee, "The Performance of the London Underground," Sixth Report of Session 2004-2005, March 9, 2005, p. 6.

52. "Tube PPP reaches the end of the line," The Guardian, December 18, 2009.

53. Transport Committee, Second Report of Session 2007-2008, January 25, 2008, Ev 43.

54. "How Blair urged his ministers to back the Dome," The Sun, November 13, 2000.

55. "The Dome may be a failure - but it's a heroic failure," The Daily Telegraph, November 13, 2000.

56. "Mandelson takes charge of millennium showpiece," The Guardian, June 21, 1997.

57. "PM will tell detractors to stop carping," The Guardian, February 24, 1998.

58. "Blair hails 'incredible' dome," The Guardian, December 14, 1999.

59. "More sackings to come in revamp," The Guardian, February 7, 2000.

60. "Tory van man - Interview with William Hague," The Sun, February 16, 2000.

61. "Welcome to Britain's prestige tourist attraction," The Guardian, May 23, 2000; "Ministers forced on defensive over Dome," The Guardian, May 25, 2000.

62. "Ministers forced on defensive over Dome," The Guardian, May 25, 2000.

63. "An extra $£ 47 \mathrm{~m}$ for the Dome - but even that may not be enough," The Guardian, September 6, 2000; "Falconer says ...," The Guardian, September 7, 2000.

64. "Dome too ambitious admits Blair," The Guardian, September 25, 2000; "Falconer admits mistakes on dome," The Guardian, September 26, 2000.

65. "Ministers break ranks on dome," The Guardian, September 23, 2000.

66. National Audit Office, "The Millennium Dome," November 9, 2000. According to this report, the main problems were flawed management, 
considerable overestimation of ticket sales, and exhibits that did not live up to 'massaged' expectations.

67. Each of the examined outlets published several hundred articles on the Dome - much more than on the CSA and METRONET controversies combined (which lasted longer than the blame game about the Dome).

68. "Dome cash 'should go to education,"' The Guardian, February 4, 1999.

69. "The Dome may be a failure - but it's a heroic failure," The Daily Telegraph, November 13, 2000.

70. “Lottery bail-out for sinking Dome," The Guardian, May 22, 2000.

71. Consider, e.g., " . . it would be terrible if it started draining cash away from other, much better, causes," ibid.

72. “Dome cash crisis 'utter nonsense,"” The Guardian, January 10, 2000.

73. “The (almost) £1bn question,” The Guardian, September 7, 2000.

74. "I feel at dome," The Sun, January 6, 1999.

75. “There for what purpose?," The Guardian, September 7, 2000.

76. "Blair visits dome to thank staff," The Guardian, December 19, 2000.

77. House of Commons, "Report of the Mid Staffordshire NHS Foundation Trust - Public Inquiry,” February 6, 2013; “Mid Staffs hospital scandal: the essential guide," The Guardian, February 6, 2013.

78. “Appalling care at foundation hospital may have cost hundreds of lives: Unprecedented criticism from health watchdog: Health minister apologises and announces inquiry," The Guardian, March 18, 2009.

79. "NHS culture that tolerated low standards and sold patients short: Francis report calls for openness and honesty to replace managerial cult," The Guardian, February 7, 2013.

80. "The NHS needs to prepare for another bout of initiative-it is," The Guardian, February 7, 2013.

81. "Cut off NHS head to save the patient," The Sun, February 11, 2013.

82. "Tory MPs accuse Labour's Burnham of failing to heed warnings," The Daily Telegraph, July 16, 2013.

83. "PM rejects call to sack health chief over Mid-Staffs scandal: PM says targets of Labour ministers were to blame; Opposition accuses him of trying to politicise tragedy," The Guardian, March 7, 2013; "PM: NHS Deaths Labour's Fault," The Sun, March 7, 2013.

84. "Failing hospitals to be named and shamed but patient groups say move is not enough," The Guardian, March 27, 2013.

85. "Fact or Fiction? Targets improve quality in the NHS," Nuffield Trust, February 13, 2005. Available at: www.nuffieldtrust.org.uk/news-item/ fact-or-fiction-targets-improve-quality-in-the-nhs.

86. "The NHS is bracing itself for a fresh onslaught from the health secretary," The Guardian, July 15, 2013. 
87. "PM rejects call to sack health chief over Mid-Staffs scandal: PM says targets of Labour ministers were to blame; Opposition accuses him of trying to politicise tragedy," The Guardian, March 7, 2013.

\section{Blame Games in Germany}

1. Otto Brenner Stiftung, "Die Berichterstattung über die NSU-Morde eine Medienkritik," OBS-Arbeitsheft 79.

2. "Zehn Mordfälle vor der Aufklärung; Rechter Terror schockiert Regierung; Sicherheitsbehörden wegen Versäumnissen in der Kritik; Merkel verlangt 'größte Sorgfalt' bei Ermittlungen," Süddeutsche Zeitung, November 14, 2011.

3. Deutscher Bundestag, "Beschlussempfehlung und Bericht des 2. Untersuchungsausschusses," Drucksache 17/14600, August 22, 2013, pp. 3-4.

4. "De Maizière wusste von Mundlos-Akte; Minister: Nicht-Weitergabe an NSU-Ausschuss war unsensibel," Süddeutsche Zeitung, September 13, 2012. All direct quotes were translated by the author.

5. "Der Mann, der von fast nichts wusste," Süddeutsche Zeitung, December 14, 2012.

6. Ibid.

7. "Kritik an NSU-Aufklärung," Süddeutsche Zeitung, September 18, 2012.

8. E.g., ibid.; "Aufklärungslawine; Merkel will weiteres Gremium zu Neonazi-Morden einsetzen," Süddeutsche Zeitung, October 16, 2012.

9. Deutscher Bundestag 2013, ibid.

10. Deutscher Bundestag 2013, ibid., pp. 1031-1032.

11. "Jedem Ministerium sein eigenes Zentrum gegen rechts," Die Welt, January 24, 2012.

12. E.g., "Verhängnisvolles Unvermögen," Süddeutsche Zeitung, November 3, 2012.

13. "Aufklärungslawine; Merkel will weiteres Gremium zu NeonaziMorden einsetzen," Süddeutsche Zeitung, October 16, 2012.

14. E.g., "Becksteins Version; Der einstige Innenminister muss im Bundestag zur Neonazi-Mordserie aussagen," Süddeutsche Zeitung, May 24, 2012.

15. "Innenminister Friedrich fordert weitere Aufklärung zu NSU-Morden,” Süddeutsche Zeitung, November 5, 2012.

16. "Geheimdienste außer Kontrolle: Wer überwacht eigentlich die Überwacher?," Bundeszentrale für Politische Bildung, available at: www .bpb.de/dialog/netzdebatte/169068/geheimdienste-ausser-kontrolle 
-wer-ueberwacht-eigentlich-die-ueberwacher?type=galerie\&show=i mage\& $\mathrm{i}=169091$.

17. "Der Mann, der von fast nichts wusste," Süddeutsche Zeitung, December 14, 2012.

18. I examined this case from a different perspective in Hinterleitner (2019).

19. Ernst \& Young, "Sachverhaltsdarstellung zu Störungen des Projektablaufes und deren Auswirkungen," 2012.

20. Abgeordnetenhaus Berlin, Plenarprotokoll 16/66, June 3, 2010, p. 6236ff.

21. Abgeordnetenhaus Berlin 2010, ibid., p. 6243ff.

22. Abgeordnetenhaus Berlin, Plenarprotokoll 17/13, May 10, 2012, p. $1002 \mathrm{ff}$.

23. Abgeordnetenhaus Berlin 2012, ibid.

24. "Baufirmen haben Schuld an später BER-Öffnung," B.Z., November 15, 2012.

25. Abgeordnetenhaus Berlin, Plenarprotokoll 17/17, September 13, 2012, p. $1553 \mathrm{ff}$.

26. Abgeordnetenhaus Berlin, Plenarprotokoll 17/19, October 25, 2012, p. $1829 \mathrm{ff}$.

27. Abgeordnetenhaus Berlin, Plenarprotokoll 17/23, January 10, 2013, p. $2238 \mathrm{ff}$.

28. E.g., "Wie geht es beim BER weiter?," Die Welt, September 6, 2012.

29. E.g., "Pressestimmen zur Verantwortung für das Flughafen-Debakel," B.Z., May 19, 2012; or "Dauersatire, nächste Folge," Süddeutsche Zeitung, February 21, 2013.

30. "So denkt Berlin über Wowereit, Henkel und die Koalition - Große Forsa-Umfrage," B.Z., January 11, 2013.

31. "Länderfinanzausgleich: Die bittere Wahrheit über die Berliner Finanzen," Die Welt, February 2, 2013.

32. "Exklusiv-Umfrage der Berliner Zeitung: Mehrheit der Berliner lehnt neuen Flughafen ab," Berliner Zeitung, January 27, 2012, available at: www.berliner-zeitung.de/berlin/exklusiv-umfrage-der-berliner-zeitungmehrheit-der-berliner-lehnt-neuen-flughafen-ab-10859058.

33. “'Klaus Wowereit hat uns alle getäuscht,"” Die Welt, June 18, 2012.

34. Abgeordnetenhaus Berlin, Plenarprotokoll 17/13, May 10, 2012, p. 1007.

35. "Macht nicht noch mehr Schulden!," B.Z., August 24, 2012.

36. "Wowereit verweigert Bekenntnis zu seinen Fehlern," Die Welt, January 11, 2013.

37. These advantages are particularly visible in a committee meeting on May 18, 2012, Abgeordnetenhaus Berlin, Ausschuss für Bauen, Wohnen und Verkehr. 
38. Abgeordnetenhaus Berlin, Plenarprotokoll 17/19, October 25, 2012, p. 1831.

39. Bericht der Strukturkommission der Bundeswehr, October 2010.

40. Deutscher Bundestag, "Beschlussempfehlung und Bericht des Verteidigungsausschusses als 2. Untersuchungsausschuss,” Drucksache 17/14650, September 2, 2013.

41. “'Euro Hawk'-Drohne wird zum 500 Millionen-Euro-Fiasko,” Der Spiegel, May 14, 2013.

42. “Drohnen-Affäre: De Maizière verteidigt sein Vorgehen,” Der Spiegel, May 24, 2013.

43. “Euro Hawk: Bundeswehr ordnete Datenlöschung an,” Der Spiegel, June 2, 2013.

44. Deutscher Bundestag, Plenarprotokoll 17/242, June 5, 2013, p. 30642.

45. Deutscher Bundestag, Plenarprotokoll 17/242, June 5, 2013, p. 30645ff; "De Maizières Strategie in der 'Euro Hawk'-Affäre ist gefährlich,” Der Spiegel, June 5, 2013.

46. “Germany's defense minister evades blame," Deutsche Welle, August 1, 2013.

47. “'Euro Hawk': De Maizière startet den Frontalangriff,” Der Spiegel, July 31, 2013.

48. "Drohnen-Auschuss; Keine Ausreden mehr," Süddeutsche Zeitung, August 27, 2013.

49. KPMG, "Umfassende Bestandsaufnahme und Risikoanalyse zentraler Rüstungsprojekte,” September 30, 2014.

50. Surveys by the Forschungsgruppe Wahlen, which track the popularity of German ministers, allow for a clear assessment of changes in the minister's popularity during the blame game. See Forschungsgruppe Wahlen, Politikbarometer 2013. www.forschungsgruppe.de.

51. Biehl, Heiko, and Rüdifer Fiebig, "Zum Rückhalt der Bundeswehr in der Bevölkerung - Empirische Hinweise zu einer emotional geführten Debatte," SOWI.Thema 02/2011.

52. “"Euro Hawk'- Drohne wird zum 500 Millionen-Euro-Fiasko,” Der Spiegel, May 14, 2013.

53. “Opposition, Medien, Wähler,” Süddeutsche Zeitung, August 3, 2013.

54. Deutscher Bundestag, Plenarprotokoll 17/240, May 16, 2013, p. $30126 \mathrm{ff}$.

55. “De Maizière: Wie ein Beamter,” Süddeutsche Zeitung, August 1, 2013.

56. “'Euro Hawk': De Maizière startet den Frontalangriff,” Der Spiegel, July 31, 2013.

57. Deutscher Bundestag, Plenarprotokoll 17/242, June 5, 2013, p. $30644 \mathrm{ff}$. 
58. “'Ethisch neutrale Waffe': De Maizière wirbt für Einsatz bewaffneter Drohnen," Die Welt, August 3, 2013.

59. Deutscher Bundestag, Plenarprotokoll 17/242, June 5, 2013, p. 30642.

60. Deutscher Bundestag, Plenarprotokoll 17/246, June 13, 2013, p. $31353 \mathrm{ff}$.

61. Basic Law for the Federal Republic of Germany, Art. 44.

62. "Künast will Meldepflicht verschärfen,” Süddeutsche Zeitung, May 29, 2002; "Politiker streiten über Schuld an der Nitrofen-Verseuchung," Süddeutsche Zeitung, June 3, 2002.

63. “Giftskandal um Öko-Produkte,” Berliner Zeitung, May 27, 2002.

64. "Einzelhandel stoppt Verkauf von Bio-Produkten," Süddeutsche Zeitung, May 29, 2002; "Raiffeisen-Verbund in der Kritik," Süddeutsche Zeitung, June 3, 2002.

65. “'Härtere Strafen für Lebensmittelvergehen,'” Süddeutsche Zeitung, May 31, 2002.

66. Deutscher Bundestag, Plenarprotokoll 14/239, p. 23835ff; "Deutschen Bio-Bauern drohen EU-Sanktionen,” Süddeutsche Zeitung, June 10, 2002.

67. "Handelsketten wollen Lieferanten schärfer kontrollieren," Süddeutsche Zeitung, June 14, 2002.

68. Deutscher Bundestag, Plenarprotokoll 14/239, p. 23837ff; " Problem trifft auch konventionelle Landwirtschaft,"' Süddeutsche Zeitung, June 7, 2002.

69. European Commission, Final Mission Report, DG(SANCO)/8686/ 2002 - MR Final, 2002.

70. Deutscher Bundestag, Plenarprotokoll 14/239, p. 23845.

71. See esp. Deutscher Bundestag, Plenarprotokoll 14/239, p. 23840.

72. "Nitrofen in konventionellem Futter," Süddeutsche Zeitung, June 13, 2002; "Zu einer Agrarwende gibt es keine Alternative," Berliner Zeitung, June 7, 2002.

73. "Vorschnelle Entwarnung," Süddeutsche Zeitung, June 7, 2002; "Total-Blockade der Union beim Verbraucherschutz," Berliner Zeitung, June 1, 2002; "Ein lehrreicher Skandal," Berliner Zeitung, June 4, 2002.

\section{Blame Games in Switzerland}

1. Parts of this section are based on Hinterleitner (2018).

2. Ninck, M., "Der Verrat,” Das Magazin, March 28, 2014, 8-19.

3. Finance Commission of the Canton of Zurich, "Bericht der Finanzkommission betreffend Sonderprüfung der Oberjugendanwaltschaft durch die Finanzkontrolle," 2014. 
4. "Carlos wurde in geschlossene Anstalt verlegt," Tages-Anzeiger, September 3, 2013.

5. "Ein unschöner, tragischer Einzelfall," Neue Zürcher Zeitung, September 7, 2013.

6. "Ich hätte Carlos das Sackgeld gekürzt," Tages-Anzeiger, September 7, 2013.

7. “Die Justizkommission ist im Fall 'Carlos' unter Druck: Nach der SVP, der FDP und der BDP schliesst auch die CVP eine PUK nicht aus,” Neue Zürcher Zeitung, September 10, 2013.

8. "Bundesgericht kritisiert das Vorgehen der Behörden scharf," TagesAnzeiger, February 25, 2014.

9. Protokoll des Zürcher Kantonsrates, 164. Sitzung, Montag, April 14, 2014.

10. Protokoll des Zürcher Kantonsrates 2014, ibid., pp. 11414-19.

11. Political experts and the justice minister himself saw the CARLOS controversy as the reason for this outcome.

12. “'Carlos' und die Journalisten; Kontroverse Selbstreflexion innerhalb der Medienbranche über einen ergiebigen Aufreger," Neue Zürcher Zeitung, May 30, 2014.

13. E.g., "Jetzt kommt die Lex Carlos," Blick, September 18, 2013; Protokoll des Zürcher Kantonsrates, 119. Sitzung, Montag, September 2, 2013.

14. E.g., Protokoll des Zürcher Kantonsrates 2013, ibid.; "Martin Graf auf Bewährung: Der Zürcher Justizdirektor muss im Fall 'Carlos' unangenehme Fragen beantworten,” Neue Zürcher Zeitung, September 4, 2013.

15. "Ich hätte Carlos das Sackgeld gekürzt," Tages-Anzeiger, September 7, 2013.

16. Ninck, "Der Verrat."

17. One can only speculate about this deliberate exposure. In Chapter 9, I discuss the implications of 'irrational' behavior for our understanding of blame games.

18. Federal Council, Botschaft zum Bundesgesetz über die Verbesserung der steuerlichen Rahmenbedingungen für unternehmerische Tätigkeiten und Investitionen, June 22, 2005.

19. SP, Unternehmenssteuerreform II: Vernehmlassungsantwort der SP Schweiz, April 29, 2004.

20. In Switzerland's system of direct democracy, citizens can call referendums on laws passed by parliament.

21. "Erhebliche Steuereinbussen; Eine Schätzung zum Effekt der Steuerbefreiung gewisser Dividenden," Neue Zürcher Zeitung, March 9, 2011. 
22. To disseminate this information, the Federal Council authorizes and sends a voting guide to the public. The voting guide for the referendum on the CTR did not contain information on the revenue implications of the retroactivity clause.

23. "Im Abstimmungsbüchlein fehlten die Milliardenverluste," TagesAnzeiger, March 6, 2011; National Council, Amtliches Bulletin der Bundesversammlung, Frühjahrssession 2011, 11.5159 and 11.5165.

24. "SP befürchtet Steuerausfälle in Milliardenhöhe," Tages-Anzeiger, March 8, 2011.

25. National Council, Amtliches Bulletin der Bundesversammlung, Aprilsession 2011, 601-613.

26. Ibid., 602 .

27. Statement by an SVP politician, ibid., 604.

28. Ibid., 613.

29. "Warmlaufen für die nächste Steuerdebatte; Die Unternehmenssteuerreform III wirft ihre Schatten voraus," Neue Zürcher Zeitung, October 3, 2012.

30. "Steuerreform für die Volksseele; Der Ständerat will mit einer defensiven Reform der Firmenbesteuerung einen Absturz an der Urne verhindern," Neue Zürcher Zeitung, May 31, 2016.

31. Milic, T., Reiss, T., \& Kübler, D., VOTO-Studie zur eidgenössischen Volksabstimmung vom, February 12, 2017, March 2017.

32. Hirter, H., \& Linder, W., Analyse der eidgenössischen Abstimmungen vom. February 24, 2008, April 2008.

33. E.g., National Council 2011, ibid., 601.

34. National Council, Amtliches Bulletin der Bundesversammlung, Aprilsession 2011, 601.

35. Parts of this section are based on Hinterleitner (2019). I also thank Tobias Arnold for interesting insights into the EXPO controversy.

36. The project was still named Expo.01 until the delay of the exposition from 2001 to 2002.

37. Rieder, S., Lehmann, L., \& Ledermann, S., Analyse der Projektorganisation und Projektsteuerung der Expo.01/02: Bericht zuhanden der Eidgenössischen Finanzkontrolle EFK, Lucerne, 2004.

38. Rais, G., \& Ammann, Y., Überlegungen zur konjunkturellen und strukturellen Entwicklung der Schweizer Wirtschaft, Neuchâtel, 2013.

39. "Lehrstück für die Bundespolitik: Die Expo 01/02 zwischen Chaos und Verwirklichung," Neue Zürcher Zeitung, October 6, 2005.

40. Swiss Federal Audit Office, Expo.01/02: Auftrag mit unbeschränkter Haftung: Sonderuntersuchung zur Landesausstellung im Drei-SeenLand, 2005, 39. 
41. "Alle Bundesparteien für Verschiebung der Expo," Nene Zürcher Zeitung, September 14, 1999.

42. National Council, Amtliches Bulletin der Bundesversammlung, Herbstsession, October 4, 1999, 1946-1949.

43. “Der Streit um die Expo eskaliert,” Basler Zeitung, October 7, 1999.

44. Swiss Federal Audit Office 2005, 27; Council of States, Amtliches Bulletin, Sommersession 2001.

45. Council of States, Probleme bei der Vorbereitung und Organisation der Landesausstellung 2001 (Expo.01) - Bericht der Geschäftsprüfungskommission, March 27, 2001, 2567; Eidgenössische Finanzkontrolle, Expo.01/02: Auftrag mit unbeschränkter Haftung Sonderuntersuchung zur Landesausstellung im Drei-Seen-Land, May 2005, 26-27.

46. E.g., "Versteckspiele am Neuenburgersee," Neue Zürcher Zeitung, August 28, 1999; “Die Korken knallen,” Neue Zürcher Zeitung, January 27, 2000.

47. "Wahlkampf flau, Lage stabil," Tages-Anzeiger, September 17, 1999.

48. National Council, Amtliches Bulletin der Bundesversammlung, Frühjahrssession 2002, 76-89.

49. E.g. "Immigration, Black Sheep and Swiss Rage," The New York Times, October 8, 2007.

50. “Empörung und Entsetzen,” Der Bund, October 8, 2007.

51. Statement by an SVP politician, Berner Stadtrat, Stadtratssitzung Donnerstag. Oktober 18, 2007, Protokoll Nr. 27, 1457. Daniele Jenni was a Green parliamentarian.

52. Berner Stadtrat 2007, ibid.; "Herr Jenni, treten Sie zurück!,” Der Bund, October 19, 2007.

53. Berner Stadtrat 2007, ibid., 1459.

54. Berner Stadtrat 2007, ibid.

55. Berner Stadtrat 2007, ibid., 1463-1465.

56. “Gemeinderat liess Stephan Hügli handeln,” Der Bund, December 20, 2007.

\section{Mapping the Influence of Issue Characteristics}

1. This causes me to infer that there was strong public feedback to the VHA controversy. This is a precondition for the later examination of whether opponents and incumbents behaved similarly to the actors in the three in-depth case studies (which also exhibited strong public feedback).

2. "V.A. accusations aggravate woes of White House," The New York Times, May 21, 2014. 
3. "Colorado: Records are falsified at veterans clinic, inquiry finds," The New York Times, May 7, 2014.

4. "Veterans secretary ousts health care official amid criticism," The New York Times, May 17, 2014.

5. "Obama faces new test in mismanagement at veterans hospitals," The New York Times, May 21, 2014; "Obama meets Shinseki over V.A. hospital problems," The New York Times, May 22, 2014.

6. "V.A. hospital officials in Phoenix are placed on leave," The New York Times, May 2, 2014.

7. "Three at Phoenix VA hospital placed on leave; VA head Shinseki says he takes seriously allegations that vets died waiting for appointments," The Wall Street Journal, May 1, 2014.

8. "Obama angry over falsification of veterans affairs data, chief of staff says," The New York Times, May 19, 2014.

9. The White House, Office of the Press Secretary, "Statement by the President on Veterans Health Care," May 21, 2014.

10. "House passes $\$ 17$ billion overhaul of Department of Veterans Affairs," The Wall Street Journal, July 30, 2014.

11. Senate Committee on Veterans' Affairs, "The State of VA Health Care" Hearing, May 15, 2014; "The scandal that shadows Memorial Day; The government has failed in its responsibility to veterans. Where is the administration's sense of urgency?, by John McCain," The New York Times, May 23, 2014.

12. "Obama pushes accountability at VA," The Wall Street Journal, May 21, 2014.

13. "Obama angry over falsification of veterans affairs data, chief of staff says," The New York Times, May 19, 2014.

14. "Obama faces new test in mismanagement at veterans hospitals," The New York Times, May 21, 2014.

15. In this case, the VA secretary refrained from treating the waiting list manipulations as a systematic problem until the inquiry results were in.

16. "U.S. will miss half its supply of flu vaccine," The New York Times, October 6, 2004; "Shortage was predicted," The New York Times, October 7, 2004.

17. "Kerry says U.S. should have prepared for flu shot shortage," The New York Times, October 10, 2004.

18. "Bush, Kerry trade blame over scarcity of flu shots," USA Today, October 19, 2004.

19. "Kerry says U.S. should have prepared for flu shot shortage," The New York Times, October 10, 2004.

20. "Flu vaccine policy becomes issue for Bush," The New York Times, October 20, 2004. 
21. "U.S. will miss half its supply of flu vaccine," The New York Times, October 6, 2004.

22. "British action on vaccine a surprise, F.D.A. says," The New York Times, October 12, 2004.

23. “Tough talk in final debate," USA Today, October 14, 2004.

24. "Kerry says Bush is indifferent to health care," The New York Times, October 19, 2004; "Kerry ad says flu vaccine shortage is typical of Bush's policy blunders," The Washington Post, October 17, 2004.

25. "Flu vaccine policy becomes issue for Bush," The New York Times, October 20, 2004; "Washington wire," The Wall Street Journal, October 29, 2004.

26. "U.S. flu vaccines face rationing as plant is shut," The Wall Street Journal, October 6, 2004.

27. Media outlets had covered the controversy in a detailed, mainly problem-centered way. Moreover, polls suggest that there was rather moderate feedback to the controversy (see, e.g., "For some seniors, vaccine not a political issue," USA Today, October 19, 2004; "Poll: Confidence in FDA still strong despite blunders," USA Today, November 24, 2004). The reason for moderate public feedback may be that most people underestimate their susceptibility to the flu and misconceive the benefits of flu shots due to cognitive biases when observing their proximate environment (Chen and Stevens, 2017). Moderate public feedback makes the FLU controversy an adequate case for testing and refining the claims about opponent and incumbent behavior derived from the three in-depth cases.

28. "Bush responds to Kerry attacks, assures availability of flu vaccine in Florida campaign speech," Kaiser Health News, June 11, 2009, available at https://khn.org/morning-breakout/dr00026332/.

29. "The year of fear," The New York Times, October 20, 2004.

30. "Solar firm aided by U.S. shuts doors," The New York Times, September 1, 2011.

31. "FBI raids solar-panel maker," The Wall Street Journal, September 9, 2011.

32. "Solar firm aided by U.S. shuts doors," The New York Times, September 1, 2011.

33. "Romney campaigns at failed Solyndra factory," The New York Times, May 31, 2002.

34. "Administration rushed solar guarantee, Republicans say," The New York Times, September 14, 2011; "Parties clash over solar-panel maker," The Wall Street Journal, September 15, 2011.

35. "Solar firm aided by U.S. shuts doors," The New York Times, September 1, 2011. 
36. "Furor over loans to failed solar firm," The New York Times, September 15, 2011.

37. "Trustee is sought for records of Solyndra," The New York Times, October 1, 2011.

38. "2 more solar companies get U.S. loan backing," The New York Times, September 8, 2011.

39. "Panel subpoenas emails on Solyndra," The Wall Street Journal, November 4, 2011.

40. "Leader picked for review of U.S. loans on energy," The New York Times, October 29, 2011.

41. The media coverage on the SOLYNDRA controversy was mainly problem-centered. While the corruption allegations drew significant attention and The Wall Street Journal ranted about 'interventionism' during the blame game, media outlets were in consensus that Republicans had indecently inflated the issue (see, e.g., "The Solyndra 'panic': One company's failure should not deter robust public investments in clean energy," The New York Times, September 25, 2011, or Paul Krugman's statement about the controversy: "Haven't written about this. But it is indeed a terrible scandal, because the private sector never ever puts money into ventures that end up failing," quoted in The New York Times, September 25, 2011). Overall, this leads me to conclude that public feedback to this controversy, as suggested by its low salience and distance to the everyday life of citizens, was indeed low. Therefore, the SOLYNDRA case can be used to test and refine the claims about opponent and incumbent behavior derived from the three indepth cases.

42. "Furor over loans to failed solar firm," The New York Times, September 15, 2011; "Republicans attack on handling of stimulus money and green jobs," The New York Times, September 23, 2011.

43. In some political systems, opponents can seek to free themselves from this constraint by pushing the controversy into inquiry procedures that regularly produce occasions for generating blame.

\section{A Typological Theory of Blame Games and Their Consequences}

1. The test cases cannot be used for the construction of the typological theory. In the test cases, I did not look at both the influence of 
institutional factors and issue characteristics on blame game interactions and, therefore, cannot interpret interaction effects between these groups of explanatory factors.

2. More specifically, they represent combinations of variables.

\section{Blame Games and Their Implications for Politics and Democracy under Pressure}

1. "Barack Obama breaks his silence," The Atlantic, July 17, 2018. 


\section{References}

Adam, C., Hurka, S., Knill, C., \& Steinebach, Y. (2019). Policy Accumulation and the Democratic Responsiveness Trap. New York: Cambridge University Press.

Adut, A. (2008). On Scandal: Moral Disturbances in Society, Politics and Art. Cambridge; New York: Cambridge University Press.

Aebersold, P. (2011). Schweizerisches Jugendstrafrecht (2nd ed.). Bern: Stämpfli.

Allern, S., \& von Sikorski, C. (2018). Political Scandals as a Democratic Challenge: From Important Revelations to Provocations, Trivialities, and Neglect - Introduction. International Journal of Communication, 12 (2018), 3014-3023.

Ansell, C. (2019). The Protective State. Cambridge: Cambridge University Press. Bach, T., \& Wegrich, K. (2016). Regulatory reform, accountability and blame in public service delivery: The public transport crisis in Berlin. In T. Christensen \& P. Lægreid (Eds.), The Routledge Handbook to Accountability and Welfare State Reforms in Europe (pp. 223-236). Abingdon: Taylor \& Francis.

Bache, I., Bartle, I., Flinders, M., \& Marsden, G. (2015). Blame Games and Climate Change: Accountability, Multi-Level Governance and Carbon Management. The British Journal of Politics \& International Relations, 17(1), 64-88.

Barberis, P. (1998). The New Public Management and a New Accountability. Public Administration, 76(3), 451-470.

Barker, A. (1994). The Upturned Stone: Political Scandals and Their Investigation Processes in Twenty Democracies. Crime, Law and Social Change, 21(4), 337-373.

Bates, G. L., Hutchinson, D., Robertson, T. M., Wadsworth, A. P., \& Watson, R. P. (2002). Identifying the Cause of the Child Support Agency's Problems: A Case of New Public Management Failure or an Issue of Inapt Accountability? Retrieved from www.childsupportanalysis.co.uk/assets/cau se_of_the_csas_problems.pdf.

Baumgartner, F. R., \& Jones, B. D. (2009). Agendas and Instability in American Politics. Chicago: University of Chicago Press. 
Bawn, K., Cohen, M., Karol, D., et al. (2012). A Theory of Political Parties: Groups, Policy Demands and Nominations in American Politics. Perspectives on Politics, 10(3), 571-597.

Béland, D. (2010). Reconsidering Policy Feedback: How Policies Affect Politics. Administration \& Society, 42(5), 568-590.

Bennett, A., \& Elman, C. (2006). Complex Causal Relations and Case Study Methods: The Example of Path Dependence. Political Analysis, 14(3), 250-267.

Berry, J. M. (2002). Validity and Reliability Issues in Elite Interviewing. PS: Political Science \& Politics, 35(4), 679-682.

Bevan, G., \& Hood, C. (2006). What's Measured Is What Matters: Targets and Gaming in the English Public Health Care System. Public Administration, 84 (3), 517-538.

Beyme, K. von. (2013). Die parlamentarische Demokratie: Entstehung und Funktionsweise 1789-1999. Berlin: Springer-Verlag.

Bijl-Schwab, B. (2017). Kulturpolitik. In P. Knoepfel, Y. Papadopoulos, P. Sciarini, A. Vatter, \& S. Häusermann (Eds.), Handbuch der Schweizer Politik (6th ed., pp. 855-888). Zurich: NZZ Libro.

Birkland, T. A. (1998). Focusing Events, Mobilization, and Agenda Setting. Journal of Public Policy, 18(01), 53-74.

Blyth, M. (2013). Austerity: The History of a Dangerous Idea. Oxford: Oxford University Press.

Boin, A., Hart, J., McConnell, A., \& Preston, T. (2010). Leadership Style, Crisis Response and Blame Management: The Case of Hurricane Katrina. Public Administration, 88(3), 706-723.

Boin, A., McConnell, A., \& 't Hart, P. (Eds.). (2008). Governing after Crisis: The Politics of Investigation, Accountability and Learning. Cambridge: Cambridge University Press.

Boin, A., 't Hart, P., Stern, E., \& Sundelius, B. (2009a). The Politics of Crisis Management: Public Leadership under Pressure. Cambridge: Cambridge University Press.

Boin, A., 't Hart, P., \& McConnell, A. (2009b). Crisis Exploitation: Political and Policy Impacts of Framing Contests. Journal of European Public Policy, 16(1), 81-106.

Boswell, J., Corbett, J., Dommett, K., et al. (2018). State of the Field. European Journal of Political Research, 54(1), 78.

Bovens, M. (2007). Analysing and Assessing Accountability: A Conceptual Framework. European Law Journal, 13(4), 447-468.

Bovens, M., \& 't Hart, P. (2016). Revisiting the Study of Policy Failures. Journal of European Public Policy, 23(5), 653-666.

Brändström, A. (2015). Crisis Accountability: Ministerial Resignations in Sweden. Scandinavian Political Studies, 38(3), 301-320. 
Brändström, A., \& Kuipers, S. (2003). From 'Normal Incidents' to Political Crises: Understanding the Selective Politicization of Policy Failures. Government and Opposition, 38(3), 279-305.

Busuioc, M., \& Lodge, M. (2016). The Reputational Basis of Public Accountability. Governance, 29(2), 247-263.

Campbell, A. L. (2012). Policy Makes Mass Politics. Annual Review of Political Science, 15, 333-351.

Campbell, J. L., \& Hall, J. A. (2017). The Paradox of Vulnerability: States, Nationalism, and the Financial Crisis. Princeton, NJ: Princeton University Press.

Capoccia, G. (2016). When Do Institutions “Bite”? Historical Institutionalism and the Politics of Institutional Change. Comparative Political Studies, 49 (8), 1095-1127.

Chen, F., \& Stevens, R. (2017). Applying Lessons from Behavioral Economics to Increase Flu Vaccination Rates. Health Promotion International, 32(6), 1067-1073.

Collier, D., LaPorte, J., \& Seawright, J. (2012). Putting Typologies to Work: Concept Formation, Measurement, and Analytic Rigor. Political Research Quarterly, 65(1), 217-232.

Dahl, R. A. (1965). Reflections on Opposition in Western Democracies. Government and Opposition, 1(1), 7-24.

Edelman, M. J. (1988). Constructing the Political Spectacle. Chicago: University of Chicago Press.

Elliott, D., \& McGuinness, M. (2002). Public Inquiry: Panacea or Placebo? Journal of Contingencies and Crisis Management, 10(1), 14-25.

Ellis, R. (1994). Presidential Lightning Rods: The Politics of Blame Avoidance. Studies in Government and Public Policy. Lawrence: University Press of Kansas.

Elman, C. (2005). Explanatory Typologies in Qualitative Studies of International Politics. International Organization, 59(2), 293-326.

Entman, R. M. (2012). Scandal and Silence: Media Responses to Presidential Misconduct. Cambridge; Malden, MA: Polity.

Falleti, T. G., \& Lynch, J. F. (2009). Context and Causal Mechanisms in Political Analysis. Comparative Political Studies, 42(9), 1143-1166.

Falleti, T. G., \& Mahoney, J. (2015). The comparative sequential method. In J. Mahoney \& K. A. Thelen (Eds.), Strategies for Social Inquiry. Advances in Comparative-Historical Analysis (pp. 211-239). New York: Cambridge University Press.

Fischer, J. (2012). “... I Take Political Responsibility!”: The Theoretical and Empirical Relation between Ministerial Responsibility and Ministerial Resignations in Germany. Public Administration, 90(3), 600-621. 
Flinders, M. (2005). The Politics of Public-Private Partnerships. The British Journal of Politics and International Relations, 7(2), 215-239.

Flinders, M. (2014). Explaining Democratic Disaffection: Closing the Expectations Gap. Governance, 27(1), 1-8.

Flinders, M., \& Buller, J. (2006). Depoliticisation: Principles, Tactics and Tools. British Politics, 1(3), 293-318.

Freeman, G. P. (1985). National Styles and Policy Sectors: Explaining Structured Variation. Journal of Public Policy, 5(4), 467-496.

George, A. L., \& Bennett, A. (2005). Case Studies and Theory Development in the Social Sciences. BCSIA Studies in International Security. Cambridge, MA: MIT Press.

Gerring, J., \& Yesnowitz, J. (2006). A Normative Turn in Political Science? Polity, 38(1), 101-133.

Goertz, G. (2006). Social Science Concepts: A User's Guide. Princeton, NJ: Princeton University Press.

Goodhart, M. (2017). Interpreting Responsibility Politically. Journal of Political Philosophy, 25(2), 173-195.

Hacker, J. S. (2004). Privatizing Risk without Privatizing the Welfare State: The Hidden Politics of Social Policy Retrenchment in the United States. American Political Science Review, 98(2), 243-260.

Hacker, J. S., \& Pierson, P. (2014). After the "Master Theory": Downs, Schattschneider, and the Rebirth of Policy-Focused Analysis. Perspectives on Politics, 12(03), 643-662.

Hacker, J. S., Pierson, P., \& Thelen, K. A. (2015). Drift and conversion: Hidden faces of institutional change. In J. Mahoney \& K. A. Thelen (Eds.), Strategies for Social Inquiry. Advances in Comparative-Historical Analysis (pp. 180-208). New York: Cambridge University Press.

Hafner-Burton, E. M., Haggard, S., Lake, D. A., \& Victor, D. G. (2017). The Behavioral Revolution and International Relations. International Organization, 71(S1), S1-S31.

Hafner-Burton, E. M., Hughes, D. A., \& Victor, D. G. (2013). The Cognitive Revolution and the Political Psychology of Elite Decision Making. Perspectives on Politics, 11(2), 368-386.

Hall, P. A. (2016). Politics as a process structured in space and time. In O. Fioretos, T. G. Falleti, \& A. Sheingate (Eds.), The Oxford Handbook of Historical Institutionalism. Oxford: Oxford University Press.

Hallin, D. C., \& Mancini, P. (2004). Comparing Media Systems. Communication, Society, and Politics. New York: Cambridge University Press.

Hansson, S. (2015). Calculated Overcommunication: Strategic Uses of Prolixity, Irrelevance, and Repetition in Administrative Language. Journal of Pragmatics, 84(July), 172-188. 
Hansson, S. (2018a). The Discursive Micro-Politics of Blame Avoidance: Unpacking the Language of Government Blame Games. Policy Sciences, 51(4), 545-564.

Hansson, S. (2018b). Defensive Semiotic Strategies in Government: A Multimodal Study of Blame Avoidance. Social Semiotics, 28(4), 472-493.

Harlow, C. (1999). Accountability, New Public Management, and the Problems of the Child Support Agency. Journal of Law and Society, 26 (2), 150-174.

Hay, C. (2011). Ideas and the construction of interests. In D. Béland \& R. H. Cox (Eds.), Ideas and Politics in Social Science Research (pp. 65-82). Oxford: Oxford University Press.

Heclo, H. (1974). Modern Social Politics in Britain and Sweden: From Relief to Income Maintenance. New Haven, CT: Yale University Press.

Hetherington, M. J. (2009). Review Article: Putting Polarization in Perspective. British Journal of Political Science, 39(02), 413-448.

Hinterleitner, M. (2017). Reconciling Perspectives on Blame Avoidance Behaviour. Political Studies Review, 15(2), 243-254.

Hinterleitner, M. (2018). Policy Failures, Blame Games and Changes to Policy Practice. Journal of Public Policy, 38(2), 221-242.

Hinterleitner, M. (2019). Salami Tactics and the Implementation of Large-Scale Public Projects. Journal of European Public Policy, 26(11), 1696-1714.

Hinterleitner, M., \& Sager, F. (2015). Avoiding Blame - A Comprehensive Framework and the Australian Home Insulation Program Fiasco. Policy Studies Journal, 43(1), 139-161.

Hinterleitner, M., \& Sager, F. (2017). Anticipatory and Reactive Forms of Blame Avoidance: Of Foxes and Lions. European Political Science Review, 9(4), 587-606.

Hinterleitner, M., \& Sager, F. (2018). Blame, reputation and organizational responses to a politicized climate. In T. Bach \& K. Wegrich (Eds.), The Blind Spots of Public Bureaucracy and the Politics of Non-coordination (pp. 133-150). London: Palgrave Macmillan.

Hinterleitner, M., \& Sager, F. (2019). Governing elites under pressure: Blame avoidance strategies and welfare state retrenchment. In R. Careja, P. Emmenegger, \& N. Giger (Eds.), Work and Welfare in a Changing World (pp. 109-122). New York: Springer.

Hirschman, A. O. (1994). Social Conflicts as Pillars of Democratic Market Society. Political Theory, 22(2), 203-218.

Hobolt, S. B., \& Klemmensen, R. (2007). Government Responsiveness and Political Competition in Comparative Perspective. Comparative Political Studies, 41(3), 309-337. 
Hood, C. (2011). The Blame Game: Spin, Bureaucracy, and Self-preservation in Government. Princeton, NJ: Princeton University Press.

Hood, C., Jennings, W., \& Copeland, P. (2016). Blame Avoidance in Comparative Perspective: Reactivity, Staged Retreat and Efficacy. Public Administration, 94(2), 542-562.

Hood, C., Jennings, W., Dixon, R., Hogwood, B., \& Beeston, C. (2009). Testing Times: Exploring Staged Responses and the Impact of Blame Management Strategies in Two Examination Fiasco Cases. European Journal of Political Research, 48(6), 695-722.

Hoppe, R. (2011). The Governance of Problems: Puzzling, Powering, and Participation. Bristol: Policy Press.

Howlett, M., \& Tosun, J. (Eds.). (2019). Policy Styles and Policy-Making: Exploring the Linkages. London: Routledge.

Iyengar, S. (1990). Framing Responsibility for Political Issues: The Case of Poverty. Political Behavior, 12(1), 19-40.

Jacobs, A. M., \& Weaver, R. K. (2015). When Policies Undo Themselves: Self-Undermining Feedback as a Source of Policy Change. Governance, 28 (4), 441-457.

Jennings, W., Lodge, M., \& Ryan, M. (2018). Comparing Blunders in Government. European Journal of Political Research, 57(1), 238-258.

Jones, B. D., \& Baumgartner, F. R. (2007). The Politics of Attention: How Government Prioritizes Problems. Chicago: University of Chicago Press.

Jupe, R. (2009). New Labour, Public-Private Partnerships and Rail Transport Policy. Economic Affairs, 29(1), 20-25.

Kang, S.-G., \& Powell, G. B. (2010). Representation and Policy Responsiveness: The Median Voter, Election Rules, and Redistributive Welfare Spending. The Journal of Politics, 72(4), 1014-1028.

Katzenstein, P. J. (1985). Small States in World Markets: Industrial Policy in Europe. Ithaca, NY: Cornell University Press.

King, A., \& Crewe, I. (2014). The Blunders of our Governments. London: Oneworld Publications.

Kirchheimer, O. (1957). The Waning of Opposition in Parliamentary Regimes. Social Research, 24(1), 127-156.

König, P. D., \& Wenzelburger, G. (2014). Toward a Theory of Political Strategy in Policy Analysis. Politics \& Policy, 42(3), 400-430.

Leong, C., \& Howlett, M. (2017). On Credit and Blame: Disentangling the Motivations of Public Policy Decision-Making Behaviour. Policy Sciences, 50(4), 599-618.

Levi-Faur, D. (2004). Comparative research designs in the study of regulation: How to increase the number of cases without compromising the strengths of case-oriented analysis. In J. Jordana \& D. Levi-Faur (Eds.), 
The Politics of Regulation: Institutions and Regulatory Reforms for the Age of Governance (pp. 177-199). Cheltenham: E. Elgar.

Levi-Faur, D. (2006a). Varieties of Regulatory Capitalism: Getting the Most Out of the Comparative Method. Governance, 19(3), 367-382.

Levi-Faur, D. (2006b). A Question of Size? In B. Rihoux \& H. M. Grimm (Eds.), Innovative Comparative Methods for Policy Analysis: Beyond the Quantitative-Qualitative Divide (pp. 43-66). New York: Springer.

Levitsky, S., \& Ziblatt, D. (2018). How Democracies Die. New York: Crown Publishing.

Lieberman, R. C., Mettler, S., Pepinsky, T. B., Roberts, K. M., \& Valelly, R. (2019). The Trump Presidency and American Democracy. Perspectives on Politics, 17(2), 470-479.

Lijphart, A. (2012). Patterns of Democracy: Government Forms and Performance in Thirty-Six Countries (2nd rev ed.). New Haven, CT: Yale University Press.

Linde, J., \& Vis, B. (2017). Do Politicians Take Risks Like the Rest of Us? An Experimental Test of Prospect Theory under MPs. Political Psychology, 38(1), 101-117.

Lodge, M., Wegrich, K., \& McElroy, G. (2010). Dodgy Kebabs Everywhere? Variety of Worldviews and Regulatory Change. Public Administration, 88 (1), 247-266.

Lowi, T. J. (1964). American Business, Public Policy, Case-Studies, and Political Theory. World Politics, 16(4), 677-715.

Mahoney, J., \& Thelen, K. A. (Eds.). (2015). Advances in ComparativeHistorical Analysis. Strategies for Social Inquiry. New York: Cambridge University Press.

Mair, P. (2007). Political Opposition and the European Union. Government and Opposition, 42(1), 1-17.

Mayhew, D. R. (1974). Congress: The Electoral Connection. New Haven, CT: Yale University Press.

McConnell, A. (2010a). Policy Success, Policy Failure and Grey Areas In-Between. Journal of Public Policy, 30(3), 345-362.

McConnell, A. (2010b). Understanding Policy Success: Rethinking Public Policy. New York: Palgrave Macmillan.

McGraw, K. M. (1990). Avoiding Blame: An Experimental Investigation of Political Excuses and Justifications. British Journal of Political Science, 20 (1), 119-131.

McGraw, K. M. (1991). Managing Blame: An Experimental Test of the Effects of Political Accounts. American Political Science Review, 85(4), 1133-1157.

Mettler, S., \& SoRelle, M. (2014). Policy feedback theory. In P. A. Sabatier \& C. M. Weible (Eds.), Theories of the Policy Process. Boulder, CO: Westview Press. 
Mettler, S., \& Soss, J. (2004). The Consequences of Public Policy for Democratic Citizenship: Bridging Policy Studies and Mass Politics. Perspectives on Politics, 2(1), 55-73.

Moe, T. M. (2005). Power and Political Institutions. Perspectives on Politics, $3(2), 215-233$.

Moran, M. (2015). Politics and Governance in the UK (3rd ed.). Macmillan Education. London: Palgrave.

Mortensen, P. B. (2012). 'It's the Central Government's Fault': Elected Regional Officials' Use of Blame-Shifting Rhetoric. Governance, 25(3), 439-461.

Mortensen, P. B. (2016). Agencification and Blame Shifting: Evaluating a Neglected Side of Public Sector Reforms. Public Administration, 94(3), 630-646.

Mounk, Y. (2018). The People vs. Democracy: Why Our Freedom Is in Danger and How to Save It. Cambridge, MA: Harvard University Press.

Moynihan, D. P. (2012). Extra-Network Organizational Reputation and Blame Avoidance in Networks: The Hurricane Katrina Example. Governance, 25(4), 567-588.

Mudde, C., \& Rovira Kaltwasser, C. (Eds.). (2013). Populism in Europe and the Americas: Threat or Corrective for Democracy? New York: Cambridge University Press.

Nai, A., \& Walter, A. (Eds.). (2015). New Perspectives on Negative Campaigning: Why Attack Politics Matters. Colchester: ECPR Press.

North, D. C. (1990). Institutions, Institutional Change and Economic Performance. New York: Cambridge University Press.

Olsen, J. P. (2015). Democratic Order, Autonomy, and Accountability. Governance, 28(4), 425-440.

Orren, K., \& Skowronek, S. (2017). The Policy State: An American Predicament. Cambridge, MA: Harvard University Press.

Page, B. I., \& Shapiro, R. Y. (1992). The Rational Public: Fifty Years of Trends in Americans' Policy Preferences. Chicago: University of Chicago Press.

Pal, L. A., \& Weaver, R. K. (2003). The Government Taketh Away: The Politics of Pain in the United States and Canada. Washington, DC: Georgetown University Press.

Parsons, C. (2007). How to Map Arguments in Political Science. Oxford: Oxford University Press.

Patashnik, E. M., \& Zelizer, J. E. (2013). The Struggle to Remake Politics: Liberal Reform and the Limits of Policy Feedback in the Contemporary American State. Perspectives on Politics, 11(4), 1071-1087.

Pierson, P. (1993). When Effect Becomes Cause: Policy Feedback and Political Change. World Politics, 45(4), 595-628. 
Pierson, P. (2007a). Public policies as institutions. In I. Shapiro, S. Skowronek, \& D. Galvin (Eds.), Rethinking Political Institutions: The Art of the State (pp. 114-131). New York: New York University Press.

Pierson, P. (2007b). The rise and reconfiguration of activist government. In P. Pierson \& T. Skocpol (Eds.), The Transformation of American politics: Activist Government and the Rise of Conservatism. Princeton Studies in American Politics (pp. 19-38). Princeton, NJ: Princeton University Press.

Powell, G. B. (2004). The Chain of Responsiveness. Journal of Democracy, 15 (4), 91-105.

Powell, G. B. (2011). Elections as Instruments of Democracy: Majoritarian and Proportional Visions. Princeton, NJ: Princeton University Press.

Ragin, C. C. (2008). Redesigning Social Inquiry: Fuzzy Sets and Beyond. Chicago: University of Chicago Press.

Richardson, J. (Ed.). (2014). Policy Styles in Western Europe. London: Routledge.

Rochefort, D. A., \& Cobb, R. W. (Eds.). (1994). The Politics of Problem Definition: Shaping the Policy Agenda. Lawrence: University Press of Kansas.

Sabato, L. (2000). Feeding Frenzy: Attack Journalism and American Politics. Baltimore: Lanahan Publishers.

Sager, F., Ingold, K., \& Balthasar, A. (2017). Policy-Analyse in der Schweiz: Besonderheiten, Theorien, Beispiele. Zurich: NZZ Libro.

Scharpf, F. W. (1997). Games Real Actors Play: Actor-Centered Institutionalism in Policy Research. Theoretical Lenses on Public Policy. Boulder, CO: Westview Press.

Schattschneider, E. E. (1935). Politics, Pressure and the Tariff. New York: Prentice-Hall.

Schattschneider, E. E. (1975). The Semi-Sovereign People: A Realist's View of Democracy in America. New York: Holt, Rinehart and Winston.

Schneider, A., \& Ingram, H. (1993). Social Construction of Target Populations: Implications for Politics and Policy. American Political Science Review, 87(2), 334-347.

Schneider, C. Q., \& Wagemann, C. (2012). Set-Theoretic Methods for the Social Sciences: A Guide to Qualitative Comparative Analysis. Cambridge: Cambridge University Press.

Schranz, M. (2015). Carlos und die Medien - eine öffentliche Debatte kritisch reflektiert. In F. Riklin (Ed.), Schweizer Jugendstrafrecht: vorbildlich oder überholt? (pp. 63-77). Bern: Stämpfli.

Seibel, W. (2014). Kausale Mechanismen des Behördenversagens: Eine Prozessanalyse des Fahndungsfehlschlags bei der Aufklärung der NSUMorde. Der moderne Staat: dms; Zeitschrift für Public Policy, Recht und Management, 7(2), 375-413. 
Shea, D. M., \& Sproveri, A. (2012). The Rise and Fall of Nasty Politics in America. PS: Political Science \& Politics, 45(3), 416-421.

Sheffer, L., \& Loewen, P. J. (2019). Accountability, Framing Effects, and Risk-Seeking by Elected Representatives: An Experimental Study with American Local Politicians. Political Research Quarterly, 72(1): 49-62.

Sheffer, L., Loewen, P. J., Soroka, S., Walgrave, S., \& Sheafer, T. (2018). Nonrepresentative Representatives: An Experimental Study of the Decision Making of Elected Politicians. American Political Science Review, 112(2): 302-321.

Snyder, T. (2018). The Road to Unfreedom: Russia, Europe, America (1st ed.). New York: Tim Duggan Books.

Soss, J. O., \& Schram, S. F. (2007). A Public Transformed? Welfare Reform as Policy Feedback. American Political Science Review, 101(1), 111-127.

Streeck, W., \& Thelen, K. A. (Eds.). (2005). Beyond Continuity: Institutional Change in Advanced Political Economies. Oxford: Oxford University Press.

Sulitzeanu-Kenan, R. (2010). Reflection in the Shadow of Blame: When Do Politicians Appoint Commissions of Inquiry? British Journal of Political Science, 40(3), 613-634.

Sulitzeanu-Kenan, R., \& Hood, C. (2005). Blame Avoidance with Adjectives? Motivation, Opportunity, Activity and Outcome. Paper for ECPR Joint Sessions, April 14-20, 2005, Granada.

Thelen, K. A., \& Mahoney, J. (2015). Comparative-historical analysis in contemporary political science. In J. Mahoney \& K. A. Thelen (Eds.), Strategies for Social Inquiry. Advances in Comparative-Historical Analysis (pp. 3-36). New York: Cambridge University Press.

Tsebelis, G. (1990). Nested Games: Rational Choice in Comparative Politics. Berkeley: University of California Press.

Tushnet, M. (2003). Constitutional Hardball. John Marshall Law Review, $37,523-553$.

Tversky, A., \& Kahneman, D. (1974). Judgment under Uncertainty: Heuristics and Biases. Science, 185(4157), 1124-1131.

Umbricht, A., \& Esser, F. (2016). The Push to Popularize Politics. Journalism Studies, 17(1), 100-121.

Urwyler, C., \& Nett, J. C. (2012). Evaluation der Wirksamkeit des neuen Jugendstrafgesetzes. Bern: Berner Fachhochschule.

Vatter, A. (2016). Das politische System der Schweiz (2nd ed.). Stuttgart: UTB Verlag.

van Kersbergen, K., \& Vis, B. (2015). Comparative Welfare State Politics: Development, Opportunities, and Reform. New York: Cambridge University Press. 
Verhoest, K., van Thiel, S., Bouckaert, G., \& Lægreid, P. (Eds.). (2012). Government Agencies: Practices and Lessons from 30 Countries. Public sector organizations. New York: Palgrave Macmillan.

Vis, B. (2011). Prospect Theory and Political Decision Making. Political Studies Review, 9(3), 334-343.

Vis, B. (2016). Taking Stock of the Comparative Literature on the Role of Blame Avoidance Strategies in Social Policy Reform. Journal of Comparative Policy Analysis: Research and Practice, 18(2), 122-137.

Vogel, S. K. (1996). Freer Markets, More Rules: Regulatory Reform in Advanced Industrial Countries. New York: Cornell University Press.

Weaver, R. K. (1986). The Politics of Blame Avoidance. Journal of Public Policy, 6(4), 371-398.

Weaver, R. K. (2013). Policy Leadership and the Blame Trap: Seven Strategies for Avoiding Policy Stalemate. Governance Studies. Washington, DC: Brookings Institution.

Weaver, R. K. (2018). The Nays Have It: How Rampant Blame Generating Distorts American Policy and Politics. Political Science Quarterly, 133(2), 259-289.

Weaver, R. K., \& Rockman, B. A. (Eds.). (1993). Do Institutions Matter? Government Capabilities in the United States and Abroad. Washington, DC: Brookings Institution.

Weible, C. M., \& Heikkila, T. (2017). Policy Conflict Framework. Policy Sciences, 50(1), 23-40.

Wenzelburger, G. (2011). Political Strategies and Fiscal Retrenchment: Evidence from Four Countries. West European Politics, 34(6), 1151-1184.

Wlezien, C., \& Soroka, S. N. (2012). Political Institutions and the OpinionPolicy Link. West European Politics, 35(6), 1407-1432.

Woodhouse, D. (2004). UK Ministerial Responsibility in 2002: The Tale of Two Resignations. Public Administration, 82(1), 1-19.

Zaller, J. (1992). The Nature and Origins of Mass Opinion. New York: Cambridge University Press. 


\section{Index}

accountability structures 28,141

Affordable Care Act 1

agencification $30,67,72$

agency strategies 22

agenda, political 2, 3, 20, 101, 154, 205

American Recovery and Reinvestment Act 164

antiestablishment feelings 203

attitude of incumbents 23, 147, 155, 172

$\mathrm{BDP}$, see Conservative Democratic Party of Switzerland (BDP)

Bennett, Andrew 177, 178

Berlin Brandenburg Airport (BER) 79

Blair, Tony 42, 59

blame avoidance 193, 197

blame barriers 8, 141, 182, 186

blame deflection $37,148,173$

blame game style 5, 9, 11, 190, 201

German 97, 106, 139, 186

stability over time 194

Swiss 130, 138, 140, 187

UK 66, 72, 139, 186

blame game, definition of 1,18

blame gateways 141, 186

blame management 22, 24

Germany 107

Switzerland 138

UK 72

blaming, definition of 21

Boin, Arjen 4

Bovens, Mark 3

Brexit 199

Brown, Gordon 47, 51, 69

Bundeswehr (German armed forces) 88

Bush, George W. 156, 158
Cameron, David 68

case selection strategy 12

causal diagram 181

CDU, see Christian Democratic Union (CDU)

chancellors 74, 88, 97

Child Support Agency (CSA) 40

Christian Democratic Union (CDU) 74, $82,87,88,103$

Christian-Democratic Party (CVP) 110, $113,119,126$

citizens, role of 203

cleavages, electoral 190

collegiality principle $28,114,122$, 129

comparative-historical analysis 11

complexity of blame games 23

conflict management $8,25,187$, 190

conflictual politics $5,7,185$

Conservative Democratic Party of Switzerland (BDP) 119

Conservative Party (UK), see Tories

conventions of resignation 28, 46, 67, 100

cost overruns 79,128

Couchepin, Pascal 127

credit claiming 174, 193, 197

crisis management 4

CSA, see Child Support Agency (CSA)

cultural policy 128

CVP, see Christian-Democratic Party (CVP)

Dahl, Robert 200

Darling, Alistair 41

decision-making biases 196

democracy 7, 10, 24, 200, 205

democratic responsiveness 204

Democrats 157,159 
Department of Veterans Affairs (VA) 149

depoliticization 67,72

dichotomization 178

elections 3, 19, 36, 204

electoral connection 3, 203

emotions, leveraging of 145

energy policy 164

Falconer, Lord 59

FDP, see Free Democratic Party (FDP)

Federal Council 29, 114, 123, 130

Field, Frank 42

Flinders, Matthew 55

focusing events 4

Food and Drug Administration, US 157

Free Democratic Party (FDP) 74, 103

generalizability 15, 192

George, Alexander L. 177, 178

Germany 27, 29, 73, 106, 139, 182, 186

government 18

green energy 164

Green Party, German 75, 82, 86, 92, 95, 102

Green Party, Swiss 110, 113, 118, 127

Hacker, Jacob 23, 40, 202

Hague, William 60

Hammond, Philip 43

Hart, Paul 't 3

Heclo, Hugh 19

Heseltine, David 63

Hirschman, Albert 8, 25, 187, 205

Hood, Christopher 5, 10, 18, 21, 22, 44

ideas about policies 198

immigration crisis, German 3

incumbents 22,33

inquiry commission 92, 97, 101

inquiry reports 55

institutions $6,8,26,185,187$

interaction effects 143,181

intercultural differences 194 investigation failure 73

issue characteristics 33,188

Japan 194

Kennedy, Edward 157

Kerry, John 157

Kirchheimer, Otto 200

Künast, Renate 103

Labour Party 41, 44, 47, 52 , 56, 69

Left Party, German 75, 94, 105

Leyen, Ursula von der 93

Liberal Democrats 42, 43, 46, 52, 55, 60, 63, 68

Liberal Party, Swiss (FDP) 110, 113, 118, 126, 135, see Free Democratic Party (FDP)

Lijphart, Arend 201

Livingstone, Ken 50

lobbying affair, Swiss 1

London Underground 47

Lowi, Theodore 19

Maizière, Thomas de 91

Mandelson, Peter 59, 62

mass persuasion situations 33

Mayhew, David 3, 203

media, role of the 35

systems 35,195

Merkel, Angela 74, 88

method of analysis 11

Metronet 50

ministerial responsibility, doctrine of 28

National Audit Office 43, 52

National Health Service (NHS) 68

National Socialist Underground (NSU) 73

natural disasters 4, 19, 36, 193

New Labour 59, 62

New Millennium Exhibition Company 56

New Public Management 30

newspaper coverage of blame games 16

Nicholson, David 69 
normative judgments 203

norms, democratic 5, 7, 169, 192, 194, 198, 199

Obama, Barack 1, 149, 150, 164, 165, 194

opponents 21,33

opposition 18

organized interests 18

parliamentary committees, role of 67 , 186

Parsons, Craig 31, 39, 196

parties, political 18, 194

Pierson, Paul 3, 23, 202

polarization 2, 7, 199

policy change $4,21,24,72,79,120$, 133, 179

policy controversies $3,6,19,20,32$, 190

management of 3, 6, 20

policy drift 40

policy failures 19, 190

policy learning 4,21

policy process 4

policy strategies 22

policy styles 4

political competition 2

political system 184

politicization 19

politics of pain 20, 193

popularity of political actors 197

populism 2, 7, 199

power 8, 144

presentational strategies 23

presidents 1, 150, 158, 164, 165,194

prime ministers $42,47,51,59,68$

privatization 55

procurement failure 88

proximity of a controversy 8,32

psychological explanations of blame game interactions 195

public feedback 16, 33, 35, 177, 178, 180

public finance initiative (PFI) 47, 53

public health fiasco 157

public holding 79

public-private partnership (PPP) 47

public, role of the 31,34 rationality 196

reframing 23, 148, 152, 155, 160, 163, 173

Republicans 149, 159, 164

research design 11

resignation of politicians 142, 179

resignation, conventions of 96, 139

resources of political actors 197

routine politics 5,185

salami tactics 128

salience of a controversy 8, 32

scandalization 19, 35, 190

scandals 3, 12, 19, 178, 190

food 102

personal 19, 171, 192, 197

Schattschneider, E.E. 8, 19, 24, 32, 187, 201

Schäuble, Wolfgang 74, 75

Schram, Sanford 33, 36

security policy 134

Seibel, Wolfgang 74

Shinseki, Eric 149

Social Democratic Party (SPD) 74, 82, 92, 95, 102

Social Democrats (SP) 110, 113, 114, 118,126

social media 195

Soss, Joe 33, 36

South Korea 194

SP, see Social Democrats (SP)

SPD, see Social Democratic Party (SPD)

Stafford Hospital 68

SVP, see Swiss People's Party (SVP)

Swiss People's Party (SVP) 110, 113, $118,126,127,134$

Switzerland 27, 29, 108, 138, 140, 183, 187

symbolic activism 145, 152

tabloids 16

tax reform 114

terrorist attacks 4, 19, 77

Tories 43, 46, 51, 52, 55, 60, 63, 68

Trumpism 199

typological theory 177,184

UK 27, 29, 40, 72, 139, 181, 186

USA $27,29,145$ 
vaccine shortage 156

Veterans Health Administration (VHA) 149

Vis, Barbara 196

Weaver, Kent 10, 19, 22, 30, 193, 197, 198 welfare state retrenchment 193

Widmer-Schlumpf, Eveline

118

Wolmar, Christian 54

Wowereit, Klaus 82

youth crime 112 